\title{
A STATISTICAL ANALYSIS OF REGIONAL CAPITAL AND OPERATING COSTS FOR ELECTRIC POWER GENERATION
}

Luis R. Sanchez, Myron G. Myers, James A. Herrman, and Anthony J. Provanzano

October 1977

PREPARED BY THE LOGISTICS MANAGEMENT INSTITUTE 4701 SANGAMORE ROAD WASHINGTON, DC 20016

For the OFFICE OF ENVIRONMENTAL POLICY NATIONAL CENTER FOR ANALYSIS OF ENERGY SYSTEMS DEPARTMENT OF ENERGY AND ENVIRONMENT

BROOKHAVEN NATIONAL LABORATORY ASSOCIATED UNIVERSITIES, INC.

UNDER CONTRACT NO. EY-76-C-02-0016 WITH THE

OFFICE OF TECHNOLOGY IMPACTS/ASEV

UNITED STATES DEPARTMENT OF ENERGY 


\section{DISCLAIMER}

This report was prepared as an account of work sponsored by an agency of the United States Government. Neither the United States Government nor any agency Thereof, nor any of their employees, makes any warranty, express or implied, or assumes any legal liability or responsibility for the accuracy, completeness, or usefulness of any information, apparatus, product, or process disclosed, or represents that its use would not infringe privately owned rights. Reference herein to any specific commercial product, process, or service by trade name, trademark, manufacturer, or otherwise does not necessarily constitute or imply its endorsement, recommendation, or favoring by the United States Government or any agency thereof. The views and opinions of authors expressed herein do not necessarily state or reflect those of the United States Government or any agency thereof. 


\section{DISCLAIMER}

Portions of this document may be illegible in electronic image products. Images are produced from the best available original document. 


\title{
A STATISTICAL ANALYSIS OF REGIONAL CAPITAL AND OPERATING COSTS FOR ELECTRIC POWER GENERATION
}

\author{
Luis R. Sanchez, Myron G. Myers, \\ James A. Herrman, and Anthony J. Provanzano
}

October 1977

PREPARED BY THE

LOGISTICS MANAGEMENT INSTITUTE

4701 SANGAMORE ROAD

WASHINGTON, DC 20016

For the

OFFICE OF ENVIRONMENTAL POLICY

NATIONAL CENTER FOR ANALYSIS OF ENERGY SYSTEMS

DEPARTMENT OF ENERGY AND ENVIRONMENT

\section{BROOKHAVEN NATIONAL LABORATORY UPTON, NEW YORK 11973}


NOTICE

This report was prepared as an account of work sponsored by the United States Government. Neither the United States nor the United States Department of Energy (DOE), nor any of their employees, nor any of their contractors, subcontractors, or their employees, makes any warranty, express or implied, or assumes any legal liability or responsibility for the accuracy, completeness or usefulness of any information, apparatus, product or process disclosed, or represents that its use would not infringe privately owned rights.

Printed' in the United States of America

Available from

National Technical Information Service

U.S. Department of Commerce

5285 Port Royal Road

Springfield, VA 22161

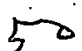

Price: Printed Copy Microfiche $\$ 3$.

$$
11 . \omega
$$


This report presents the results of a three and one-half-month study conducted for Brookhaven National Laboratory to develop capital and operating cost relationships for seven electric power generating technologies: oil-, coa1-, gas-, and nuclear-fired steam-electric plants, hydroelectric plants, and gas turbine plants. The methodology is based primarily on statistical analysis of Federal Power Commission data for plant construction and annual operating costs. The development of cost-output relationships for electric power generation is emphasized, considering the effects of scale, technology, and location on each of the generating processes investigated. The regional effects on cost are measured at the Census Region level to be consistent with the Brookhaven Multi-Regional Energy and Interindustry Regional Model of the United States.

Preliminary cost relationships for system-wide costs - transmission, distribution and general expenses - were also derived. These preliminary results cover the demand for transmission and distribution capacity and operating and maintenance costs in terms of system service characteristics. They have been forwarded to Brookhaven National Laboratory under separate cover. 
Page No.

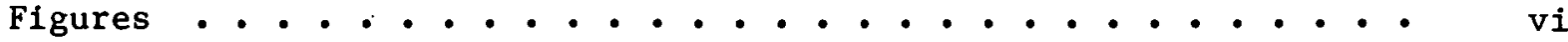

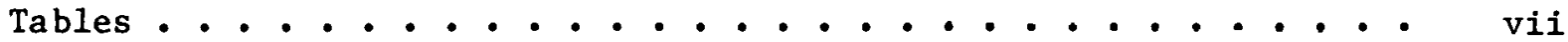

Abstract . . . . . . . . . . . . . . . . . . ii

Chapter

I. Introduction ................... 1

A. Scope and Purpose .. . . . . . . . . . . 1

B. Methodology .................. 1

C. Summary of Statistical Results . . . . . . . . 3

1. Capital Costs ................ 3

2. Fuel ................... 4

3. Non-Fuel Operating and Maintenance Costs ..... 4

D. Report Organization . . . . . . . . . . . . 4

II. Preliminary Analysis of Electric Power Generation

Cost and Technical Variables . . . . . . . . . . .

A. Introduction .................... 5

B. Cost Elements ..................... 5

C. Electric Power Generation Systems . . . . . . . 8

1. Generation Costs ................. 8

2. Cost and Plant Characteristics . . . . . . 10

D. Pollution Abatement ................ 21

1. Air Pollution Control .............. 21

2. Water Pollution ............... 26

III. Statistical Analysis of Electric Power

Generation Costs .................. 31

A. Overview of Cost-Estimating Methodology . . . . . . 31

1. Introduction .................. 31

2. Model Specification: General . . . . . . . 33

3. Model Spectfication: Regional Analysis . . . . . 34

4. Use of Price Indices and Measurement of

Technological Change . . . . . . . . 39

B. Regression Results .................. 41

1. Fossi1-Fueled Steam-Electric Plants . . . . . . 42

a) Capital Costs ............. . . . 42

b) Fuel Costs................. 50

c) Non-Fuel o\&M Costs ............. 53 
CONTENTS (cont1nued)

Page No.

2. Gas Turbine Plants ............. 56

a) Capital Costs................. 56

b) Fuel Costs ............. 58

c) Non-Fuel O\&M Costs ........... 60

3. Hydroelectric Plants . ............ . 63

a) Capita1 Costs.............. 69

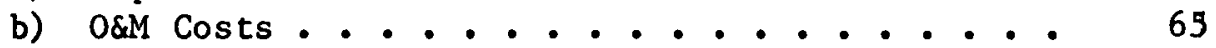

4. Nuclear Steam-Electric Plants.......... 68

a) Capital Costs............ 68

b) Fuel Costs .............. 71

c) Non-Fuel O\&M Costs ........... 73

Apendices

A. Data Base Documentation 76

B. Construction Costs Indices

C. Data and Data Codes 93 


\section{FIGURES}

Page No.

II-1 Nuclear Power Plants (Trend Values of Capacity Cost and Technical Parameters) . . .........

II-2 Trend Values of Average Investment Cost and Technical Parameters of Nuclear Plants as

Function of Plant Capacity . . . . . . . . . . .

II-3 Trend Values of Average Investment Cost and Technical Parameters of Nuclear Plants as

Function of Plant Vintage ...............

II-4 Average Equipment Cost for Fossil-

Fueled Steam-Electric Power Plants

as Function of Vintage . . . . . . . . . . . 22

II-5 Average Equipment Cost per $\mathrm{kW}_{\mathrm{e}}$ for

Fossi1-Fueled Steam-Electric Power

Plants as a Function of Scale . . . . . . . . .

III-1 Confidence Limits ( + Two Standard Error)

for Linear and Exponential Models 
TABLES

Page No.

II- 1 Capital Costs Data - Electric Power Plants . . . . . . . . 11

II- 2 Non-Fuel Operation and Maintenance Costs - Electric

II- 3 Sample Data for Analysis of Nuclear Power

Plant Scale and Vintage Effects .......... 15

II- 4 Nuclear Power Plant Grouping According to

Size and Vintage ............... . 17

II- 5 Northeast Regions 1 and 2 Average

Equipment Cost for Fossil-Fueled Plants

for Various Vintage and Capacity Groupings . . . . . . .

II- 6 West South Central Region 7 Average

Equipment Cost for Fossil-Fueled Plants

for Various Vintage \& Capacity Groupings . . . . . . 20

II- 7 Pollution Control Systems With. $\mathrm{SO}_{2}$ Removal

Capability Installed Through 1973 ... . . . . . 24

II- $8 \mathrm{CAT}-\mathrm{OX} \mathrm{SO}_{2}$ Removal Costs . . . . . . . . . . 25

II- 9 Air Pollution Control Costs . . . . . . . . . 29

II-10 Water Pollution Control Costs . . . . . . . . 30

III- 1 Results of Coal-Fired Steam-Electric Coal/Mixed

Capital Cost Regression ............ . . 44

III- 2 Results of 0i1-Fired Steam-Electric Capital Cost

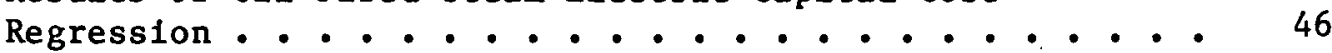

III- 3 Results of Gas-Fired Steam-Electric Capital Cost

Regression .......................

III- 4 Results of Fossil-Fueled Steam-Electric Fuel

Consumption Regression............. 52

III- 5 Results of Fossil-Fueled Steam-Electric Non-Fue1 O\&M

Cost Regression ................ 54

III- 6 Results of Gas Turbine Capital Cost Regression . . . . 57 
TABLES (continued)

Page No.

III- 7 Results of Gas Turbine Fuel Consumption Regression . • . 59

III- 8 Results of Gas Turbine O\&M Cost Regression . . . . . . 62

III- 9 Results of Hydro-Electric Capital Cost Regression . . . 64

III-10 Results of Hydro-Electric O\&M Cost Regression . . . . 67

III-11 Results of Nuclear Steam Plant Capital Cost

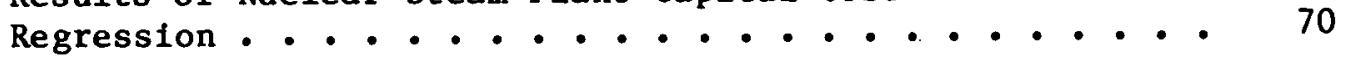

III-12 Results of Nuclear Fuel Consumption Regression . . . . 73

III-13 Results of Nuclear Non-Fuel O\&M:Cóst Regression . • . . 75

- viii - 


\section{INTRODUCTION}

A. Scope and Purpose

This study was undertaken to develop parametric cost relationships for electric power generation. These cost-estimating relationships are for initial investment costs for generating capacity and...for annual operating expenses, including those associated with fuel, operations, and station maintenance. Primary consideration was given to the effects'of technology, scale, and. location on each of these cost categories.

The generating technologies discussed are: conventional coal-, oil-, and gas-fired steam-electric stations, gas turbine generators, conventional hydroelectric stations, pumped storate facilities, and nuclear light water reactor (LWR) stations. For each generating technology and cost category, cost-estimating relationships were developed to reflect differences across regions. To be consistent. with:the Hevel of detail contemplated for the Brookhaven Nationa1. Laboratory'si (BNL) Multi-Regional Energy and Interindustry Model of the United States, regional analysis was conducted by U.S. Census Region. State identification.; was retained in the data base, however, to facilitate more detailed regional analysis in the future should this prove desirable.

Capital and operating cost relationships will be incorporated into the BNL Regional Energy Model while fuel prices and demands are specified within the mode1. Consequently, no attempt was made. in this report to integrate the various cost components so as to determine total electric power generation costs. All relationships required for both average and marginal cost determination are available here, however.

\section{B. Methodology}

The study began with the compllation of a statistical data base describing capital costs, station characteristics, and operating expenses for each generating technology. Plant-level data were collected from annual reports filed by utilities with the Federal Power Commission (FPC), starting as early as 1938. Use of statistical data for a period of significant technological advances, fluctuations in general price levels, and variations in plant design and operating characteristics required a substantial data base. 
In general, plants were observed in the initial year of operation and their capital costs and physical characteristics recorded. Operating cost data were obseved in the most recent year for those plants that remained unchanged from the data of initial operations. Thus, plants incurring capacity expansion, major modification, or backfitting subsequent to initial operations were excluded from the operating cost sample. This required tracking each plant from initial operation to the year(s) for which operating data were recorded.

Capital costs recorded at the inception of commercial operations werc normalized to constant 1975 dollars, using region-spectfic price deflators developed from the Handy-Whitman Index of Public Utility Construction Costs. Price indices that reflected the pricing behavior for the various categories of structures and equipment comprising the overall generating plant were developed for each generating technology. In addition, information about the phasing of actual cash outlays over the plant construction period was used to develop the price deflators used in this report.

Three broad categories of costs were analyzed: capital costs, fuel input (Btu) and non-fuel operating and maintenance (O\&M) expenditures. In some cases, engineering design parameters reflecting plant efficiency or design characteristics were used in the analysis of capital costs to explain cost differences among otherwise similar plants. In others, construction time proved to be a significant cost-determining variable, since interest on funds employed during construction is included in reported investment costs.

Our usual practice was to use separate or component variables for the specification of independent variables_plant capacity and utilization (plant factor)_-instead of the composite variable, net generation (kilowatt hours). Although cost relationships were specified and computed in both linear and exponential form, whenever, possible we attempted to select the exponential form 
as preferable because of the following desirable features:

- Marginal costs vary with the level of output or capacity and other independent variables.

- Cost elasticities are constant.

- The error term is proportional to output or capacity.

Liberal use was made of dummy variables for location (Census Regions) and other qualitative independent variables, such as plant type, operating mode, type of cooling, etc. Dummy variables for location and plant characteristics often were found to be significant and indicated substantial cost differences depending on station location and design characteristics.

C. Summary of Statistical Results

1. Capital Costs. All generating technologies evidenced (static) . economies of scale in the capital cost of physical plant, with the greatest economies present in nuclear steam-electric plants, followed by hydroelectric, conventional steam technologies and gas turbines. The partial cost elasticity was estimated to be in the neighborhood of 0.75 to 0.80 for each of the base load technologies and 0.95 for gas turbine plants. Additionally, significant dynamic improvements were noted for all technologies except nuclear-fired steam stations. Technological improvement was on the order of 2 to $3 \%$ per year in the early 1950's and dropped to 1 to $2 \%$ by the early 1970's. The relatively., recent gas turbine technology evidenced greater dynamic improvements of 4 to 4. 5\% per year. A general tendency was noted for Census Regions 5, 6, 7, and 8 (South Atlantic, East and West South Central, and Mountain States) to experience lower costs per unit of installed capacity in comparison to the rest of the country. For specific technologies,: regional cost differences were $y_{.}, \ldots$ : sometimes of substantial magnitude. Exceptions to these general conclusions: $:$. were noted for gas turbine stations, where units are often shipped preassembled. and site preparation and structures are minimal. 
2. Fue1. Overa11, economies of scale for fuel consumption were noted: large plants consume less fuel at a given utilization rate than smaller plants. Furthermore, fuel consumption increases less than in proportion to increases in plant output. Several exceptions were noted. Gas turbines evidenced constant returns to scale, with no advantage gained by increasing plant size or unit capacity. Nuclear stations showed the largest ecunomies of scale and improvements in fuel efficiency with increased utillzation, but the results were clouded by the apparent proration of Btu consumption based on estimated fuel life and capacity.

3. Non-Fuel Operating and Maintenance Costs. These costs displayed a remarkably similar pattern across all generating technologies. A high fixed cost component was observed, with substantial economies of scale as plant size increased. The degree of plant utilization generally had a significant impact on contemporaneous O\&M costs, although the magnitude of the impact was rather sma11. Estimates indicated that $0 \& M$ costs were around $20 \%$ variable with output. The impact of age was generally found to be significant. Regional cost differences arise chiefly on account of wage and material price differentials. The Middle Atlantic and East North Central Regions generally exhibited higher than average O\&M cost levels, while the West North and South Central Regions displayed consistently lower than average costs. The South (At lantic and East South Central) and Mountain States evidenced lower than average: cost levels for certain technologies.

D. Report Organization

The balance of this report is organized so that the reader is first introduced to pertinent concepts of technology, functional activities, and cost. elements in Chapter II, where results of preliminary analysis of the effects of scale, time, and location are presented. Chapter III formally presents the statistical methodology and results by cost category within each generating technology .

Three technical appendices are included. Appendix A documents the data sources and procedures undertaken to compile each data base. Appendix $B$ 
describes the procedure used to develop the construction cost indices for each generating technology analyzed. Appendix $C$ documents the variables used and presents the actual data bases.

\section{PRELIMINARY ANALYSIS OF ELECTRIC POWER GENERATION COST AND TECHNICAL VARIABLES}

\section{A. Introduction}

This chapter discusses the attempt to identify the effects of time, scale, technology, and regional differences on capital, O\&M costs, and fuel use for different types of electric power generation systems, and analyzes technical variables that may reflect such effects in the cost functions. Electric power generation systems are discussed in terms of power generation and pollution control processes and costs. Approaches to incorporate the effects of vintage, size, technological, and regional characteristics on the cost functions are investigated.

The estimation of electric power generation system costs requires some background knowledge of the pertinent technologies, functional activities, and cost elements involved. Accordingly this chapter introduces the basic cost elements, functional activities, and technical parameters of electric power generation systems and analyzes the possible cost effects of system scale, technology, and regional location that these parameters represent.

\section{B. Cost Elements}

The basic purpose of the electric power generation regional cost model developed in this study is to relate resource requirements (costs) to system characteristics and outputs, so that investment and production costs for alternative systems or configurations may be derived. The structure of the . model provides a logical representation of the total electric power generation system and of system operation within a region; it relates costs to capacity 
(thousands of kilowatts - $M W_{e}$ ) and to final measures of output (kilowatt-hours$\mathrm{kWh}$ ), and to the system processes that achieve these outputs.

The analytical structure of the cost model defines the cost elements that must be considered for each major process in the system, and determines the system variables to which cost-estimating relationships or cost functions must be sensitive if the estimates are to measure the cost impacts of alternative systems adequately. The latter requires an understanding of the underlying physical properties of the system, how the values of the selected variables are generated, and the interactions between the variables themselves. For example, the knowledge that boiler pressure is a cost-sensitive variable in estimating the investment cost of electric power generating capacity must be supplemented with an understanding of both the metallurgical state-of-the-art problems involved in achieving a given increment in boiler pressure and the impact of boiler pressure on plant capital costs, heat rates, and fuel use.

Investment costs for generating capacity are divided into three major categories: land, structures and improvements, and equipment. Land accounts for a very small proportion of investment costs and varies widely in physical and dollar terms across plants of similar capacity and vintage. This cost element was therefore dropped from the cost sample and estimated as a ratio of other initial investment costs for a particular generating plant.

The investment cost data for the various plants in the sample showed more variability between interplant structures and improvements and equipment cost categories than between combined interplant capital cost categories. The greater variability between component capital costs is understandable, because construction costs and equipment installation costs are closely related. This is especially true of nuclear power plants where, if an item of heavy equipment is improperly, installed or malfunctions in operation, the cost of dismantling and reassembling the unit may be charged to either of the two accounts. In addition, the utility could either purchase the equipment separately and have it installed by the construction contractor; which would be reflected in the structure cost account, or have the equipment contractor include the installation cost in his contract. For these reasons, both accounts were 
combined into a single plant capital cost account for all activities as the dependent variable in the investment equations. Costs of various vintage plants were deflated to 1975 dollars by use of the Handy-Whitman Construction Index, modified to reflect average construction time and out lay profiles for different technologies.

Production costs are broken down by the FPC into three major accounts: operation, maintenance, and fuel. Additional detail is shown under the O\&M accounts, but time and funding limitations precluded derivation of cost functions at that level of detail. Besides, the reason behind the aggregation of investment costs into a single capital cost variable for each system activity is also applicable to $O \& M$ cost categories. Thus, a single value for O\&M costs and physical measures of fuel usage were used in all the production expense equations.

Operation and maintenance costs for the various plant types and activities used in the study are in current year dollars. No index for deflating O\&M costs was considered appropriate for several reasons. The labor and material dollar values for each functional activity are not broken down in the FPC reports. Regional wage rates and material cost price levels are not available on an annual basis even if the composition of labor and material impacts is known. 1

Fuel costs in the fuel cost equations are presented in physical units: British thermal units (Btu). Physical rather than monetary values are used for a number of reasons, including: regional variations in both type and price of primary fuel used, which tend to distort the true fuel consumption relationship, variations in Btu content of different fuels used, and the advantage of estimating fuel consumption in Btu for each plant type and then applying constant regional prices to arrive at total costs comparable between fuel types and regions. Since the cost relationships, are to be used in conjunction with a regional energy model, endogeneous regional prices can then be applied to the physical fuel impacts to.determine regional costs.

Interest and escalation costs during construction are not reported separately in the FPC reports. Alternate data sources provide estimates of these costs for future plants, but because they are embedded in the 
construction costs of the plants in our sample, we were not able to develop separate equations for this cost element. The estimates gathered from other sources may provide the basis for development of an adjustment factor tied to plant construction time, which is one of the independent variables in some of our captial cost equations.

\section{Electric Power Generation Systems}

Electric power systems generate, transmit, and distribute electric power to meet varying demands with an adequate amount of reserves. An electric power system consists of power generation (production) facilities, transmission lines to link production facilities to consumption centers, and distribution networks to carry electric power to individual customers. On1y cost-output relationships and related air and water pollution control costs for generating activities are considered in this report.

1. Generation Costs. The largest components of capital equipment in an electric generating activity are the steam generator (boiler) and the turbine generator units that produce electric power. The capacity of the system which is usually prescribed by the manufacturer on the name plate rating is measured in $\mathrm{MW}_{\mathrm{e}}$. The bulk of U.S. electric power is produced by generators with turbines driven by steam from fossil fuel or light water reactor (LWR) nuclear power derived heat. The balance is primarily generated by hydroelectric, gas turbine, and combined cycle power plants. The output of the system is measured in $\mathrm{kWh}$, a composite variable reflecting electricity generated (instaneous output times duration).

New technologies such as breeder and fusion reactions, magnetohydrodynamics (MHD), solar energy, geothermal energy, and fuel cells are under development, but are not far enough advanced to be included in this study. The technologies considered available_fossil-fueled plants, LWR nuclear-fueled plants, gas-driven turbines, and hydroelectric (especially, pumped storage) plants were used to develop the cost functions in this study. Combined cycle plants, although already in operation, were excluded, as too few were 
operational in 1974 for reliable statistical coefficients for either their capital or their operating costs to be derived.

Electric power generation requires land for the site, structures and buildings, methods of heat rejection, fuel supply and handing, and $0 \& M$ personnel and materials. Fuel and cool water are fed into a plant and electric current, combustion residuals, and warm water are produced. Pollution abatement equipment to recycle the cooling water and to capture fuel residuals is considered part of the generation plant.

The "heat rate" of a thermal generation unit (one or more units per plant) is the average amount of Btu of fuel input energy per kWh of electricity output produced. Since fuel is the single most important operating input, this ratio is considered the most important measure of plant generating efficiency. A combination of technical innovation and scale effects has resulted in a gradual reduction of heat rate over time.

The best heat rates are usually attained by larger units with higher steam pressures and temperatures. However, the plant factor, the kind and grade of fuel burned, turbine start and stops, outages for maintenance, circulatory water conditions, the age of the plant, and the overall operating condition of all its equipment have a direct effect on a unit's annual heat rate.

By definition, the generating activity stops at the generation "bus" a term used for the contact point between the generator and the switchyard, where voltage is increased for more economical transmission to demand centers. Generation costs account for roughly half the average total cost of electric service and appear to be rising rapidly, owing to increases in new plant construction costs, fuel costs, and interest rates. The fixed-cost component of average electricity generation depends not only on the initial construction costs of generating facilities, but also on the plant factor (ratio of actual output to potential output) and the fixed-charge (or gross profit) rate. required to yleld an acceptable rate of return to investors.

Fuel costs account for more than $80 \%$ of operation costs for generating facilities. Fuel costs for nuclear plants are lower than those for large conventional units. For fossil-fueled plants, unit fuel cost is easily 
computed from the average price paid for the fuel and the thermal heat rate of the plant (Btu/kWh generated). The latter is largely a function of plant design. Currently, the heat rate averages around $10,500 \mathrm{Btu} / \mathrm{kWh}$, but some plants do notably better; in 1974, the most efficient plant had a rate of 8,915 $\mathrm{Btu} / \mathrm{kWh}$. The statistical results reported in Chapter III show how fuel consumption is affected. by plant size, utilization and age.

2. Cost and Plant Characteristics. Prior to application of formal statistical methods, a preliminary analysis was conducted to select appropriate cost and system technical variables for the development of electric power generation system cost functions. Table II-1 displays the electric power generating plants in the captial cost sample, showing number of plants by fuel type and region and the range of values of capital costs and plant characteristics selected as explanatory variables for the cost functions. Table II-2 presents a similar tabulation of the operation and maintenance cost sample. Appendix A describes the criteria used to select the sample.

These samples show a wide variation in the range of both cost and plant characteristics and adequate regional representation for all technologies, which should allow for both the development of significant and stable cost relationships for each type of plant by region, and the measurement of technology and scale impacts on the costs of the plants in the sample.

The data base for this study includes fossil-fueled steam-electric, hydroelectric, and gas turbine plants built through 1974 and nuclear power plants in operation by the end of 1975. The sample thus includes enough large plants of the most recent vintage to test an hypothesis about capital cost. economies of scale for plants larger than $400 \mathrm{MW}_{\mathrm{e}}$.

Most previous studies have assumed that vintage alone captures the effect of dynamic technological change and that size reflects the effect of static economies in steam-electric generating plants. A strong correlation between size and vintage can obscure the separate effects of time and scale on costs. An attempt was made to use technological design parameters, such as system pressures and temperatures, as variables to separate the effects of dynamic and static techonological changes on capital cost. A number of technical design 
Table II-1

Capital Costs Data - Electric Power Plants

\begin{tabular}{|c|c|c|c|c|c|c|c|c|c|c|c|c|c|c|c|c|c|c|}
\hline \multirow[t]{2}{*}{$\therefore$} & \multirow[b]{2}{*}{$\begin{array}{l}\text { Number of } \\
\text { Plants }\end{array}$} & \multirow[b]{2}{*}{ Vintage } & \multirow[b]{2}{*}{$\begin{array}{l}\text { Plant } \\
\text { capacity } \\
\left(\mathrm{MW}_{\mathrm{e}}\right)\end{array}$} & \multicolumn{3}{|c|}{ Values of sample variables } & \multirow[b]{2}{*}{$\begin{array}{l}\text { Heat } \\
\text { rate }\end{array}$} & \multirow[b]{2}{*}{$\begin{array}{l}\text { Boiler } \\
\text { pressure } \\
\text { (psi) }\end{array}$} & \multirow[b]{2}{*}{$\begin{array}{c}\text { Capital } \\
\text { cost } \\
\$ 10^{6}\end{array}$} & \multicolumn{9}{|c|}{$\begin{array}{l}\text { Regional representation } \\
\text { (No. of plants per region) }\end{array}$} \\
\hline & & & & $\begin{array}{c}\text { Construction } \\
\text { time } \\
\text { (months) }\end{array}$ & $\begin{array}{l}\text { Number of } \\
\text { generating } \\
\text { units }\end{array}$ & $\begin{array}{l}\text { Capacity } \\
\text { per } \\
\text { unit }\end{array}$ & & & & $\mathrm{R}_{1}$ & $\mathrm{R}_{2}$ & $\mathrm{R}_{3}$ & $\mathrm{R}_{4}$ & $\mathrm{R}_{5}$ & $\mathrm{R}_{6} \mathrm{~F}$ & $\mathrm{R}_{7} \mathrm{R}$ & $\mathrm{R}_{8} \mathrm{R}$ & $R_{9}$ \\
\hline $\begin{array}{l}\text { Steam- } \\
\text { electric }\end{array}$ & & & & & & & & & & & & & & & & & & \\
\hline oil & 73 & $\begin{array}{l}1928 \\
1974\end{array}$ & $\begin{array}{r}11.5 \\
1827.7\end{array}$ & & $\begin{array}{l}1 \\
4\end{array}$ & $\begin{array}{r}11.0 \\
913.0\end{array}$ & $\begin{array}{r}8962 \\
17913\end{array}$ & & $\begin{array}{r}4.9 \\
436.3\end{array}$ & 7 & 7 & 0 & 2 & 10. & 01 & 19 & 82 & 20 \\
\hline Coa1 & $\begin{array}{c}214 \\
\therefore\end{array}$ & $\begin{array}{l}1920 \\
1974\end{array}$ & $\begin{array}{r}8.0 \\
2932.6\end{array}$ & & $\begin{array}{r}1 \\
10\end{array}$ & $\begin{array}{r}4.0 \\
1460.0\end{array}$ & $\begin{array}{r}8486 \\
18921\end{array}$ & & $\begin{array}{r}5.2 \\
628.0\end{array}$ & 7 & 38 & 49 & 30 & 44 & 24 & 02 & 20 & 2 \\
\hline Gas & 37 & $\begin{array}{l}1928 \\
1974\end{array}$ & $\begin{array}{r}15.0 \\
892.8\end{array}$ & & $\begin{array}{l}1 \\
3\end{array}$ & $\begin{array}{r}7.0 \\
781.0\end{array}$ & $\begin{array}{r}8918 \\
14179\end{array}$ & & $\begin{array}{r}4.6 \\
111.5\end{array}$ & 0 & 0 & 1 & 5 & 0 & 62 & 23 & 2 & 0 \\
\hline $\begin{array}{l}\text { Hydro- } \\
\text { electric }\end{array}$ & 177 & $\begin{array}{l}1948 \\
1974\end{array}$ & $\begin{array}{r}11.0 \\
2430.0\end{array}$ & & & & & & $\begin{array}{r}4.9 \\
756.4\end{array}$ & 11 & 9 & 6 & 7 & 21 & 181 & 19 & 38 & 33 \\
\hline$\frac{\text { Gas- }}{\text { turbines }}$ & 215 & $\begin{array}{l}1967 \\
1973\end{array}$ & $\begin{array}{r}14.2 \\
821.5\end{array}$ & & $\begin{array}{r}1 \\
24\end{array}$ & $\begin{array}{r}14.0 \\
167.0\end{array}$ & & & $\begin{array}{r}1.5 \\
80.9\end{array}$ & 25 & 48 & 49 & 18 & 43 & 12 & 2 & 9 & 9 \\
\hline
\end{tabular}


Table II-2

Non-Fuel Operation and Maintenance Costs - Electric Power Plants

\begin{tabular}{|c|c|c|c|c|c|c|c|c|c|c|c|c|c|c|c|}
\hline & \multirow{2}{*}{$\begin{array}{l}\text { Number of } \\
\text { plants }\end{array}$} & \multirow{2}{*}{ Values } & \multirow{2}{*}{$\begin{array}{l}\text { f sample } \\
\text { Plant } \\
\text { capacity }\end{array}$} & \multirow{2}{*}{$\begin{array}{l}\text { Range of Val } \\
\begin{array}{c}\text { variables } \\
\text { Net } \\
\text { generation }\end{array}\end{array}$} & \multirow{2}{*}{$\begin{array}{l}\text { ues of } \\
\text { Plant } \\
\text { factor }\end{array}$} & \multirow{2}{*}{$\begin{array}{l}\text { Jample } \\
\text { O\&M } \\
\text { cost } \\
\$ 10^{3}\end{array}$} & \multicolumn{8}{|c|}{$\begin{array}{l}\text { Variables } \\
\text { Regional representation } \\
\text { (No. of plants per region) }\end{array}$} & \multirow[b]{2}{*}{$R_{g}$} \\
\hline & & & & & & & $\mathrm{R}_{1}$ & $\mathrm{R}_{2}$ & $\mathrm{R}_{3}$ & $R_{4}$ & $\mathrm{R}_{5}$ & $\mathrm{R}_{6}$ & $\mathrm{R}_{7}$ & $\mathrm{R}_{8}$ & \\
\hline \multicolumn{16}{|l|}{$\frac{\text { Steam- }}{\text { electric }}$} \\
\hline \multicolumn{16}{|l|}{ Oil } \\
\hline Coal & 131 & $\begin{array}{l}1947 \\
1974\end{array}$ & $\begin{array}{r}22.0 \\
2932.0\end{array}$ & & $\begin{array}{r}6.3 \\
113.2\end{array}$ & $\begin{array}{r}216 \\
20652\end{array}$ & 4 & 16 & 17 & 16 & 20 & 15 & 16 & 21 & 6 \\
\hline \multicolumn{16}{|l|}{ Gas } \\
\hline Nuclear & 39 & $\begin{array}{l}1962 \\
1975\end{array}$ & & & & & & & & & & & & & \\
\hline$\frac{\text { Hydro- }}{\text { electric }}$ & 151 & $\begin{array}{l}1948 \\
1974\end{array}$ & $\begin{array}{r}11.0 \\
2430.0\end{array}$ & $\begin{array}{r}27.9 \\
17366.5\end{array}$ & & $\begin{array}{r}31 \\
19447\end{array}$ & 7 & 4 & 6 & 7 & 18 & 16 & 17 & 11 & 65 \\
\hline $\begin{array}{l}\text { Gas- } \\
\text { Turbines }\end{array}$ & 234 & $\begin{array}{l}1961 \\
1972\end{array}$ & $\begin{array}{r}11.2 \\
821.5\end{array}$ & . & 86.8 & $\begin{array}{r}4 \\
3521\end{array}$ & 30 & 55 & 46 & 15 & 54 & 9 & 10 & 5 & 10 \\
\hline
\end{tabular}


variables and plant and unit scale measures were analyzed for the 31 nuclear power plants in our sample, which show large variations in design characteristics between observations.

Three technical variables intuitively presumed to affect construction costs were considered as explanatory variables for the nuclear power plant capital cost equations. The first variable represents the number of first units of multi-unit plants completed during the year. This variable should refect the embedded expenditures for future unit extensions, such as general site improvements, circulating water, fuel storage and handling facilities, system control equipment, etc., which would properly be reallocated when the new units are added. Some engineering studies conducted by the Atomic Energy Commission (AEC) estimate the cost of the first unit of a two-unit plant to be $10 \%$ higher than the cost of the second unit.

The second technical variable is boiler pressure measured in psi. This variable is a key determinant of the generating unit's thermal efficiency and fuel use. Given escalating costs for both fossil and nuclear fuels worldwide, it seems logical that the utilities would be willing to invest to increase the thermal efficiency of their new plants. This assumption has already been borne out for plants becoming operational in 1974 and 1975.

The third technical variable included in our analysis is the average construction time in months for plant completions in a given year. The average construction time for the two plants completed in 1962 was 56 months. The averaging construction time for the four plants completed in 1975 was 78 months, an increase of nearly $40 \%$.

Construction delays are costly. Interest and escalation of costs during construction, both reflected in the construction time variable, are estimated by the AEC to account for more than $40 \%$ of the cost of a two-unit $2600-\mathrm{MW}_{\mathrm{e}}$ plant completed in the early 1980's. Some delays are due to safety and environmental requirements and should thus be considered as policy variables in the development of capital cost functions. 
Table II- 3 presents average costs in 1975 dollars for 31 plants and 41 nuclear power generating units completed between 1962 and 1975. The table shows average cost per plant and per generating unit for the number of plants and units which became operational in any given year. Average capacity per plant and per generating unit are similarly computed and a cost per $\mathrm{kW}_{\mathrm{e}}$ of capacity in constant 1975 dollars is derived. Values for the three technical design parameters - number of first units, average boiler pressure, and average construction time - are then listed.

Figure II-1 presents the data in Table II-3 graphically. It seems clear that, when measured in constant dollars, a large part of the escalation in average capital cost per $\mathrm{kW}_{\mathrm{e}}$ of installed capacity since 1970 can be explained by changes in system technical and operational variables.: From cursory observation of the trends, it appears that some real cost increases were experienced during the period, probably due to more stringent safety and environmental standards, but that the downward trend in cost per $\mathrm{kW}_{\mathrm{e}}$ observed from 1962 through 1970 might have started again in 1975.

Table II-4 presents the same information classified into size and vintage groupings. The size and vintage groups were selected so that they contained a reasonable number of observations, the size groups represented real trends in plant and unit capacity growth, and the vintage groups reflected trends in technological change.

Figures II-2 and II- 3 present the information in Table II-4 graphically. Figure II-2 shows again the underlying relationship between capital cost per $\mathrm{kW}_{\mathrm{e}}$ and boiler pressure and construction time. Also, except for the 800 to 900-MWe group, which includes a large number of first unit plants, the underlying economies of scale in plant capital cost are reflected. Figure II-3 shows the upward trend in cost and the corresponding increases in boiler pressure and construction time.

The impact of technological effects and the existence of scale effects in capital costs with the nuclear power plant sample are difficult to discern for three reasons. First, many of the plants in the sample are experimental, and design standardization has not yet been achieved. Even though a wide range of 
Table II -3

Sample Data for Analysis of Nuclear Power Plant Scale and Vintage Effects

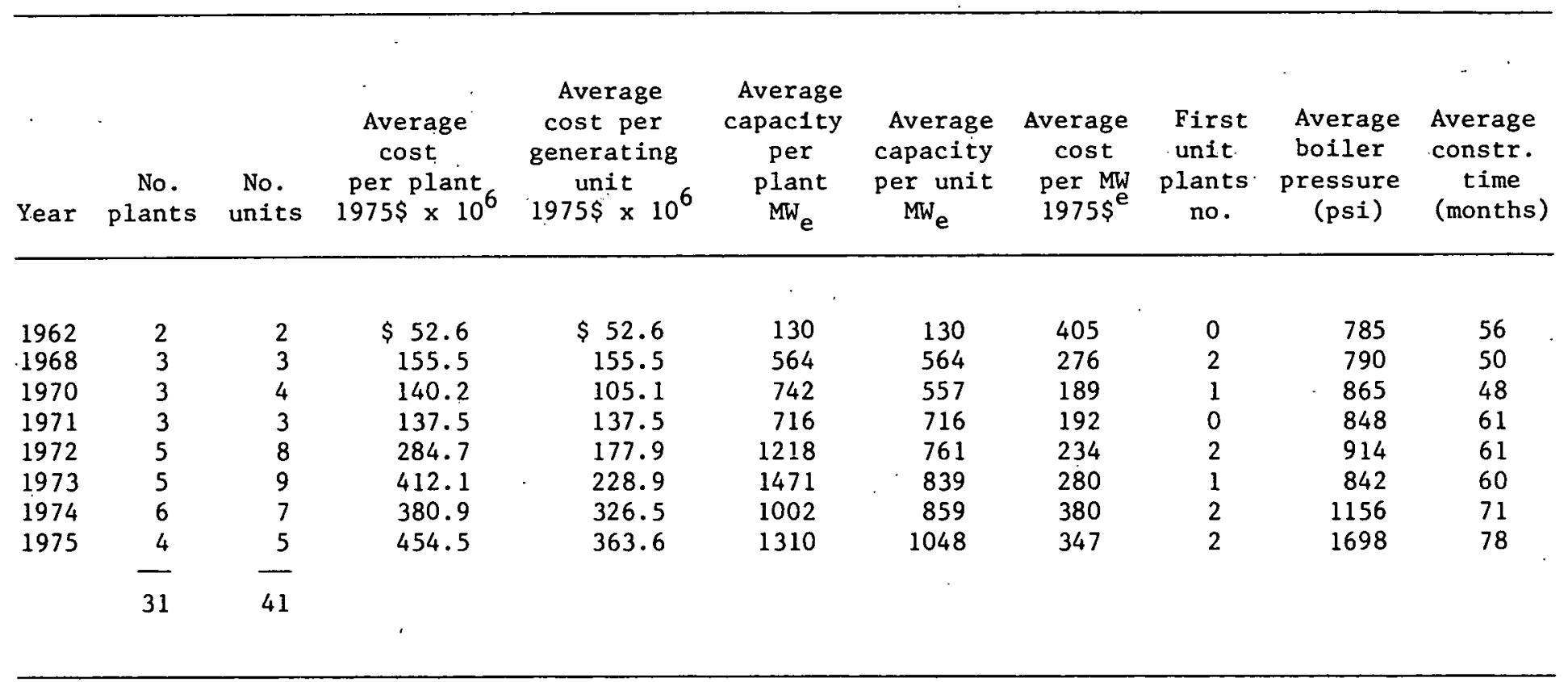




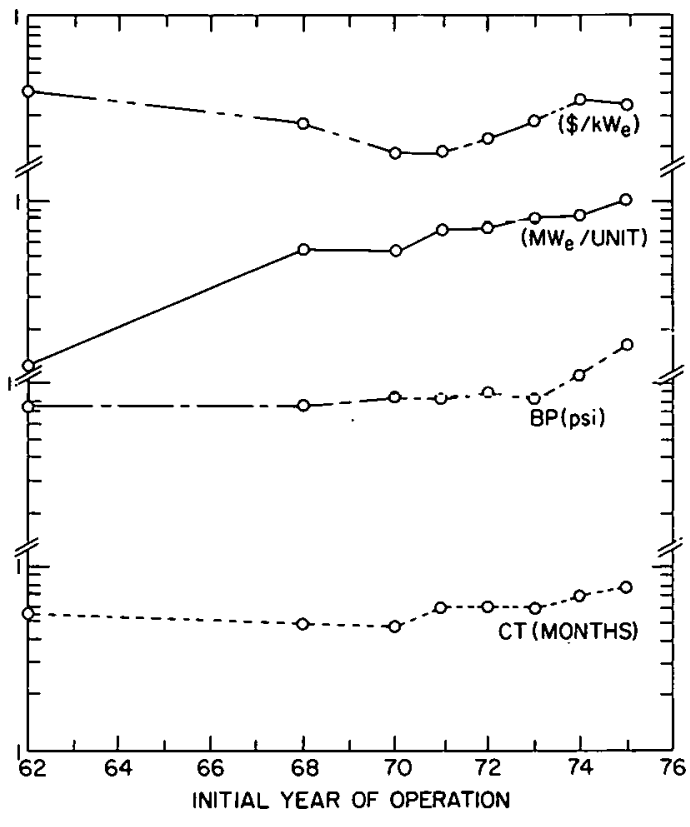

Figure II-1. Nuclear power plants. Trend values of capacity cost and technical parameters. Cost in 1975 dollars

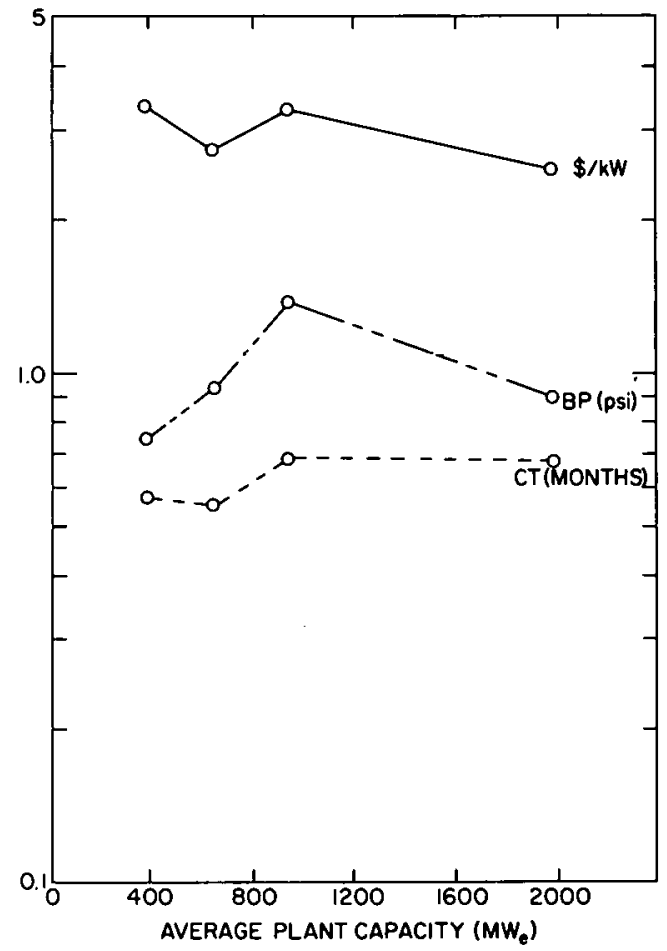

Figure II-2. Trend values of average investment cost and technical parameters of nuclear plants as function of plant capacity

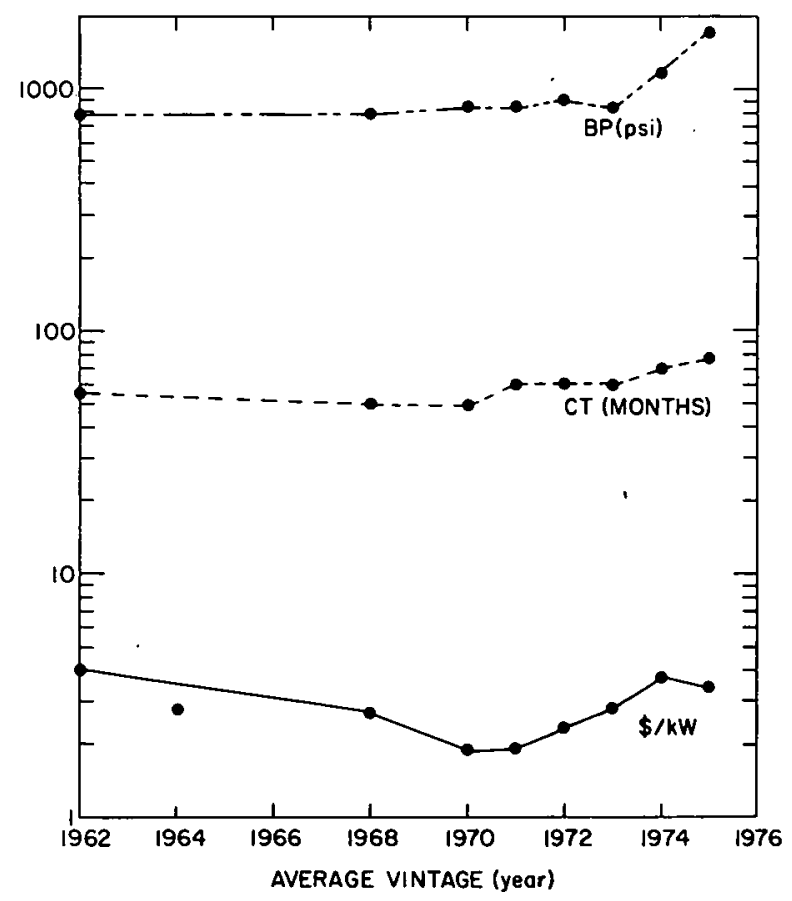

Figure II-3. Trend values of average cost and technical parameters of nuclear plants as function of plant vintage 
Table II-4

Nuclear Power Plant Grouping According to Size and Vintage

\begin{tabular}{|c|c|c|c|c|c|c|c|c|}
\hline $\begin{array}{c}\text { Plant capacity } \\
\text { range } \\
\mathrm{MW}_{\mathrm{e}}\end{array}$ & $\begin{array}{l}\text { No. plan } \\
\text { uni } \\
\text { plants }\end{array}$ & $\begin{array}{l}\text { ats and } \\
\text { lts } \\
\text { units }\end{array}$ & $\begin{array}{c}\text { Total plant } \\
\text { capacity } \\
\mathrm{MW}_{\mathrm{e}}\end{array}$ & $\begin{array}{c}\text { Total plant } \\
\text { cost } \\
\$ 10^{6}\end{array}$ & $\begin{array}{l}\text { Av. plant } \\
\text { capacity } \\
\mathrm{MWe}_{\mathrm{e}}\end{array}$ & $\begin{array}{l}\text { Av. cost } \\
\text { per } \mathrm{kW}_{\mathrm{e}} \\
\$ / \mathrm{kW}_{\mathrm{e}}\end{array}$ & $\begin{array}{c}\text { Boiler } \\
\text { pressure } \\
\text { (psi) }\end{array}$ & $\begin{array}{c}\text { Construction } \\
\text { time } \\
\text { (months) }\end{array}$ \\
\hline \multicolumn{9}{|l|}{ S1ze groups } \\
\hline $0-550$ & 6 & 6 & 2243.1 & 749.5 & 373 & 334 & 747 & 57 \\
\hline $551-800$ & 8 & 8 & 5025.6 & 1375.8 & 628 & 274 & 942 & 55 \\
\hline $801-1100$ & 9 & 10 & 8233.5 & 2870.3 & 914 & 327 & 1373 & 68 \\
\hline $1101-2700$ & 8 & 17 & 15521.7 & 3901.4 & 1940 & 251 & 901 & 67 \\
\hline \multicolumn{9}{|l|}{ Vintage groups } \\
\hline $1962-1969$ & 5 & 5 & - & - & 390 & 293 & 788 & 52 \\
\hline $1970-1971$ & 6 & 7 & - & - & 729 & 190 & 856 & 54 \\
\hline $1972-1973$ & 10 & 17 & - & - & 790 & 244 & 878 & 61 \\
\hline $1974-1975$ & 10 & 12 & - & - & 938 & 356 & 1373 & 74 \\
\hline
\end{tabular}


plant and unit sizes was observed in the sample, the fact that each plant is almost one of a kind precludes any learning effect in equipment manufacturing and plant construction costs as additional units are built. Second, concern about the environment has led to the imposition of increasingly stringent standards by Federal and state regulatory commissions, which have increased the real cost of building a unit of nuclear power capacity. Also, uncertainty about future demand and tight capital markets has forced utilities to postpone, and in some cases extend, construction of new nuclear capacity. The resultant increase in real cost over time is reflected in Figure II-3.

To study trend behavior and regional differences in the capital costs of fossil-fueled plants and units, we selected a sample of all the plants in three regions-Northeast Regions 1 and 2 and West South Central Region 7. Regions 1 and 2 were combined into a single sample because our preliminary analysis showed no difference in the equipment unit costs between them. plants in these regions are predominantly coal and oil fired. Plants in Region 7 are predominantly gas, and oil fired.

The costs analyzed are for equipment, instead of the combined structures and equipment. Most of the technology and scale-related capital cost savings in fossil-fueled systems which we wish to discern in the preliminary analysis are achieved through improvements in steam and electric generating equipment. This might not be true of nuclear systems where structures and equipment are difficult to separate. Also, we are interested in testing for regional differences between the high-cost Northeast and the low-cost West South Central regions that are caused by technical requirements rather than price difference.

Table II-5 presents average equipment costs for five vintage and four capacity groupings of fossil-fueled steam-electric plants in the Northeast region. Table II-6 presents similar data for plants in the West South Central region. Examination of these tabulations shows that average equipment costs per $\mathrm{kW}_{\mathrm{e}}$ of capacity decline for each vintage group within a capacity group and for each vintage group as capacity per unit is increased. Figures II-4 and II-5 present trend lines showing decreasing costs per unit of capacity as both average vintage and average capacity increase. 
Table I I-5

Northeast Regions 1 and 2 Average Equipment Costs for Fossi1-Fueled Plants for Various Vintage and Capacity Groupings

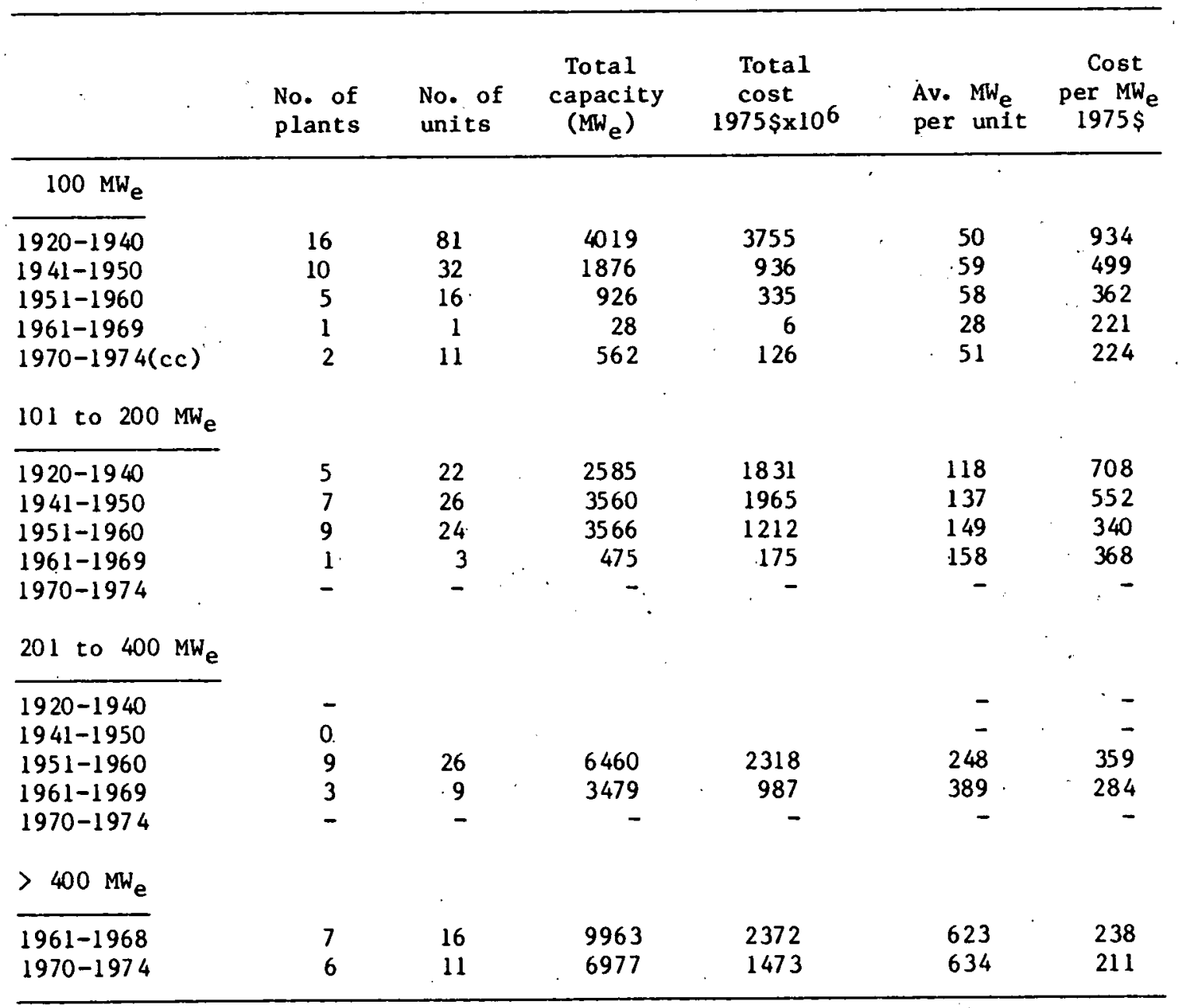


Table II-6

West South Central Region 7

Average Equipment Cost for Fossil-Fueled Plants

For Various Vintage and Capacity Groupings

\begin{tabular}{|c|c|c|c|c|c|c|}
\hline & $\begin{array}{l}\text { No. of } \\
\text { plants }\end{array}$ & $\begin{array}{l}\text { No. of } \\
\text { units }\end{array}$ & $\begin{array}{c}\text { Total capacity } \\
\mathrm{MW}_{\mathbf{e}}\end{array}$ & $\begin{array}{l}\text { Total cost } \\
1975 \$ \$ 10^{6}\end{array}$ & $\begin{array}{l}\text { Av. capacity } \\
\text { MWe per unit }\end{array}$ & $\begin{array}{l}\mathrm{Av} \text {. cost } \\
1975 \$\end{array}$ \\
\hline \multicolumn{7}{|l|}{$\leq 100 \mathrm{MWe}$} \\
\hline $\begin{array}{l}1920-1940 \\
1941-1950 \\
1951-1960 \\
1961-1969 \\
1970-1974\end{array}$ & $\begin{array}{l}8 \\
8 \\
9 \\
6 \\
1\end{array}$ & $\begin{array}{r}33 \\
31 \\
21 \\
14 \\
3\end{array}$ & $\begin{array}{r}1564 \\
1935 \\
1211 \\
1024 \\
290\end{array}$ & $\begin{array}{r}971 \\
415 \\
232 \\
131 \\
32\end{array}$ & $\begin{array}{l}47 \\
62 \\
58 \\
73 \\
97\end{array}$ & $\begin{array}{r}\$ 620 \\
214 \\
192 \\
128 \\
110\end{array}$ \\
\hline \multicolumn{7}{|c|}{100 to $200 \mathrm{MW}_{\mathrm{e}}$} \\
\hline $\begin{array}{l}1920-1940 \\
1941-1950 \\
1951-1960 \\
1961-1969 \\
1970-1974\end{array}$ & $\begin{array}{l}1 \\
4 \\
7 \\
1 \\
2\end{array}$ & $\begin{array}{r}8 \\
18 \\
25 \\
1 \\
3\end{array}$ & $\begin{array}{r}945 \\
1484 \\
3507 \\
120 \\
387\end{array}$ & $\begin{array}{r}424 \\
610 \\
578 \\
13 \\
54\end{array}$ & $\begin{array}{l}118 \\
138 \\
140 \\
120 \\
129\end{array}$ & $\begin{array}{l}449 \\
245 \\
165 \\
109 \\
140\end{array}$ \\
\hline \multicolumn{7}{|c|}{200 to $400 \mathrm{MW}_{\mathrm{e}}$} \\
\hline $\begin{array}{l}1920-1940 \\
1941-1950 \\
1951-1960 \\
1961-1969 \\
1970-1974\end{array}$ & $\begin{array}{l}0 \\
0 \\
4 \\
5 \\
4\end{array}$ & $\begin{array}{r}- \\
\overline{16} \\
15 \\
6\end{array}$ & $\begin{array}{r}- \\
- \\
5444 \\
4575 \\
1669\end{array}$ & $\begin{array}{c}- \\
- \\
889 \\
482 \\
203\end{array}$ & $\begin{array}{l}- \\
- \\
340 \\
297 \\
278\end{array}$ & $\begin{array}{l}- \\
- \\
163 \\
105 \\
122\end{array}$ \\
\hline \multicolumn{7}{|l|}{$\geq 400 \mathrm{MWe}$} \\
\hline $\begin{array}{l}1961-1969 \\
1970-1974\end{array}$ & $\begin{array}{l}2 \\
3\end{array}$ & $\begin{array}{l}5 \\
5\end{array}$ & $\begin{array}{l}2155 \\
2523\end{array}$ & $\begin{array}{l}244 \\
241\end{array}$ & $\begin{array}{l}431 \\
505\end{array}$ & $\begin{array}{r}113 \\
96\end{array}$ \\
\hline
\end{tabular}


Figures II-4 and II-5 also show significant differences between average equipment cost per unit capacity $\left(\mathrm{kW}_{\mathrm{e}}\right)$ for the Northeast and South West Central regions, but the slopes of the two curves are very similar. This indicates that the effects of technological improvement and economies of scale are not significantly affected by regional differences and that both technological improvements and generating unit size have been increasing at a similar rate for all fossil-fueled generating units, i.e., coal, oil, and gas.

The regional differences observed in Figures II-4 and II-5 can be explained by a number of factors. First, the Northeast region's generating capacity consists primarily of residual oil- and coal-fired power plants which are more polluting than gas-fired plants. There is not a single gas-fired steam-electric plant in the Northeast region, while they predominate in Region 7. Second, the Northeast region is heavily congested and afflicted by severe air and water pollution problems that require heavy investment in pollution abatement equipment. Region 7 is more sparsely populated and its plants burn low-sulfur oil and clean gas, thus requiring lower investment in air pollution equipment. Third, coal and oil plants require more fuel-handling equipment and burners and are thus more expensive than gas-fired plants. There may be other reasons for the large differences in average plant equipment costs between the two regions, which we will try to measure by the use of appropriate variables in the regression equation.

D. Pollution Abatement

The principal emissions from electric generation plants are sulfur dioxide $\left(\mathrm{SO}_{2}\right)$, nitrogen oxides $\left(\mathrm{NO}_{\mathrm{x}}\right)$, particulates, and thermal polution. Methods and costs for abatement of each pollutant are discussed below.

\section{Air Pollution Control. Electrostatic precipitators are generally} recognized as providing the cheapest, most reliable process for fly-ash (particulates) removal rates of up to the $99 \%$ required to meet both the particulate and $\mathrm{SO}_{2}$ standards established by EPA. They are usually used with pulverized coal furnaces. Most new base load coal plants use electrostatic precipitators, and this study considers them only for $\mathrm{fly}$-ash and $\mathrm{SO}_{2}$ abatement in coal-fired power plants." 


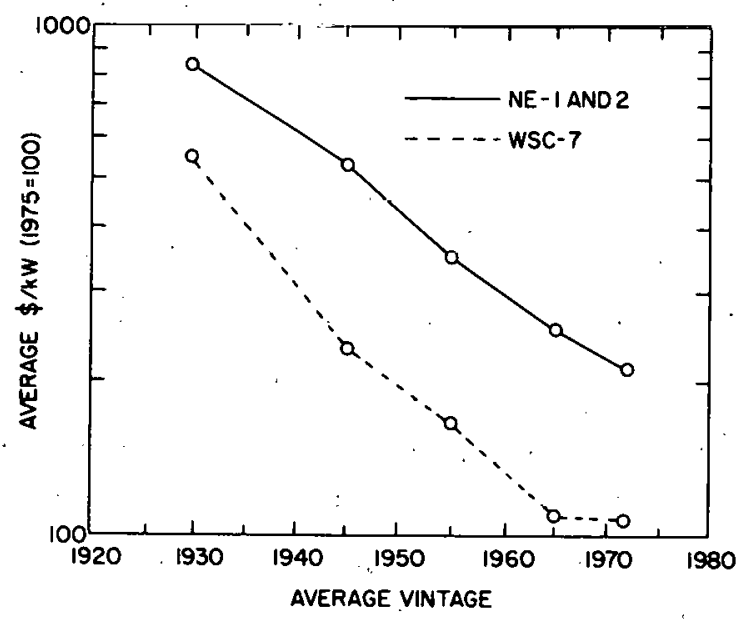

Figure II-4. Average equipment cost for fossil-fueled steam-electric power plants as a function of vintage. Northeast regions 1 and 2 and WSC region 7

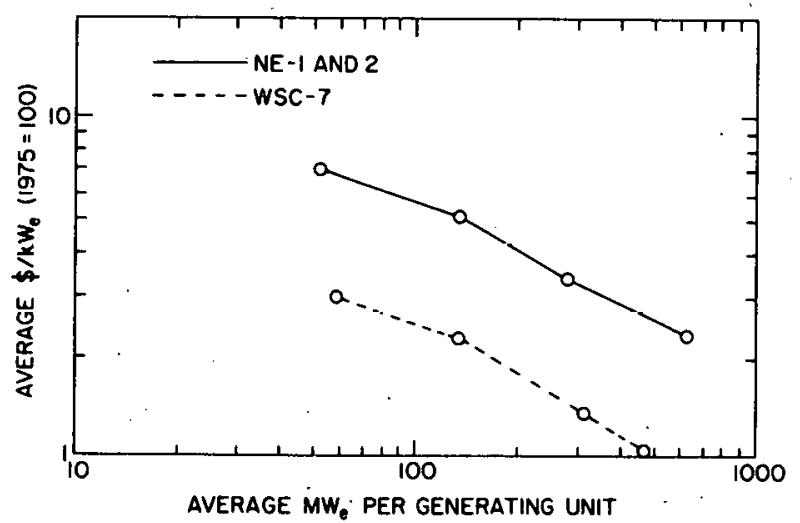

Figure II-5. Average equipment cost per $\mathrm{kW}_{\mathrm{e}}$ for fossil-fueled steam-electric power plants as a function of scale. Northeast regions 1 and 2 and WSC region 7 
Scherer questioned a number of electric utilities about fly-ash precipitation and removal and found that the average cost of air pollution control equipment for existing plants was approximately $2.5 \%$ of initial capital costs for 1970 vintage plants. 2 Additional information gathered for his study showed fly-ash removal equipment capital costs for four pre-1970 plants amounting to $\$ 1.73$ million against initial capital costs of $\$ 84.1$ million. The ratio of fly-ash removal equipment cost to total plant cost was $2 \%$. This finding gives credibility to the utilities' $2.5 \%$ estimate for post-1970 plants. The later ratio could be used as an adjustment factor to estimate fly-ash removal equipment costs in existing plants if the regression analysis does not provide an adequate estimation for total pollution control capital and O\&M costs.

$\mathrm{SO}_{2}$ abatement by stack removal has not been completely proven, although several methods had been tested by 1973. The abatement of $\mathrm{SO}_{2}$ emissions from fossil-fueled plants is accomplished either by removing $\mathrm{SO}_{2}$ from stack gases or by using a low-sulfur fuel.

The $\mathrm{SO}_{2}$ stack removal processes under development may be categorized as either "throwaway," or "by-product recovery." The throwaway processes include limestone injection, dry removal, and wet removal. In the dry process, lime or limestone is blown into the boiler, reacts with the $\mathrm{SO}_{2}$ to forin calcium sulfite, and is then collected in the electrostatic precipitator from which it is removed and discarded. In the wet process, lime or limestone is injected into the boiler, and then removed along with the particulates by wet scrubbers. The recovery processes' are also divided into "wet" and "dry": systems.

Table II-7 reproduces a tabulation from the FPC Form S-253 listing pollution control systems with $\mathrm{SO}_{2}$ removal capability installed through 1973. Quick calculations from the cost data in the table result in cost ranges for fly-ash and $\mathrm{SO}_{2}$ removal systems operating at 80 to $90 \%$ efficiency of between $\$ 20-30 / \mathrm{kW}_{e}$ for oil-fired plants and $\$ 60-90 / \mathrm{kW}_{e}$ for coal-fired plants.

Table II-8 reproduces Cat $-0 \times \mathrm{SO}_{2}$ removal cost estimates published by Mansanto Eviro-Chem Systems; Inc., in 1972.3 The table shows estimates (1972 dollars) of both capital and operating costs to retrofit existing plants and 
Table II-7

Pollution Control Systems With $\mathrm{SO}_{2}$ Removal

Capability Installed Through 1973

\begin{tabular}{|c|c|c|c|c|c|c|}
\hline $\begin{array}{l}\text { Utility } \\
\text { (plant) }\end{array}$ & $\begin{array}{l}\text { Year FGD } \\
\text { placed In } \\
\text { service }\end{array}$ & $\begin{array}{l}\text { FGD capacity } \\
\text { serviced (MW) }\end{array}$ & $\begin{array}{c}\text { Fuel } \\
\text { burned }\end{array}$ & $\begin{array}{l}\text { Design } \mathrm{SO}_{2} \\
\text { removal } \\
\text { efficiency }(\%)^{\mathrm{a}}\end{array}$ & $\begin{array}{l}\text { Installed cost } \\
(\$ 1000)\end{array}$ & $\begin{array}{l}\text { Type of } \\
\text { FGD system }\end{array}$ \\
\hline $\begin{array}{l}\text { Dairyland Power Co. } \\
\text { (Alma) }\end{array}$ & 1971 & 81.6 & Coal & 70.0 & 300 & $\begin{array}{l}\text { Dry lime } \\
\text { injection }\end{array}$ \\
\hline $\begin{array}{l}\text { I11inois Power Co. } \\
\text { (Wood RIver) }\end{array}$ & 1972 & 112.5 & Coal & 85.0 & 6,800 & $\begin{array}{l}\text { Catalytic } \\
\text { oxidation }\end{array}$ \\
\hline $\begin{array}{l}\text { Commonwealth Edison } \\
\text { (W111 County) }\end{array}$ & 1972 & 167.0 & Coal & 76.0 & 15,000 & $\begin{array}{l}\text { Wet limestone } \\
\text { scrubber }\end{array}$ \\
\hline $\begin{array}{l}\text { Boston Ed1son } \\
\text { (Myst1c) }\end{array}$ & 1972 & 137.5 & Residual ofl & 90.0 & 4,000 & $\begin{array}{l}\text { Magnesium oxide } \\
\text { scrubber }\end{array}$ \\
\hline $\begin{array}{l}\text { Potomac Electric Power } \\
\text { Co. (Dickerson) }\end{array}$ & 1973 & 100.0 & Coal & 90.0 & 6,307 & $\begin{array}{l}\text { Magnesium oxide } \\
\text { scrubber }\end{array}$ \\
\hline $\begin{array}{l}\text { Louisville Gas \& } \\
\text { Electric (Paddy's Run) }\end{array}$ & 1973 & 65.0 & Coal & 85.0 & 3,760 & $\begin{array}{l}\text { Wet lime } \\
\text { scrubber }\end{array}$ \\
\hline $\begin{array}{l}\text { Key West Utillty Board } \\
\text { (Stock Island) }\end{array}$ & 1973 & 37.0 & Residual ofl & 85.0 & 800 & $\begin{array}{l}\text { Dry limestone } \\
\text { injection }\end{array}$ \\
\hline $\begin{array}{l}\text { Ar1zona Public Service } \\
\text { Co. (Cholla) }\end{array}$ & 1973 & 57.5 & Coal & 80.0 & 6,553 & $\begin{array}{l}\text { Wet limestone } \\
\text { scrubber }\end{array}$ \\
\hline
\end{tabular}

a To be distinguished from total system efficlency which includes system

b avallability in addition to $\mathrm{SO}_{2}$ removal efficiency.

Regenerative type which produces a salable product. 


\section{Table II-8}

Cat-Ox $\mathrm{SO}_{2}$ Removal Costs*

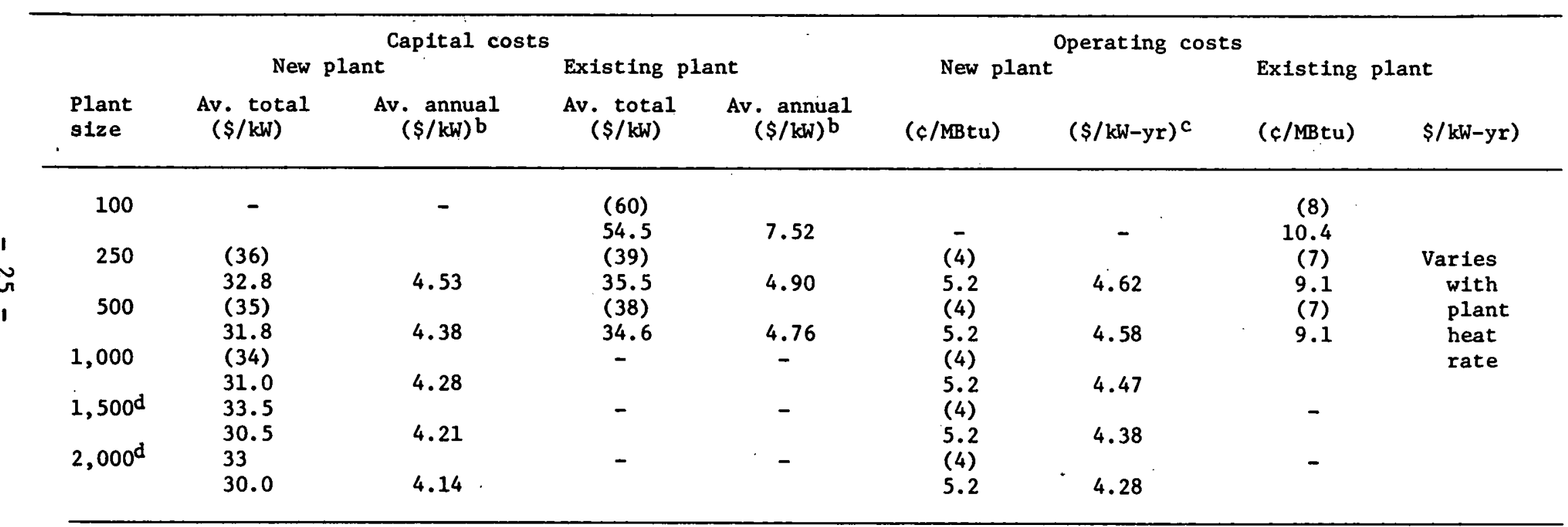

adata in parentheses taken from Monsanto Enviro-Chem Systems, Inc., Air Pollution Control for Electric Utilities b Cat-0x Systems, Air Pollution Control Department, 800 Lindbergh Blvd., St. Louis, Mo. 63166, 1972.

FCF $=13.8 \%$ for existing and new plants.

d Heat rates from table 6.8; heat rate for $Y$ MW plant is heat rate for unit of $Y / 2$ MW.

Extrapolated. 
install the system at new plants of various sizes. Capital cost estimates average approximately $\$ 35 / \mathrm{kW}_{\mathrm{e}}$ for new plants and $\$ 40-60 / \mathrm{kW}_{\mathrm{e}}$ for retrofits. O\&M costs range from approximately $\$ 5 / \mathrm{kW}-\mathrm{yr}$. for new plants to $\$ 10$ for existing plants.

Estimates of future costs for pollution abatement are given by the AEC in current and 1974 dollars for coal- and oil-fired plants going into service in 1983, with and without $\mathrm{SO}_{2}$ removal equipment. 4 The capital cost of air pollution abatement per $\mathrm{MW}_{e}$ of installed capacity is shown as $\$ 47$ for coal-fired plants and $\$ 26$ for oil-fired plants in 1974 dollars. The same source estimates the cost of safety and pollution control for a $1000-\mathrm{MW}_{\mathrm{e}}$ nuclear LWR to be $\$ 60 / \mathrm{kW}_{\mathrm{e}}$ in current dollars by 1983 . This source does not show estimates of $O \& M$ costs.

O\&M cost estimates for particulate and $\mathrm{SO}_{2}$ removal and disposal are given in a 1975 ERDA study, based on engineering estimates for coal- and oil-fired power plants.5 The estimate assumes limestone slurry scrubbers for the flue-gas desulfurization, and a 2-unit, 1,000-MWe per unit plant, operating at a $78 \%$ plant factor with mechanical draft evaporate cooling towers.

The results show a cost of $2.13 \mathrm{mills} / \mathrm{kWh}$ for $\mathrm{SO}_{2}$ removal and disposal for the coal plant and $0.83 \mathrm{mills} / \mathrm{kWh}$ for the oil plant. These costs translate into $\$ 14.55 / \mathrm{kW}-\mathrm{yr}$ for the coal plant and $\$ 5.67 / \mathrm{kW}-\mathrm{yr}$. for the oil plant. The $\mathrm{SO}_{2}$ abatement costs for the coal plant represent $70 \%$ of the tota $1.0 \& \mathrm{M}$ cost and $53 \%$ for the oil plant.

2. Water Pollution Control. Water pollution from power plants occurs chiefly in the form of hot water discharges into streams and other bodies of water. Modern fossil-fueled plants emit $75 \%$ of their waste heat in this manner, and nuclear plants, $94 \%$. The stated goals of the Federal Water Pollution Control. Act Amendments of 1972 and the 1977 guidelines enacted by the states to implement the act are the virtual elimination of water pollution discharges by 1985 .

As of 1973, a majority of the nation's generating capacity were using simple once-through cooling systems. Such systems will clearly fail to meet 
the 1977 EPA guidelines. The principal alternatives are cooling ponds or cooling towers. With these systems, the excess heat in the discharge water is transferred to the atomosphere before release to natural water bodies.

Four main sources of information were used to gather water pollution costs. The first source presents estimates of the initial investment costs for cooling systems as of 1970.6 According to this report, the incremental capital costs for water pollution control range from 2 to $\$ 6 / \mathrm{kW}_{\mathrm{e}}$ at fossil-fueled plants and from 3 to $\$ 9 / \mathrm{kW}_{e}$ at nuclear plants, depending on the type of system installed - once-through, ponds, or mechanical and natural draft cooling towers. The report also gives estimates for dry-cooling towers of 25 to $\$ 28 / \mathrm{kW}_{e}$ for mechanical draft and 27 to $\$ 30 / \mathrm{kW}_{e}$ for natural draft cooling systems.

The FPC estimates unit capital costs per $\mathrm{kW}$ capacity in 1973 dollars as follows :

$$
\begin{array}{ll}
\text { Once-through fresh water } & -\$ 4.39 / \mathrm{kW}_{e} \\
\text { Once-through saline water } & -5.38 / \mathrm{kW}_{e} \\
\text { Cooling ponds } & -5.29 / \mathrm{kW}_{e} \\
\text { Cooling towers } & -6.95 / \mathrm{kW}_{e}
\end{array}
$$

These estimates are based on cooling systems installed as of the end of 1973 and fall within the range of the 1970 Joint Economic Committee estimates. Scherer, using equations developed by Dickey and Cates, 7 estimates forced draft cooling tower costs of $\$ 5.50 / \mathrm{kW}_{\mathrm{e}}$ for fossil-fueled plants and $\$ 7.50$ for nuclear plants. Natural draft tower costs are estimated at $\$ 4.20 / \mathrm{kW}_{\mathrm{e}}$ for fossi1-fueled plants and $\$ 5.70 / \mathrm{kW}_{e}$ for nuclear plants. The cost data uncovered for once-through cooling ponds and wet-cooling towers are in close agreement after adjustment for differences in the years the estimates were made.

Petruschell and Salter estimated incremental cooling system captial costs for wet and dry cooling towers. 8 For wet towers, the estimates were ( 1970 dollars): $\$ 3.70 / \mathrm{kW}_{\mathrm{e}}$ for coal-fired plants and $\$ 4.80$ for nuclear plants for mechanical draft towers, and $\$ 7.48 / \mathrm{kW}_{e}$ for oil plants and $\$ 9.60 / \mathrm{kW}_{e}$ for nuclear plants for natural draft systems. For dry towers, they estimated $\$ 23 / \mathrm{kW}_{\mathrm{e}}$ for coal plants and $\$ 30 / \mathrm{kW}_{e}$ for nuclear plants for mechanical draft systems, and 
$\$ 30 / \mathrm{kW}_{e}$ for coal plants and $\$ 46 / \mathrm{kW}_{e}$ for nuclear plants for natural draft systems. These numbers are essentially in agreement with the estimates prepared by the Joint Economic Committee.

Tables II-9 and II-10 show a summary of capital costs per $\mathrm{kW}_{\mathrm{e}}$ and $0 \& \mathrm{M}$ cost per $\mathrm{kW}-\mathrm{yr}$ collected from the various sources mentioned, and converts the estimates to 1975 dollars for ease of comparison. The averages of the various estimates in 1975 dollars could be used as adjustment factors in the regression equations developed in this study for projection of future costs. Appropriate escalation factors are available in the literature if current dollar estimates are desired.

\section{REFERENCES}

1. The Bureau of Labor Statistics publishes a report (Bulletin 1834), Industry Wage Survey: Electric and Gas Utilities, which shows reglonal wage levels by occupational category. No indication of individual plant skill mix is given, and the data are for November 1972 only.

2. Scherer, Charles R., Estimating Electric Power System Marginal Costs, North Holland, N.Y., 1977.

3. Air Pollution Control for Electric Utilities - Cat-0x Systems, Air Pollution Control Department, 800 Lindbergh Blvd., St. Louis, Mo. 63166.

4. Power Plant Capital Costs, Current Trends and Sensitivity to Economic Parameters, U.S. Atomic Energy Commission, Division of Reactor Research and Development, October, 1974.

5. A Procedure for Estimating Non-Fuel Operating and Maintenance Costs for Large Steam-Electric Power Plants, Office of Energy Systems Analysis, U. S. Energy Research and Development Administration, October 1975.

6. U.S. Congressional Joint Economic Committee, The Economy, Energy and the Environment, Washington, D.C., 1970.

7. Dickey, J.B., and Cates, R.E., Managing Waste Heat with the Water Cooling Tower, report to the Marley Corp., Kansas City, Mo., 1972.

8. Petruschell, R.L., and Salter, R.G., Electricity Generating Cost Model for Comparison of California Power Plant Siting Alternatives, The RAND Corp., $\mathrm{R}-1087-\mathrm{RF} / \mathrm{CSA}$, January 1973. 
Table II-9

Alr Pollution Control Costs

\begin{tabular}{|c|c|c|c|c|c|c|c|c|c|}
\hline \multirow{3}{*}{$\stackrel{\mathrm{SO}_{2}}{\text { control }}$} & \multirow{3}{*}{ Source $^{a}$} & \multicolumn{4}{|c|}{ Capital costs $\left(\$ / \mathrm{kW}_{e}\right)$} & \multicolumn{4}{|c|}{$0 \& M \cos t(\$ / k W-y r)$} \\
\hline & & \multicolumn{2}{|c|}{ Current $\$$} & \multicolumn{2}{|c|}{$1975 \$$} & \multicolumn{2}{|c|}{ Current \$ } & \multicolumn{2}{|c|}{$1975 \$$} \\
\hline & & New & Retrofit & New & Retrofit & New & Retrofit & New & Retrof it \\
\hline Watson & (Ref 2) & $33-45$ & - & $46-63$ & - & $4.29-7.98$ & - & $5.36-9.98$ & - \\
\hline MeSorley & (Ref 3) & 25 & 75 & 33 & 100 & 3.06 & 9.18 & 4.08 & 12.24 \\
\hline Tarquin & (Ref 4) & 35 & $45-60$ & 44 & $56-75$ & - & - & - & - \\
\hline Gakner & (Ref 5) & 57 & 77 & 71 & 96 & 8.58 & 11.67 & 10.73 & 14.59 \\
\hline Myers & (Ref 6) & 36 & - & 50 & - & 6.13 & - & 8.51 & - \\
\hline FPC & (Ref 1) & & & & & & & & \\
\hline 011 & & $20-30$ & - & $27-38$ & - & - & - & & \\
\hline Coa1 & & $60-90$ & - & $80-113$ & - & - & - & & \\
\hline Cat-Ox & (Ref 9) & 15 & $40-60$ & 44 & $50-75$ & 5.00 & 10.00 & 6.33 & 13.00 \\
\hline $\mathrm{AEC}$ & (Ref 10) & & & & & & & & \\
\hline 011 & & 26 & - & 28 & - & - & - & - & - \\
\hline Coa1 & & 47 & - & 51 & - & - & - & - & - \\
\hline ERDA & (Ref 11) & & & & & & & & \\
\hline 011 & & - & - & - & - & 5.67 & - & 5.67 & - \\
\hline Coal & & - & - & - & - & 14.34 & - & 14.34 & - \\
\hline
\end{tabular}

a Sources 11sted in References at the end of Appendix A. 
Table II-10

Water Pollution Control Costs

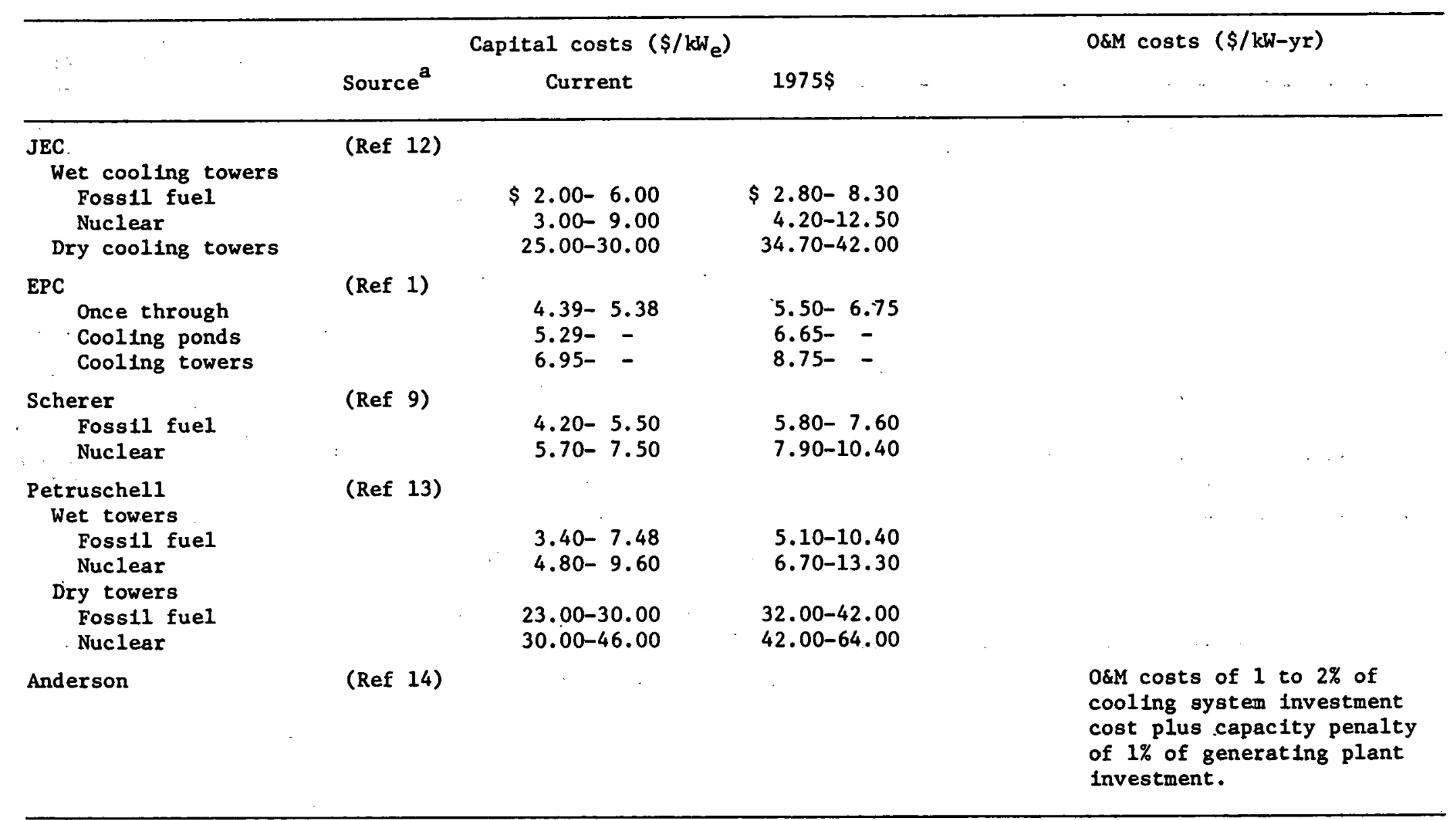

\footnotetext{
${ }^{a}$ Sources 11sted in References at the end of Appendix A.
} 


\section{STATISTICAL ANALYSIS OF ELECTRIC POWER}

GENERATION COSTS

\section{A. Overview of Cost-Estimating Methodology}

1. Introduction. This study focuses primarily on developing capital and operating cost-estimating relationships for a number of generating technologies, based on historic plant-level data published annually by the FPC. Cost-estimating relationships are for initial investment costs and annual operating expenses at the Census Region level. The generating technologies covered are: conventional coal, oil, and gas steam-electric, nuclear LWR, gas turbine generators, and conventional hydroelectric and pumped storage facilities.

These generating technologies lend themselves to a statistically based cost determination approach, since a great deal of historic information covering a large number of plants in each Census Region is available. Use of statistical data for. a period of significant technological advances, fluctuations in general price levels, and variations in plant design and operating characteristics requires a substantial effort. For conventional steam technologies, plant-level data are available from reports filed with the FPC and published annually since 1938. Data are available for individual plants from the year of initial commercial operation for capacity, construction costs, and engineering characteristics, and for annual production expenses in subsequent years.

Plants were generally observed in the initial year of operation, and their capital costs and physical characteristics recorded. Operating cost. data for those plants that remained unchanged from the date of initial operations were observed in the most recent year available. Thus, plants undergoing capacity expansion, major modification, or back-fitting subsequent to initial operations were excluded from the sample. This procedure required tracking each plant . from initial operation to the year(s) for which operating data were recorded. Capital costs recorded at the inception of commercial operations were normalized to constant 1975 dollars, using region-spectfic price deflators 
developed from the Handy-Whitman Index of Public Utility Construction Costs. A procedure which reflected pricing behavior for various categories of structures and equipment comprising the overall generating plant was used to develop price indices for each generating technology. In addition, information about the phasing of actual cash outlays over the plant construction period was utilized to develop the price deflators used here. Thus, a price deflator was developed by weighting the Handy-Whitman annual or semiannual series to account for the typical timing of outlays and length of construction period. (See Appendix B for a complete description of the procedure employed.)

Although the Handy-Whitman price index is compiled separately on a six-region geographical basis, it is critical to note that all regions were assigned an index value of 100 in the base period (1947), and rates of change from this common base value are recorded subsequently: Only regional rates of change in costs can be determined from this source, not relative differences in the level of costs between regions. Relative differences in the level of capital and operating costs were therefore determined by /statistical analysis.

Operating costs are composed of fuel and non-fuel labor and material expenditures. Fuel input data at the plant level of detail are available on both a monetary and physical (Btu) basis. Non-fuel expenditures are grouped into separate $0 \& M$ cost accounts, which we have treated as aggregate total production expenses exclusive of fuel. Fuel. input was measured in physical terms (Btu) and estimating equations were developed on a Btu basis.1 O\&M costs, however, are measured in dollässand, in the absence of a reglonal or national cost index, cannot be expressed on a constant dollar basis over time.

To avold this difficulty, two options are possible: use average annual employees per plant as a proxy for total O\&M costs, or take a cross section of plants in the latest year for which data are available and determine costs in constant dollars for the year observed. The first option was rejected because: 1) regional wage levels needed to derive costs for utility employees were only avallable for $1972^{2}$; 2) no data for the $\mathrm{mix}$ of skill categories or quality differences were available; 3) available statistical studies Indicated reasonably good, but not outstanding, results using the number of employees, since O\&M costs can vary without variation in the number of assigned 
employees. 3 Consequently, cross-section O\&M: expenditure data for the most years available were pooled and deflated:'through the use of dummy variables. In instances where a large sample was available from a single cross section, pooling was avoided.

2. Modei Specification: General. Model specification involves the determination of the level of disaggregation for the cost categories to be estimated, the selection of independent variables, and the use of functional form(s). Each of these topics is discussed below.

As previously mentioned, three broad categories of costs were analyzed: capital costs, fuel input, and non-fuel O\&M expenditures. Capital expenditures for each planticomprise structures and.timprovements, equipment, and land and land rights. As prescribed in the F.PC Uniform System of Accounts, these costs cover accounts 311 through 316, andinclude direct and overhead construction costs, structures, equi.pment, and:an. allowance for funds used during construction, but exclude the step-up transmission substation associated with the plant. Interestiand escaltation costs during construction have assumed increasing importance ast: lthe period required for construction has lengthened in recent years. Note that:land and land rights were excluded from the capital costs used in this study, isince wide variability in this item unrelated to technical requirements wastobserved. Further investigation of land costs in the "19th Steam Station Cost Survey" published by Electric World revealed enormous variability in site acreage for plants with similar generating capacity. 4 Plants ranging in size from 500 to $1,000 \mathrm{MW}$ of capacity were, for example, observed to "require" sites from as small as 187 acres to nearly 8,000 acres. Some utilities are able to include additional land beyond the amount strictly required for the plant site as part of the investment cost base.

Fuel expenses are by far the largest production expense category for steam plants and gas turbine generators. Utilities report to the FPC the amount, cost per unit, Btu per unit, and cost per million Btu for each plant and type of fuel used. In general, cost per unit, and to some extent Btu per unit and consequently cost per Btu differed appreciably even for plants burning the same fuel and belonging to the same utility system. Accordingly, we have chosen to 
use as the dependent variable the physical input of fuel measured in Btu. For multi-fuel plants, data recorded were Btu consumed for each fuel type and in total. 5 To eventually compute total generating costs, the fuel input relationship will have to be converted from physical to monetary terms. For this purpose, the regional price for each fuel type at future points in time will be provided as an endogeneous variable from the BNL Multi-Regional Energy and Interindustry Model.

Non-fuel O\&M costs for labor and materials are the third cost category. The available FPC accounts are nut broken out by cost category (i.e., labor, water, maintenance supplies, and materials) but rather by activities such as supervision and engineering, steam expenses, maintenance of boilers, etc. Because accounting treatment of operating as opposed to maintenance activity is somewhat arbitrary, we have chosen to combine both categories into total production expenses (exclusive of fuel).

As we examined the data in detail, it became apparent that regulated utilities prefer to treat modification or backfitting activities as expenses when such activities are really of a capital nature. Unfortunately, little can be done to separate such costs from O\&M costs. We have, however, excluded from the sample the partial year of operating data for a new plant beginning commercial operations. Apparently, many pre-operating expenses are spread over into operating costs after the plant begins commercial generation.

3. Model Specification: Regional Analysis. Prior to presenting the results of the analysis undertaken to derive regression equations for estimating capital and operating costs for each generating technology, the theoretical basis and statistical principles of our techniques should be explained. We have developed estimating equations in both additive (Iinear) and exponential (log-linear) forms. Our a priori preference is for the exponential form, on account of its greater consistency with the technical features of modeling productive relationships and its preferable statistical properties. The selection of potential explanatory variables includes output unit parameters and characteristics of generating plant logically related to 
the costs being estimated. Whenever possible, we have avoided the use of composite variables, such as total capacity and $\mathrm{kWh}$ of output, which tend to mask the specific structure of the underlying independent variables. Instead, independent variables are broken down into several separate component variables, depending on whether the cost category is a capital or an operating variable.

$$
\text { Capacity }\left(\mathrm{MW}_{\mathrm{e}}\right)=\frac{\text { installed capacity }}{\text { turbine generator unit }} \times \text { number of } \mathrm{T}-\mathrm{G} \text { units, }
$$

$$
\text { Net generation }(k W h)=\text { installed capacity } \mathbf{x} \text { plant factor, }
$$

where

$$
\text { Plant factor }=\frac{\text { net generation }(\mathrm{kWh})}{8760 \text { hours per year } \mathrm{x} \text { installed capacity }}
$$

An additional feature of the regression analysis is the liberal use of dummy variables, especially to measure regional effects, and also to represent qualitative variables that may affect costs.

Equations. The exponential equation form has many desirable statistical properties that make it more appropriate than the additive form for regression analysis of costs. The most important of these are:

- The marginal cost per unit of output (or capacity) can vary with the level of output (capacity) and other plant characteristics.

- The cost elasticity is constant.

The error term is proportional to the magnitude of out (or capacity).

Consider the advantages of the exponential form with regard to marginal cost and cost elasticity. If we attempted to estimate $O \& M \operatorname{costs}(C)$ with $a:$ linear equation in terms of, say, a size variable $(S)$ and output $(0)$, the $2 n i$ equation would be as follows:

$$
c=a+b_{1} s+b_{2} \dot{0}
$$


Regression coefficient $b_{2}$ is equal to the estimated marginal costs per unit output. In this model, a given increase in output will increase costs by a fixed number of dollars, $b_{2}$, regardless of level of output or plant size. The exponential form relates a percentage change in cost to a percentage change in output (or size). That is, if we have an exponential equation to

$$
C=\operatorname{AS}^{\mathrm{b}} 1_{0} \mathrm{~b}_{2}
$$

then differentiating it with respect to output and dividing both sides by $C$, we get

$$
\frac{D C}{C}=b_{2} \frac{d o}{0} \text {, }
$$

which means that a $10 \%$ change in output implies a change in costs of $\mathrm{b}_{2} \mathrm{x} 10 \%$. Furthermore, the size of the coefficient $b_{2}$ immediately signifies whether the cost relationship is of increasing $\left(b_{2}>1\right)$, decreasing $\left(b_{2}<1\right)$, or constant costs $\left(b_{2}=1\right)$. The cost elasticity coefficient $b_{1}$ is constant over all levels of output.

With the exponential equation form, the marginal cost per unit output will also vary with size or any other variables included in the equation. Taking the derivation of cost with respect to output gives the following expression for marginal cost:

$$
M C=\frac{d C}{d O}=A S^{b} 1_{b_{2}}{ }^{b} 2-1
$$

Thus we see that. the marginal cost is related to both the level of output and the size variable.

The nature of the error term is another desirable feature of the exponential model. Because the regression equation for the exponential model 
is developed in log-linear form, the estimating error is proportional to the size of the dependent variable. This assumes that the error which perturbs costs for small plants will be no worse than that for large plants on a relative basis. The log linear regression equation has the following form:

$$
\log C=\log a+b_{1} \log S+b_{2} \log 0+\varepsilon,
$$

where $\varepsilon$ is the regression error. When transformed into exponential form, the cost equation is as follows:

$$
C=\operatorname{AS}^{b} 1_{0} b_{2} \cdot \varepsilon^{\prime},
$$

where $A=e^{a}$ and $e e=e$. We see, therefore, that the error term associated with the estimated cost is proportional to $C$. Contrast this result with the linear model which has a constant error for all values of $\mathrm{C}$ :

$$
c=a+b S+b_{2} O+\varepsilon \text {. }
$$

A comparison of the two models is illustrated below in Figure III-l for a simple regression of cost and output.
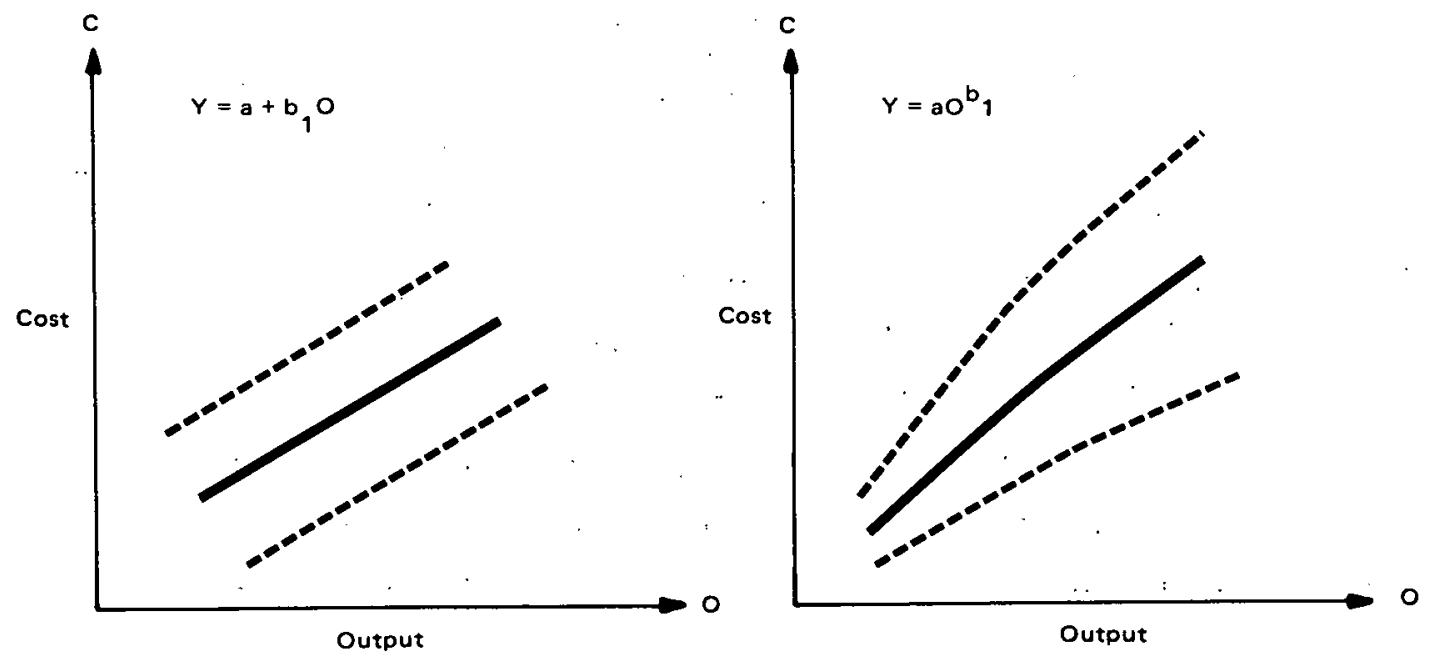

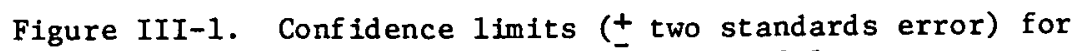
linear and exponential models 
Another advantage of the exponential model, which follows from the error term being proportional to the size of the dependent variable, involves unequal variance of residuals along the axis of the independent variable. The problem of hetroscedasticity or unequal variance of the residuals can arise when the dependent variable displays a great deal of variability. While resulting regression coefficients are unbiased with heteroscedasticity, the estimates do not have minimum variance. The exponential model is usually adequate to avoid the problem of heteroscedasticity.

Use of Dummy Variables. Dummy regional variables were included in the preliminary specification of all regression equations. The regional dummies were defined for each of the nine Census Regions to correspond to the level of geographical detail in the BNL Multi-Regional Model. Thus, plant location, although available by state, was aggregated into Census Regions. We realized that this level of aggregation could create regions too homogeneous to differ as to wage and material prices, physical and load characteristics, environmental constraints, and other factors that might cause regional cost variations. Nevertheless, the regression results reported in the next section do demonstrate significant differences among Census Regions for a number of cost categories and technologies.

Both regional dummy variables and the others introduced to capture the effects of additional qualitative independent variables were treated as shift parameters. Many of the non-regional dummies were related to engineering or physical characteristics, such as building type, operating type (manual, automatic), type of cooling, etc. They were usually unique to the particular technology being investigated-for example, hydroelectric facilities operated by the Corps of Engineers were distinguished from privately owned plants, while cooling technologies (towers, reservoirs, etc.) were distinguished by dummy variables for nuclear generating plants.

For a regression equation containing sets of dummy variables for regional and other factors, the dummy variable was tested to verify if it deviated significantly from the constant term of the regression. Since the regions 
were defined as the nine Census Regions, eight dummy variables were used to designate regions and the ninth region was assigned as the intercept. The significance tests on the coefficients of the dummy variables then applied to the hypothesis of whether or not the intercept term for the $i^{\text {th }}$ region was the same as the region defined to be the intercept. Dunmy variables representing non-regional factors are defined when introduced in the discussion of results later in this chapter.

When dummy variables are used in the linear model, the estimated coefficient for the dummy term is added to or subtracted. from the estimated intercept, thus shifting. the linear equation upward or downward by a constant amount depending on the coefficient sign. For the exponential model, the estimated coefficient of the dummy term becomes a shift parameter over the entire range of the function:

$$
\mathrm{C}=\operatorname{AS}^{\mathrm{b}} 1_{0}{ }^{\mathrm{b}} \mathrm{e}^{\mathrm{db}} 3
$$

Thus, when $d=1$, costs for every value of $\mathrm{S}$ and 0 are $\mathrm{e}^{\mathrm{b}} 3$ more or less than, costs when $d=0$. For example, an estimated value of $b_{3}=0.2$ gives $e^{b_{3}}=1.22$, so that costs are $22 \%$ higher for the case represented by $d=1$. 4. Use of Price Indices and Measurements of Technological Change. It is helpful to state at the outset of the analysis, the assumptions, limitations, 'and possible sources of bias and misinterpretation that are possible with the historic statistical adopted in this study.

Improvements in Capital. The selection by utilities of plant size, operating characteristics, and configuration is a complex decision; load projection and the future course of input prices are primary considerations. It can be expected that for a given state of the art, expectations of higher operating costs will cause utilities to select more capital-intensive plants to reduce the need for operating inputs (labor, fuel, material). 
Technological change for capital equipment, per se, means that a plant representing a given level of capacity and the same level of operating efficiency can be purchased at a lower real price. Technological change may, of course, be achieved in the form of improved operating efficiency, but this can be distinguished from technical improvement for capital equipment.

Technical change for capital equipment is what we are trying to measure in the capital cost regressions. Since at a given point in time a plant with greater operating efficiency is more costly, the technique to identify technical change for capital equipment is to include measures of operating characteristics as independent variables in the capital cost regression equation.

Prices indices used to achieve constant dollar prices at different points in time should only reflect inflationary price increases. Price increases caused by increased plant efficiency (i.e.,quality change) should in principle be netted out from the price index. Thus an increase in plant efficiency without inflation should be reflected as an increase in real unit cost of capital equipment. By the same token, if manufacturers of electric plants and equipment can generate greater operating efficiency at no additional manufacturing cost, they may be able to increase equipment prices to reflect the increased efficiency. Under competitive conditions, without adjustment lags, and with perfect and costless information transfer, however, it can be expected that the price charged a utility for a plant will reflect only the extra cost of resources ( $R \& D$, equipment, etc.) required to achieve greater operating efficiency.

A second important consideration in measuring technological change in captial is the possibility that economies of scale are the real cause of observed reductions in plant costs per unit of capacity. Increasing trends towards larger plants will tend to reduce unit capital costs when economies of scale are present, regardless of technological improvements. Thus, it is important to differentiate between decreasing costs over time versus static decreasing costs from scale economies. Capital cost equations should be specified to include time and capacity as independent variables. Otherwise, economies of scale and technological change are inseparable. 
Improvements in Operating Efficiency. In principle, the

identification of technical improvements in operating efficiency (fuel, labor, material inputs) requires measurement of shifts in the estimated operating function over plants of different vintages. However, the design of plant to achieve lower operating costs through substitution of capital for operating inputs is not the same as technological change. Similarly, operating economies achieved as a result of scale (i.e., a larger plant) are not technological improvements. Theoretically, if the operating cost regression equations contain all the factors affecting demand for input, including relative prices or design characteristics at the time of plant design, then substitution effects can be separated from technological change-i.e., shifts of the isoquant can be distinguished from movements along the isoquant.

A second, more fundamental consideration, given the data limitation inherent in our sample, is the separation of technological shifts in operating functions from the impact of plant age on costs. It can be expected that technological improvements will reduce the $0 \& M$ requirements (after adjustment for inflation), so that newer plants will display lower real O\&M costs. But newer plants observed at a fixed point in time (i.e., data cross section) are also younger plants. Are the reduced $O \& M$ costs observed under these conditions attributable to technological change or to age? The only way to quantify the two effects separately is to pool cross sections so that plants of a given vintage are observed in their first, second, and subsequent. years of operation. Use of a single cross section to identify either vintage or age leads to an overstated estimate of technological change and an understated estimate of the impact of age. It is, of course, not possible to include both age and vintage as independent variables when data points come from a single cross section, since vintage is merely a linear transformation of age.

\section{B. Regression Results}

The estimated regression equations for each cost category and technology are presented in this section. These results are organized by technology: fossil-fueled steam-electric plants, gas turbine plants, hydroelectric plants, 
and nuclear plants. Within each technology, captial cost equations are presented first, followed by fuel and non-fuel O\&M cost relationships. For fossil-fueled steam-electric plants, separate capital cost equations are developed for coal-, gas-, and oil-fired plants. For the other technologies and cost categories, generic plant differences, such as those between oil- and gas-fired gas turbine units are treated through dummy variables.

The format for the presentation of each regression result indicates sample characteristics, discusses the analysis conducted, including the selection of variables, preliminary findings, and statistical results, and interprets the final estimates in terms of the economic and technical meaning of the coefficients. Except where otherwise noted, all equations are for the logarithm of the dependent variable. Significant independent variables are listed together with the estimated regression coefficient and $t$-value. A single asterisk denotes that the variable is significantly different from zero at the $1 \%$ level of significance, a double asterisk denotes a $5 \%$ level of significance, and a triple asterisk denotes a $10 \%$ level of significance. A list of sample characteristics for the dependent and the more important explanatory variables can be found in Tables II-1 and II-2 in Chapter II.

1. Fosil-Fueled Steam-E lectric Plants

a) Capital Costs

Coa1-, Coal/Gas-, Coal/Oil-Fired Plants. The sample for estimating capital costs for these facilities consists of 214 plants, ranging in size from $8 \mathrm{MW}_{\mathrm{e}}$ to $2,932.6 \mathrm{MW}_{\mathrm{e}}$ and representing vintages as old as 1920 and as recent as 1974. All Census Regions except Region 7 are represented by at least 2 and as many as 49 plants. Most of the plants (154) burn coal exclusively, and 60 have the capability of burning coal and another fuel. Thirty-one plants were put in service in 1970 or later and can be expected to have included in their capital costs the pollution abatement equipment required to comply with environmental standards for new units. 
At the outset of the analysis, caution was required in specifying the independent variables because of reasonably strong pairwise correlations. High correlation coefficients between pairs of potential explanatory variables were:

Vintage and unit capacity; 0.70 .

Vintage and design heat rate; -0.69 .

Vintage and reheat capacity; 0.62 .

Reheat capacity and capacity per unit; -0.48

Over time these coal-fired plants have become larger, with more reheat capacity and lower design heat rates. The joint use of these variables may lead to insignificant coefficients for one of the pairs due to high collinearity. This phenomenon did occur when reheat capacity and design heat rate were both included as independent variables. Design heat rate became insignificant and the estimated regression coefficient was incorrectly signed. Both variables were significant, however, and correctly signed when vintage was excluded - either vintage or design heat rate, captured the same effect.

Both linear and exponential models were run, with no appreciable differences found in signs, significance levels, or overall explanatory capability. In no case could a difference between coal-burning plants and those able to burn a second fuel be found. Dummy variables for Census Regions 1,2 , and 3 were found to be insignificant and were therefore combined with the intercept term (Census Region 9). The remaining regions were found to be from 15 to about $30 \%$ less expensive than the other locations. Finally, plants coming into service after 1.970 were found to exhibit higher real costs than those of earlier vintages. Table III-l shows the final regression equation.

Capacity. The coefficients for the capacity per unit of the component variables and the number of units indicate the presence of substantial economies of scale in the capital costs of coal-fired plants. The coefficients are significantly different from both zero and unity. The use of two-component variables to present composite capacity means that the elasticity 
Table III-1

\author{
Results of Coal-Fired Steam Electric Coal/Mixed \\ Capital Cost Regression \\ (Logarithm of Thousands of 1975 Dollars)
}

\begin{tabular}{lcc}
\hline Independent variables & Coefficient & t-Value \\
\hline Intercept & 9.723300 & $16.183 *$ \\
Ln vintage & -0.677824 & $-4.057 *$ \\
Ln capacity per unit (MW)e & 0.790713 & $20.406 *$ \\
Ln number of units & 0.799367 & $16.708 *$ \\
Reheat capacity (\%) & -0.180619 & $-2.360 * *$ \\
Dummy for Census Region 4 & -0.189221 & $2.518 * *$ \\
Dummy for Census Region 5 & -0.226532 & $-3.685 *$ \\
Dummy for Census Region 6 & -0.344571 & $-4.456 *$ \\
Dummy for Census Reglon 8 & -0.184726 & $-2.143 * *$ \\
Dummy for post-l969 plants & 0.250906 & $3.143 *$ \\
$R^{2}$ raw $=0.8820$ & & \\
$R^{2}$ corrected $=0.8768$ & &
\end{tabular}

of costs with respect to total capacity lies between the estimated coefficients for the two explanatory variables. Where the elasticity lies depends on how capacity increases - additional units, greater capacity per unit, or some combination of the two. Increasing capacity by equal increases in unit capacity and number of units gives an elasticity equal to the average of the two coefficients. As the coefficients are nearly identical, the magnitude of the cost coefficlent is nearly identical, regardless of how capacity is increased. 
Vintage and Post-1970 Shift Parameter. The coefficient for the vintage term indicates continuous downward shifting of the cost function due to technology. Real costs declines at an annual rate of $1.2 \%$ in the early $1950^{\prime} s$, and decreased to about $1 \%$ by 1960 and $0.865 \%$ by the early 1970 's. Note that superimposed on these shifts is an upward shift of about $28 \%$ for plants introduced after 1970, primarily because of pollution abatement costs, longer construction times, and higher interest rates.

Reheat Capacity. The coefficient for percentage of reheat capacity indicates that for otherwise identical plants, those having a higher percentage of reheat capacity are less costly. Increasing reheat capacity by $10 \%$ reduces total capital costs by $1.8 \%$. This effect explains why newer plants in the sample tend to have higher reheat capacities-the simple correlation coefficient between percentage reheat capacity and vintage is 0.62 .

Regional Effects. Capital costs for plants in Census Regions 4, 5, and 6 were found to range from 15 to about $30 \%$ less costly than the remaining regions, with Census Region 6 (the TVA region) having the lowest absolute costs. This result is not affected by undue concentration of either coal or mixed-fuel plants in any one region, since the dummy variable for fuel type proved highly insignificant.

0i1- and 0il/Gas-Fired Plants. The sample for oil- and oil/gas-fired plants consisted of 73 plants representing all Census Regions except Region 3 (East North Central) and Region 6 (East South Central). Of the total 73 plants in the sample, 58 are capable of burning both oil and gas. Their vintages range from 1928 to 1974; the smallest has a name plant rating of $11.5 \mathrm{MW}_{\mathrm{e}}$ and the largest $1827.7 \mathrm{MW}_{\mathrm{e}}$. Plants with. from one to four turbogenerator units were observed with unit capacity ranging from $11 . \mathrm{MW}_{e}$ to $913 \mathrm{MW}$ •

Linear and exponential equation forms were run, using the composite capacity variable and the component variables, capacity per unit, and number of units. The exponential form with the two-component variables proved superior and was selected.

In addition to vintage, two engineering design parameters, reheat capacity and heat rate, were included as explanatory variables. However, relatively 
- high correlation between vintage and heat rate reduced the statistical significance of the latter and it was dropped. Dummy variables for mixed-fuel plants and for plants going on line beyond 1970 were also used. Mixed-fuel plants were significantly more costly than pure oil plants. The impact of pollution abatement and lengthened construction time, as measured by the dummy variable for 1970 and later years, proved insignificant. Apparently the plants in our sample either were built too early for pollution abatement costs to be captured or were switched to low sulfur fuel oil instead of investing in pollution abatement equipment.

Table III-2

Results of Oil-Fired Steam-Electric

Capital Cost Regression

(Logarithm of. Thousands of 1975 Dollars)

\begin{tabular}{lcc}
\hline Independent variables & Coefficient & \multicolumn{1}{c}{ t-Value } \\
\hline Intercept & 10.386900 & $9.515 *$ \\
Ln vintage & -0.934040 & $-3.232 *$ \\
Ln capacity per unit (MW) & 0.815272 & $14.965 *$ \\
Ln number of units & 0.828328 & $10.833^{*}$ \\
Reheat capacity (\%) & -0.185504 & $-1.966 *$ \\
Dummy for mixed fuels & 0.214370 & $2.264 \star$ \\
Dummy for Census Region 2 & 0.257360 & $-5.822 \star$ \\
Dummy for Census Region 7 & -0.508460 & $-4.293 *$ \\
Dummy for Census Region 8 & -0.513360 & \\
$R^{2}$ raw $=.9208$ & & \\
$R^{2}$ corrected $=.9109$ & & \\
\hline
\end{tabular}


Capacity. Estimation results again evidence considerable economies of scale, about the same as those found for coal plants. Increases in capacity lead to less than proportional increases in plant costs. The coefficients for capacity per unit and number of units indicate that a $100 \%$ increase in capacity from a $50 \%$ increase in unit capacity and number of units (i.e., from two to three) causes an $82.15 \%$ increase in costs, $0.5(0.828)+0.5(0.815)$. Note that the coefficients for component capacity terms are significantly different from unity (constant returns to scale.)

Vintage. The effect of vintage is to shift the total cost curve downward at a decreasing rate over time. The exponential form and coefficient estimated in the regression equation indicate technological change at a rate of nearly $2 \%$ per year in the early 1950 's, $1.33 \%$ in the 1960 's, and $1.25 \%$ by the early 1970 's. Note that the dummy variable used to distinguish plants beginning operations after 1969 proved very insignificant, indicating that pollution abatement requirements had little effect on our sample.

Mixed-Fuel Plant. Plants capable of burning either oil or gas are significantly more expensive than otherwise comparable plants that can burn only oil. The coefficient. for the mixed-plant dummy variable is surprisingly high, indicating captial costs nearly $24 \%$ higher for this capability.

Regional Effects. Cost differences among Census Regions are statistically significant and of relatively large magnitude. Census Regions included in the intercept term are Regions 1, 4, 5, and 9. (No plants were found in Regions 3 and 6.) Relative to the intercept, Census. Region 2 (Mid-At lantic) was found to have $29 \%$ higher costs, while Census Regions 7 and 8 (West South Central and Mountain) were $40 \%$ less costly. These variations in relative costs arise from differences in construction and materials prices, in pollution control requirements, in design requirements for burning fuels with different characteristics, and in configuration and equipment requirements related to climate and site characteristics.

Gas-Fired Plants. Gas-fired plants tend to be smaller than coal or oil units. The average station capacity in our sample is $175 \mathrm{MW}_{e}$, compared to 
$301 \mathrm{MW}_{e}$ for oil-fired stations and $446 \mathrm{MW}$ for coal-fired stations. Gas-fired plants are also more highly concentrated in a limited number of Census Regions, primarily the West South Central Region (Region 7). A limited number of sample observations are available for Regions 3, 4, 6, and 8 , however.

The sample consists of 37 gas-fired plants, ranging in vintage from 1928 to 1974. Variables considered were: location, capacity, design heat rate, and reheat capacity. Both linear and exponential equation forms were tested, using both composite and component capacity variables. This technology was the only one of those analyzed, in which the linear forms proved superior. With the linear forms, the estimated coefficients do not immediately indicate the cost elasticities and the consequent degree of returns to scale. Elasticity terms can be computed at a specific value; usually the mean value of the independent variable is more meaningful. That is,

$$
\begin{gathered}
c=a+b X \\
\text { Elasticity }=\text { marginal cost/average cost }=\frac{b X}{a+b X} .
\end{gathered}
$$

The regression results presented in Table III-3 include the value of the partial cost elasticity computed at a mean for each relevant independent variable.

Capacity. The coefficient for the unit capacity term indicates a (constant) marginal capital cost of $\$ 147$ per $\mathrm{kW}_{\mathrm{e}}$ of capacity in 1975 dollars for a plant with a given number of units. The computed elasticity coefficients for both units and unit capacity indicate substantial scale economies - more so than with the other technologies. Of course, with the linear form; the elasticity value approaches unity as the capacity expands, so that the computed value is only applicable for values around the sample mean (1.29 unit stations of $147-\mathrm{MW}_{\mathrm{e}}$ unit capacity). The computed elasticities indicate that a $10 \%$ increase in total capacity through capacity through equal increases in number of units and unit capacity increases costs about $6.7 \%$. 
Table III-3

Results of Gas-Fired Steam-Electric

Capital Cost Regression

(Capital Costs in Thousands of 1975 Dollars)

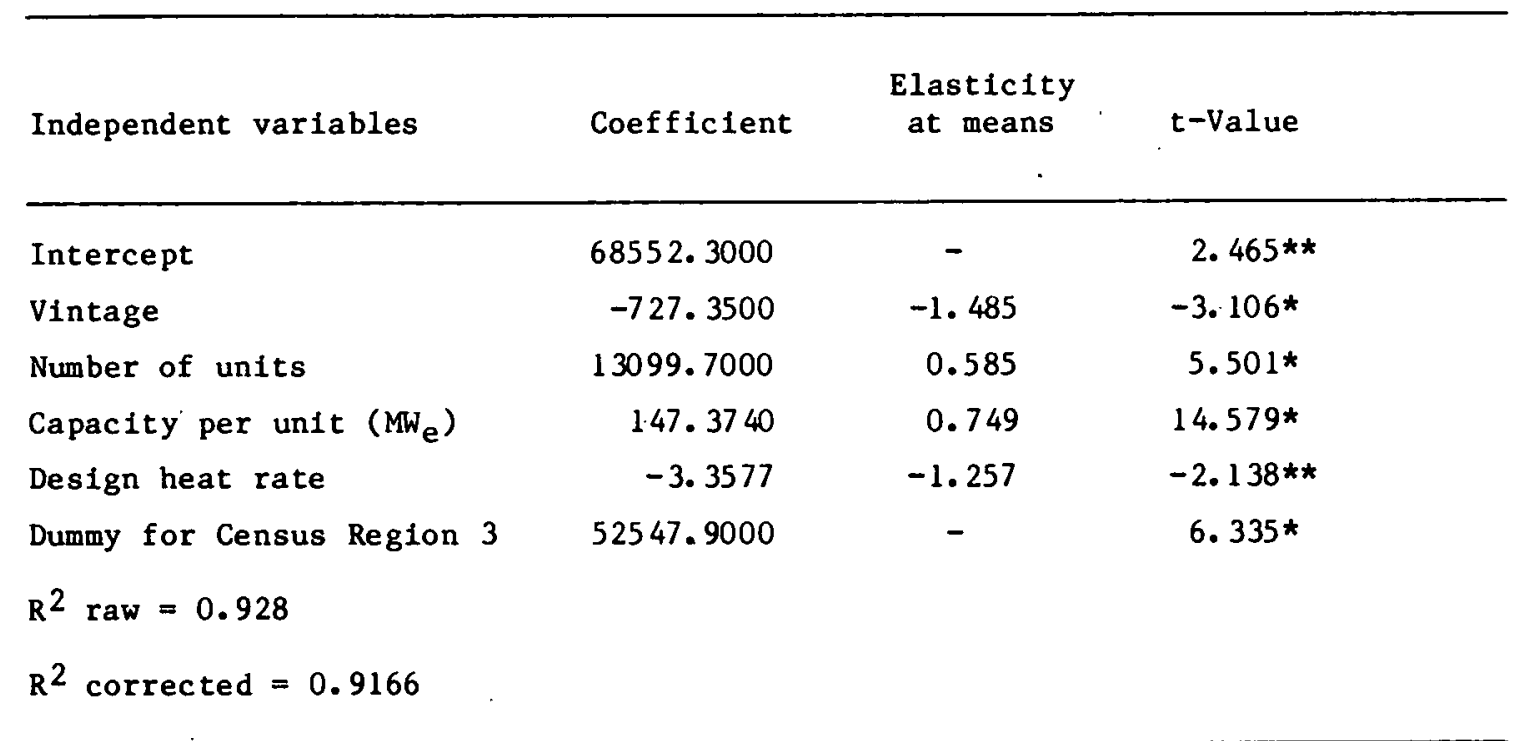

Vintage. The coefficient for the vintage term indicates annual costs reduction of $\$ 727,000$ through technological changes, regardless of station size, location, etc. The computed elasticity indicates that for stations of sample-average characteristics, the downward shift in costs amounted to nearly $3 \%$ in the early $1950^{\prime}$ 's, 2 to $3 \%$ in the early $1960^{\prime}$ s, and slightly more than $2 \%$ in 1970 .

Design Heat Rate. The design parameter for the fuel efficiency of gas-fired plants is both significant and of the correct sign. The coefficient indicates that an investment of $\$ 3,357$ is required to reduce the design heat rate by 1 Btu per $\mathrm{kWh}$. The elasticity coefficient indicates that a $10 \%$ 
reduction in heat rates adds about $12.5 \%$ to initial capital costs. To judge the reasonableness of the design heat rate coefficient, a rough calculation was made to compare the additional investment in capital with the annual value of fuel savings. The cost coefficient can be considered reasonable if it indicates a rate of return on extra investment consistent with utility discount rates for investment decision-making (i.e., perhaps 8 to $15 \%$ ). Higher or lower rates of return would indicate disequilibrium and thus an unreasonable coefficient. To reduce the station heat rate by $1,000 \mathrm{Btu} / \mathrm{kWh}$ requires an investment of $\$ 3,357,700$ in 1975 dollars. A $200-\mathrm{MW}$ e plant operating at a $57 \%$ plant factor produced 1,000 million kWh per year and saves $1,000,000 \times 10^{6} \mathrm{Btu}$ per year by investing the additional $\$ 3,357,700$. Fuel prices for 1974 in Census Region 7, where most gas-fired plants are located, was about $50 \notin$ per $10^{6} \mathrm{Btu}$, yielding an annual fuel cost savings of $\$ 500,000$. Thus, the investment implies an undiscounted payback period of six to seven years or an internal rate of return of 13.7 to $14.4 \%$ for plants with useful lives of 20 and 25 years, respectively.

Regional Effects. A significant upward shift in the intercept of $\$ 52$ million was found for Census Region 3, the East North Central, when compared with Regions 4, 6, 7, and 8. This represents a $78 \%$ upward shift at the origin, but because of the nature of the linear form, the importance of the cost difference declines as plant size increases.

\section{b) Fuel Costs}

The estimated fuel relationship is for the physiccal input of fuel measured in Btu. Cross-section data at two points in time were compiled to apply a pooled cross section regression. Data on Btu consumed for plants of various types, locations, capacities, and utilization rates were gathered for. 1969 and 1974. Only plants tracked as unchanged from the initial year of operation to the year observed were included. Thus, plants that were modified, expanded, or otherwise altered before 1969 and 1974 were eliminated. These years were selected to obtain contrasting cross sections of data: pre-oil embargo, high economic activity and plant utilization (1969), and post-oil-embargo, low economic activity and plant utilization (1974). 
With such a multiyear cross section, the effects of both vintage and age can be modeled, as wel1. A plant of vintage 1960, observed in 1969 and again in 1974, can be recorded first with vintage 1960 and age 9 and then with vintage 1960 but age $14(1974-1960)$. A pooled cross section in theory allows vintage effects to be separated from depreciation effects. The pooled sample consists of a total of 234 plants, ranging in vintage from 1950 to 1974 and in capacity from $22 \mathrm{MW}_{e}$ to $2932.6 \mathrm{MW}_{e}$. The plants are reasonably well distributed across fuel types and regions.

Several preliminary regression runs were attempted to test for differences in the fuel efficiencies of plants burning various types of fuel and located in different regions. First, regressions with plant capacity, plant factor, vintage (to measure trends in technology), and age (to measure the degradation effect of age) were combined with regional and fuel-type dummies. Both regional and and fuel dummies were included to test whether differences in fuel types or fuel sources influenced fuel efficiency. Is there a difference between the thermal conversion efficiency of Btu equivalent gas, oil, and coal, or between, say, eastern and western coal, perhaps on account of ash, moisture, or sulfur content? None of the regional or fuel-type dummies proved significant in either the combined regional and fuel-type runs or subsequent runs using first only regional dummies and then only fuel-type dummies.

A second result from these preliminary regressions was that when vintage and age were employed together, both were highly insignificant. A check showed an extremely high correlation (simple correlation coefficient of -0.094) between these variables accounting for the results. Using each variable separately showed vintage to be insignificant, while age (i.e., degradation effect) became significant at the $10 \%$ level. 6

Table. III-4 displays the regression results for the fuel consumption equation derived from the pooled cross section of 234 fossil-fueled steam-electric stations. The estimated equation is relatively uncomplicated, involving plant capacity, utilization, and age. A striking feature is its lack of a vintage term, indicating that the reduction in plant heat rate over time is a man- 
ifestation of static economies of scale rather than dynamic changes in the quality of plant at every level of capacity. Note also that the estimating equation can be converted to the nore famillar heat rate function showing Btu per $\mathrm{kWh}$ against plant factor. 7

Table III -4

Results of Fossil-Fueled Steam-Electric

Fuel Consumption Regression

(Logarithm of Btu $\times 10^{9}$ )

\begin{tabular}{lcr}
\hline Independent variables & Coefficient & t-Value \\
\hline Intercept & 0.551969 & $5.954^{\star}$ \\
Ln capacity (MW $)$ & 0.934769 & $107.689 \star$ \\
Ln plant factor (\%) & 0.925549 & $47.758 *$ \\
Age (years) & 0.002333 & $1.676 *$ \\
$\mathrm{R}^{2}$ raw $=0.9926$ & & \\
$\mathrm{R}^{2}$ corrected $=0.9851$ & &
\end{tabular}

Capacity and Utilization. The partial elasticity of fuel consumption with respect to plant size indicates economies of scale-larger plants require less fuel at a given plant factor. However, a larger plant does not necessarily consume less fuel for a given level of output (net generation), since the larger plant operates at a lower plant factor. Larger and smaller plants will consume the same fuel per unit of output when the coefficients for capacity and plant factor are equal. Larger plants will consume less fuel per unt of output when the regression coefficient for capacity is less than the coefficient 
for plant factor, and conversely. Our results indicate nearly equivalent regression coefficients so that the $200-\mathrm{MW}_{\mathrm{e}}$ plant producing at a $25 \%$ plant factor consumes as much fuel as the $100-\mathrm{MW}_{\mathrm{e}}$ plant operating at a $50 \%$ plant factor.

Age. The age coefficient is measured in years, rather than the logarithm of years, and indicates that fuel efficiency declines as plants age. The rate of fuel degradation is slight at $0.23 \%$ per year (exp. 0.002333).

\section{c) Non-Fuel O\&M Costs}

The analysis of non-fuel O\&M costs presents many of the same problems associated with estimation of fuel consumption relationships, with the additional problem of inflation when pooled cross sections are used. No suitable method of normalizing costs to a constant dollar basis exists for the many types and combinations of inputs that comprise $0 \& M$ costs. Pooling cross sections is desirable for these costs, as both age and vintage can be influential.

A pooled sample of 235 plants was complled, consisting of 131 plants observed in 1974 (a recession year) and 105 plants observed in 1969 (a year of high economic activity). Rather than applying an arbitrary deflator to the current dollar O\&M costs observed in the sample, a dummy variable was introduced to distinguish 1969. observations from 1974 observations. The sample had good regional representation, with no single Census Region having fewer than 9 or more than 35 plants. Included were 17 oil plants, 36 gas plants, 25 coal/oil or coal/gas plants, 25 oil/gas plants, and 134 coal plants.

A preliminary examination of the correlation matrix of potential explananatory variables was next conducted to gauge the ability of the sample to separate age/vintage and regional/fuel-type effects. A high correlation ( -0.94$)$ was found between age and vintage in our two-year cross section and between gas plants and the dummy variable for Census Region $7(0.67)$. Later regression results confirmed what had been found with the fuel analysis: vintage and age effects cannot be separated. Preliminary analysis indicated very little cost difference between plants burning different fuels, except for gas plants, which exhibited an $0 \& M$ cost advantage. 
The desirability of using component variables (capacity and plant factor) in place of the composite variable (net generation) was confirmed, since vastly different coefficients were estimated for capacity and plant factor. A high fixed-cost component accounts for this result, although costs do vary significantly with activity. Recall that when similar coefficients are estimated, no advantage is gained by using the single composite variable in place of the several component variables. We found that the vintage effect captured much of the age effect in regression estimates. However, when age was used instead of vintage, the latter's effect was to a large extent captured in the intercept. The reason for this is that when a plant appears in both cross sections, there is no difference in the vintage variable in the 1969 and 1974 cross.sections. When age is used, the plant appears at a certain age in 1969 and then as five years older in the 1974 cross section. The regression results are shown in Table III-5 below.

Table III-5

Results of Fossil-Fueled Steam-Electric Non-Fuel O\&M Cost Regression

(Logarithm of Thousands of 1974 Dollars)

\begin{tabular}{lcc}
\hline Independent variables & Coefficient & t-Value \\
\hline Intercept & 1.053670 & $3.341^{\star}$ \\
Ln capacity (MW $)$ & 0.875129 & $27.870 *$ \\
Ln plant factor (\%) & $0.274883^{\circ}$ & $4.445 *$ \\
Age (years) & 0.038800 & $8.208 *$ \\
Dummy for Census Region 3 & -0.167596 & $-1.842 \star \star \star$ \\
Dummy for Census Region 5 & -0.327123 & $-3.703 *$ \\
Dummy for Census Region 6 & -0.304537 & $-3.140 *$ \\
Dummy for Census Region 7 & -0.465342 & $-3.891 *$ \\
Dummy for gas-fired plants & -0.192726 & $-1.679 * \star *$ \\
Dummy for 1969 & -0.364272 & $-6.024 *$ \\
$\mathrm{R}^{2}$ raw $=0.8441$ & & \\
$\mathrm{R}^{2}$ corrected $=0.8372$ & & \\
\hline
\end{tabular}


Capacity and Utilization. The inclusion of a significant capacity variable with a coefficient significantly less than unity suggests two important conclusions: (1) O\&M costs have a high fixed element, and (2) there are economies of scale in O\&M costs. The plant factor variable, although small in absolute value, is significant, indicating that changes in the rate of output do drive some portion of these costs. The coefficient for capacity indicates that a $10 \%$ increase in capacity induces a lessthan proportional $8.7 \%$ increase in fixed $0 \& M$ costs. An increase in plant activity of say $10 \%$ causes a relaatively small $2.7 \%$ increase in these costs; O\&M costs are $27 \%$ variable with output.

Age. The coefficient for the age variable is highly significant and indicates an increase in $0 \& M$ costs (most likely maintenance) as the plant ages. These costs appear to increase in absolute terms, growing at a constant percentage rate of about $4 \%($ exp. 0.0388$)$ per year:

Plant Type. Only gas-burning steam-electric stations were found to have O\&M costs different from those of the other plant types. This variable was barely significant and represents an $18 \%$ cost difference in comparison to. the other fossil steam technologies. It should be recalled that gas plants are concentrated in Census Region 7, so that the effects of real cost differences for gas. plants and regional price differences were difficult to separate. (The correlation between the dummy variables for gas and for Region 7 was .67.) Still, both dummies were significant.

Regional Effects. Census Regions $3,5,6$, and 7 were found to have from 16 to $37 \%$ lower O\&M costs in comparison to the rest of the country. These results are consistent with Bureau of Labor Statistics 1972 Industry Wage Survey. which showed a trend for the Border, Southeastern, and Southwestern states to have lower wage levels for electric systems workers.

Inflation Dummy. This variable is reported for completeness and is not intended for use in costing or projection. The regression results are constant 1974 dollars, with the dummy for 1969 observation included to distinguish 
the impact of inflation. The coefficient shows a $30 \%$ increase in prices between 1969 and 1974. This variable should be suppressed when using the regression equation, and the resultant cost estimation should be interpreted as constant 1974 dollars.

\section{Gas Turbine Plants}

\section{a) Capital Costs}

Gas turbine technology is unique in that units tend to be relatively standard and often are shipped already assembled from the manufacturer to the plant site. The site itself requires minimum preparation and the structure is often no more than a concrete slab. Widespread use of this technology is relatively recent, with the oldest observations in our sample dating back only to 1967. It is therefore not surprising to find nearly constant returns to scale and extremely small (though statistically significant) regional cost differences. These differences amounted to about 90 to $95 \%$ of the average value and were detected for three out of the nine Census Regions.

The gas turbine sample consisted of 215 plants brought on line between 1967 and 1973. Unit capacity ranged from 14 to $167 \mathrm{MW}$, while plant capacity ranged from 14 to $821.5 \mathrm{MW}_{\mathrm{e}}$. The high plant capacity was achieved by combining many individual units; some plants in the sample consisted of as many as 24 units. Plants were observed in all Census Regions, although Regions 2, 3, and 5 had the most observations - 48, 49, and 43, respectively. The fuel burned by the plants varied, with 19 plants capable of burning only gas, 125 burned oil exclusively, and 71 burned ofl and/or gas.

Because of the rapid growth in gas turbine capacity in the past decade, considerable care was taken in the analysis. However, despite its growth rate, this technology still contributes but a small fraction of overall capacity and an even smaller fraction of output. Our procedure was to regress capital costs against vintage, capacity per unit and number of units, first with dummies for all Census Regions, fuel types, and operating types. Insignificant dummy variables were then eliminated in subsequent runs. A tendency for gas-fired units to be less costly than oll-fired or mixed units was evidenced. However, the 
dummy for gas-fired units proved to be only marginally significant and was eventually dropped from the regression equation. The final regression equation presented below in Table III-6 contains three regional dummies in addition to vintage, capacity per unit and number of units, and has extremely high explanatory power overall.

Capacity. Gas turbines evidenced nearly constant returns to scale, with coefficients for capacity per unit and number of units estimated as 0.967 and 0.952 , respectively. The coefficient for unit capacity is not significantly different from unity (constant returns to scale), while that for number of units is significantly different from unity and evidences returns to scale.

Table III-6

Results of Gas Turbine

Capital Cost Regression

(Logarithm of Thousands of 1975 Dollars)

\begin{tabular}{lcc}
\hline Independent variables & Coefficient & $t$-Value \\
\hline Intercept & 17.5350000 & $8.071^{*}$ \\
Ln vintage & -2.9958300 & $-5.724^{*}$ \\
Ln capacity per unit & 0.9674000 & $34.803^{*}$ \\
Ln number of units & 0.9517270 & $63.690 *$ \\
Dummy for Census Region 1 & -0.0997838 & $-2.755^{*}$ \\
Dummy for Census Region 3 & -0.0572437 & $-2.023^{*}$ \\
Dummy for Census Region 5 & -0.0521320 & $-1.772 * \star \star$ \\
$\mathrm{R}^{2}=0.968$ & & \\
$\mathrm{R}^{2}$ corrected $=0.9671$ & & \\
\hline
\end{tabular}


Vintage. The effect of technology has been rather dramatic, considering the short six-year span represented by the sample. To a considerable extent, the rapid growth of installed turbine capacity probably explains a good deal of the reduction in the real price of capacity. Cost improvements in manufacturing these units due to the large number produced and the concomitant reduction in real price to purchasers is no doubt reflected in this coefficient. The rate of technological change at the beginning of the sample period was. about $4.5 \%$ per year and tapered down to slightly more than $4 \%$ per year by 1974 .

Regional Variables. Regional differences were observed for Census Regions 1, 3; and 5, which achieved lower cost than the other regions. The calculated regional differences were, however, no more than $10 \%$ below the cost level for the rest of the country. The nature of the technology - preassembled standard units and minimal site preparation and structures - suggests that the regional cost differences may well be attributable to transportation charges.

b) Fuel Costs

A sample of 232 gas turbine stations observed in 1973 (latest available year) was compiled for analysis of the fuel consumption relationship. The plants in the sample varied in vintage from 1961 to 1972 , with most plants coming on line in the late 1960's. Most, but not all, stations are intended to meet peaking requirements, as evidenced. by the very low observed plant factormean of $6.34 \%$ and standard deviation of 2.73 . All regions are well represented in the sample with no fewer than five plants nor more than 55. Out of the total sample of 232 plants, 28 burn gas, 134 burn oil, and 70 burn oil and/or gas.

The same general model was used here for the fuel relationship as was previously developed for conventional steam generating stations. The Btu consumption was estimated in exponential form, using capacity, plant factor, and vintage with regional and fuel-type dummies. Regional and fuel-type dummy variables were employed first jointly and then separately. The use of capacity and plant factor instead of net generation was justified since estimated coef- 
ficients were different. Preliminary regression results indicated in fuel consumption due to regional effects or fuel type burned. These results held when regional and then fuel-type dummies were employed separately in the regression equation. This was, of course, anticipated from the preceding analysis conducted for the steam technologies.

In contrast to the steam technologies, however, vintage was not found to be significant. Since the data are from a cross-section sample of plants in 1973, vintage is equivalent in a statistical sense to age (age $=1973$ vintage). Advances in technology may improve the fuel efficiency of a plant while the impact of age (depreciation) may reduce fuel efficiency. Older plants are expected to be less fuel efficient since they represent an older technology and because age degrades the plant efficiency. However, a single cross section is not sufficient to untangle the separate effects of technology and age. Neither effect could be separately detected in the analysis. The final estimated fuel consumption equation is presented in Table III-7.

Table III-7

Results of Gas Turbine Fuel

Consumption Regression

(Logarithm of Btu $\times 10^{9}$ )

\begin{tabular}{llr}
\hline Independent variables & Coefficient & t-Value \\
\hline Intercept & 0.477010 & $5.856 *$ \\
Ln capacity $\left(M_{\mathrm{e}}\right)$ & 1.000520 & $47.437 \star$ \\
Ln plant factor $(\%)$ & 0.929752 & $47.175 *$ \\
$\mathrm{R}^{2}=0.9608$ & & \\
$\mathrm{R}^{2}$ corrected $=0.9605$ & & \\
\hline
\end{tabular}


Capacity. The regression coefficient for capacity indicates constant returns to scale for fuel use as plant capacity increases. Thus, no gain ensues in terms of fuel efficiency as larger capacity plants are built. To verify this result, a second equation with capacity per unit, number of units, and plant factor was estimated. It was anticipated that the original specifification using capacity and plant factor was masking differences in efficiency between plants with a single large unit versus one with several smaller units but of equivalent overall size. Coefficient estimates for capacity per unit and number of units were both virtually unity, indicating results equivalent to the first specification.

Output. The coefficient estimated for the plant factor variable indicates that fuel consumption increases less than in proportion to increases in plant output. This coefficient has nearly the same value as was found for steam-electric plants and confirms the prevalent engineering concept of optimal heat rate at highest plant utilization. Combining the results for the capacity and utilization variables indicates that a smaller plant will burn less fuel than a larger plant when both plants achieve the same annual output. of course, these plants are installed to meet peaking requirements and are sized to meet maximum instantaneous load requirements. However, reduction of absolute naximum peaking requirements and spreading the load over longer durations will save fuel even if gas turbines are used to supply the load.

\section{c) Non-Fuel O\&M Costs}

Estimation of the non-fuel $O \& M$ cost relationship for gas turbine stations proved the least satisfactory of all estimates attempted. The primary reason for the realtively poor results arises from the fact that these plants are often co-located or otherwise associated with a larger base load station and often rely on personnel assigned to the base load plant for O\&M resources. Consequently, it can be expected that inconsistent attribution of costs is likely depending on specifics of the plant. Inconsistent or improper attribution of costs may be for supplies and materials as well as for manpower. 
The sample employed to estimate this cost relationship was relatively large-234 plants observed in 1973 with from as few as 5 to as many as 55 plants in a region. The sample is essentially similar to the one used for estimating gas turbine fuel consumption. The estimation procedure employed was to estimate an equation in capacity, plant factor, regional, and fuel-type dummies plus an age variable. Age rather than vintage was used, since we were reasonably confident that the short technological cycle represented by the sample embodied essentially the same technology with respect to operating characteristics and maintenance reliability. However, we did not wish to preclude the possibility that increased costs (especially maintenance) occur as the plant ages. The sample is a cross section of 1973 plants, so it is impossible to differentiate the effect that technological advance and age each have on $0 \& M$ costs. Three regional dummies proved significantly different (less costly) in comparison to the other regions. Gas-burning units are also slight ly less costly to operate and maintain than oil-burning units. However, gas units tend to be concentrated in Census Region 7, so to some extent there is a mingling of regional price and fuel-type effects. Note that the dumm variable for Census Region 7 was not significant. The estimated operating and maintenance cost relationship is presented in Table III-8.

\section{Ut1lization and Capacity. The estimated coefficients for capacity} and plant factor display much the same pattern as conventional steam plants. There is a high fixed-cost component for these expenditures which decreases on a relative basis as station size increases. A plant with double the generating capacity of another requires only $92 \%$ more fixed O\&M resources. Secondly, changes in plant utilization have a statistically significant impact on $0 \& M$ costs, but these expenditures are only " $27 \%$ variable" with output. That is, a $100 \%$ increase in output causes O\&M costs to increase by $27 \%$.

Age. As the unit ages, O\&M costs are seen to increase. The estimated impact from Table III-8 is approximately $6 \%$ per year. 
Table III-8

Results of Gas Turbine O\&M

Cost Regression

(Logarithm of Thousands of 1973 Dollars)

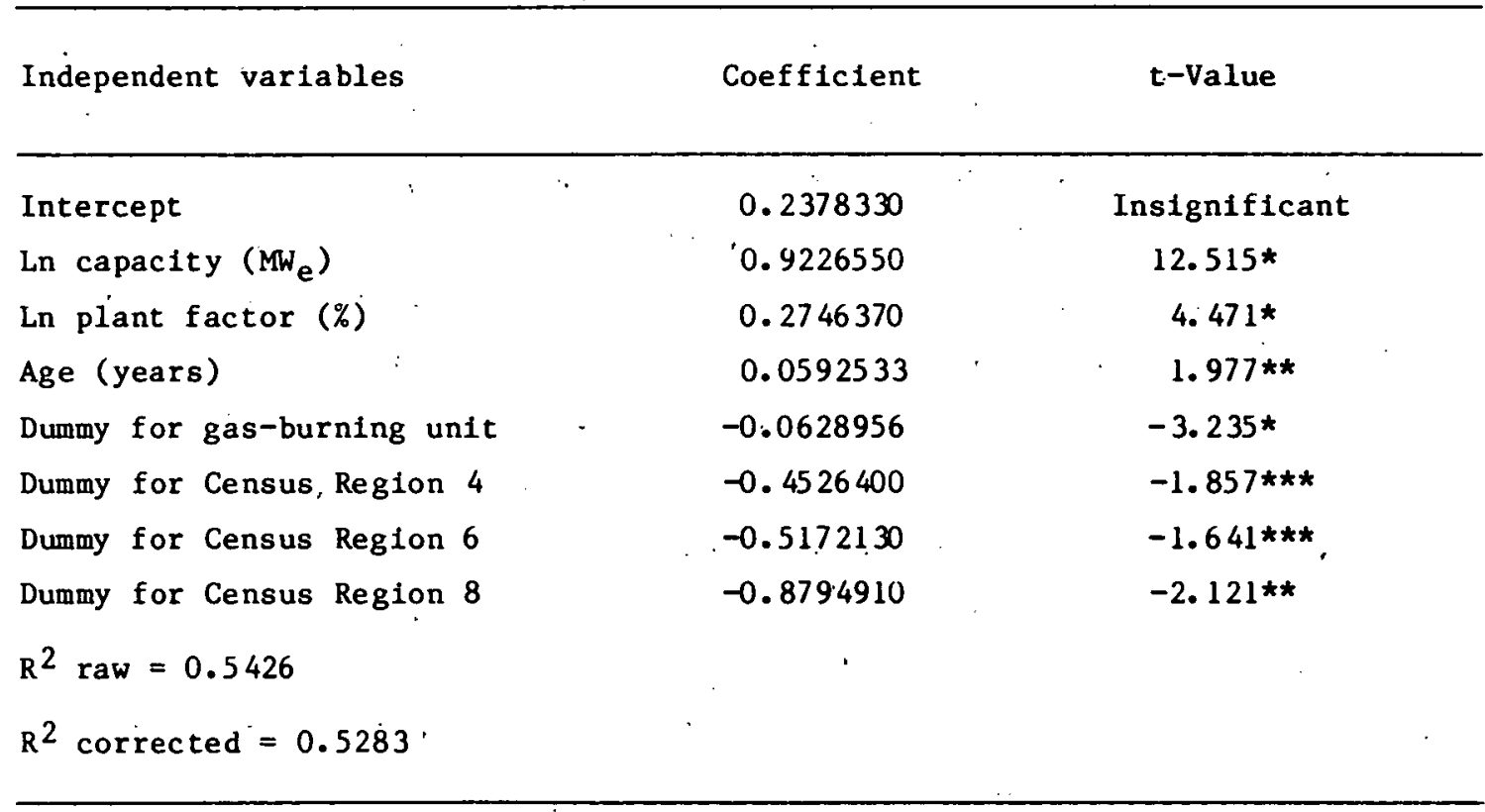

Fuel Type and Region Effects. There is a minor cost difference between gas- and oil-burning units, the former being about $6 \%$ less costly to operate and maintain. Some of this effect represents the impact of price levels in Census Region 7 where many of these gas units are located. Substantial regional cost differences were found for Census Regions 4, 6, and 8 . It is possible that these differences arise from the accounting attribution between the base load unit and the associated gas turbine plant. Utility systems in these regions may systematically under-report (attribute) O\&M costs. This seems very likely for Census Region 8 , since the dummy coefficient value shows a $60 \%$ cost difference. 


\section{Hydroelectric. Plants}

\section{a. Capital Costs}

The hydroelectric plant sample consists of 177 plants built between 1948 and 1974. The sample includes stations that are privately. owned, plus those built and operated by the Corps of Engineers ( 52 plants). Although Census Region 9 dominates the sample with 83 plants, all others are represented, with as few as 3 or as many as 21 plants. The sample covers both conventional and pumped storage units which were differentiated in the analysis by a dummy variable. Conventional plants were further subdivided into automatic, manual and semiautomatic units depending on their operating mode.

Captial costs for the 177 hydroplants in our sample, normalized to 1975 dollars, were regressed against capacity, vintage, and dummy variables representing Census Region, plant type, and a dummy for whether the plant was privately built or constructed by the Corps of Engineers. Preliminary results indicated significant capital costs differences depending on plant type, location, and for privately built versus Corps of Engineers built plants. Substantial costs differences were indicated between pumped storage and conventional facilities and between Census Regions 1, 3, 4; and 9 and the. remaining regions of the country. Corps of Engineers plants are of the order of $30 \%$ more costly than private plants. Examination of simple correlation coefficients included a tendency for the high cost Corps of Engineers plants to be concentrated in Census Region 7. However, Census Region 7 was shown to be a significantly lower cost region than the average. Both the dummy for Corps of Engineers plants and for Census Region 7 remained significant despite correlation between the variables.

Following the appraisal of the preliminary results, Census Regions that proved insignificant were dropped, while manual and automatic pumped storage plants were combined into a single dummy variable since their separate impacts on cost were indistinguishable. The final estimated equation for hydroelectric capital costs involves vintage, capacity, and 9 dummy variables for regional, plant-type, and Corps of Engineers plants. Substantial difference between 
regions and between regular and pumped storage plants were found. The final relationship had an overall explanatory power of $89 \%$ and is presented in Table III-9, where it should be noted that costs for pumped storage facilities are found by suppressing dumies for plant type.

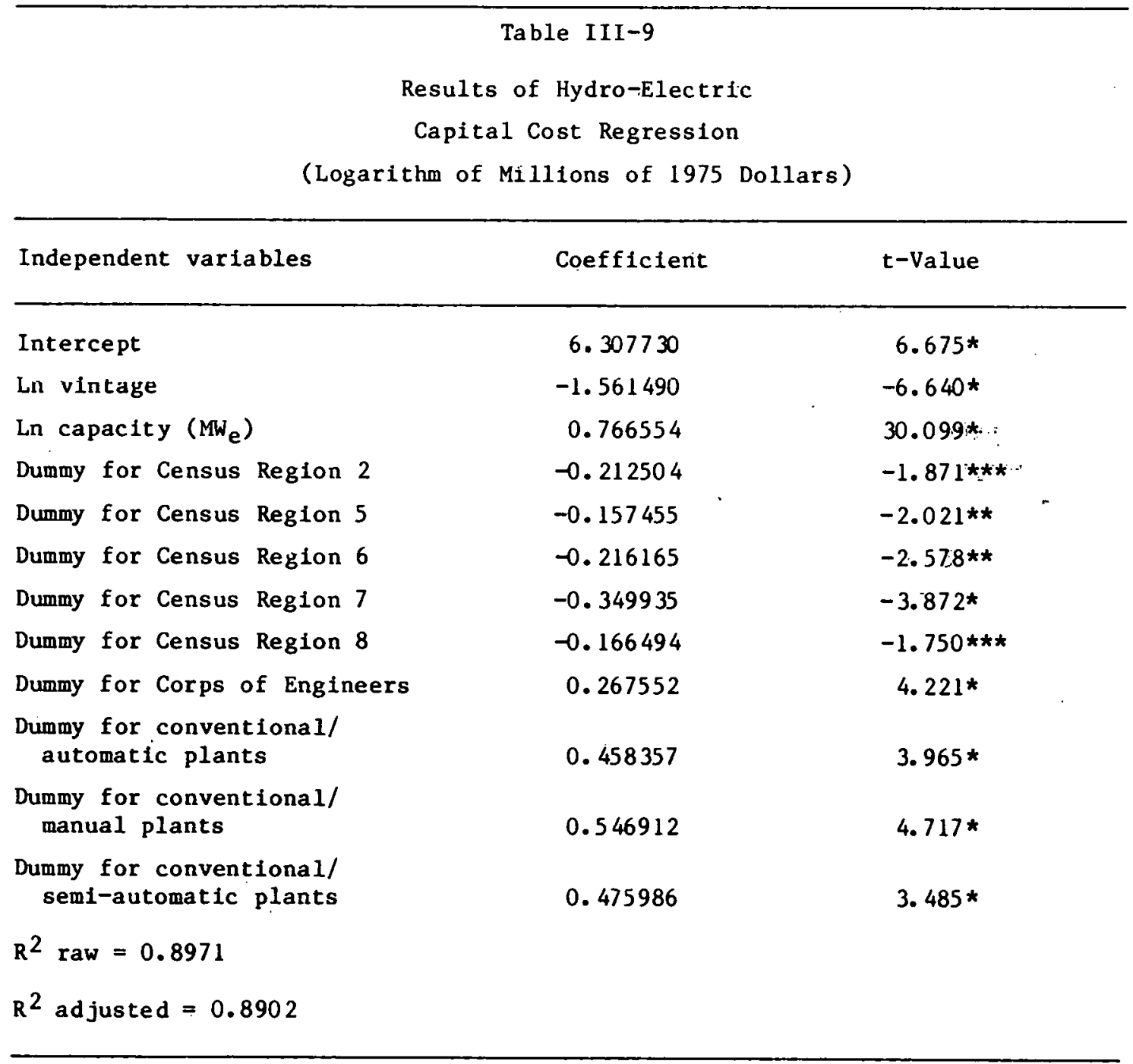


Capacity. The regression results evidence substantial economies of scale_comparable to but even somewhat more substantial than those for the steam-electric technologies. The partial elasticity of cost with respect to size is 0.766. UUnlike steam technologies, hydro:capacity is limited mainly by site characteristics which dictate potential capacity. Consequently, utilities have been precludèd from taking advantage of.scàle-- the simple correlation between capacity and vintage was only 0.34 in our sample.

Vintage. Vintage effects were highly significant and relatively large for this technology. The estimated coefficient indicates about $3 \%$ annual reduction in real capital costs per unit of capacity in the early 1950 's dropping to about $2.2 \%$, by the early 1970 's.

Plant-Type Effects. 'As expected, pumped storage facilities evidenced much lower costs thancconventional facilities of equivalent capacity, location, and vintage. Little differences was discerned between manual, automatic, and semi-automatic plants for.conventional,plants, which were around $60 \%$ more costly than pumped storage facilities.

Regional Effects. : Census Regions 2, 5, 6, 7, and 8 were found to be significantly less costly than the other locations. Differences ranged from Census Region 5, which was about $14 \%$ less costly than the higher cost regions, to Census Region 7, which was nearly $30 \%$ less costly despite the high concentration of Corps of Engineers plants in the region.

Corps of Engineers. Plants built by the Corps were found to be significantly more expensive. A disproportionate number of Corps plants are in Census Region 7, which is the lowest cost location after adjustment is made for the Corps representation. The higher cost with Corps-built plants may to a large extent reflect accounting differences-Corps projects are multipurpose -so perhaps more of recreational and flood control costs are borne by users of electric power.

b) $0 \& M \operatorname{Cos} t s$

Analysis of $O \& M$ costs was anticipated to be difficult for hydroelectric plants because they operate in many different ways. Some plants must purchase 
water; pumped storage facilities may purchase off-peak electric power from within the system or as imports, others may have water available in plant reservoirs. Corps of Engineers plants may be subject to high charges for water from the associated multipower project. In addition to water and electric charges, these facilities have the usual O\&M costs for turbine plant and associated pumping and electrical equipment.

The sample utilized for analysis of hydroelectric O\&M costs consisted of 151 plants, representing all nine Census Regions. Again Census Region 9 dominated the sample, but the remaining regions had a minimum of four plants in the sample. Corps of Engineers plants accounted for 50 observations; seven plants were pumped storage facilities.

Preliminary regressions employed vintage, capacity, and plant factor as explanatory variables; and dummy variables for location, plant type, and Corps of Engineers plants. Significant differences were found between pumped storage and conventional plants, but not for operating-type characteristics among conventional facilities. Plants in Census Regions 2 and 3 and those operated by the Corps of Engineers were found to be significantly more costly to operate and maintain than plants located elsewhere or privately operated plants.

vintage was not found to be significant variable, which leads to the conclusion that operating economies were achieved through static scale effects, not advances in technology. Recall that vintage was not found to be highly correlated with other explanatory variables, so the insignificance is real. Table III-10 presents the final O\&M cost-estimating relationship.

Utilization and Capacity. Hydroelectric facilities exhibit the same $O \& M$ cost properties associated with the other generating technologies economies of scale with respect to plant size and a high percentage of fixed O\&M costs. A $10 \%$ increase in plant size utilization (output) has a sma11, but statistically significant impact on $0 \& M$ costs: $1.8 \%$ for every $10 \%$ increase in plant utilization. Although utilization is a significant driver of costs, the low elasticity is the result of the high fixed costs. 
Table III-10

Results of Hydroelectric

O\&M Cost Regression

\begin{tabular}{lcc}
\hline Independent variables & Coefficient & t-Value \\
\hline Intercept & 8.791640 & $11.463 *$ \\
Ln capacity (MW $)$ & 0.650137 & $17.731 *$ \\
Ln plant factor (\%) & 0.187778 & $2.477 * *$ \\
Dummy for conventional (non- & -2.027170 & $3.946 *$ \\
pumped storage) plants & 0.346264 & $1.717 * * *$ \\
Dummy for Corps of Engineers & 0.469580 & $2.595 * *$ \\
Dummy for Census Region 2 & 0.538182 & \\
Dummy for Census Region 3 & & \\
$\mathrm{R}^{2}$ raw $=0.8126$ & & \\
$\mathrm{R}^{2}$ corrected $=0.8047$ & &. \\
\hline
\end{tabular}

Plant-Type Effects. Pumped storage facilities require purchased off-peak power and consequently have higher unit operating costs than conventional plants. The regression results show that conventional plants are a significant $87 \%$ less costly to operate for a given level of output than pumped storage facilities. Corps of Engineers plants are also more costly to operate and maintain, compared to otherwise similar privately operated facilities. This cost difference amounts to a substantial $41 \%$ and may to some extent reflect higher costs from user charges placed on power facilities. 
Regional Effects. Census Regions 2 and 3 are indicated to be locations with substantial higher costs when compared to the rest of the country. Cost differences are high, on the order of $60 \%$ more. It is plausible that a concentration of high-cost pumped storage facilities in Regions 2 and 3 may account for some of the indicated higher cost. That is, the dummy coefficients for Census Regions 2 and 3 may be overestimated, while the coefficient for conventional plants may be underestimated. A check on this hypothesis revealed very little correlation between pumped storage facilities and Census Regions 2 and 3 (simple correlation coefficients of 0.36 and 0.11 , respectively).

\section{Nuclear Steam-Electric Plants}

\section{a) Capita1 Costs}

The published FPC information available for nuclear-fired steam-electric generating plants is much more limited than that for the other, better established technologies. The capital cost sample consisted of 31 stations brought on line between 1962 and 1975, ranging in size from $75 \mathrm{MW}$ to $2660 \mathrm{MW}$ of rated generating capacity. The average total station size and unit capacity in the sample were quite large, nearly $1,000 \mathrm{MW}$ and $717 \mathrm{MW}$, respectively.

Nuclear teichnology is evolving rapidly; capacity has grown quickly during a period of high price escalation; the period covered by our sample is short; and the size of the sample itself is limited. For these reasons, we endeavored to incorporate more cost-driving engineering design parameters into the analysis than we did for the other technologies. These variables should reflect technological impacts on capital costs that are explained by vintage in the other technologies examined.

In certain instances, sources other than the FPC annual publications were employed for engineering design characteristics and other variables. Annual 1975 FPC data that had yet to be published at the time of this study were also utilized. Of primary interest in this regard was capturing changes in eng 1 neering paramaters, such as higher boiler pressures and temperatures, and accounting for the impact on costs of construction delays, safety, and 
environmental protection standards. Amoung the variables compiled in the data base were boiler temperature and pressure, type of cooling, type of reactor container, reactor type (PWR,BWR), and total construction time. Recall that interest on funds used during construction is part of the reported plant investment costs.

Preliminary regression analysis began with the observation that boiler pressure and temperature are highly correlated with each other and with vintage. Boiler pressure and temperature were, therefore, not jointly used as independent variables. A regression equation was developed, using unit capacity, number of units, boiler pressure, construction time, reactor type, container type, and regional dummies. Dummy for Census Regions 1, 2, and 4 were marginally significant, as was vintage and boiler pressure. Container type was not significant. Additional runs were developed, retaining significant or nearly significant variables and adding dummies for cooling type and a new dummy to distinguish if reported sample costs were for the initial unit of a multiunit station. Regional dummies for Census Regions 1 and 2 were combined since the estimated coefficients for the regional dummies were identical. In the subsequent regressions, cooling type and vintage were found to be insignificant. Vintage had a positive but insignificant coefficient, which might be due to the inclusion of boiler pressure and construction time explanatory variables. The final cost estimating relationship that eventually evolved is presented in Table III- 11 .

Capacity. The coefficients for unit capacity and number of units evidence substantial economies of scale. This finding seems to be supported by the observed tendency for the size of new stations to increase quite rapidly ( $13 \%$ per annum) during the 14 years covered in the sample. The simple average for the two coefficients is 0.77 , indicating that equal increases in unit capacity and number of units to produce a $100 \%$ increase in overall capacity results in $77 \%$ higher costs. However, the lower coefficient for unit capacity suggests that most of the economies come from increasing unit capacity. 
Table III-11

Results of Nuclear Steam Plant

(Milions of 1975 Dollars)

\begin{tabular}{lcl}
\hline Independent variables & Coefficient & t-Value \\
\hline Intercept & 1.099110 & 0.999 \\
Ln number of units & 0.920290 & $6.245 *$ \\
Ln capacity per unit (MW $)$ & 0.622736 & $6.476 *$ \\
Ln boiler pressure & 0.317297 & $1.903^{* * *}$ \\
Ln construction time (months) & 1.149440 & $3.734^{*}$ \\
Dummy for BWR (0 for PWE) & -0.259434 & $-2.699 * *$ \\
Dummy for first of two units & 0.198409 & $2.004^{* * *}$ \\
Dummy for Census Regions 1 \& 2 & 0.314333 & $2.713^{* *}$ \\
Dummy for Census Region 4 & 0.379635 & \\
$\mathrm{R}^{2}$ raw $=0.9120$ & & \\
$\mathrm{R}^{2}$ corrected $=0.880$ & & \\
\hline
\end{tabular}

Construction Time. Funds used during construction are an explicit component of reported total plant investment. Furthermore, delays for technical, environmenta1, and safety reasons have increased in recent years. The estimated impact of construction time on total costs is significant and quite substantial. The regression coefficient shows that an increase in construction time of $20 \%$ (for example, from 60 to 72 months) causes a $23 \%$ increase in total capital costs. This relatively large impact reflects the timing of the delay (cumulative effect if early) and the associated additional costs such as increased interest costs for capital funds embodied in the unfinished plant and construction overhead. 
Plant Type/Boiler Pressure. The effect of plant type and design boiler pressure are of the expected sign and reflect the trade-off between higher plant first cost and lower operating costs. Boiler pressure is the key to increasing a plant's thermal efficiency and lowering fuel costs. Most of the dramatic increases in boiler pressure registered from 1973 to 1975 were. incorporated in PWR-type plants, which explains their significant increase.. in cost per $\mathrm{kW}_{\mathrm{e}}$ during this period. The coefficient for boiler pressure (a. continuous variable) shows that an increase of $10 \%$ increases plant costs by 3. $17 \%$. The dummy for BWR indicates that BWR's are $23 \%$ less costly to build than comparable PWR plants.

Other Dummy Variables. The dummy variable for the first generating unit of a multi-unit plant shows that such units are $22 \%$ more costly than if the observation represents a complete plant. The higher costs associated with such first generating units reflect infrastructure and equipment costs procured with the first unit which are common to the additional units to be built at the site.

Significant regional differences were found for Census Regions 1, 2 and 4. Regions 1 and 2 were combined into a single dummy to increase the available degrees of fredom for the regression. Cost differences amount to a $46 \%$ increase for Census Region 4 and a 36.8\% increase for Census Regions 1 and 2 as compared to the rest of the country. (No plants were observed in Region 8 ).

b) Fuel Costs

For nuclear-fueled plants, we again sought to determine a relationship for physical fuel usage in terms of numbers of Btu consumed and plant size, vintage, utilization, etc. The direct attribution of fuel consumed per period of time is not available and the physical measure of Btu consumption is an estimate based on attributed fuel cost per $\mathrm{kWh}$ of net generation and the heat rate. The attribution of costs per $\mathrm{kWh}$ is necessary since the fuel is purchased as a unit (usually with provision for refueling), not as divisible units of known Btu content. Furthermore, the station heat rate reported in our sample exhibited very little varlation. 
The estimating procedure to determine Btu consumption is not consistent from plant to plant. The general procedure seems to be to calculate the initial cost of fuel on the basis of the cost of uranium (net of residual value, plutonium buildup) and all other added costs such as fabrication and reprocessing, and to prorate this cost as an annual fuel charge based on an estimate of thermal unit of production rate (cents per million Btu). Estimates are then subject to adjustment when actual cost and output are determined. In some cases, the fuel charge is based on amounts payable to the supplier of leased fuel-actual lease carrying costs and amortization of investment.

As a consequence of this variation in allocation procedures, we really do not have data that accurately report units of fuel consumed and average Btu content per unit of fuel. Instead we are estimating an equation that represents the procedure used by the industry to determine the physical amount and value of fuel attributable to annual output. The annual estimate from this procedure is itself subject to revision once the actual useful life and associated costs of the fuel bundle are known.

The regression equation reported in Table III-12 explains $60 \%$ of the observed variability in reported station fuel consumption. Attempts to improve the overall explanatory power of the relationship using boiler pressure, reactor type, vintage, and other variables were unsuccessful. We have concluded that the regression equation is superior to a simple point estimate, and that because of the difficulty and inconsistency of the techniques used to estimate actual Btu consumption, it is the best estimate that can be developed with existing data.

Capacity. The estimated coefficient for plant capacity indicates substantial economies of scale in fuel consumption as plant size increases. Doubling plant size requires only $80 \%$ more fuel, if the utilization rate is held constant. However, a plant with twice the previous plant's capacity operating at the same plant factor produces twice the output with $20 \% 1$ less fuel. This suggests that as the price of nuclear fuel increases, economics will dictate the building of larger capacity plants. The extent of economies of scale appears to be greater for nuclear steam-electric plants than for conventionally fired units. 
Table III-12

Results of Nuclear Fuel

Consumption Regression

(Logarithm of Btu $\times 10^{9}$ )

\begin{tabular}{lll}
\hline Independent variables & Coefficient & t-Value \\
\hline Intercept & 2.745290 & $1.848 * \star \star$ \\
Ln capacity $\left(\mathrm{MW}_{\mathrm{e}}\right)$ & 0.791846 & $7.871 *$ \\
Ln plant factor $(\%)$ & 0.681999 & $2.358 * *$ \\
$\mathrm{R}^{2}$ raw $=0.6264$ & & \\
$\mathrm{R}^{2}$. corrected $=0.6062$ & & \\
\hline
\end{tabular}

Utilization. Fuel consumption of nuclear plants appears to be less variable with changes in output than is the case with conventional steam plants. Conventional steam plants evidence growth in fuel consumption nearly in proportion to that of output. Nuclear-fired plants appear to provide substantial operating economies as utilization increases. A $10 \%$ increase in net generation requires less than a $7 \%$ increase in fuel consumption. This result is, of course, subject to the above stated reservations concerning determination of fuel consumption.

c) Non-Fue1 O\&M Costs

Non-fuel O\&M costs of nuclear power plants were estimated from a sample of 40 plants obtained from pooled 1974 and 1975 cross sections. To account for inflation-induced price differences between the two years, a dummy variable for the year of observation was introduced. Plants beginning operation in either 1974 or 1975 were omitted from the sample for the initial year. This was done because of the fear that preoperating costs were charged to operating costs in the initial year of commercial operation, which, would unduly bias the sample. 
Regression equations were derived, with capacity, plant factor, vintage, dummy for year of observation, and regional dummies as explanatory variables. In contrast to similar formulations for other technologies, plant factor and vintage were both insignificant. Usually, plant factor proved statistically significant, although the estimated coefficient indicated high fixed costs compared to variable costs. O\&M costs appear to be fixed by plant capacity and do not vary substantially with output.

Subsequent runs were made with regional dummies. The coefficients for all Census Regions, except Region 7, were insignificant and were eliminated. Reactor type and age, instead of vintage, were introduced as separate variables and capacity was replaced with capacity per unit and the number of units. Age became significant, but vintage did not, because the two-period cross section differentiates age, while vintage stays invariant from one cross section to the next. Table III-13 presents the final regression results for nuclear plant O\&M costs.

Capacity. The coefficients of unit capacity and number of units evidence substantial economies of scale, more so as units are added to a station than as capacity per unit is increased. This result is the opposite of that obtained from the capital cost equations. Doubling capacity through equal $50 \%$ increases in units and unit capacity causes on $1 y$ a $49 \%$ increase in operating costs. Holding a station at say the traditional two-unit configuration and increasing unit capacity by $10 \%$ causes $0 \& M$ costs to increase by only $7.6 \%$. Note that utilization rate is not included as a significant explanatory variable, indicating. that the manning of nuclear units is essentially fixed with capacity and that maintenance is periodic, regardless of output. Increasing plant output apparently has little impact on required operating or maintenance expenditures.

Age. This variable apparently captures much of the impact of output as a driver of $O \& M$ costs. It is significant and large - O\&M costs increase at a proportionate rate of $5.7 \%$ per year, regardless of plant size or utilization. This effect is much more substantial than for other steam-electric technologies. 
Table III-13

Results of Nuclear Non-Fuel.

O\&M Cost Regression

(Logarithm of Thousands of 1975 Dollars)

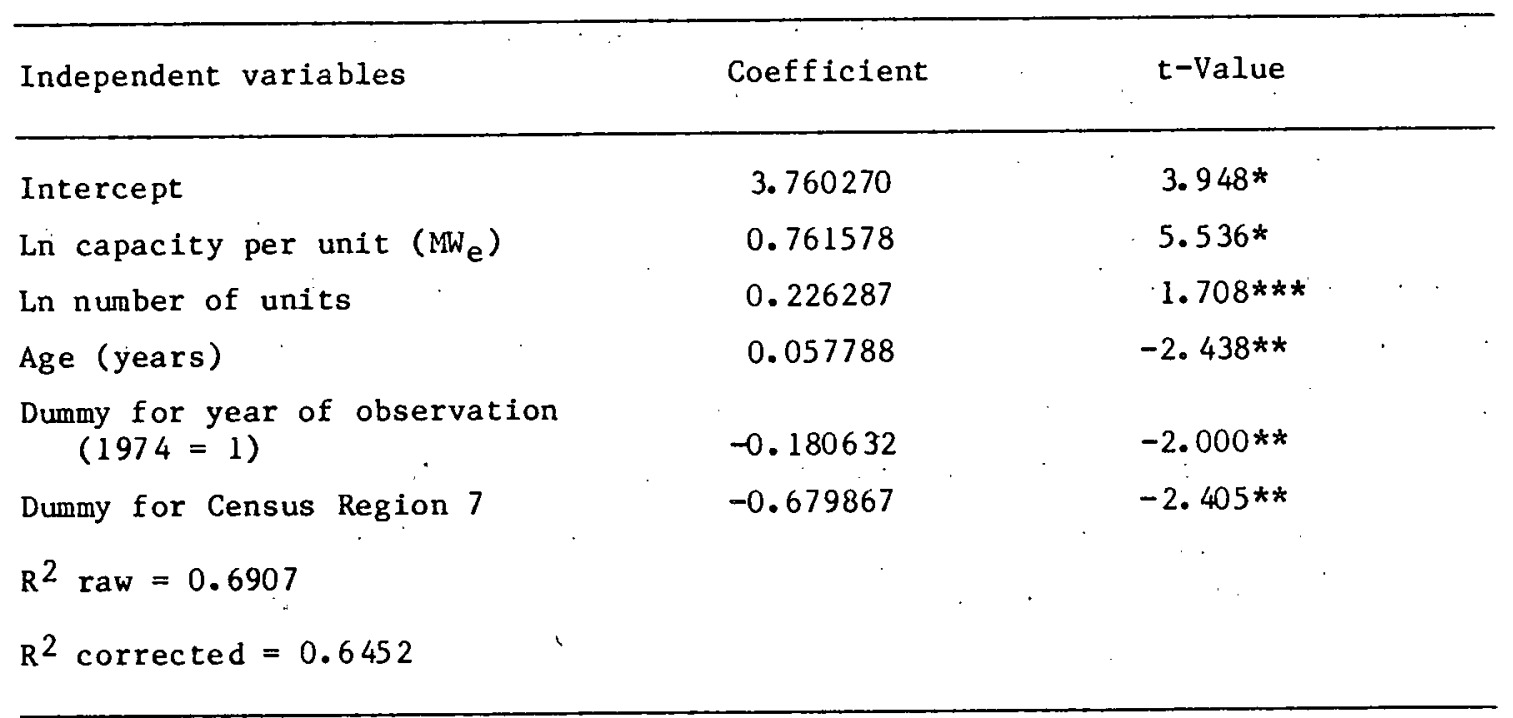

Regional Effects. Census Region 7 was estimated to be a lower cost region in comparison to the rest of the country. Cost differences amount to a substantial $50 \%$ markdown from those of the rest of the country. This result. should be viewed skeptically, as there is only one nuclear plant in Region 7 , and the total sample contains only 40 observations.

Dummy for Year. This dummy variable is not to be used for projections, but was included to account for the impact of inflation between 1974 and 1975. The coefficient, incidenta11y, indicates that 1975 prices for O\&M inputs were $17 \%$ higher than in 1974. 
APPENDIX A

DATA BASE DOCUMENTATION

A. Introduction

For the results of this study to be credible, they must be reproducible by other analysts following the same procedures. To this end, every effort has been made to document the data base fully.

The sample selection and data collection efforts are described for fossil-fueled, nuclear, hydro, and gas turbine electric generation and pollution control facilities and equipment. The discussion under each electric power generation plant type covers capital and O\&M costs and fuel consumption data.

The data for this study came primarily from FPC Form 1 reports. To establish a basis for cost function estimation, it was necessary to adjust the cost data to reflect constant 1975 dollars. The procedure for adjustment of capital costs is described in Appendix $B$.

\section{B. Electric Power Generatiom}

The FPC publishes annual capital and production costs separately for each electric power plant to reflect the cost of electric power generation. These reports are entitled: "Steam-Electric Plant Construction Cost and Annual Production Expenses, which contains data on fossil-fueled and nuclear power plants; Hydro-Electric Plant Construction Costs and Annual Production Expenses, and Gas Turbine-E lectric Plant Construction Costs and Annual Production Expense. All the capital, O\&M fuel cost, and plant characteristics data used in this study were extracted from these reports unless otherwise specified.

The data in the FPC reports do not include a separate account for the capital and $O \& M$ costs of pollution control equipment; therefore, it was necessary to use other sources to determine how much of the plant-reported costs were for pollution abatement. These data will be described in the section on "Pollution Control Costs" later in this appendix. 
1. Plant Cost Data. The FPC reports aggregate capital costs of plant generating capacity in three accounts: land, structures and improvements, and equipment. Since land is on the average less than $2 \%$ of total plant cost, the amount of land varies widely between plants of similar type and capacity, and the cost per acre is independent of plant characteristics, the cost of land was excluded from the capital cost samples.

Plant production costs are reported in three major accounts: operating costs, maintenance costs, and fuel expense. For each plant, we calculated the aggregate operating cost (excluding rents and fuel). Our efforts to compare O\&M and capital costs consistently necessitated the omission of rents from operating costs, because the corresponding capital account, land, was left out of capital costs. Total fuel dollar costs were likewise not considered in operating expenses, but fuel use, measured in Btu by fuel type, was calculated for each plant. The advantage of analyzing actual physical amounts of fuel burned is the removal of variability caused by regional and system price differences. Estimates of fuel costs can then be developed by applying regional prices to each type of fuel. These costs can finally be added to arrive at total plant operating costs.

Steam-Electric Plants. The data base for capital costs of steam-electric plants was selected from the 1974 and 1975 FPC reports, Steam-Electric Construction Cost and Annual Production Expenses. These reports have been published annually since 1947, and the first edition includes yearly data back to 1938 for fossil-fueled plants, and 1960 for nuclear plants. There are not published data for prior years.

The total fossil-fueled steam-electric plant population listed in the 1974 report, from which the sample was chosen, consisted of approximately 635 plants located in the continental U.S. Data on plant capital costs were obtained for 340 plants. The principal criterion for choosing plants for our capital cost sample was the ability to track back and capture initial investment cost and related plant characteristics for the year the plant became operational. of the total 635 plants listed in the 1974 report, 135 were in operation prior to 1938 and 1947. Approximately two-thirds of the post-1938 plants were eligible according to our initial criterion. 
Many of the older plants were excluded from the sample because of such reasons as: the absence of cost data, conflicting data, the mixing together of data for several plants operating within the same utility system, and unexplained time lapses between the first year of operation and the initial year of FPC reporting.

Data for the 340 plants included in the final sample were traced from the first year of FPC. reporting through 1974. When the information was available, all changes in capacity and corresponding changes in capital investment were documented. The model uses only those cost and capacity data that reflect the initial period of a plant's operation. Initial operation was defined as the early years of a plant's existence when single or multiple units were being placed in service. Thus, the capacity and investment data include all units comprising the original plant. In many cases, plants had units that began operating one year after the other over a span of two to four years. In these situations, all units were judged to be part of the original plant, and their cost data were aggregated and expressed in constant 1975 dollars. The indices used to convert to constant dollars were based on the Handy-Whitman, Building Construction Cost Trend Tables from 1912 to January 2, 1977.*

Operations and maintenance and fuel consumption data for fossil-fueled steam-electric plants were gathered from the annual FPC reports for 1969 and 1974. The groups of plants sampled in those years were selected of plants sampled in those years were selected from the 340 plants from which capital costs were collected. Only 105 plants had usable 1969 data; 133 had usuable 1974 data. The criterion for plant selection was the absence of major changes in equipment or structures from the period of initial operation to the year in which $O \& M$ and fuel data were collected. Information about plants that began

*The procedure for developing the weighted annual deflation factors took into consideration the average construction lead time for the different types of technologies, i.e., 10 years for nuclear and hydro, etc. Appendix $B$ describes the procedure. 
operations during 1969 or 1974 was omitted from one sample or the other, because it was felt that a partial year of operations would produce distorted information.

Capital cost data gathered for 33 nuclear-powered plants that began operations between 1960 and 1975. This sample comprised almost the entire population of plants operating in 1975. We attempted to include all nuclear plants in this sample, but had to exclude several because they were prototypes or had questionable cost data. The capital cost sample included four plants that began operations in 1975 for which there appeared to be sufficient information about costs and physical characteristics to make them eligible for the capital cost sample.

Unlike the data reported for fossil-fueled steam-electric plants, those for nuclear plants were clearly trackable. Most plants are of recent vintage and report requested information regularly. Also, most nuclear plants have a few large units that entered service in consecutive years; few plants have more than two units; none have reheat capacity; and few have changed the ratings of their generating capacity. All these factors simplified the sample selection process.

The sample used in the analysis of $O \& M$ costs and fuel consumption for nuclear-powered plants consisted of the same plants that made up the capital cost sample. Operations and maintenance and fuel consumption data were collected for the years 1974 and 1975 for all plants except those that began operations in each of these years.

The operations cost accounts for nuclear plants are the same as those for fossil-fueled plants, with the addition of the "Coolants and Water" account. The various categories of maintenance costs used by both types of plants are identical.

Hydroelectric Plants. Capital and O\&M costs were collected for 177 of the 184 hydroelectric plants constructed since 1948. These data were reported in the 1974 edition of Hydro-Electric Plant Construction Cost and Annual Production Expenses, published by the FPC. Several plants were excluded from the sample because they reported insufficient or conflicting data. 
Of the 177 plants in the sample, 52 were constructed by the Corps of Engineers. Such plants were identified as a separate subsample to be "dummied" for possible cost differences from privately built plants because their accounting system varies from that generally followed by private industry, and the reported costs were observed to be significantly higher than those for private plants.

A number of adjustments to the capital data for hydroelectric plants had to be made. Certain privately owned plants lack their own reservoir and purchase water from another utility to power their turbines. In such instantces, plants purchasing water and reporting costs in excess of $50 \%$ of total operating cost were deleted from the sample. The assumption was that these plants (typically small) wre auxiliary units operating downstream from a larger power plant and thus would not be representative of the hydroelectric plant population.

Another major adjustment involved the allocation of the investment and operating costs of central dams and reservoirs. Central facilities provide the water to a number of plants within a river basin and were allocated to those plants identified as part of the system. This had to be done to make these plants compaable to those owning their own dams and reservoirs.

Gas Turbine Plants. Capital and $O \& M$ costs and fuel consumption data for gas turbine facilities were taken exclusively from the FPC's publication, Gas Turbine-Electric Plant Construction Costs and Annual Production Expenses, First Annual and First Annual Supplement. The FPC publication began in 1972, following the increased use of this technology for peaking purposes. However, the initial 1972 publication lists all existing plants as of 1972 and compiles investment costs, $0 \& M$ costs, and fuel consumption for units installed as far back as the late 1950 's. This publication also recorded operating data for 1972.

The comparable 1973 publication (entitled First Annual Supplement) presents cost data, investment cost and physical characteristics for new plants added in 1972, and annual operating statistics for existing plants in a manner 
similar to that for the steam-electric plant data. Since gas turbine plants represent a relatively small fraction of overall. capacity and an even smaller fraction of net generation, low priority is placed on the timeliness of publication of data by the FPC. The latest data now available are for calendar 1973.

Since publication of construction costs began in 1972, it was not possible to separate construction costs into the amounts attributable to initial capacity or to subsequently added capacity. Consequently, plants were only considered for our sample if rated capacity and investment cost remained unchanged from the initial values. Secondly, multi-unit plants were included in the sample only if the units were of identical capacity.

Many recently acquired plants are leased to the utility, in which case no capital investment cost is recorded. Annual rental charges for the leased equipment appear in operating costs. Leased plants were therefore excluded from the capital cost data base, but when otherwise suitable were included in the operating cost data base. In the latter case, rental (lease) payments were excluded from non-fuel operating costs.

Capital costs were aggregated and inflated to constant 1975 dollars for structures and improvements, and equipment. Land costs usually are not attributed to the gas turbine unit since the plant is often co-located with a base plant. When land costs were reported, they were not included in investment costs.

Operating cost data were compiled for the two available years, 1972 and 1973. Plants were excluded from the operating cost data base when they operated for less than a full year, or when costs were shared with another plant.

2. Plant Characteristics. Collection of power plant capital and O\&M cost data was accompanied by compilation of key physical and operational characteristics common to electric power generating plants. Of the available characteristics in the FPC reports, those thought to be most useful were: region, fuel 
type, construction type, number and capacity of generating units, number and capacity of reheat units, the design heat rate and related technical variables, such as boiler pressure and temperature and the vintage of the plant.

Plant location in one of the nine energy regions considered in the study was assumed to be an important explanatory variable for both capital and O\&M expenditures. The nine U.S. Census Regions were used as proxy energy regions for this study. These are: New England, Middle Atlantic, East North Central, West North Central, South Atlantic, East South Central, West South Central, Mountain, and Pacific.

Plants situated in regions with mild climates have, in many instances, constructed outdoor facilities. In other regions the climate has necessitated semi-outdoor or enclosed facilities, which are more costly to build.

Differences. in regional wage rates and materials prices also affect reported capital costs.

The availability of different fuels for electric power generation also varies by region and affects capital and production expenditures. There are four predominant types of steam-electric and gas turbine plant fuel: coal, oil, nuclear, and gas. Hydroelectric plants require no fuel, except that pumped storage plants require off-peak electricity to pump water to the upper reservoir. The fuel consumed by a plant determines what types of structures and equipment it will: need. For example, a coal-burning plant requires coal handling and pulverzing, as well as ash removal equipment not used by plants fueled by oil or gas. In addition, coal plants must install costly scrubbers to meet environmental regulations and relatively greater storage facilities for bulk storage of coal. .

Steam-Electric Plants. The most important design parameters for steam-electric plants were assumed to be the number of units and their generating capacity. For fossil-fueled plants, operating efficiency of the units is related to other characteristics, such as whether or not the unit is equipped to reheat the steam and power a secondary turbine. Therefore, information concerning reheat capacity was also collected and analyzed. 
Another aggregate indicator of operating efficiency is the amount of fuel required to produce a kilowatt-hour of electricity, i.e., the heat rate. The lower the heat rate, the more efficient the plant. We attempted to incorporate this design characteristic using actual heat rates and capacity utilization information for each plant. Design heat rate was estimated using an engineering relationship for the design heat rate in terms of the actual heat rate and plant utilization as reported by S. Ling. 15

Plant characteristics for nuclear-powered steam-electric stations were compiled from FPC reports and other sources. Some of these characteristics, such as vintage, region, number of units, and generating capacity, are identical to those collected for fossil-fueled plants. Relevant data were available in the nuclear section of Steam-Electric Plant Construction Cost and Annual Production Expenses.

Other design characteristics affecting investment costs in nuclear power plants reported by the FPC are boiler pressure and temperature, and reactor type. In addition, we included the type of cooling facility, length of construction, and type of reactor containment. These data are reported in Electric World's Annual Nuclear Plant Survey reported every 15 th of October. Appendix $C$ describes the various breakouts for type of cooling facility and reactor containment available in this survey.

Hydroelectric Plants. The plant characteristics compiled for hydroelectric plants generally are the same as those used in analyzing steam-electric plants, and the same justification exists for their selection. However, one of the physical factors, plant type, has a different meaning. Where applied to a hydroelectric facility, the plant type reflects the classification of the plant as a conventional or pumped storage plant. In the case of steam-electric plants, plant type indicated whether or not the facilities were outdoor, semi-outdoor, or conventional.

Two additional technical variables are available for hydroelectric facilities head, and water flow ( $\mathrm{gpm})$. Data for these two technical factors were incomplete. Less than $50 \%$ of the reporting plants showed this information, and for this reason they were not included in the final data sample. 
Combined Cycle Plants. Rising fuel prices, increasing environmental requirements, and greater flexibility for mid- and base-load applications as dictated by changing system load requirements have contributed to renewed interest in combined cycle electric generating plants. By the end of 1974 , approximately $1372 \mathrm{MW}_{\mathrm{e}}$ of gas turbine capacity was in combined cycle plants, and many thousands of additional $\mathrm{MW}_{e}$ are on order for installation in the late 1970 's and 1980's. Because cost and capacity data for combined cycle plants cannot be sepaated from that for the conventional plants they are usually a part of, combined cycle plants were deleted from our sample. Further data-gathering effort may be necessary to obtain a clean sample of combined cycle plants to develop cost functions for this type of generating plant.

\section{Pollution Control Costs}

The FPC does not include a separate account for the costs of pollution control at each plant. It was therefore necessary to use other data sources to determine how much of the total plant cost in each of the samples was for fly-ash, for $\mathrm{SO}_{2}$ and $\mathrm{NO}_{x}$ control (air pollution), and for cooling towers and artificial lakes for water pollution control. The technology for control of $\mathrm{SO}_{2}$ and $\mathrm{NO}_{\mathrm{x}}$ emissions is still in the development stage, although a number of prototype $\mathrm{So}_{2}$ removal systems had been installed by 1973 . The consensus among the various sources reviewed points to very low inftial costs for $\mathrm{NO}_{x}$ abatement. The preferred technique for $\mathrm{NO}_{\mathrm{x}}$ abatement is currently combustion modification, which would result in lower plant efficiencies and increased costs per unit of output.

Thus, the cost data and system characteristics discussed in the previous sections do not identify the cost of air and water pollution control facilities and equipment in existing plants. We therefore examined a number of previous studies for purposes of understanding the abatement technologies being developed, identifying pollution control costs in our sample data, and estimating the future cost of implementing these technologies in new plants.

The references below are the sources of the data used in the air pollution control cost analysis. Comparison and analysis of the various air pollution control cost data are presented in Chapter II. Table II-6 in that chapter shows the range of cost estimates for air pollution control, and attempts to normalize these costs by adjusting them to 1975 dollars. 


\section{REFERENCES}

1. FPC Report-Form S-253, Federal Power Commission, Washington, D.C., December 1973.

2. Watson, W.D., Jr., Costs of air pollution control in the coal-fired electric power industry, $\underline{Q}$. Rev. Econ. Bus., pp. $63-85$, Vol. 12, No. 1 , 1972.

3. McSorley, J.A., Applicability of $\mathrm{SO}_{2}$-Control Processes to Power Plants, Environmental Protection Agency, Washington, D.C., 1972.

4. Tarquin, A.J., et al., Cost of air pollution controls in the power industry, Public Utilities Fortnightly, pp.40-44, Vol. 91, No. 7, March 29, 1973.

5. Gakner, A., and R.M. Jimeson, Environmental and Economic Cost Considerations in Electric Power Supply, presented at 74 th Nat. Mtg., Am. Inst. Chem. Eng., New Orleans, La., March 11-15, 1973.

6. Myers, M.L., Cost Estimate for Limestone Wet Scrubbing Sulfur Oxide Control Process, ORNL-TM-4142, July 1973.

7. Blakeslee, C.E., and H.E. Burback, Controlling $\mathrm{NO}_{\mathrm{x}}$ emissions from steam generators, J. Air Pollut. Control Assoc., Vol. 23, No. 1, pp. 37_42, January 1973.

8. Bartok, W., et al., Control of $\mathrm{NO}_{\mathbf{x}}$ emissions from stationary sources, Chem. Eng. Prog., Vo1. 67, No. 2, pp. 64-72, February 1971.

9. Scherer, Charles R., Estimate Electric Power System Marginal Costs, North Holland, N.Y., 1977.

10. Power plant capital costs, current trends and sensitivity to economic parameters, U.S. Atomic Energy Commission, Division of Reactor Research and Development, October 1974.

11. A procedure for estimating non-fuel operating and maintenancé costs for large steam-electric power plants, U.S. Energy Research and Development Administration, October 1975. 
12. U.S. Congressional Joint Economic Committee, The Economy, Energy and The Environment, Washington, D.C., 1970.

13. Petrusche11, R.L., and Salter, R.G., Electricity Generating Cost Model for Comparison of California Power Plant Siting Alternatives, The RAND Corp., R-1087-RF/CSA, January 1973.

14. Anderson, K.D. and DeHaven, J.C., The Long-Run Marginal Costs of Energy, R-1590-NSF, February 1975.

15. Ling, S., Economics of Scale in the Steam-E electric Power Generating Industry, North Holland Press, N.Y., 1964.

$-86-$ 
APPENDIX B

CONSTRUCTION COST INDICES

The observed cost of plants included in the data base reflects the level of prices prevailing at the time and place of construction. In order to normalize total capital costs associated with plants of varied vintages and locations, construction cost price indices were developed. The indices account for the timing of expenditures over the construction period and the length of the construction period of the original plant. This is accomplished by weighing semiannual indices for each period with semiannual expenditures expressed as a percentage of total cost. The indices are specific to the type of power plant and region. The generating station types are fossil-fueled, hydropowered, gas turbine and nuclear production plants. The regions are the North Atlantic, South Atlantic, North Central, South Central, Plateau and Pacific sectors of the U.S.

The annual construction cost indices used were those contained in the Handy-Whitman Index of Public Utility Construction Costs. 1 Specific indices used were the "Total Fossil Production Plant," "Total Hydraulic Production Plant," and the "Gas Turbo-Generator" categories of the Electric Utility Construction section of the Index for each of the six regional categories indicated above. Since an index for "Total Nuclear Production Plants" did not exist, one was developed from component categories available as explained below.

The Handy-Whitman Index does not identify the level of costs in a particular region for a particular generating technology but the rate of change in costs through changes in the price of requisite materials and labor. Consequent1y, the Handy-Whitman Index cannot be used to discern regional cost difference (all regions are normalized at an index value of 100 in 1949), only differential rates of change among regions at a point in time. Secondly, the index does not account for the fact that a plant is constructed over many periods. Price changes are in accordance with the index only for the period reported. To correct this deficiency, annual indices were weighted by annual out lays over a representative construction period. Outlays were expressed as 
a percent of total construction expenses. These weights were obtained from the cumulative cash flow curves depicted in Figure B-1. It was assumed that construction expenditures for hydroelectric and gas turbine plants would follow the same distributive pattern as that for fossil-fueled plants. It was also assumed that fossil-fueled, hydroelectric, and gas turbine plants are constructed over 5-, 10-, and 2.5-year periods, respectively. While the construction period of nuclear power stations was estimated to be ten years, major expenditures were made only in the final six years of construction. Therefore, the latter time period was used in developing an index.

The construction period for each type of power plant was divided into semiannual segments and expressed as a percent of the overall construction period. Corresponding expenditure percentages were extracted from the cash flow curves. The incremental percent expenditures reported in Tables $B-1$ to B-4 were used as weights and applied to the appropriate annual construction index and then summed to obtain an index for the total construction costs of a plant for the year in which it was completed. A fossil-fueled production plant in the South At lantic Region completed in 1973 with expenditures beginning in 1969 would have the following index:

HANDY-WH ITMAN INDEX

$$
\begin{array}{r}
1973-\begin{array}{r}
255 \\
247
\end{array} \\
1972-245 \\
233 \\
1971-222 \\
212 \\
1970-205 \\
197 \\
1969-192
\end{array}
$$$$
188
$$

WEIGHT

0.014

0.016

0.065

0.102

0.216

0.174

0.215

0.088

0.096

0.014
WEIGHTED

SEGMENT

3.57

3.95

15.93

23. 77

47.95

36.89

44.08

17.34

18.43

2.63

Total $214.54=$ expenditure weighted price index 

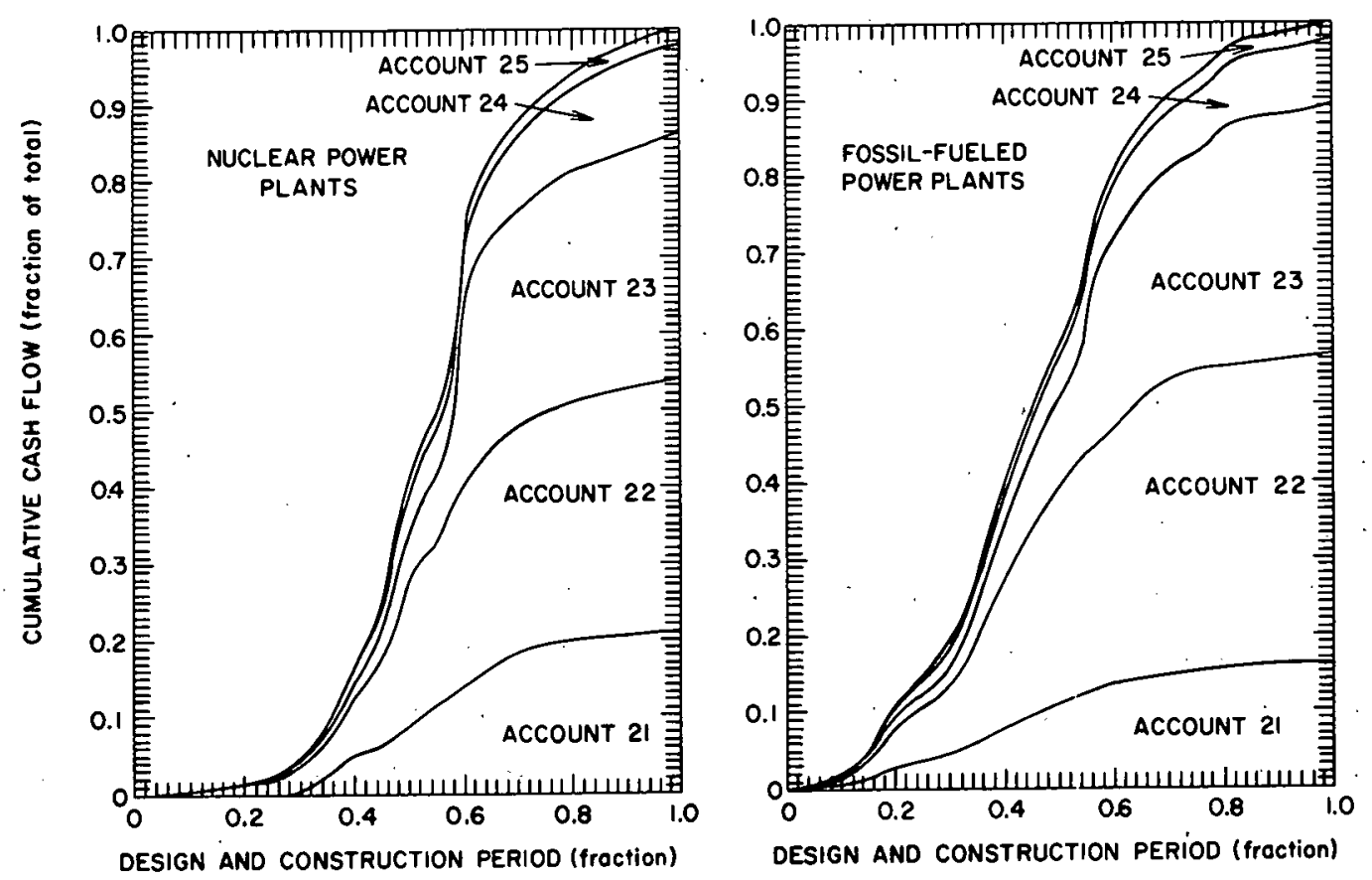

Figure B-1. Typical cumulative cash flow curves for major direct cost accounts

Source: Concept A computer code-for conceptual cost estimating of steam-electric power plants, U.S. energy research and development administration, June 1975 
"The Nuclear Index was constructed by weighting the indices for nuclear production plant structures and improvements and reactor plant equipment with the fossil production plant indices for turbogenerator units, accessory electrical equipment, and miscellaneous power plant equipment. The weights for these indices were taken from the cash flow curve power plants as depicted in Figure $\mathbb{B}-1$. The weights are as follows:

Account \#21 Structures \& Facilities

Account \#22" Reactor Plant Equip pmemt

Account $\$ 23$ Turbo-Generator Units

Account \#24 Electrical Plant Erquïpmenit

Account \#25 Miscellaneous Plant Equipment
0.21

0.33

0.31

0.125

0.025

Indices for nuclear production plants we me mot provided in Handy-Whitman for years prior t io 1965. In order to construct the weight ied index for total construction costs, these, indices were estimated. The Nuclear Production Plant Structures and Improvements Index most closely parallel the Fossil Production Plath Structures \& Improvements (Indoors) Index; there, the Nuclear Index for 1962-1964 was estimated using this trend. There also was a close correspondence between the Reactor Plant Equipment Index and the Accessory Electrical Equipment Index. Therefore, a Reactor Plant Equipment Index for 1962-1964 was estimated using the rates of change from the electrical equipment index as a guide.

$-90-$ 
Tabile B-1

Time-Phased Construction Expenditures

For Eossil-Fueled. Power Plants

(5-year average: construction period)

\begin{tabular}{cccc}
\hline $\begin{array}{c}\text { Time } \\
\text { period }\end{array}$ & $\begin{array}{c}\text { Cumulative } \\
\text { percent }\end{array}$ & Percent expenditures \\
\hline & Cumulative & Incrementail $^{\prime}$ \\
1 & 0.10 & 0.014 & 0.014 \\
3 & 0.20 & 0.110 & 0.096 \\
4 & 0.30 & 0.198 & 0.088 \\
5 & 0.40 & 0.413 & 0.251 \\
6 & 0.50 & 0.587 & 0.174 \\
7 & 0.60 & 0.803 & 0.216 \\
8 & 0.70 & 0.905 & 0.102 \\
9 & 0.80 & 0.970 & 0.065 \\
10 & 0.90 & 0.986 & 0.016 \\
& 1.00 & 1.000 & 0.014 \\
\hline
\end{tabular}

Table B-2

Time-Phased Construction Expenditures

For Hydro Production Plants

(10-year average construction period)

\begin{tabular}{cccc}
$\begin{array}{c}\text { Time } \\
\text { period }\end{array}$ & $\begin{array}{c}\text { Cumulative } \\
\text { percent }\end{array}$ & \multicolumn{2}{c}{ Percent expenditures } \\
\hline & & & Cumulative \\
1 & 0.05 & 0.004 & 0.004 \\
2 & 0.10 & 0.014 & 0.010 \\
3 & 0.15 & 0.045 & 0.031 \\
4 & 0.20 & 0.110 & 0.065 \\
5 & 0.25 & 0.150 & 0.040 \\
6 & 0.30 & 0.198 & 0.048 \\
7 & 0.35 & 0.280 & 0.082 \\
8 & 0.40 & 0.413 & 0.133 \\
9 & 0.45 & 0.500 & 0.087 \\
10 & 0.50 & 0.587 & 0.087 \\
11 & 0.55 & 0.700 & 0.113 \\
12 & 0.60 & 0.803 & 0.058 \\
13 & 0.65 & 0.861 & 0.044 \\
14 & 0.70 & 0.905 & 0.025 \\
15 & 0.75 & 0.930 & 0.040 \\
16 & 0.80 & 0.970 & 0.007 \\
17 & 0.85 & 0.977 & 0.009 \\
18 & 0.90 & 0.986 & 0.009 \\
19 & 0.95 & 0.995 & 0.005 \\
20 & 1.00 & 1.000 & \\
\hline
\end{tabular}


Table $B-3$

Time-Phased Construction Expenditures

Gas Turbo-Generator Production Plants

(2.5-year average construction period)

\begin{tabular}{cccc}
\hline $\begin{array}{c}\text { Time } \\
\text { period }\end{array}$ & $\begin{array}{c}\text { Cumulative } \\
\text { percent }\end{array}$ & Cumulative & Percent expenditures \\
\hline & 0.20 & 0.110 & 0.110 \\
2 & 0.40 & 0.413 & 0.303 \\
3 & 0.60 & 0.803 & 0.390 \\
4 & 0.80 & 0.970 & 0.167 \\
5 & 1.00 & 1.000 & 0.030 \\
\hline
\end{tabular}

Table B-4

Time-Phased Construction Expenditures

Nuclear Production Plants

(10-year average construction period*)

\begin{tabular}{|c|c|c|c|c|}
\hline \multirow[b]{2}{*}{$\begin{array}{l}\text { Time } \\
\text { period }\end{array}$} & \multirow[b]{2}{*}{$\begin{array}{l}\text { Cumulative } \\
\text { percent }\end{array}$} & \multicolumn{2}{|c|}{ Percent } & \multirow{2}{*}{$\begin{array}{l}\text { es } \\
\text { Over last } \\
\text { six years }\end{array}$} \\
\hline & & Cumulative & Incremental & \\
\hline 1 & 0.05 & 0.000 & 0.000 & - \\
\hline 2 & 0.10 & 0.004 & 0.004 & - \\
\hline 3 & 0.15 & 0.009 & 0.005 & - \\
\hline 4 & 0.20 & 0.015 & 0.006 & - \\
\hline 5 & 0.25 & 0.023 & 0.008 & - \\
\hline 6 & 0.30 & 0.042 & 0.019 & - \\
\hline 7 & 0.35 & 0.100 & 0.058 & - \\
\hline 8 & 0.40 & 0.172 & 0.072 & - \\
\hline 9 & 0.45 & 0.258 & 0.086 & 0.103 \\
\hline 10 & 0.50 & 0.411 & 0.153 & 0.184 \\
\hline 11 & 0.55 & 0.490 & 0.079 & 0.095 \\
\hline 12 & 0.60 & 0.681 & 0.191 & 0.230 \\
\hline 13 & 0.65 & 0.820 & 0.139 & 0.167 \\
\hline 14 & 0.70 & 0.869 & 0.049 & 0.059 \\
\hline 15 & 0.75 & 0.900 & 0.031 & 0.037 \\
\hline 16 & 0.80 & 0.932 & 0.032 & 0.038 \\
\hline 17 & 0.85 & 0.952 & 0.020 & 0.024 \\
\hline 18 & 0.90 & 0.970 & 0.018 & 0.021 \\
\hline 19 & 0.95 & 0.991 & 0.021 & 0.025 \\
\hline 20 & 1.00 & 1.000 & 0.009 & 0.017 \\
\hline
\end{tabular}

*Major expenditures take place during last six years. 
APPENDIX C

DATA AND DATA CODES

C-1 OPERATION AND MAINTENANCE - FOSSIL-FUELED STEAM-ELECTRIC

C-2 PLANT CHARACTERISTICS - FOSSIL-FUELED STEAM-ELECTRIC

C-3 PLANT CHARACTERISTICS - GAS TURBINES

C-4 OPERATION AND MAINTENANCE - GAS TURBINES

C-5 PLANT CHARACTERISTICS/OPERATION AND MAINTENANCEHYDROELECTRIC PLANTS

C-6 PLANT CHARACTERISTICS/OPERATION AND MAINTENANCENUCLEAR-POWERED PLANTS

C-7 ELECTRIC UTILITY SYSTEMS - ANNUAL EXPENSE AND PHYSICAL CHARACTERISTICS DATA 
OPERATION AND MAINTENANCE - FOSSIL-FUELED STEAM-ELECTRIC

Column A - Five-digit identification code

The first digit identifies the plant by the Census Region in which it is located.

The second and third digits are the state identification code. The state codes are numerically sequenced 01 to 50 and correspond to an alphabetical listing of the states. Code \#51 indicates the District of Columbia.

The final two digits denote the specific plant within a state.

Column B - Two-digit vintage code

Year in which the plant observed was brought into initial operation.

Column C - Eight-digit region code

Regional code constructed for analytical purposes. This code for the nine Census Regions is as follows:

$\begin{array}{lllllllll}\text { Region } 1 & 1 & 0 & 0 & 0 & 0 & 0 & 0 & 0 \\ \text { Region 2 } & 0 & 1 & 0 & 0 & 0 & 0 & 0 & 0 \\ \text { Region 3 } & 0 & 0 & 1 & 0 & 0 & 0 & 0 & 0 \\ \text { Region 4 } & 0 & 0 & 0 & 1 & 0 & 0 & 0 & 0 \\ \text { Region 5 } & 0 & 0 & 0 & 0 & 1 & 0 & 0 & 0 \\ \text { Region 6 } & 0 & 0 & 0 & 0 & 0 & 1 & 0 & 0 \\ \text { Region 7 } & 0 & 0 & 0 & 0 & 0 & 0 & 1 & 0 \\ \text { Region } 8 & 0 & 0 & 0 & 0 & 0 & 0 & 0 & 1 \\ \text { Region } 9 & 0 & 0 & 0 & 0 & 0 & 0 & 0 & 0\end{array}$

Column D - Three-digit fuel type code

Identifies the types of fuel for which the boiler was designed.

\begin{tabular}{|c|c|c|}
\hline Coal & 0 & 0 \\
\hline 011 & 1 & 0 \\
\hline Gas & 0 & 1 \\
\hline Mixed & 0 & 0 \\
\hline
\end{tabular}


Column E - Three-digit building code

Indicates the plant's construction type.

$\begin{array}{llll}\text { Conventional } & 0 & 0 & 0 \\ \text { Outdoor } & 1 & 0 & 0 \\ \text { Semi-Outdoor } & 0 & 1 & 0 \\ \text { Other } & 0 & 0 & 1\end{array}$

Column F - Number of units installed at the plant observed.

Column G - Total capacity of the plant in megawatts; the sum of the capacity of all units.

Column $\mathrm{H}$ - Number of units within the plant having reheat capability.

Column I - Total capacity of the reheat units within the plant.

Column $J$ - Heat rate (Btu's/kWh of net generation).

Column K - Plant factor (net generation/(capacity x 8,760 hours)).

Column L - Average employment.

Column $M$ - Construction cost in $\$\left(x 10^{3}\right)$. The cost has been adjusted to a base year of 197.5 .

Column N - Adjusted heat rate.

Column 0 - Internal code used for programming purposes only; indicates the number of years in which the plant was observed.

Column P - Net generation, in kWh $\left(x 10^{6}\right)$, of the plant in the year observed.

Column Q - Total Btu!'s (x 109) of coal consumed by the plant in the year observed.

Column R - Total Btu's (x 109) of oil consumed by the plant in the year observed.

Column S - Total Btu's $\left(x 10^{9}\right)$ of gas consumed by the plant in the year observed.

Column $\mathrm{T}$ - Operating expense, in $\$\left(x 10^{3}\right)$, of the plant for the observation year.

Column $U$ - Annual maintenance expense, in $\$\left(x 10^{3}\right)$, of the plant for the observation year.

Column V - Year in which observation was made. 


\begin{tabular}{|c|c|c|c|c|c|c|c|c|c|c|c|c|c|c|c|c|c|c|c|c|c|}
\hline $\begin{array}{l}v L \\
v L\end{array}$ & $\begin{array}{l}27.00 \\
2512\end{array}$ & $\begin{array}{l}\mid E Y Y 1 \\
|Y| 1\end{array}$ & $\begin{array}{l}9 C_{1} E I \\
0\end{array}$ & $\begin{array}{l}0 \angle O Z \\
0\end{array}$ & $\begin{array}{l}0.211 \\
00+28\end{array}$ & 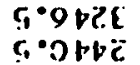 & $\begin{array}{l}\mathrm{c} \\
\mathrm{f}\end{array}$ & $\begin{array}{l}011.18 \\
11.7,8\end{array}$ & $\begin{array}{l}1 . \log (1) \cdot 8 \\
c r, c(1) !\end{array}$ & $\begin{array}{l}\text { rat } \\
\text { (x) } 1\end{array}$ & $\begin{array}{l}\text { ny } \\
\text { in }\end{array}$ & $\begin{array}{l}\text { f:I.IK } \\
V L T: K\end{array}$ & 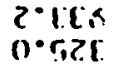 & $\begin{array}{l}\mathcal{E} \\
\mathcal{E}\end{array}$ & 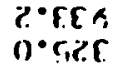 & 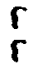 & $\begin{array}{l}\text { non } \\
\text { ono }\end{array}$ & $\begin{array}{l}\text { mo } \\
\text { mon }\end{array}$ & $\begin{array}{l}\text { noono ino } \\
\text { nooninas }\end{array}$ & $\begin{array}{l}9 \varphi \\
2 \tilde{6}\end{array}$ & $\begin{array}{l}\text { 907.?. } \\
\text { co?.?. }\end{array}$ \\
\hline & 1002 & $9(12)$ & 0 & $|c|$ & IEOOC & a'nzeC & i & incin & ECZIII & $a r_{1}$ & (I) & marn & $0 \circ 0<s_{1}$ & $=$ & $0 . n \in c_{4}$ & & non & ron & monoim & A.C, & mere \\
\hline & En & 1112 & 0 & botel & & 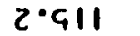 & $\boldsymbol{C}$ & con?.1 & ?!?? & 02 & $r_{1} r_{1}$ & $(362)$ & $\cdot 0$ & 0 & $C \cdot 1 ?$ & & (ich) & DOI & noononol & 90 & 18 \\
\hline 1 & दा & STH & $\mathbf{0}$ & 127.9 & OOAE & $E \cdot I . A K$ & E & giten & T,ItLE & eb & $r_{i}$ & $c k 19 x$ & $0.0+1$ & 1 & $0.0 \times 1$ & 1 & mI & 000 & monomi & 199 & 80181 \\
\hline$v L$ & LLPZ & noriz & 0 & $\mid \mathrm{T}, \mathrm{b} / \mathrm{C}$ & & $y \cdot z \angle n C$ & [ & bens. & $0 / 0401$ & Sis & $K L$ & ElK & $L \cdot\langle I l$ & 2 & $1 \cdot 111$ & $?$ & om & MI & momonol & .9 & 0121 \\
\hline$v L$ & RIIE & T.201 & 0 & b & S||Y| & L.90र9 & 1 & $8.1 .1 A$ & 2.21.15i2 & 1.9 & C. & 7.916 & & 2 & $0 \cdot|T, 7|$. & 7 & mo & mo & molnool & $n l$ & 7.9 \\
\hline t. & LARZ & $\operatorname{coth}$ & $\mathbf{0}$ & $\left.\mid r_{1},\right\} \mid$ & & 1 onbrif & E & pous & I.UPZE। & St. & $\%$ & Doris. & S•9nx: & $\boldsymbol{E}$ & $\Gamma^{\bullet}$ • & r. & no & mo & 00010000 & C.द & 1007.9 \\
\hline vit & LAE & ASD & $Y<9<1$ & EOI & & $b r_{1} \mid 1$ & E & GRE है। & zoprit & i- & 10 & Gr.f?. & $\bullet 0$ & 0 & $0 \cdot(., 1.1$ & $\boldsymbol{E}$ & con & inn & $0100 \times 00$ & nq & EOnI:. \\
\hline & SE II & AC & 0 & 0 & 69222 & $r_{1} \cdot 1.012$ & I & ce.26 & || $D E E \mid$ & BnI & Do & oblis. & 0.111 & 2 & $0:|| \mid l$. & 2 & Dov & no & no innono & 7.2 & $0<10$ \\
\hline$b l$ & 106 & SiEs & $\mathbf{0}$ & $\mathbf{0}$ & $A(x<<2$ & A.ALIL & I & R9AR & Gב̈RBII & 9 & $n-$ & $199 \mathrm{KR}$ & K.999 & I & $a^{\circ}$ G्रG $r_{1}$ & 1 & $\operatorname{con}$ & noo & m $1000 m$ & $+l$. & 10110 \\
\hline$L$ & $C L E$ & 012 & 0 & 21 & LACS & $U \cdot G E$ & E & COEE II & GLOLII & 12 & 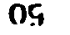 & LOnII & $9 \cdot 1 ! 1$ & 1 & $9 \cdot 1 n$ & 1 & (110 & mo & conono & c. & 101.19 \\
\hline$b L$ & on & nLI & {$\left[r_{1},{ }_{1} l\right.$} & na & & $E \cdot 9$ & E & nIKn & $\$ 97$ & (1) & Xy & fil $\times 4$ & 0 & 0 & $n^{\circ} \mathbf{2 E}$ & 1 & nin & n10 & monolmo & 10 & ڤ \\
\hline$L$ & EII & $I . n !$ & cori & 0 & VRA & $L \cdot V l . I$ & C & cEril & $2 ?, 6(1)$ & 8 & $v$ & (2) & 0 & n & $\pi \cdot 18$ & 1 & 000 & 100 & moniono & no & COG \\
\hline 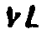 & $g b E$ & 292 & o & $\ell$ & 1006 & $9 \cdot 1.9 n$ & $\boldsymbol{E}$ & ZLLA & $\nabla C 99 E$ & 97. & $L G$ & 20101 & 0.218 & I & 0.7 .12 & 1 & mon & 000 & $000 n+1000$ & ค9 & enr, b \\
\hline$L$ & Ooiv & $E L E$ & IE & $\mathbf{0}$ & 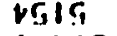 & C.915 & C & $A Z S, A$ & IOE IE & n- & 98 & enon I & $r \cdot n+1$ & I & $n \cdot n+1$ & 1 & noo & 100 & $00(0) 1000$ & pq & lorilo \\
\hline$L$ & I I,EZ & 6911 & $\mathbf{0}$ & 9 & LHOKG & $q \cdot 1.10 \theta$ & 1 & HZVA & LAEOHI & COI & 8.9 & EgOK & $0 \cdot 2.901$ & i & $0 \cdot 2901$ & ?. & oxio & 100 & 100 & $n L$ & AOPIC \\
\hline 1 & $1 \times 02$ & RICI & $\mathbf{0}$ & oE & PUALI & $G \cdot x O K I$ & E & Z.bPr & nटtrII & Sח & $\mathbf{O L}$ & Z.P & $9 \cdot c_{1} n l^{\circ}$ & I & $p \cdot r_{n} b$ & 1 & $n(0)$ & ono & 100 & no & \\
\hline$\nabla L$ & Erine & $90+2$ & n & 0 & (x)y!; & $x^{\circ} E 2 Z L$ & E & $L 1 \cdot A$ & SRbTSOE & Et: & AH & $1.61 \%$ & $y^{\circ} \cos 1$ & $\boldsymbol{\varphi}$ & $9^{\circ}$ rofl & 9 & DNO & 100 & 100 & Cद & IVIE \\
\hline$\| 1$. & $09<1$ & $9+L$ & 0 & $\mathbf{0}$ & ar. Lne & $1 \cdot 201.2$ & E & $r(0001$ & YดII9A & $n-$ & $n l$. & coon! & $0 \cdot 25 t$ & E & $0 \cdot 25$ & $\boldsymbol{r}$ & nol & (x)O & 1100 & $r 9$ & (IE \\
\hline$\nabla L$ & 200 & SLE & n & () & Rose? & $h \cdot 1 \cdot C_{1}$ & \& & PNG, II & 21892 & 16 & Z.E & $|v| .2 . \mid$ & $\bullet 0$ & $\mathbf{0}$ & $0^{\circ} A x$ & C & 010 & $0 \times 10$ & monoloo & r.9 & 2IEIE \\
\hline$L$ & e৮G & $99 \mathrm{~L}$ & $\mathbf{0}$ & 0 & $\operatorname{Lin} A$ & $E \cdot \operatorname{Ln} A$. & E & 2ZEOI & LAI AG & 0.8 & $\mathbf{O L}$ & 2.2001 & $c^{\circ} 2 m$ & $\ddot{2}$ & $E^{\circ} \mathrm{ZAI}$ & $?$ & 010 & 100 & monolos & Gद & nitis. \\
\hline v!. & KEY & 96.02 & 0 & $\mathbf{0}$ & zciens & $0 \cdot$ H, 2, & E & $9 \angle B A$ & LOAVGI & 101 & 16 & A.E.101 & tonfl & 2 & -astri & 2 & 000 & mon & & 10 & 18 \\
\hline$\checkmark L$ & $218 C$ & cy)1 & L290 & 7.0 & $\varepsilon r_{1} b t z$ & $n \cdot n / D 2$ & $\varepsilon$ & 91.56 & $0 !$ & 1.1 & 1.9 & $Y L T: R$ & Dैaถ! & 2 & berar & ?. & ono & mo & 00 & 69 & bnol? \\
\hline$b l$. & BRIE & 99,12 & & $\angle \angle B$ & & $9 \cdot 0609$ & 1 & 29KA & & 1.2 & ab & 01 th & $y=9 b !, 2$. & $\boldsymbol{E}$ & $9^{\circ} 964,2$ & r & (x) & Don & & 12 & (9) \\
\hline 12 & 1927. & $\|G\|$ & $\mathbf{0}$ & $\mathbf{0}$ & tonte & prouzp & 1 & bylla & $\mid E \varphi_{1}\left[T_{1} \mid\right.$ & (n) & $C_{1}, 9$ & 5.101 & O. Inf & 2 & $n \cdot \operatorname{Ing}$ & ? & oIn & mo & oon & n!. & anAnG \\
\hline$\geqslant f$ & sogs & $1 ?<9$ & 0 & & C:OKLI & $A^{\bullet} Z . C L 1$ & $\varepsilon$ & $x \mid D)(0 \mid$ & $400(1)$ & iv & TL & 1.1001 & 0.048 & 2 & $0^{\circ} 0+8$ & $\boldsymbol{z}$ & X)0 & DO0 & molcoso & C9 & Lnanr \\
\hline & 2212 & 1602 & |OCSI & $\angle I L I E$ & & $G^{\circ} \mathrm{CE \beta P}$ & C & Acto & L2rinl. & G! & C9 & 2.01 .6 & $1 \cdot 600$ & 2 & 1.mon & $\tau$ & OnI & 100 & Doolonon & 19 & ?חanr, \\
\hline$V L$ & $1+28$ & m! | I & & NALES, & 0 & $b \cdot r_{1}<4 c_{1}$ & E & 9PZR & $96 r, v 21$ & 96 & 16 & oEkn & $i \cdot 69 n$ & 2 & $c^{\circ} 10 n$ & $\tau$ & ono & mo & noro & po & EO1AOG \\
\hline$V L$ & ol.p & POL & 0 & 16,201 & 0 & $2 \cdot 0201$ & 1 & cara & $26 n$ & $6-$ & 20 & $(1,001$ & $R \cdot \mathcal{G} p$ & 1 & $q \cdot s ; b$ & 1 & 010 & 001 & 1000 & C.2 & znmor, \\
\hline$V L$ & $2 \times 1$ & 192 & n & 0 & I.f. द. & $0 \cdot+1.1$ & E & $2 \subseteq, A 2.1$ & COI.Z.1 & 22 & 1.2 & lox $r+1$ & $\cdot n$ & G & PE & r. & 10 & non & & A? & กค \\
\hline$v e$. & LIA & $b A_{B}$ & $\mathbf{0}$ & 5,1 & Eoyn & $9^{\circ} \mathrm{C}, 1,1$ & E & 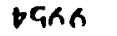 & $P \mid 5,09$ & 95 & bi! & Vink & $z \cdot C y 1$ & ! & Y9I & 1 & 000 & (no & ? & 9.9 & זח \\
\hline$b l$ & p9r, & 1891 & 91 & LG & EISEZ & $9 \cdot 2 n 22$ & 1 & nn?ol & $\angle 9 \mid \pi(0)$ & \$1 & 169 & mzol & $\varphi^{\bullet} \cdot 2 n$ & I & $G^{\circ}$ zne & 1 & 010 & 100 & Inorionco & r. & bก9nR \\
\hline & $L E ?$ & กZद & S๑R! & 5012 & & ؟ & E & ounso & VI190E & $2 E$ & En & conk & $\varphi \cdot n<1$ & ? & $Q^{\circ} \mathrm{DE} 1$ & $\boldsymbol{Z}$ & no! & $I(1)$ & $\operatorname{mon}$ & 19 & 17ron \\
\hline & EIIE & ib21 & yEGं & $\ln (\mathrm{S} / \mathrm{C}$ & $\mathbf{0}$ & 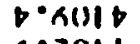 & 1 & ¿YRil & 5211002 & 18 & 2.5 & $01 \mathrm{pr}$ & $\theta \cdot Z|y|$ & $?$ & $n \cdot 7 . \mid 91$ & $?$ & 001 & 100 & nou & 12. & RIsnK \\
\hline 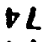 & $00 ?$ & SLS & $\angle 2 P C$ & EIE & 0 & $x^{\circ} 2011$ & E & rexa & 20101 & 15 & () & Cor.n & $x^{\circ} 9 b !$ & $?$ & $x^{\circ} 961$ & 7 & 001 & Ino & Onononon & 19 & - $190 x$ \\
\hline$V L$ & $a \times() L$ & ARSI & T,2611 & I IIS, & $\mathbf{0}$ & $L$ Laxpl & E & 12001 & 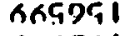 & 421 & $\varphi 0$ & $|2| 0 \mid$ & 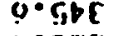 & 1 & $e_{1} c_{i} b c_{1}$ & 2 & 0,1 & 100 & 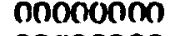 & $\log$ & r.0n \\
\hline$P L$ & $25 n$ & IT, & 8016 & $96 ! .9$ & n & $\checkmark \cdot 999,1$ & E & ES:A & E(1) & $n+1$ & yn & 1916 & 0.978 & ?. & D. & 2 & mo & Ino & 00 & 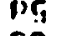 & en \\
\hline & IदI & 202 & A9 & FI & 0 & $l \cdot 9$ n & $\boldsymbol{E}$ & 111 & 10 & 91 & 06 & SIAII & 0 & 0 & $p \cdot R C_{j}$ & 1 & 010 & 100 & 000 & 10 & . \\
\hline & $9 p 1$ & al. & 210 & $a b(1)$ & 0 & I nEI & C & !9xa & SPAQI & 91 & nit & cont & $n \cdot 0 ? .1$ & I & 0.021 & I & 010 & 100 & 000 & 09 & 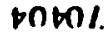 \\
\hline$p$ & $\mathrm{Cg}$ & $b \varepsilon$ & 0 & $9 b r, ?$ & 0 & | & E & oni:II & Evrive & +6 & 140 & oxi:II & $\cdot 0$ & ( & $0 \cdot \mathrm{ml}$ & 8 & nI & 100 & olnoconon & | & come. \\
\hline$D L$ & AEE & allo & noII & 27.0? & 0 & T'Once. & E & 99511 & 1.1.A52 & XI & KP & $49 \mathrm{EI}$ & n & n & $0^{\circ} 06$ & $?$ & (x)I & 100 & 000 & 2.5 & con \\
\hline$\forall L$ & n!t & $\forall 25$ & $2 x 05$ & 2015 & 0 & $0 \cdot b 2 n$ & C & $H(1) \wedge$ & $p \operatorname{lng}$ & It & III. & moln & $\cdot 0$ & $\mathbf{0}$ & $5 * 1.22$ & ? & 001 & 100 & $M O N$ & n9 & encno \\
\hline$V L$ & GSLA & 5092 & 2AD & 0 & Ans 18 & $\theta^{\circ} \times \Delta+8$ & 1 & $2 \div-7.01$ & [GOEIi & $0<1$ & 1.9 & 8.7801 & $2 \cdot 0[91$ & 2 & Z•9巨9) & $\boldsymbol{z}$ & O) & 100 & noo & ni) & rornn \\
\hline & Gก|D & 85,11 & $6 E 9$ & 0 & II.R.QE & $Z \bullet L Z E C$ & $\tilde{E}$ & 11.7 .01 & 101.121 & n & $y 2$ & 1.2801 & $\varphi^{\circ} \mathrm{CC} 9$ & E & o.ero & E & on! & non & 00 & ro & ?חกค \\
\hline & 0,9 & 25,5 & GI & 0 & cyיk & $1 \cdot b \nabla 6$ & E & 25190 & romine & $\mathrm{m}$ & ח & pqon & $9^{\circ} E 11$ & & $9 \cdot C I \mid$ & 1 & (MI & non & non & 7.9 & lorne \\
\hline & $\angle 96 \mid$ & 191.1 & 0 & 0 & 5,2129 & $\left(y^{\circ}+i^{\prime} c^{\prime}<9\right.$ & E & l.HIA & YCKnLI & $x-$ & (a) & 1.716 & $\mathrm{H}^{\circ} \mathrm{Cog} / \mathrm{l}$ & $b$ & $\left(1^{\circ}(x)+3\right)$ & 6 & DOO) & mo & 00 inoonn & no & 80100 \\
\hline$V L$ & 899 & Sก̣y & $\mathbf{0}$ & 0 & $\mid V\langle q|$ & L.9lnk & 1 & EER & $c 0101.1$ & $\Leftrightarrow$ & $n-$ & e.cua & $D^{\circ} Z$ ? & I & $0 \cdot 2 C_{1} n$ & 1 & $\infty$ & (n) & no 100000 & 1. & mlng \\
\hline$V L$ & LI.Z2. & cosil & n & (1) & $2 A D L 2$ & $\varepsilon \cdot 0 G L Z$ & E & glen & bol bn & 28 & of & Ixkn & r. & $\ddot{\imath}$ & $G_{1} \cdot$ क9 & 7 & o110 & mo & OMISOONO & द9 & Ening \\
\hline 12 & ¿C, & I.RA & !โ9 & 0 & Arir. & 1. & E & $00 n 11$ & $B 2 . F L C$ & ?in & noil & consil & $\cdot 0$ & & $0^{\circ}$ R I I & 7. & mo & 100 & no inconon & ab & ?n100 \\
\hline
\end{tabular}
$\wedge \mathrm{n}$
L S
y
d
o $N$
W
$1 x$

\begin{abstract}
$r$
\end{abstract}

\begin{abstract}
I II
\end{abstract}

\begin{abstract}
he
\end{abstract}
$\begin{array}{lllll}1 & 0 & 0 & 8 & \end{array}$ 
123023300010000 on 010 13304 68 00010000 000
$i 23000$ 42301 45 00010000 001 000 6240174 vocout 00010010 62403 53 00000100 010 010 6240451 vóioulou 010 010 425037300016000 UOI 100 425051200010000 ULC 000 42307 10 N0010000 001 0is) $4250 y$ of 00010000 o0il 0uo o2001 ós ixou00001 001 100 $42 \%$ ja nouluoou onl 000 5201)2 64 60000001 010 010 $0200 \mathrm{~J}$ od 00000001 OU1 010 $1240274 \quad 10000000 \quad 100000$ $23002 \quad 7401000000 \quad 100 \quad 000$ 23005 ou 01000000 001 100 431027300000001001 oux 431036100000001010010 232027401000000100000 2.32037201001000 001 000)

1 ?.1206 6301000000001000

v 232114801000000 000 000

1.33u2 o0 00(x)1000 000 100 ij3306 74 v000 1000 00. $n(x)$ 4.3402 io c00010000 000 000) 4340370 (100101000 001 000

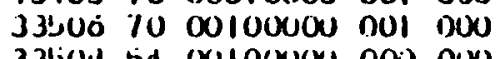
33 jous 54 o0100000 00J Dov 331,12 53 00100000 000 000 33.147400100000 001 U100 730015300000010010000 136037100006010 001 001 7360673 0i)0U1010 10 010 001 736077400000100010000 23002 31 01000000 000 000 2.3403 6y $010000000000(x)$ $2300 \mathrm{k} 72$ ol 1000000 o0s $/(x)$

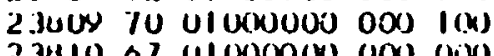
23410 of 131000000 009 000 234124701000000 o01 $D(x)$ 23131001000000000000 23017 50 01001000 o6n 010 23010 oy $0100 \mathrm{i} i) 00$ 001 010

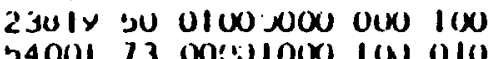
b4003 70 w0001000 001 010 44101 ou $3001001 \times$ (o) 010

$\mathbf{p}$

$\begin{array}{rrr}2 & 116.1 & 0 \\ 1 & 3511.01 & 1 \\ 1 & 75.0 & 0 \\ 2 & 25.0 & 0 \\ 1 & 101.5 & 1 \\ 2 & 100.0 & 0 \\ 1 & 00.0 & 0 \\ 2 & 84.3 .4 & 1 \\ 1 & 0.20 .0 & 1 \\ 4 & 2442.0 & 4 \\ 2 & 1044.0 & 2\end{array}$

$\begin{array}{cc}2 & 1044.6 \\ 1 & 172.3\end{array}$

100.0

(B) .0
220.0

414.0

$2 u^{\prime} j .2$

602.4

3213.7

173.6
1242.0

1021.0

$\begin{array}{rr}2 & 1027.7 \\ 2 & 46.5\end{array}$

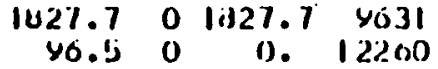

310.02310 .0 Yis(1)

$206.6 \quad 200.6 \quad 4317$

1080.0 I 1080.0 3001

240.0 I 240.0 lUs

240.5 I $250.51131 \%$

312.625312 .0 प021

ij 1046.3

$1300.0,1300.0$ У०21

74.6

$1137.6 \quad 0 . \quad 11447$

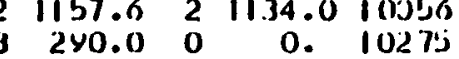

472.51472 .5 Y 1641

$\begin{array}{lllll}3 & 225.0 & 3 & 225.0 & \text { प्र(34) }\end{array}$

$\begin{array}{lllll}2 & 1314.4 & 2 & 1314.4 & 10263 \\ 3 & 1641.7 & 2 & 1024.5 & 4046\end{array}$

$21: 17.0$ 2 1.572 .0 प्र34.

2 1672.0 211372.0 प्र०1?

$\begin{array}{ccccc}2 & 345.0 & 0 & 0 . & 11 \times 63 \\ 1 & .205 .3 & 1 & 503.3 & 4.173\end{array}$

$\begin{array}{lllll}1 & 203.1 & 1 & 563.3 & 4.173 \\ 2 & 320.4 & 2 & 330.4 & \text { yid.31 }\end{array}$

31120.031720 .0 y.140 $46.1)$

0.32 .7

2111.112
0. 12146

\$.32. 7 प/1:

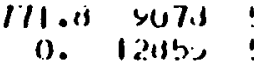

K L N

N 0

$\mathbf{P}$

$Q$

R

S

T

J V

$46 \quad 12$ 245.7? Inنsy 3 4.31.4 bilij;

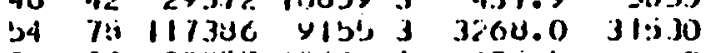
3.3 ?.2051 12.104 1 120.5 $24 \quad 1234.11 \div 4103$

120.3

$\therefore$ d1 11140\%103\%6! 14.2

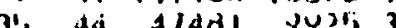

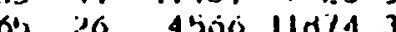

6ut 3.

134.3

is 140211341 134tio 1 1453.6 19374

10 $101 \quad 170703 \quad \forall 003 / 2173.122 .35$

I4 316.171710 प021 | 10561.1 102067

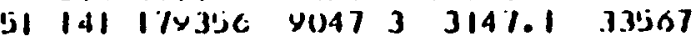

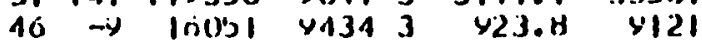

47 25 34471 प्रक.3 3 624.4

j4 $24 \quad 17220 \quad 46173 \quad 496.4$

\begin{tabular}{lllll|l}
71 & 31 & 43106 & 113234 & 1287.0
\end{tabular}

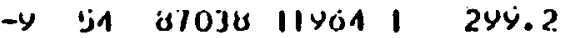

$\begin{array}{llllll}-y & 6 & 3543 \text { H } 12224 & 125.7\end{array}$

64 131 170344

$\begin{array}{llllll}62 & 111 & 94530.1010 . j 1 & 1 & 1776.5 & 18650\end{array}$

jo 25 lo004 10044 3 b41.5

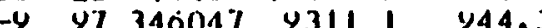

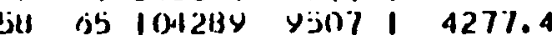

ój 123436241 4631 37343.5

yy $70 \quad 30544 \quad 126603 \quad 541.4$

87 64 6.5177 4.jo4 3 2040.2 प5

क४ $42 \quad 41477$ पषण17 3 प35.1 1212

$-y \quad 130$ 16+3242 isy04 I 2640.5 2356.

02 50 42061 10411 3 i544.2 17704

(14) 50 152013 11212 | |Y.36.4 221i1\}

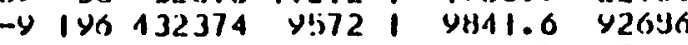

$\begin{array}{lllllll}76 & 62 & 716.11 & 4627 & 3 & 1463.7 & 15328\end{array}$

10 240 2b2143 y

$\begin{array}{lllllll}-4 & 272 & 3510.34 & 9621 & 174 \% & 16663\end{array}$

$\begin{array}{lllll}33 & 20043 \quad 11947 & 344.9\end{array}$

$\begin{array}{llllll}40 & 54 & 98484 & 9163 & 5330.2\end{array}$

14 $3223710273 \quad 740.0$

40 उ3षdy עny4 1447.0

$43 \quad 62$ 11षातy प्रा140 3 15/4.3

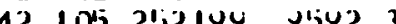

5) 143 310714 प्य 323

1036.0

b) 17.3246040 प्र116 17.33 .5

733.15
246.0

yo yid 1710471146331101.5

5y ils 1643st) .202 1 3131.2

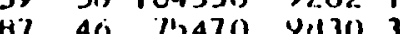

su $100 \quad 324330$ ग10́! !

3131.2

j2.

2 jo loyiyl. y3ix 21375.3

(i) 6? 6/124 נ734 । 2210.5

23.2 dy.3 $12 \% 433$

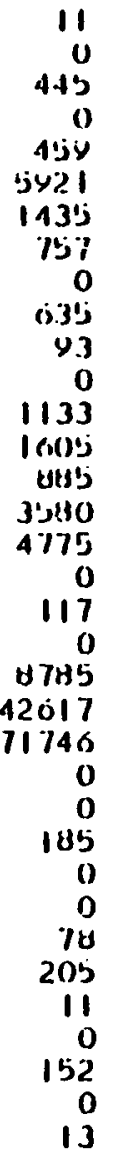

3

2.34
2.64
1170

1170

1170

386

14227

334

0

1445

201 $\begin{array}{llll}0 & 448 & 627 & 74\end{array}$ $\begin{array}{rrr}0 & 1263 & 15.1571 \\ 1384 & 374 & 30571\end{array}$

$\begin{array}{lll}1.352 \quad 252 & 77 & 71\end{array}$

$\begin{array}{llll}0 & -y & -4 & 74\end{array}$

$\begin{array}{llll}2166 & 504 & 02374\end{array}$

$353 \quad 247 \quad 20371$

0
0 257 3425 74

- 818 145174

0 3tiv5 6y31 74

o $2344 \quad 875374$

503 251 104 74

5.30'j 211'j 14.374

3622 jvo 22.374

10774

24.374

$\begin{array}{lll}0 & 415 & 10174\end{array}$

$\begin{array}{rlrl}2357 & 1633 & 3547 & 71 \\ 0 & 1154 & 2215 & 71\end{array}$

6046 24:5 10774

$\begin{array}{llll}0 & 2277 \quad 16474\end{array}$

$\begin{array}{llll}140 & 2234 & 2313 & 71\end{array}$

15403766 עill 71

() 637 2ע5 74

$\begin{array}{rll}0 & 775 & 74074 \\ 1457 & 244 & 72274\end{array}$

(1) $2 \times 5$ 120 71

630 U10 74

604 SOY 74

1906 3065 74

$642 \quad 104174$

21 कУ $3 \% 274$

37134974

424y 245 11274

j4611 605 71571

$\begin{array}{llll}7603 & 32.3 & 544 & 74 \\ 14034 & 536 & 154074\end{array}$

$1036 \quad 172774$

35161025774

$\begin{array}{lll}3516 & 10257 & 74 \\ 3018 & 5051 & 71\end{array}$

370151197274

$3782 \quad 1636074$

15j5 201574

$\begin{array}{lll}1314 & 225774\end{array}$

$691 \quad 116074$

$1901 \quad 346574$

$\begin{array}{lll}446 & 26474\end{array}$

iili3 74274

$\begin{array}{rr}643 & 2377 \\ 216 & 4674\end{array}$ 


\begin{tabular}{|c|c|c|c|c|}
\hline 99 & $p h$ & 201 & 0 & n \\
\hline 9 & $2 n ?$ & LZE & 0 & 0 \\
\hline $\begin{array}{l}69 \\
64\end{array}$ & $\begin{array}{l}\text { HL? } \\
\text { I0OI }\end{array}$ & $\begin{array}{l}\text { VEL } \\
\text { EIS }\end{array}$ & $\begin{array}{l}\text { S180 } \\
\text { OntGद }\end{array}$ & $\begin{array}{l}\varepsilon ? 1 \\
c_{c} \varepsilon_{1}\end{array}$ \\
\hline 8 & .99ट & $0 ? . \mathrm{C}$ & CG19 & \\
\hline 9 & $\begin{array}{l}\angle L O 1 \\
990\end{array}$ & $\begin{array}{l}\text { ọ.zI } \\
\text { ois }\end{array}$ & $\begin{array}{l}\text { OLOnI } \\
\text { II.861 }\end{array}$ & 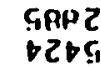 \\
\hline 39 & $O L$ & $0 \times 1$ & (B) & \\
\hline & $0 r_{1}$ & AII & $9<5,0$ & 0 \\
\hline $\begin{array}{l}69 \\
69\end{array}$ & $8 \times 1$ & $1 / 2$ & 227.5 & l.no \\
\hline $\begin{array}{l}69 \\
60 \\
69\end{array}$ & LE? & LRE & g10E2 & o \\
\hline $\begin{array}{c}69 \\
69 \\
69\end{array}$ & $\begin{array}{l}951 \\
96 \geq 2\end{array}$ & $02 E$ & ObAx & o \\
\hline 8? & हne. & $\begin{array}{l}\text { pos } \\
\text { or, }\end{array}$ & 912 & $\begin{array}{l}0 \\
0\end{array}$ \\
\hline 89 & iinI & $\nabla L G$ & 0 & 0 \\
\hline 69 & 109 & 100 & o & 0 \\
\hline 69 & 19,2 & SOS & $\operatorname{Ln} \times 5$ & 0 \\
\hline 12 & En & 191 & 0 & 0 \\
\hline & 280 & Eटg & 0 & 02 \\
\hline $\begin{aligned} V L \\
V L\end{aligned}$ & SKR & Ers & 0 & 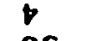 \\
\hline$b l$ & $\begin{array}{l}\text { R9L1 } \\
\text { ROSG }\end{array}$ & $\begin{array}{l}806 \\
91 . x 1\end{array}$ & $\begin{array}{l}0 \\
0\end{array}$ & $\begin{array}{l}9 \varepsilon \\
G \otimes L\end{array}$ \\
\hline$V L$ & 9BLE & $|c 2|$ & 0 & 92 \\
\hline$D L$ & $2 E \times I$ & $\forall \forall 21$ & n & 0 \\
\hline$V L$ & (49) & 209 & 0 & 0 \\
\hline 01 & $n<11$. & \$001 & o & 6I \\
\hline$v L$ & ZnOS & 0ZZE & 0 & $E B L 1$ \\
\hline$b L$ & O285 & 1802 & 0 & al. \\
\hline$\forall l$ & 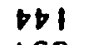 & $0 द 2$ & 0 & $9 \angle 9$ \\
\hline$\forall 2$ & $\forall E \varepsilon$ & COE & 0 & 91 \\
\hline$b L$ & onl. & DIE & 0 & $n$ \\
\hline$V L$ & ب.or. & KPOI & 0 & K! \\
\hline 01. & LED & 116 & OI & $\angle 1$ \\
\hline 2 & CIE & 610 & $\angle A S$, & 0 \\
\hline$P L$ & ong & 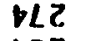 & 0 & A \\
\hline 12 & 125 & $\operatorname{nnz}$ & & 0 \\
\hline$b 2$ & 092 & ?.6 & SGPAnZ & $L$ \\
\hline $1<$ & EZ! & 5,22 & 乌225 & Ka \\
\hline DL & $2 \varepsilon !$ & 122 & LOER & AEI \\
\hline 12 & 801 & प्र? & $\angle I A B$ & 092 \\
\hline & $9 \hookrightarrow, ?$ & ots & ELOGI & LST. \\
\hline$L$ & Znt & NIL & 1.2222 & bonl \\
\hline 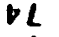 & $b+1$ & CSTE & 10001 & 21 \\
\hline 2 & $96 ?$ & 016 & ¿EGOI & b. \\
\hline & 91:? & ont & DKIP & 01 \\
\hline 1 & 1025 & canz & 0 & n \\
\hline$L$ & EIbG & $\angle B !: Z$ & 0 & 0 \\
\hline IL & 1102 & 1101 & $\mathbf{0}$ & 0 \\
\hline$V$ & 9002 & $y<01$ & & 0 \\
\hline$r L$ & Incé & 2601 & c7.1.1 & ) \\
\hline
\end{tabular}
0

(1)

0 0 0 0 0 0 0 c.960 hein TrZOLL mites

nद ES

note

UIBL
CIOII

$\angle P(x)=$

IBS.LD KAOIA
YLOII GRIAZ

CPOCSI
OPOOV

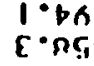
E bदr.x $\nabla \mid r, 09$

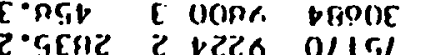

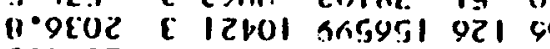
Gengor. E Eciln sancol nol ga

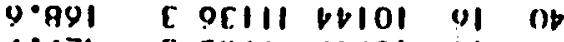

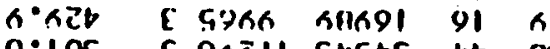
o.loe conell curibe Ub a E.PAI E OOEII LLAEZ OI

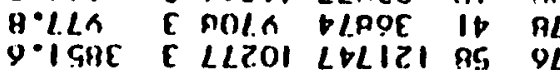
g.ola e zaus evonz ne $c$ jezzor c luia oranli a- nL

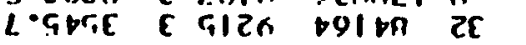
E.Z.LL C nOBII bZPIE SA 9.KOE I USEOI GIZPBI AL $\mathrm{g} \cdot \mathrm{c} \cdot \mathrm{zL}$ E ZOAR POAGE की 1.ELAI $\mathrm{C}$ gISA

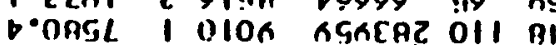
$1 \cdot 2005$ olon KGAERz OII AD

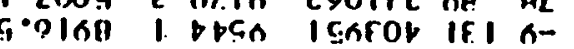

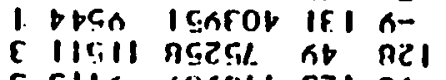
E.nIOE E clio henhII EZI AR

$a \cdot L b+9 \mid$
$b \cdot t<t$ arins? g(h)Hzo pice a$\zeta \cdot \times b$

V.LLO GARALr का EE $\mathbf{0}$ 9दEE। $\rightarrow 10 \mathrm{l}$ bRiol baxige n- no

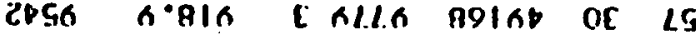

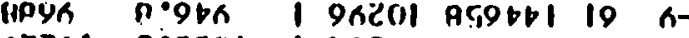

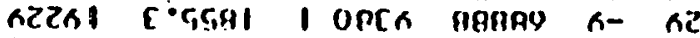

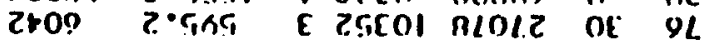

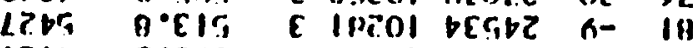
IEIP $c \cdot E, t e$

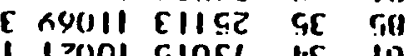

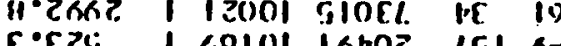

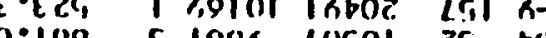

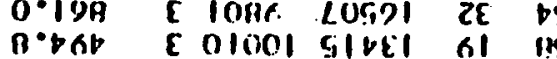

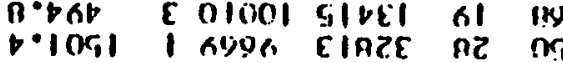
l.ozer I z.96II ocipiol l.l te B Las I Fagol nmor. TE h-

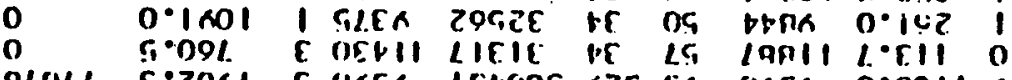

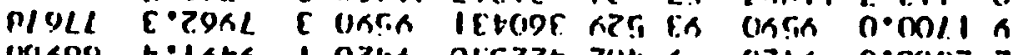

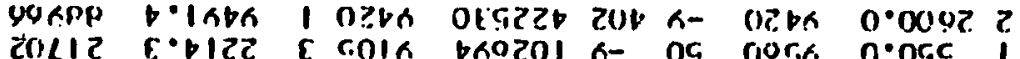

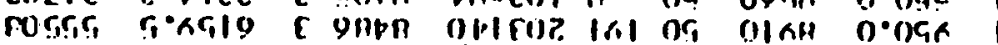

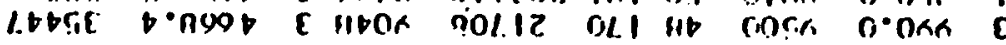

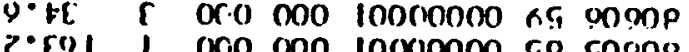

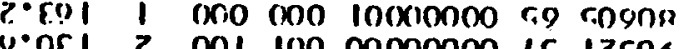

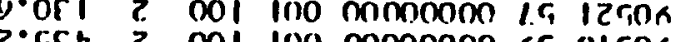

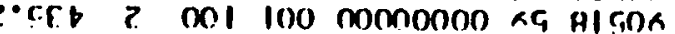

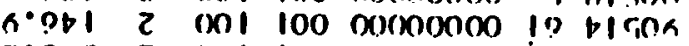

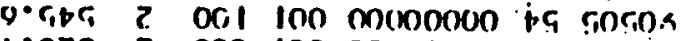

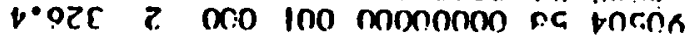

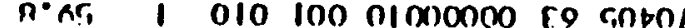
0.021

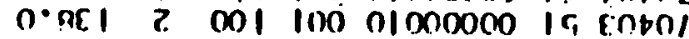

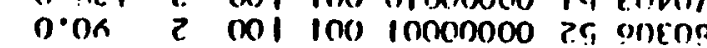

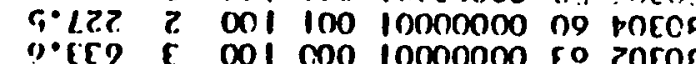
o.ril l al mo inomonono 70 incos h.coni c.mer z 000 mo f.

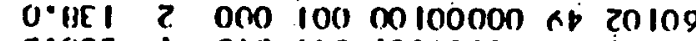
g.0ng i 010 ino 10000000 l.L iOnca

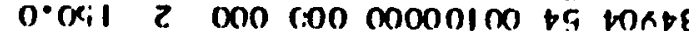

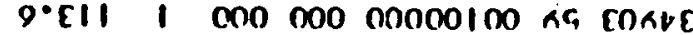
o.rite I DOO ONO nOMOIOn rig lonbe $0^{\circ} z E 91 z$ onl 000 nonlono0 il. IIatc 0.2511 z 000000 nonionon 1.9 innos 0.zanz a oin 000 notionno r.l gnat. r.alz e Onl lno 000I0000 25 conts

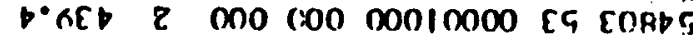

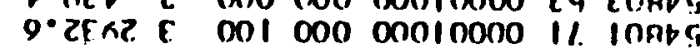
0.00 i 010 loo mononon zi inetro

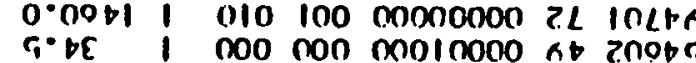

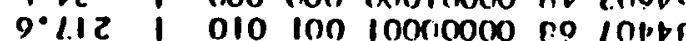
$2 \cdot 1.91$ I 010100 IOInomo b9 onben

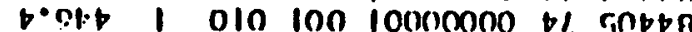
-98E I oin ino loonomu ni. ontba

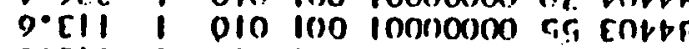
o.cil I 01010010000000 lis zober $0 . c 2$ I OID 1001000000 br lobpo p.zvr 2 onI 100 nIMOOM CI niet

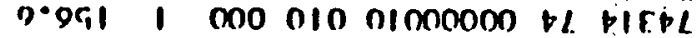
c.ECI 2 00.1 0In ni000000 ov cirtel

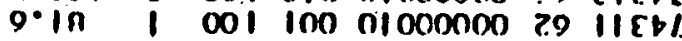
c.l.b? I Do0 010 nimionuo il meve q.ikn $z$ ool 010 nI00000n z.L onebl a.zGr I nol cio 010000m bl cocbl o.19z I mi nin nimonon it zocbl. L.PAi ? mi nin oInoonom ir incel

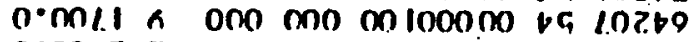
$0.009 ?$ ?. (xin on minocion rl cozbo $0 \cdot b ! c$ i

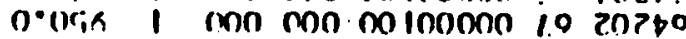
o-bía e DOO ino no inonon na in?.bo
d $\mathrm{ON}$

\begin{abstract}
$\boldsymbol{W}$
\end{abstract}

\begin{abstract}
$7 x$
\end{abstract}

\begin{abstract}
C I H
\end{abstract}

\begin{abstract}
9
\end{abstract}
d

\begin{abstract}
$a$
\end{abstract}

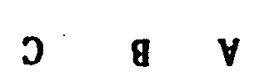




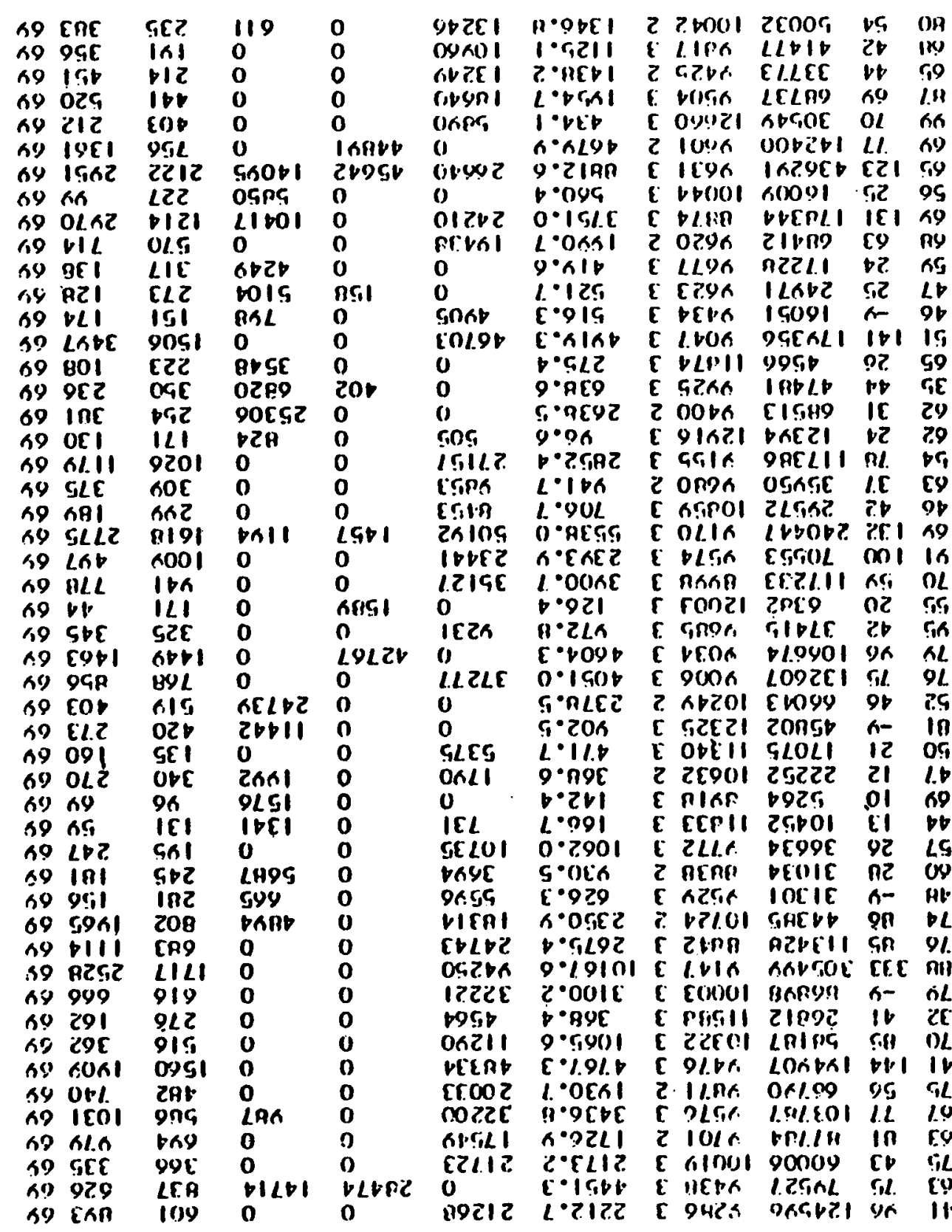

zenol $5 \cdot 511$ I $0 \cdot 6.25$ lisix $y \cdot 00 \%$ i $y \cdot(x)$ ? cibs $9 \cdot 0(1)$ l Wrin o.nis ? O.01E

lo\% $z \cdot v 1.1$ z $\quad \cdot .01 .1$ IE9K $L$ - LZPI 0 i.iz?

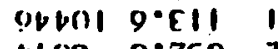

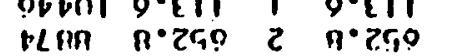

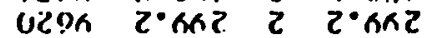
loka 9. in 00.18 (10)1)1 0.001 1 0.001 moni $p \cdot z l 1$ i

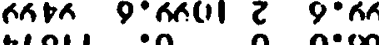
alin: boyk 9 - ops T.OTEI 0 IZTS D.RAT. IGA O०ObI $\|G\|$ त

(il. Is zoces

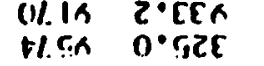
marion ooner ravis in

SnOR $0 \cdot 9)^{\circ} 1$

DEOA 1.211 onon gounc
orgoll g.06s r.zrr. 0 $1.0 \times 119 \cdot 19$ icont 0 DI kP 0 tre.?. 0 coini $0.21 \%$

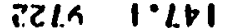
soln I $p \cdot a b 1$ tor I01 I ArI zorm $y \cdot r_{1}$ in iola o.eOt coon 10.25

IVI.B.

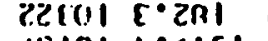

सEIOI ०AISI

II.HIr. noore

gicin venat.

l.l.ns $0 . \cos$

cilcol 0.ciot ionia limp $0^{\circ} \infty$

o.0n!

o. vpr 0.62 V०ASG 0.001

$1 \cdot 411$

b.tra notir. $0 \cdot 0 \in \mathbb{4}$ E. $\mathrm{O} \cdot \mathrm{OEI}$ c.1.11 c.0Re $0 \cdot \mathbf{c}$. $0 \cdot 19$ $0 \cdot \ln$ $0 \cdot 2 \varepsilon$ $\left.0^{\circ}\right) . C$
$0 \cdot 21 ?$ 1.201

0.810

$1 \cdot \mathrm{PE} \mid$ o. çn o. coEl o. zer o.ak cosni D.hIE|

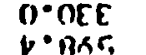
o.nor. $n \cdot m) 5$ $0 . \operatorname{cit} c$ 0.00
$1.00 n$
On! ino moisono bG bOEE mi non moicom no zores

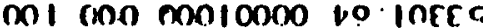

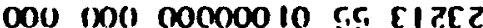
oxo doo monon 10 no 11 zr Doo nl CD000010 19 m?E? noo inn DoOm io co mis? 010010 lomonoo lo rnir.a oni 100 mronnio ne rone 010 ino momoolo co loorz 0in 0in 1000000 to zonzo 000 ino mooinon ne; 101.z. nol 100 loomom on inoz? ono ono conoloon 1.9 anc.zb 010 oin 00 inonon ic moz? Dí 010 nolmono ra cotzo 010 oln nolonom og znezo

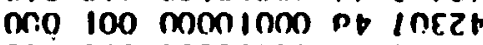
ONO MO InThion po VAE? oln mo mominon मद Enez DIO $100 \mathrm{mminOn}$ ra zOEZ mon ono monolm or, onzze Do0 ono monolon zes enzze Don mo monoldo ar bnz? Oon mi moncxul no colzl mI mo mo00001 00 20121 OMO mI momonol r,9 1012 Orn ino Doolnono Kr, inozs Dil 100 olmonon ac mall 000 100 OIO00000 DG EOAIL

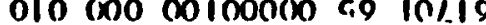
100100 ononlano go lnot: 010 clo 0000inon ro rnolt

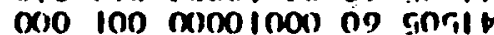
Do c.00 moniono po Eacil OnO 100 monimo 1.9 zncilt mo 100 mom Iono po locit noo 000 monolno or nntels $010000 \mathrm{momol} 10$ oo ontis noo ono monolm er. rntis dol omo nonolon ce tntic $010 \mathrm{mon}$ monolon ro zisir olo mo momolon r.4 rilcis ono mo onmolon 19 sncle Don mo 0000010 r.o zncis

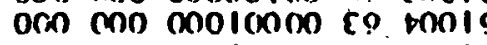
DOM Mo noolonon be Fols ow mo noolnodo ro lonsc (x)1 $1100 \mathrm{~mol}$ mom $1.9 \mathrm{mat}$ Ixn noo molomo on zinar:
$\Lambda \mathrm{n}$
$\downarrow$
S
H
d $\mathrm{O} N$
N
$7 \mathrm{x}$
I H
D d
a. $\mathbf{a}$
J $8 \quad \forall$ 


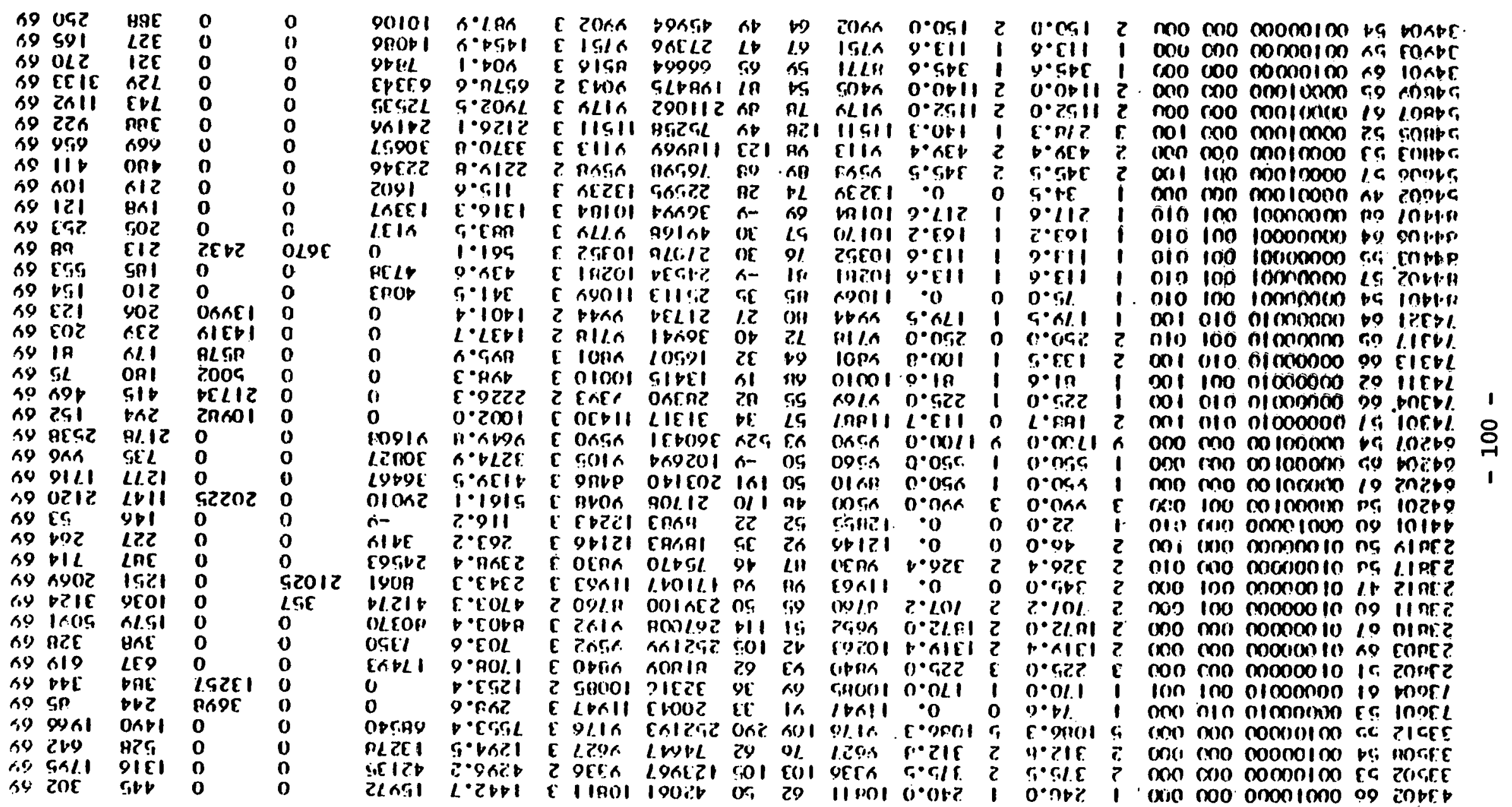
$\wedge \mathrm{n}$
L
S
y
0
d
O N
W
$7 x$

\begin{abstract}
i I
\end{abstract}
H 9 d
$\begin{array}{llllll} & 0 & \mathbf{3} & \mathbf{g} & \boldsymbol{1}\end{array}$ 
Column A - Five-digit identification code

The first digit identifies the plant by the Census Region in which it is located.

The second and third digits are the state identification code. The state codes are numerically sequenced 01 to 50 and correspond to an alphabetical listing of the states. Code \#51 indicates the District of Columbia.

The final two digits denote the specific plant within a state.

Column B - Two-digit vintage code

Year in which the plant observed was brought into initial operation.

Column C - Eight-digit region code

Regional code constructed for analytical purposes. This code for the nine Census Regions is as follows:

$\begin{array}{lllllllll}\text { Region 1 } & 1 & 0 & 0 & 0 & 0 & 0 & 0 & 0 \\ \text { Region 2 } & 0 & 1 & 0 & 0 & 0 & 0 & 0 & 0 \\ \text { Region 3 } & 0 & 0 & 1 & 0 & 0 & 0 & 0 & 0 \\ \text { Region 4 } & 0 & 0 & 0 & 1 & 0 & 0 & 0 & 0 \\ \text { Region 5 } & 0 & 0 & 0 & 0 & 1 & 0 & 0 & 0 \\ \text { Region 6 } & 0 & 0 & 0 & 0 & 0 & 1 & 0 & 0 \\ \text { Region 7 } & 0 & 0 & 0 & 0 & 0 & 0 & 1 & 0 \\ \text { Region } 8 & 0 & 0 & 0 & 0 & 0 & 0 & 0 & 1 \\ \text { Region 9 } & 0 & 0 & 0 & 0 & 0 & 0 & 0 & 0\end{array}$

Column D - Three-digit fuel type code

Identifies the types of fuel for which the boiler was designed.

Coal

$0: 11$

Gas:

$\begin{array}{lll}0 & 0 & 0\end{array}$

Mtxed

$1 \quad 0 \quad 0$

$\begin{array}{lll}0 & 1 & 0\end{array}$

$\begin{array}{lll}0 & 0 & 1\end{array}$ 
Column E - Three-digit building code

Indicates the plant's constraction type.

$\begin{array}{llll}\text { Conventionall } & 0 & 0 & 0 \\ \text { Outdoor } & 1 & 0 & 0 \\ \text { Semi-Outdoor } & 0 & 1 & 0 \\ \text { Other } & 0 & 0 & 1\end{array}$

Column F - Number of units installed at the plant observed.

Column G - Total capacity of the plant in megawatts; the sum of the capacity of all units.

Column H - Number of units within the plant having reheat capability.

Column I - Total capacity of the reheat units within the plant.

Column J - Heat rate (Btu's/kWh of net generation).

Column K - Plant factor (net generation/(capacity x 8,760 hours)).

Column L - Average employment.

Column $M-$ Construction cost in $\$\left(x 10^{3}\right)$. The cost has been adjusted to a base year of 1975 .

Column N - Adjusted heat rate.

Column 0 - Internal code used for programming purposes only; indicates the number of years in which the plant was observed. 


\begin{tabular}{|c|c|c|c|c|c|c|c|c|c|c|c|c|c|}
\hline A & B. & C & v & F: & 15 & (3) & If. & $\mathbf{I}$ & $\mathbf{J}$ & $k$ & L & $\mathbf{M}$ & $\mathbf{N}$ \\
\hline & & & & & & & & & & & & & \\
\hline & & & & (jix) & & & & & & I (x) & & & \\
\hline & & & & (1):45) & & & & 5 sol. & $: 4 y \mid$ & עy & 32 & & \\
\hline & & & 3 & 0,10 & & & & $y=32.6$ & $1 / 433$ & $-y$ & 240 & & 33 \\
\hline & & & & $\omega$ & & & 4 & & & 20 & $\vec{u}$ & & \\
\hline & 02 & & $o(x)$ & & 1 & & 1 & & vis? & B5 & 315 & & \\
\hline & 03 & & & & & & & 6.3 .3 & 10271 & 16 & 5t & & 10?25? \\
\hline & oy & & nol & 100 & & & & & 102 & 64 & 130 & & \\
\hline & & & wol & (100) & & & & & $\begin{array}{l}x / 103 \\
x>43\end{array}$ & $\begin{array}{l}714 \\
48\end{array}$ & $\begin{array}{l}41 \\
34\end{array}$ & & $\begin{array}{l}y+170 \\
\text { y }\end{array}$ \\
\hline & $\begin{array}{l}31 \\
52\end{array}$ & & & $\begin{array}{l}10 x \\
1(100\end{array}$ & & & ( & & $\times 4.3$ & $\begin{array}{l}48 \\
114\end{array}$ & & & \\
\hline & iins & & & & & & 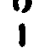 & 174.0 & $|(x)| 4$ & 10 & $-y$ & & \\
\hline & 41 & 0 & 010 & 100 & 1 & & 0 & 0 & & 47 & $2 d$ & & \\
\hline & & & 001 & 010 & & & & (1). & & 100 & $3 i$ & & \\
\hline & & & 1301 & {$[(1)]$} & 2 & & & 0. & & ou & 44 & & \\
\hline & 00 & & 001 & 010 & & $12 i$ & 1 & 120.0 & 10463 & $4 y$ & 16 & & \\
\hline & & & 001 & 01 & & & & o. & & 10 & 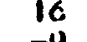 & & \\
\hline & by & ors & 001 & $0(100$ & & 4.0 & & 0. & & 78 & -9 & & \\
\hline & 43 & & 000 & & 1 & & 0 & o. & 110 & 90 & 96 & & 34 \\
\hline & $\begin{array}{l}02 \\
\text { bo }\end{array}$ & & & $\begin{array}{l}10 \\
00\end{array}$ & o & & $\begin{array}{l}4 \\
2\end{array}$ & & & $\begin{array}{l}68 \\
y 6\end{array}$ & $\begin{array}{l}106 \\
14 i \mid\end{array}$ & & \\
\hline & b4 & & 001 & 10 & & & 1 & 345.6 & 10421 & nó & 126 & & 1104 \\
\hline & 31 & & 001 & 100 & & & & o. & 13 & 20 & & & \\
\hline & & & & & & & 2 & 3311.2 & $970{ }^{0 j}$ & j5 & $-y$ & & \\
\hline 19. & 50 & & 001 & $10 x$ & & & & o. & & $-y$ & $-y$ & & \\
\hline & & & & $(0)$ & 4 & & 1 & $2 b .0$ & & 77 & $-y$ & & \\
\hline & & & 001 & & & & & & & 3 & & & \\
\hline & j.4 & & oul & 0 & i & & & 200 & & 6 & 75 & & \\
\hline & 01 & & 001 & & & & & & & & 44 & & \\
\hline & ס & & 001 & 10 & & & & & & & & & \\
\hline & & & 001 & 10 & & & & & yy & 80 & إj & & \\
\hline & סט & & & 10 & & & & & & & & & \\
\hline & נ. & & 001 & 100 & 4 & & & & & $y$ & 24 & & \\
\hline & & & & (1) & 2 & & & & & 74 & .27 & & \\
\hline & j) & & DU & I $x$ & & & & & & & 4.3 & & \\
\hline & & & 00 & 10 & & & & 1618 & 10 & 5 & 01 & & \\
\hline & 40 & & 00 & & & & & & & H & & & \\
\hline & إ' & & (1) & & & & & 130 & & & & & \\
\hline & & & & & & & & & & & 26 & & \\
\hline & & & 0 & & 1 & & & & & & & & \\
\hline & & & & & & & & & & & 24 & & \\
\hline & 1 & & & & & & & & & & & & \\
\hline & & & UC & & I & & & & & & & & \\
\hline & & & & & & & & & & & 2. & & \\
\hline & & & & & I & & & & & & 43 & & \\
\hline & 34 & & & & I & & 0 & & & 7 & 4.3 & & \\
\hline & & & & & & & & & & & 41 & & \\
\hline & & & & & 0 & & () & & & & & & \\
\hline & & & & & & & 0 & & & BY & 75 & & \\
\hline & & & & & & & & & 50 & 12 & -5 & J4206 & 4343 \\
\hline
\end{tabular}




\begin{tabular}{|c|c|c|c|c|c|c|c|c|c|c|c|c|c|}
\hline $\mathbf{A}$ & B & C & D) & $\mathbf{L}$ & $\Gamma$ & G & $H$ & I & $\mathbf{J}$ & $\mathbf{K}$ & L & $M$ & $\mathbf{N}$ \\
\hline 2003 & 57 & $00(x) 1000$ & o(x) & 100 & 2 & 10.3 .2 & ? & 16.1 .2 & & 71 & 64 & & \\
\hline & Sos & $\dot{0} \cup(x) 1000$ & $I 00$ & $0 i x$ & i & & & & & & $1 j .3$ & & \\
\hline & ón & ixu(10 / 1000 & vou & 1)u(s) & 2 & & 2 & & \$4 36 & & Yo & 124546 & \\
\hline 3) & 003 & $(00(x) / J 00$ & $v(v)$ & 100 & 1 & & 1 & 4i)?. 1 & प्र००1 & & 4.3 & & \\
\hline 3) 44 & $\dot{b} \dot{b}$ & $0(x) 1000$ & $I \omega$ & 100 & I & & & $12 j .0$ & & & & & \\
\hline & 60 & 000 & 100 & 110 & i & & i & & YASY & & 44 & & \\
\hline & $\delta 7$ & 100 & $(x) 1$ & 100 & $\dot{2}$ & & 2 & & 4702 & & 15 & & \\
\hline & $5 ;$ & & oivis & 1000 & & & & 310.0 & $|(x)| y$ & & 43 & & \\
\hline & 60 & & 001 & (200) & I & & I & & & & 35 & & \\
\hline yy & 10 & 000 & $v(x)$ & 010 & 2 & $U Y 1.0$ & 2 & & ذر |0| & jo & 104 & 13 & \\
\hline & bl & & 000 & 010 & 2 & 240.0 & 2 & 210.0 & $1(1950$ & (if) & $-y$ & & \\
\hline & 213 & 00 & $I 00$ & $O(x)$ & I & & & & $17 \times 13$ & 17 & $-y$ & $7 b$ & \\
\hline & 71 & & OWU & $O(x)$ & 3 & 2340. & 3 & $20 j 40.6$ & $44(1)$ & 48 & $2 \%$ & 342 & \\
\hline & 63 & (x) & ov1 & $O(x)$ & 1 & 1746. & 4 & 17.40 .2 & 92 uxs & $5 y$ & 176 & & \\
\hline & 24 & (x) & vou & 0,10 & 3 & 300 . & 3 & 300.0 & $y \times 73$ & & iII & & \\
\hline & 63 & Out & $u(x)$ & $O(x)$ & 2 & SYU & 2 & 548.4 & Y.j70 & & 71 & 103 & 70 \\
\hline & j & 000 & 100 & 000 & 1 & & & & 120 & & לj) & 20000 & \\
\hline & 40 & ouc & $O(N)$ & $U(x)$ & 2 & & 0 & & & & & & \\
\hline & jo & $(x) c$ & 001 & orxo & 2 & 200 & 0 & 0 & I Uxtis & Uis & $4 y$ & $7 \mathrm{i} 340$ & 46 \\
\hline & 60 & 001 & $0(1)$ & out & 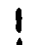 & & 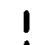 & 125.0 & 4760 & 74 & 33 & & 60 \\
\hline & $6 b$ & o)! & 000 & $0(x)$ & i & 331 & I & & 41171 & & 56 & & \\
\hline & 4() & $\infty \cup 1$ & 000 & oixo & 2 & & 0 & & 127 & Ui) & $-y$ & 157 & jo \\
\hline & 415 & 00 & 000 & vin & 2 & 10 & 0 & o. & $\mathbf{I}$ & 63 & 71 & & 113 \\
\hline & 67 & $\infty 01$ & ODO & 000 & 2 & 131.8 & 2 & 1314.4 & 10 & 41 & & Iy & \\
\hline & סد & 001 & 001 & 1000 & 2 & 34 & 0 & 0 & 10 & (3) & |j' & & 10 \\
\hline & 3' & $\infty$ & 000 & mixo & 2 & & 2 & 3.113 & & 70 & 117 & & \\
\hline & 70 & $00 !$ & $0(x)$ & 000 & & o.?. & 1 & & & 62 & $\mathbf{H U}$ & b & \\
\hline & $\because 3$ & $(x) / c$ & $O(x)$ & $O(x)$ & 1 & 60 & 1 & & & (45) & 70 & & \\
\hline & ע: & $\alpha u !$ & 000 & 010 & 2 & & 2 & 182 & & 70 & j & & \\
\hline & 4. & $(x) 1$ & 001 & 001 & 3 & I ic & 0 & & & libj & $-y$ & & \\
\hline & ij & & 100: & 010 & 3 & & 0 & & & $3:$ & 41 & & \\
\hline & 22 & 001 & O(N) & $O(\lambda)$ & & & 0 & 0 & & 57 & $\rightarrow$ & & \\
\hline & د'2 & $|x|$ & $O(x)$ & $U 00$ & & & 0 & & & ho & j' & & \\
\hline & 31) & 001 & 000 & $O(x)$ & ? & 0 & $\boldsymbol{U}$ & & & & & & \\
\hline & 70 & $(x))$ & $v(x)$ & 100 & $i$ & 300 & 1 & & & $\mathbf{b u}$ & 100 & & \\
\hline & 63 & OUI & 000 & $I(x)$ & $\mathbf{J}$ & & .1 & & & & $-y$ & & \\
\hline & د'ذ & 000 & $0(x)$ & $o(x)$ & 0 & 130 & 6 & 1.30 & & HE & 3.33 & & \\
\hline & OU & $(x)$ & $0(x)$ & $(110)$ & 1 & & I & & & 16 & 'B' & & \\
\hline & 1 & 001 & OUi) & 000 & 1 & & 1 & & & 110 & ن2 & & \\
\hline & ס j & (j)ixu & UOS & $O(x)$ & 1 & & 1 & & 10 & 74 & 86 & & \\
\hline & (i) & (x) & 001 & $0(x)$ & 2 & 100 & 2 & 1062 & & $6 ?$ & 103 & & \\
\hline & ני & 001 & 00.1 & נצ(נ) & I & & $\mathbf{0}$ & & & $y$ & 31 & & \\
\hline & ou & (א) & 001 & U(x) & I & 14 & 1 & & 10 & 48 & $-y$ & & \\
\hline & 04 & 000 & 001 & ().) & 1 & & 1 & & & $n$ & 2. & & \\
\hline & $\dot{j o d}$ & Uou & UON & sox & I & & 1 & & & & $2 \dot{0}$ & & \\
\hline & 4ע & 1000 & 001 & Ui & 4 & & 0 & & & $2 j$ & 21 & & \\
\hline & 60 & & 001 & 00 & 1 & & & & & 11 & I. & & \\
\hline & $.0 J$ & .000 & 010 & (1) 1 & 1 & & & & & ענ' & & & \\
\hline & 3.3 & & $(0)$ & UI & I & & () & & & 6 & 1 & & \\
\hline & & . & U10 & I (x) & & & 1 & 149.0 & 115 & 37 & & & \\
\hline
\end{tabular}




\begin{tabular}{|c|c|c|c|c|c|c|c|c|c|c|c|c|c|c|}
\hline A & B & C & II & I: & $\mathbf{F}$ & G & H & I & $\mathbf{J}$ & K & L. & $M$ & $\mathbf{N}$ & \\
\hline 4 lisu. & 32 & $c(x) 1(x)(x)$ & 1110 & Iix & & 10.4 .0 & () & 0. & ( $\left.144^{\prime}\right)$ & 77 & 33 & 321.37 & II iys & \\
\hline & & 1):3 o1100 & 1.) & & & 12.0 & (i) & (1). & IS I:I & 64 & 10 & 1:2014 & 5416 & \\
\hline & נ'ני & 100100 & OUI & & & & U & ). & $1131: 1$ & $5 ! 1$ & $4 i$ & 22.741 & 11.3686 & \\
\hline & ciri & 000 & 001 & 101 & & & 0 & i). & I Uoj3? & 47 & 12 & $22: 32$ & 0032 & \\
\hline & زji & 100 & ow & $U(1)$ & & & 1 & il.6 & 11401 & 50 & 21 & 17073 & 40 & \\
\hline & (i) & ixy & $O(x)$ & ix) & & & 1 & & & 60 & 40 & & & \\
\hline & j1 & $(n)$ & (o)(1): & $i(x)$ & & & 0 & (1). & | IJ4S & $2 y$ & (j) & Sעd & 10.560 & \\
\hline & i) & 00 & $O(x)$ & (n) & & 265.0 & I & 265.01. & עצ.1 & BI & 61 & jilox)b & sy.3y & \\
\hline & ו & נu & Uisu & (nis) & & 100.0 & 1 & 110.0 & 10175 & ny & $3 i d$ & & 75 & \\
\hline & טن. & 00 & 000 & $O(x)$ & & (x). 0 & 0 & o. & 11464 & 100 & 6() & & & \\
\hline & 74 & ou & (1)ij) & $(1)(20)$ & & על. & 1 & ע. . . & YYO $: 3$ & $-y$ & jo & 110 & 6ió & \\
\hline & 5.4 & $\infty 0$ & (00). & 0100 & & Yo.0 & $\mathbf{0}$ & o. & jo6 106 & 74 & 41 & & Iositis & \\
\hline & 72 & 100 & ONAS & 000 & & 711 & 2. & 111.0 & & 44 & 104 & & 9263.3 & \\
\hline & 42 & 100 & $\omega(x)$ & $13(x)$ & & 31.0 & 0 & 11. & 12403 & Y4 & 102 & 26364 & & \\
\hline & 40 & 10 & 010 & I(ii) & & 15.0 & () & il. & & -4 & IH & $77 \mathrm{dj}$ & & \\
\hline & 5.1 & a) 10 & 010 & 100 & & 20 & 0 & u. & & 47 & $-y$ & 11 & & \\
\hline & نu & 010 & $0(1) 1$ & 000 & 1 & 173 & 0 & 0. & & 41 & $-y$ & & & \\
\hline & עy & 110 & 001 & 100 & & $3 \times 0$ & 3 & jy.j & & i2 & 46 & & & \\
\hline & (iv) & 00 & 001 & 100 & & 10.3 .2 & 1 & 16.1 .2 & & 57 & 24 & & 41 & \\
\hline & 01 & ors & 001 & I (x) & & 24.1 .0 & 1 & 247.11 & $y_{i}$ & 64 & 41 & & 110 & \\
\hline & أ & & 010 & 100 & 1 & & 0 & & & 76 & 27 & & & \\
\hline & 1 & 00 & $00 !$ & I & 1 & 113.0 & 0 & 0. & & 60 & 36 & & & \\
\hline & 47 & $\alpha(x)$ & $0(1)$ & 100 & & $2 j$ & () & 0. & & 47 & 22 & & & \\
\hline & \$I & 000 & 100 & 0130 & 2 & $10 x$ & $\mathbf{0}$ & & & $13 !$ & 4 & 37160 & & \\
\hline & 24 & & 100 & $O(x)$ & & & 0 & & 151 & 56 & -4 & 4906 & | & \\
\hline & נر. & & OU:S & 000 & 3 & bu & $\mathbf{3}$ & ذ. & 4006 & $7 i$ & 75 & 007 & $y(x) 3$ & \\
\hline & 70 & & $00 u$ & 000 & 2 & 1 & 2 & & Y1 02 & 63 & 67 & $172 \%$ & $\checkmark \mid H 2$ & \\
\hline & OS & & 100 & $v(x)$ & 2 & & 2 & & 40.34 & 74 & Y6 & 106674 & 4034 & \\
\hline & ou & & o(i) & 100 & 1 & & 1 & 0 & Yous & زיני & 42 & 37415 & 635 & \\
\hline & $\dot{c o j}$ & & 100 & $00(0)$ & 1 & & $\mathbf{0}$ & & 1248.1 & ت5ز & 20 & 6302 & 003 & \\
\hline & 03 & & 001 & $0 \times 0$ & 2 & & 2 & 482.0 & 08310 & YI & y! & 1094.34 & 24010 & \\
\hline & 32 & & 001 & 000 & & & 0 & . & $4 \times 72$ & 42 & 116 & 213 & & \\
\hline & $4 y$ & & 001 & $O O X)$ & 2 & & 0 & 0 . & ذ' | | | & 71 & 64 & & & \\
\hline & 24 & & $o(x)$ & ouso & 8 & & $\mathbf{u}$ & 0 & $(440)$ & 44 & $-y$ & 16 & j) & \\
\hline & 6.? & & 010 & $0, x)$ & & & I & 203.0 & U.J lal & 64 & iid & & & \\
\hline & 40 & $u c$ & oiv & O(x) & 3 & & 0 & & 112 & 76 & 133 & & & \\
\hline & עy & 000 & $O(x)$ & $O(x)$ & 2 & .0 & 2 & .0 & UYYIJ & 70 & jע & 11 & YU & \\
\hline & 52 & & 000 & 00 & & & 3 & & & YI & 100 & & 74 & \\
\hline & 30 & & u(x) & oix & 3 & & 3 & & & 64 & $13 ?$ & & & \\
\hline & 3.3. & 1) 00 & (00) & $0 \times 0)$ & 4 & סט & 4 & $i 00.0$ & 4220 & 15 & 100 & 88 & & \\
\hline & ניذن & & o)(us & 010 & & & 0 & 0. & 12412 & 63 & Iy & 61 & 97 & \\
\hline & $3 x$ & $O(1)$ & $O\left(\omega^{\prime}\right)$ & (j) & ; & & 0 & 1) & & 50 & 41 & & & \\
\hline & נj. & 00 & 001 & $(0) 0$ & 2 & & 0 & & 115 & 46 & 42 & & لإزنا & \\
\hline & كن & & uos & 01 & & & 2 & & & 6.3 & 37 & & $y(3) 10$ & \\
\hline & ou & (Ji) & $00)$ & (1) & & & 1 & j) & $4+j 21$ & 94 & 7.5 & 1173616 & ذ1514 & \\
\hline & $4(s$ & oou & 1001 & $0 !$ & & & 0 & & 14212 & fill & 22 & 10078 & 1.12112 & \\
\hline & oy & & oul & or & & & () & & I Jy' & 24 & 3.3 & 22457 & 12464 & \\
\hline & 40 & & () & & & & 0 & & 1.3205 & 62 & 24 & 12344 & 12916 & \\
\hline & $1:$ & & 0.10 & & & & 1 & & 10.343 & -4 & 41 & $1 / 146 t$ & ניטי.0.19 & \\
\hline & & 00000100 & (U.11) & & & & 1 &.$j 14.6$ & Yó6.1 & Gi2 & .31 & 64513 & Y400 & \\
\hline
\end{tabular}




\begin{tabular}{|c|c|c|c|c|c|c|c|c|c|c|c|c|c|}
\hline A. & B & C & D & $\mathbf{E}$ & $\mathbf{T}$ & $\mathbf{G}$ & H & I. & $\mathbf{J}$ & K & 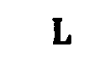 & $M$ & $\mathbf{N}$ \\
\hline & & & & & & & 0 & 0. & & 35 & 44 & & \\
\hline & SI. & & (1) & & & & 0 & 0. & & 65 & & & \\
\hline & & ousouldov. & 010 & & & 77.0 & ) & & I Iuyin & 115] & 30 & & \\
\hline & I I I & $000100(x)$ & $(0) .11$ & (Di)I & & 1.32 .0 & 0 & o. & | lossol & 71 & 60 & & ins \\
\hline & ندئ & 000 & Dou & 100 & & & 2 & 312.6 & & 77 & 61 & & \\
\hline & 7.3 & ovoi usoos & (iv) & 100 & & Uy.3:4 & 1 & 373.0 & & 10 & & & \\
\hline & 60 & 000100000 & ouv & 010 & & 100.0 & 0 & o. & ||$x+\mid$ & $\theta \dot{y}$ & 18 & & 41 \\
\hline & 72 & & $o(i)$ & O1s0 & & 0.0أ & 1 & 650.0 & 10 & 363 & 107 & & 46 \\
\hline & Ja & novili & ow & ن/ & 2 & 67.7 & 0 & 0 & |1fur & yo & 33 & & 114 \\
\hline & 70 & & (jol & DIXO & & $24 d ? .0$ & 4 & 24132.0 & 4124 & $4 y$ & 316 & & \\
\hline & j. & $(x)$ & OUI & 010 & 2 & 250.0 & 2 & 250.0 & 10131 & yo & IIf & & 101.37 \\
\hline & 6 & 1000 & $O(x)$ & 000 & 2 & $104 y .6$ & 2 & 1049.6 & Y4YY & 51 & 141 & & \\
\hline & j. & 300 & oul & $n(x)$ & & 10.0 & 0 & 0. & $121 \% 3$ & 72 & 27 & & 127 \\
\hline & b & 000 & 001 & OIO & & 44.0 & $\mathbf{0}$ & 0. & & 50 & 36 & & \\
\hline & uo & & 001 & 100 & & 172.0 & I & 172.8 & 10 & 46 & & & \\
\hline & Sנ & ooul & 001 & 000 & I & 100.0 & $i$ & 0.0 & 102 & 47 & 25 & & 9623 \\
\hline & be & & 001 & 000 & 3 & & 3 & & & 72 & $-y$ & & \\
\hline & زأ & & (100) & 010 & 1 & & 1 & 113.6 & 94 & $S B$ & 32 & & II \\
\hline & 04 & 01 & olv & 010 & 1 & & 0 & dI. & yyd & $5 y$ & & & \\
\hline & ous & & & 010 & 2 & 2210.0 & 2 & 210.0 & 10244 & $7 !$ & 31 & & 102 \\
\hline & 03 & 001 & 0() 1 & 010 & & 3.3 .1 & 0 & 0. & 11751 & 50 & $2 \mathrm{H}$ & & 11301 \\
\hline & $4 y$ & & & $u u$ & 3 & & & 0 & & 87 & 33 & & \\
\hline & 74 & & 100 & $0(x)$ & 1 & 414 & 0 & & 110 & $-y$ & :j4 & & 114 \\
\hline & 63 & & 001 & Ull & 2 & & 2 & 294.2 & & obs & 6.3 & & \\
\hline & 74 & & 100 & ouo & 4 & $20^{\circ}$ & 0 & 0. & 12224 & $-y$ & 6 & & 122 \\
\hline & لاز & UI & OUI & 10 & ! & 360 & 1 & 360.4 & y4 & 67 & 114 & & 941 \\
\hline & & & & & 1 & & & & & 64 & & & \\
\hline & $\infty 0$ & OIC & DUI & $f(x)$ & 2 & o5? & 2 & 052.0 & 6474 & 64 & $131^{\circ}$ & & du74 \\
\hline & 48 & 010 & 001 & $\mid 01\}$ & a & & 3 & $33 ! 5.0$ & & 6.3 & 112 & & \\
\hline & 30 & & 000 & oov & 2 & 70.5 & 0 & 0 & 141 & 33 & 46 & & 13 \\
\hline & .30 & 110 & 000. & 000 & i & o. ز'ز & 0 & 0 & & 72 & 10 & & \\
\hline & & & & 018 & & 44.0 & 0 & & $10 i$ & $7 y$ & 23 & & $10:$ \\
\hline & 13 & & 001 & ou & 1 & 3211.7 & & 328.7 & & 62 & U1 & & 105 \\
\hline & 07 & & & 01 & & & 1 & 113.6 & & 56 & $2 j$ & & \\
\hline & 62 & & ou & 01 & 1 & bn & 0 & & 127 & 5.3 & 15 & & 122 \\
\hline & bl & & vos & 00 & i & & 0 & & & 100 & $5 ?$ & & \\
\hline & 14 & & 100 & $o(x)$ & 2 & 1242 & 2 & 1242. & yj II & -4 & 47 & 34 & y.3 \\
\hline & 12 & 010 & 001 & ou & & 021 & & 621 & प' & jes & $6 j$ & & \\
\hline & 47 & & $v(x)$ & $0: J$ & I & 20 & 0 & & 124 & 117 & 35 & & 124 \\
\hline & 3 3 & & 001 & ou & 1 & & 1 & 100.0 & ys & 40 & 42. & & \\
\hline & of & & 001 & oixs & & $142 !$ & 0 & 132 & & oj & & & \\
\hline & jo & & & $1(x)$ & 1 & & 1 & & & .100 & & & \\
\hline & 01 & & & $o x$ & 2 & 174 & 2 & 174 & & $6 y$ & & & \\
\hline & 40 & & ou & 100 & 2 & & $\mathbf{0}$ & 0. & 111 & 132 & 70 & & \\
\hline & 38 & & Ui) & ou & 1 & & $\mathbf{0}$ & & & 104 & 46 & & \\
\hline & 40 & & (j): & $O(x)$ & 2 & נים & () & 0. & 122 & yy & 10 & & 12 \\
\hline & $4 !$ & & & or) & 1 & 30 & $\mathbf{0}$ & & 130 & YH & & & 130 \\
\hline & & & . 1000 & $a x$ & 2 & & 2 & & j & 47 & $6 y$ & cies & \\
\hline & 2? & & O(x) & our & 1 & & 4 & $1(1)(0) .0$ & ys & 113 & 111 & & \\
\hline & jo & ui vououe & now & 000 & 2 & 100.0 & 0 & u. & .430 & yy & i13 & 11012 & Y430 \\
\hline
\end{tabular}




\begin{tabular}{|c|c|c|c|c|c|c|c|c|c|c|c|c|c|c|}
\hline A & B & C. & D & $\mathbb{E}$ & $\mathbf{F}$ & G & Ii & $\boldsymbol{I}$ & $\mathbf{J}$ & $\mathbf{K}$ & L & $M$ & $\mathbf{N}$ & 0 \\
\hline & & & (fowi) & 000 & 2 & 100.0 & 0 & o. & 11003 & 74 & 174 & 60006 & 11003 & \\
\hline & id & cooro:1000 & arisg & 300 & 1 & & & $213 i \cdot i$ & & (a) & & & $4.42 \cdot 3$ & \\
\hline & so & cedivilowo & inesj & 100 & i & .0 & $i$ & $51)(5.6$ & vis 11 & axs & 12 & & 11117 & \\
\hline & & 9000110000 & Q.o.j & 100 & i & & i & 110.7 & $\times 211$ & 76 & 32 & & 4271 & \\
\hline & & WOOADOOO & 0000 & 100 & 2 & (1) & i & & 10012 & 810 & $\vdots \$ 4$ & 5(x.3\% & 1.0042 & \\
\hline & 37 & ouovidoov & 0000 & 000 & 2 & .1311 & 2 & & 4171 & 76 & $\$ 34$ & & $\times 173$ & \\
\hline & & Oo0011: & $0(x)$ & 000 & 1 & (Utsil.s) & i & lijdo. 10 & $\mathrm{~d} \times 01$ & $-y$ & 131) & 1082 & JYOA & \\
\hline & 40 & $000010(x)$ & ưv & vixo & 2 & 150.0 & d. & 0 & $110 \%$ & 74 & j'j & 150 & 11.642 & \\
\hline & 18 & $000 \times 1000$ & 000 & 000 & 2 & $1+10 .(1)$ & 0 & 0. & 1.1642 & 47 & 74 & & 10) $(-12$ & \\
\hline & إد & vo001.001) & $0(x)$ & 000 & 2 & $1(x) .0$ & 2 & $13(0.0$ & $1(1)](k)$ & 100 & b' & . & 111300 & \\
\hline & 6) & 0uoviouo & Oou & 000 & 2 & $r(x) .0$ & 2 & 100.0 & sries? & Yi: & $7 y$ & IIjojsy & $J(\dot{k}) ?$ & \\
\hline & 54 & ocnol viow & OUI & 010 & $i$ & 20.0 & 0 & 1). & 1701 it & 34 & 26 & 130044 & ני(ואימנו & \\
\hline & Ses. & oxot anow & $O(x)$ & 000 & 1 & 240.10 & $\mathbf{I}$ & 240.0 & 100111 & 62 & jo & 42001 & 100111 & \\
\hline & (a) & ours uimo & oof & (uiso & $i$ & 200.1 & j & 200.5 & $1 / 212$ & By & 5i) & 52,013 & 11212 & \\
\hline & 32 & $001000(x)$ & $\dot{G(x)}$ & $v \infty 0$ & 1 & 100.0 & 1 & 100.0 & 1020 & $-y$ & 60 & $b^{4} 32$ & 111204 & \\
\hline & 23 & ovionotes & o(i) & $v(x)$ & 2 & נ. & 2 & 5.3.5 & Y336 & 103 & $10 j$ & Y6\% & 2336 & \\
\hline & 31 & oul ojoce & U(1)!) & $(1 x)$ & 1 & 125.0 & 1 & 12 & 3יב & 63 & 61 & 136 & yy & \\
\hline & 13 & (x)ivouos & 01) 1 & 000 & 1 & נ3. & i & & 10022 & & $-y$ & 131356 & 47 & \\
\hline & עy & $03100 \times 100$ & $u(x)$ & 100 & 2 & $v 0.0$ & $\mathbf{0}$ & & 11642 & 73 & 53 & 4UUSj! & 11642 & \\
\hline & 10. & colooxis) & 001 & $0(0)$ & 4 & 2440.13 & 4 & 2440 & 4572 & $-y$ & 146 & 432374 & $y 472$ & \\
\hline & 40 & 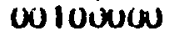 & 001 & 100 & 2 & 120.0 & 0 & & 10700 & $-y$ & 73 & 45165 & 10100 & \\
\hline & 34 & 0010 (xuln & ow & 000 & 2 & 312.4 & 2 & 312.8 & 4627 & 76 & 62 & 745247 & Y627 & \\
\hline & 61 & 0010.1000 & o(x) & 010 & 2 & 1100.0 & 2 & 1150.0 & $y 0(i)$ & 74 & 104 & 193 & 40317 & \\
\hline & 53 & $(x): 0 \cup(x)(x)$ & $(001)$ & 000 & 2 & & 2 & & 9234 & 101 & & & 92 & \\
\hline & 4t & 0000 & vow & 000 & 1 & $1(x)$ & 0 & & $111 \% 0$ & 192 & $\boldsymbol{U}_{j}$ & 63 & 111 & \\
\hline & sb & nov & $O(x)$ & $\mathbf{o ( x )}$ & $j$ & 1086.3 & 3 & Juss6..3 & yi 7is & $10 y$ & 240 & $2 b 2$ & 9176 & \\
\hline & מاj & 0000 & 000 & 000 & 1 & 125.0 & $\mathbf{I}$ & 1210.0 & 42132 & 40 & 43 & & $y_{2}$ & \\
\hline & 74 & 1000 & O0I & oino & 1 & 130 & $\mathbf{1}$ & 1300 & Yij?! & $-y$ & 272 & 351 & 46 & \\
\hline & 53 & $(x) 10$ & UIU & 000 & $i$ & & u & & 118 & Y1 & & & $11 y$ & \\
\hline & 64 & (x)ui & 001 & 010 & 1 & & 0 & & زن:107t & $y 4$ & & & $10 \%$ & \\
\hline & 71 & vor & 001 & 0.01 & 2 & ز11 & 2 & 11.3 & 100 & 38 & 54 & Yils & & \\
\hline & 61 & 001 & DOI & 001 & 1 & & $\mathbf{1}$ & 11 & 1000b & 64 & 36 & & $10(x)$ & \\
\hline & 52 & 00 & $0(1)$ & 001 & $\mathbf{I}$ & & 0 & & 111 & 72 & IU & & 115 & \\
\hline & 73 & 000 & 01 & DuI & 3 & & 0 & & 10 & & & & 102 & \\
\hline & 74 & 000 & 010 & $0(0)$ & 1 & 47 & $\mathbf{I}$ & 41 & & -4 & 40) & 530 & 16 & \\
\hline & jo & 010 & 000 & 100 & 1 & & 1 & & & 73 & 60 & & & \\
\hline & 31 & 01000000 & ous & $0: 10$ & 3 & 22 & 3 & $22 !$ & Yis & 43 & 62 & & & \\
\hline & 6y & olus & ) (:) & 000 & 2 & & 2 & & 102 & 42 & IOS & $2 \mathrm{j} 2$ & $y: j y ?$ & \\
\hline & ij & ondus & 000 & 010 & $\dot{2}$ & & 2 & & & j5 & 67 & & $y$. & \\
\hline & 40 & (1) 1000000 & $00 \mathrm{~J}$ & $0(x)$ & 2 & & 0 & & 11470 & 48. & زاز' & & $11 \times 70$ & \\
\hline & 61 & OI 001$) 0(0)$ & J() & $f(x)$ & 1 & & $\mathbf{I}$ & $3: 33$ & $y_{2}$ & 73 & j5 & & & \\
\hline & 54 & 300000 & $O(x)$ & (vi) & 1 & & $\mathbf{0}$ & (1) & $10132 \mathrm{~J}$ & & 10 & 41 & 10 & \\
\hline & 72 & 01000000 & 000 & 10 & 3 & & 2 & 1624 & YoY & 51 & 113 & 14 & & \\
\hline & 10 & 0I (N00000) & $(10)$ & 1.10 & 2 & Iis $7:$ & 2 & () & 434 & زلز & 173 & 10 & yo & \\
\hline & 01 & $000(x)$ & 000 & $1)(x)$ & 2 & 1012 & 2 & 1072 & Yó,? & ازا. & 111 & 1)o & & \\
\hline & ou & ol (і) & UUI & $0(x)$ & 2 & $|10\rangle$ & 2 & 107.2 & $\operatorname{sic}(x)$ & נ'וo & (j) & 100 & 1360 & \\
\hline & 41 & $0100\left(x_{1}(x)\right.$ & 001 & $0 . x)$ & 2 & 341,13 & 0 & & 11403 & Yis & Yil & 171017 & 11463 & \\
\hline & 10 & () $1000 x(x)$ & $0(1) 0$ & $(x)$ & 1 & & $i$ & $56 \cdot j \cdot 3$ & 0.470 & $5 y$ & bis & I of jiso & $4: 02$ & \\
\hline & .22 & UI (vi)(1)000 & ovis & 0 & 2 & ن. & $\mathbf{U}$ & W. & 10343 & 102 & 72 & bis074 & (11).345 & \\
\hline ת & & Uivinta & OU:) & $U(x)$ & I. & oij. 0 & $\mathbf{0}$ & ixh.0 & $121(1)$ & 62 & 71. & 41216 & 12100 & \\
\hline
\end{tabular}




\begin{tabular}{|c|c|c|c|c|c|c|c|c|}
\hline & Irol & $2<12$ & T.L & 69 & Ixo! & 0 & 0 & \\
\hline & vp1.01 & VAKYYS. & $x-$ & 109 & GIOI & $s \cdot 1.1 .2$ & 1 & $9 \cdot 1.17$ \\
\hline & oLI. & AOIKD & $O E^{\circ}$ & ISG & $(1.101$ & $z \cdot[0 \mid$ & 1 & $z \cdot|9|$ \\
\hline & 9xiol & $|3 ! i \varphi \vee v|$ & 10 & $x-$ & पxर? 1 & $6: 900$ & 1 & $v^{\circ} 0+v$ \\
\hline & orres & (H⿻上丨) & $n-$ & nट & II & $1.92 \varepsilon^{\circ}$ & 1 & $6 \cdot 97.5$. \\
\hline & ?.5़EOI & $9 / 01.2$ & or: & $9 L$ & 25,501 & $9^{\circ} \mathrm{EII}$ & 1 & 9.1111 \\
\hline & 10201 & $\Delta c r i v e$ & $n-$ & 18 & 1n? & ${ }^{\circ} \varepsilon \mid$ & $\mathbf{I}$ & $0^{\circ}: 111$ \\
\hline & x9011 & Ell! & SE & ? & 09011 & $\cdot 0$ & () & $O^{\circ} C_{1} L$ \\
\hline & $n<|\forall|$ & & ni. & hn & $\mathrm{Kl.}$ & $\cdot 0$ & 0 & $0 \cdot r, 1$ \\
\hline & Vl.kn & & 1.?. & OR & & $G^{\circ} \times I .1$ & 1 & $\zeta \cdot x l .1$ \\
\hline & I I sin & ONSISP & or & 00 & I & $I^{\circ} \cap<b$ & 2 & $L A I D$ \\
\hline & 12001 & ril & $\boldsymbol{D E}$ & 10 & $12 \mathrm{ml}$ & $8^{\circ} 265$ & $?$ & $p \cdot 3 . p q^{\circ}$ \\
\hline & СНZ2I & & 12 & $=\int \mathrm{C}$ & & $\bullet$ & n & $0 \cdot c, l$ \\
\hline & PII.A & & OV & ?.I. & & $0 \cdot 0,1 ?$ & 0 & $0.0 r_{1}$ ? \\
\hline & $0 \times 181$ & & AI & HL & & $: 0$ & n & $9^{\circ} \ln$ \\
\hline & $0 \angle I||$ & $|R \overline{C Z}|$ & 1.1 & E9 & & $\bullet$ & 0 & $0 \cdot ?: \ell$ \\
\hline & AYIOI & $\ln 602$ & $|\subseteq, \mathbf{i}|$ & n- & (.0) & $9^{\circ} 951$ & $\mathbf{I}$ & Iיו \\
\hline & IOPG & $L 0 !, 91$ & $2 E$ & 69 & $10 n$ & $p^{\circ}(x) 1$ & 1 & $S^{\circ}$ CE I \\
\hline & RṬı $\|$ & 202 & 22 & 99 & $\left.X G_{1}\right)$. & $\cdot 0$ & 0 & $0^{\circ} \mathrm{O}$ \\
\hline & 01001 & TSIVEI & nI & ค9 & 1110 & $9 \cdot 18$ & 1 & $Q \cdot 18$ \\
\hline & Hก!II & $\angle I$ & YE & $n-$ & (3x?II & 0 & 0 & $0 \cdot 06$ \\
\hline & $1 . \mathrm{MLO}$ & $\angle 2 t$ & IE & $\angle !$ & PLI & $0 \cdot 001$ & 1 & ()$^{\circ} \times() 1$ \\
\hline & Sx) & E I & R?. & 0 & 29101 & $T^{\circ}<\forall 2$ & 1 & $T<1+7$ \\
\hline & CZLLII & $r_{1} \cap !+C_{1}$ & ZE & $C L$ & ECI.II & $\cdot 0$ & 0 & $0 \bullet n$ \\
\hline & 29011 & $x \leq 101$ & $L l$. & GE & $x L O A$ & $p^{\circ}$ Ch & 2 & " 2 .6n \\
\hline & Sinfial & $624 n$ & .2. & $\mathbf{O L}$ & (SAfre I & 0 & 0 & O०)E \\
\hline 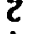 & ERER & OKE & Z.A & , 9 & $n 9 l n$ & $0 \cdot$ cic? & 1 & 0.922 \\
\hline & CPGOI & Aroos & $G$ & $n-$ & Cด? & $8 \cdot 25,8$ & 1 & $n \cdot 2 r_{1} s$ \\
\hline & CI.E6 & zor,ze & te & $0 \subseteq$ & top?n & $0 \cdot 192$ & 1 & $0.19 ?$ \\
\hline 8 & $0 c t 11$ & $\angle I C \mid C$ & $\boldsymbol{P C}$ & $\angle G$ & $|.9 P| \mid$ & $L^{\circ} \varepsilon \|$ & 0 & L.R!I I \\
\hline 0 & OLPe. & GEATLE & I! & ris & otn & $0 द 21$ & 01 & ०0दा. \\
\hline 0 & nata & $\operatorname{LnZ} 091$ & 1.12 & 99 & (KXER & r.ọu & $\nabla$ & $i^{\circ} 9 b R$ \\
\hline C & OnG6 & I Erogr. & (.25 & En & $\left(1 x_{1}, A\right.$ & $0 \cdot 0011$ & 6 & $0^{\circ} 00<.1$ \\
\hline & $0 t$ n & 02.1161 & (1). 1 & $E L$ & (I) & $0 \leq 10$ & Z & $0 r, 6$ \\
\hline & $026 n$ & otsit, : & 2016 & n- & (1) ph & 0.0002 & 2 & $0^{\circ} \mathrm{xonz}$ \\
\hline & GO/R & 609201 & $x-$ & 09 & (n) & $0^{\circ} 0 c_{1} C_{1}$ & 1 & $0^{\circ}\left(r r_{1} r_{1}\right.$ \\
\hline & Oxto & E?ONI & 002 & r, & $n x \in R$ & $(1 \cdot \mathrm{mor})$ & $\bullet$ & $0^{\circ}(x) n$ \\
\hline$r$ & $9 p 6 n$ & $0+1802$ & $|x|$ & 0. & $01 \times 8$ & $0^{\circ} 0$ sin & 1 & $0 \cdot(1)_{1} x^{\prime}$ \\
\hline & ntok & $n+L I$ ? & 01.1 & np & אי?:n & $0^{\circ}$ OKA & $\boldsymbol{E}$ & $0^{\circ} 0$ ) \\
\hline & $0<1 \cdot 1)$ & $2 m o 1$ & $n-$ & B9 & (1).tol & $\cdot 0$ & () & $0 \cdot \nabla 2$ \\
\hline & c 8231 & EFAA & 22 & $2 \sqrt{1}$ & I, I I I I & 0 & 0 & $0 \cdot 7 ?$ \\
\hline & N2I1! & $071<9$ & $2 !$ & 94 & PLOR & $11 \cdot 111$ & $?$ & $n^{\circ} \mid 1 / 1$ \\
\hline & I LAP & $2 \angle 105$ & 20 & 69 & $12 \times 8$ & $0 \cdot 01 . ?$ & $\boldsymbol{Z}$ & $0 \cdot 7.1 .2$ \\
\hline & aIER & GRLARI)I & $g r_{i}$ & $2 r_{i}$ & S(I)<n & 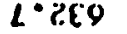 & 1 & 1. ZE 9 \\
\hline & OnVリ1 & I & 191 & 12 & AE $|P|$ & $\bullet 0$ & $\mathbf{0}$ & $R^{\circ} 9111$ \\
\hline & OCGII & $r_{i} \angle P(x) !$ & Cy & 29 & or ? & 0 & 0 & $c^{\circ} \times b \mid$ \\
\hline & $0+121$ & ExnחI & ?E & 26 & $9 \mid 8.1$ & 0 & () & $0 \cdot$ osp \\
\hline & G,9l6 & UcE तरI: & (x) 1 & 45 & (1) $b 6$ & $0 * \mid 3 i .1 .1$ & $\boldsymbol{E}$ & $0 \cdot m 2.11$ \\
\hline & Ut:Hr. & $0 \leq \vee c_{i} l$. & 90 & $\angle A$ & CER & t. öf & 7 & ०.98. \\
\hline & SOR II & $\left.0:|c| T_{1}\right)$ & 09 & On & AORII & 0 & 0 & $n \cdot r e$ \\
\hline
\end{tabular}

(x)i (x)o morenom r.t. 10?bc

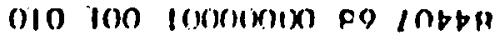
Dil) $1001000(x)(x)$ 1.9 90 DQR

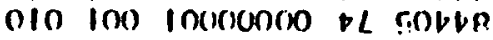
010 ion inmonixn nI. BOtba 010 IOO I0000000 G., CObGa 010100 inCnODOO l.9 ZO)

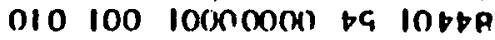
on nIn olgoonkI nz zzr.VL mi oin nimomoo po izcul onI IOn nIDOOOn zo oret. mi 100 ni $x$ ononon ni. sirbl.

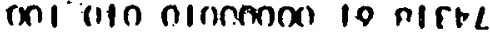
oln 100 ol (c) IOn nImonon nci sicol nol 100 nImIOOD po rifet docio nin ninoono vl. picbl mi nio aloximem !) firbl

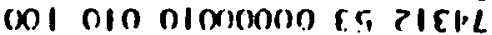
(X) 100 nImonoon 20 II rel.

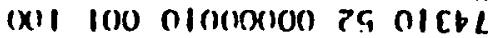
(x) I nIn niconoori no rorbl.

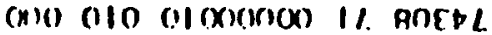
onI $010010000 \%$ b! InEVL

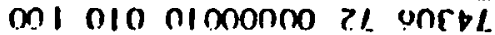
cxil 110 nICOCOON ab cocbl

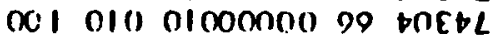
nol cin niminom ol enrul. col nin ninemono il zotel. DI 110 ol I mo noo no Imono EG sir.vo oon mo minonno ris moz.po no son minomen tic lnzpo (x) roo no inonon sc 9n?. (x) min minchon El. enz.p9 oxis 000 nolnonno co bnzbo

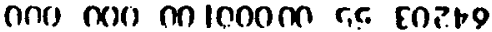
oxin mo minox) in zizto oxio ino minonol nद loz\$s cris mo onoxinoo mi enIto nI0 r.oo moninon no inllib nio 100 molonon ne. COOH:G oln ion molonon ?? zMnts

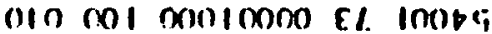

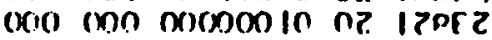

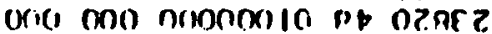

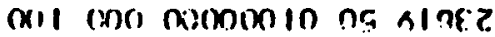

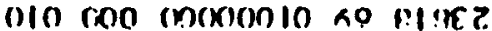
blo ino nunorsin na libe?

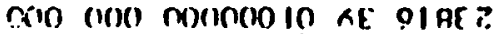
0 N
W
$7 x$
I H
9) $d$
30
J 


\begin{tabular}{|c|c|c|c|c|c|c|c|c|c|c|c|c|c|}
\hline A & $\mathbf{B}$ & C & $\mathbf{U}$ & $\mathbf{E}$ & $\mathbf{F}$ & $\mathbf{G}$ & $\mathbf{H}$ & I & $\mathbf{J}$ & $\mathbf{K}$ & L & $\mathbf{M}$ & $\mathbf{N}$ \\
\hline & 4y & 00001000 & 000 & 000 & 1 & 34.0 & 0 & ॥. & 1.3238 & 74 & $2 i 3$ & 225y!, & 1.3234 \\
\hline & 44 & oovis luow & o(n) & $0(x)$ & $i$ & bu. 0 & 0 & 0 & | 1450 & 42 & uI & $2 \mathrm{j} 3250$ & \\
\hline & 3 & 000001 000 & ow & 000 & ? & 100.0 & 2 & 100.0 & Y. & 4.3 & BI & $\Delta 071.3$ & \\
\hline & d, & on)(H) $($ indi) & ovi) & 000 & 2 & 134.0 & 0 & 0 & 11010 & 40 & (WI) & 1jy44 & 11616 \\
\hline & 15 & cosulous & $0(0)$ & 100 & $?$ & 3415.3 & 2 & $34{ }^{\prime} 3.15$ & Y!jyo & By & ou & 7 ibsus & נינים \\
\hline & 31 & uUuis I OOKs & cow & (i) $(x)$ & j & & (1) & 0 & 14440 & 40 & 61 & 16.134 & 133411 \\
\hline & 72 & (xouvinix) & U0I & 010 & 1 & $148(0.1)$ & i & Is(i).i) & 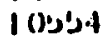 & 33 & 100 & 37 utus & $\times 7 / 2$ \\
\hline & 71 & 00001000 & (10) & ion & 3 & $2 \times 12.6$ & 3 & $2+32.0$ & עמצענ & $-y$ & 3.JH & 62150013 & us!iy \\
\hline & jod & $00(v) 1000$ & (u) & $\mid(x)$ & 2 & 140.0 & 2 & 140.0 & Sif 11 & ises & 131 & $10 x+412$ & 2011 \\
\hline & 53 & $0(u x) 10(x)$ & $0(0,0$ & (s) 0 & 2 & 134.4 & 2 & & $y \mid 13$ & Yis & 123 & I 1045y & 4113 \\
\hline & ijo & 01001000 & uow & outi & 4 & 010.0 & 4 & 1.0 & 4370 & $-y$ & $-y$ & 1130144 & 4378 \\
\hline & 52 & 00001000 & 000 & 100 & 3 & $: 1 / 1.3$ & $i$ & 140.3 & $|10 j| 1$ & 1283 & $4 y$ & $752 \mathrm{jo}$ & 11511 \\
\hline & 12 & ()0001000 & UUS & 010 & $j$ & $20,22.0$ & 3 & 2052 . & Ylj 41 & $-y$ & 131 & 403931 & $y 544$ \\
\hline & 07 & $0 \times 1001000$ & $(s)(x)$ & o(x) & 2 & $11,2.0$ & 2 & 1152.0 & $41 \%$ & $7 s$ & 34 & 211062 & $\$ 174$ \\
\hline & $4 x$ & $0 \times 100 / 0) 0$ & $(1)(x)$ & $n(x)$ & $\mathbf{i}$ & (ji). 0 & 0 & & $1136^{\circ}$ & 101 & 42 & 364 & 11.365 \\
\hline & $\dot{0}$ & $0000(00 x)$ & o(x) & coon & 2 & 1140.0 & 2 & 1140.0 & زAd & 34 & 177 & $19834 / 5$ & $\because(1) 43$ \\
\hline & 50 & $\begin{array}{l}00001000 \\
000 \times 11000\end{array}$ & $\begin{array}{l}1)(x) \\
\text { D(x) }\end{array}$ & $\begin{array}{l}100 \\
100\end{array}$ & $\begin{array}{l}1 \\
2\end{array}$ & $\begin{array}{r}223.0 \\
10.32 .0\end{array}$ & $\begin{array}{l}1 \\
2\end{array}$ & $\begin{array}{r}23.5 .0 \\
1632.0\end{array}$ & $\begin{array}{l}720.1 \\
\text { Y.161 }\end{array}$ & $\begin{array}{l}-y \\
48\end{array}$ & $110^{-4}$ & $\begin{array}{r}15474 \\
24.30554\end{array}$ & $\begin{array}{l}920.3 \\
\text { yi)10 }\end{array}$ \\
\hline & oy & 00100000 & i) & ous & $i$ & 345.6 & $i$ & & जाT & 54 & $\sigma^{\prime}$ & 60061 & \\
\hline & $4 y$ & a) 100 ision & OON & 000 & 2 & & 0 & & $|d y ?|$ & 67 & 15 & 52153 & $|A y 2|$ \\
\hline & עن & 00100000 & $O(x)$ & 000 & $\vec{I}$ & 113.6 & 1 & & إبإ & 67 & 47 & $27.3 \times 6$ & \\
\hline & 54 & 001100000 & 000 & 000 & 2 & 150.0 & 2 & 150.0 & $4 \times 02$ & 64 & $4 y$ & $15 \% 64$ & 4902 \\
\hline & $\$ 4$ & $001001) 1 \times 0$ & $u(x)$ & nuo & 1 & ou. 0 & 0 & & 11741 & 1.3.3 & 32 & 228.31 & 11292 \\
\hline & & 00000001 & 001 & 010 & I & jou.jo & I & & 10353 & -4 & 70 & Itod2 Iy & 10.358 \\
\hline
\end{tabular}


Column A-Five-digit identification code

The first digit identifies the plant by the Census Region in which it is located.

The second and third digits are the state identification code. The state codes are numerically sequenced 01 to 50 and correspond to an alphabetical 11sting of the states. Code \#51 indicates the District of Columbia.

The final two digits in the identification code denote the specific plant within a state.

Column B - Two-digit vintage code

Year in which the plant observed was brought into initial operation.

Column C - Eight-digit region code

Regional code constructed for analytica1 purposes. This code for the nine Census Regions is as follows:

$\begin{array}{lllllllll}\text { Region 1 } & 1 & 0 & 0 & 0 & 0 & 0 & 0 & 0 \\ \text { Region 2 } & 0 & 1 & 0 & 0 & 0 & 0 & 0 & 0 \\ \text { Region 3 } & 0 & 0 & 1 & 0 & 0 & 0 & 0 & 0 \\ \text { Region 4 } & 0 & 0 & 0 & 1 & 0 & 0 & 0 & 0 \\ \text { Region 5 } & 0 & 0 & 0 & 0 & 1 & 0 & 0 & 0 \\ \text { Region 6 } & 0 & 0 & 0 & 0 & 0 & 1 & 0 & 0 \\ \text { Region 7 } & 0 & 0 & 0 & 0 & 0 & 0 & 1 & 0 \\ \text { Region 8 } & 0 & 0 & 0 & 0 & 0 & 0 & 0 & 1 \\ \text { Region 9 } & 0 & 0 & 0 & 0 & 0 & 0 & 0 & 0\end{array}$

Column D - Two-digit fuel type code

Identifies the types of fuel for which the turbine was designed.

$\begin{array}{lll}011 & 0 & 0 \\ \text { Gas } & 1 & 0 \\ \text { Mixed } & 0 & 1\end{array}$


Column E - Two-digit building code

$$
\text { Indicates the plant's construction: type. }
$$

$\begin{array}{lll}\text { Conventional } & 0 & 0 \\ \text { Outdoor } & 1 & 0 \\ \text { Other } & 0 & 1\end{array}$

Column F - Three-digit operating code

Indicates the four different types of operation possible in gas turbine plants.

$\begin{array}{lrrr}\text { Semi-automatic } & 0 & 0 & 0 \\ \text { Automatic } & 1 & 0 & 0 \\ \text { Manual } & 0 & 1 & 0 \\ \text { Other } & 0 & 0 & 1\end{array}$

Column G - Contains the number of gas turbine units installed at the plant observed.

Column H - Total capacity of the plant in megawatts; the sum of the capacity of all units.

Column I - Construction cost in $\$\left(x 10^{3}\right)$. The cost has been adjusted to a base year of 1975 .

Column J - Internal code used for programing purposes only; indicates the number of years in which the plant was observed. 


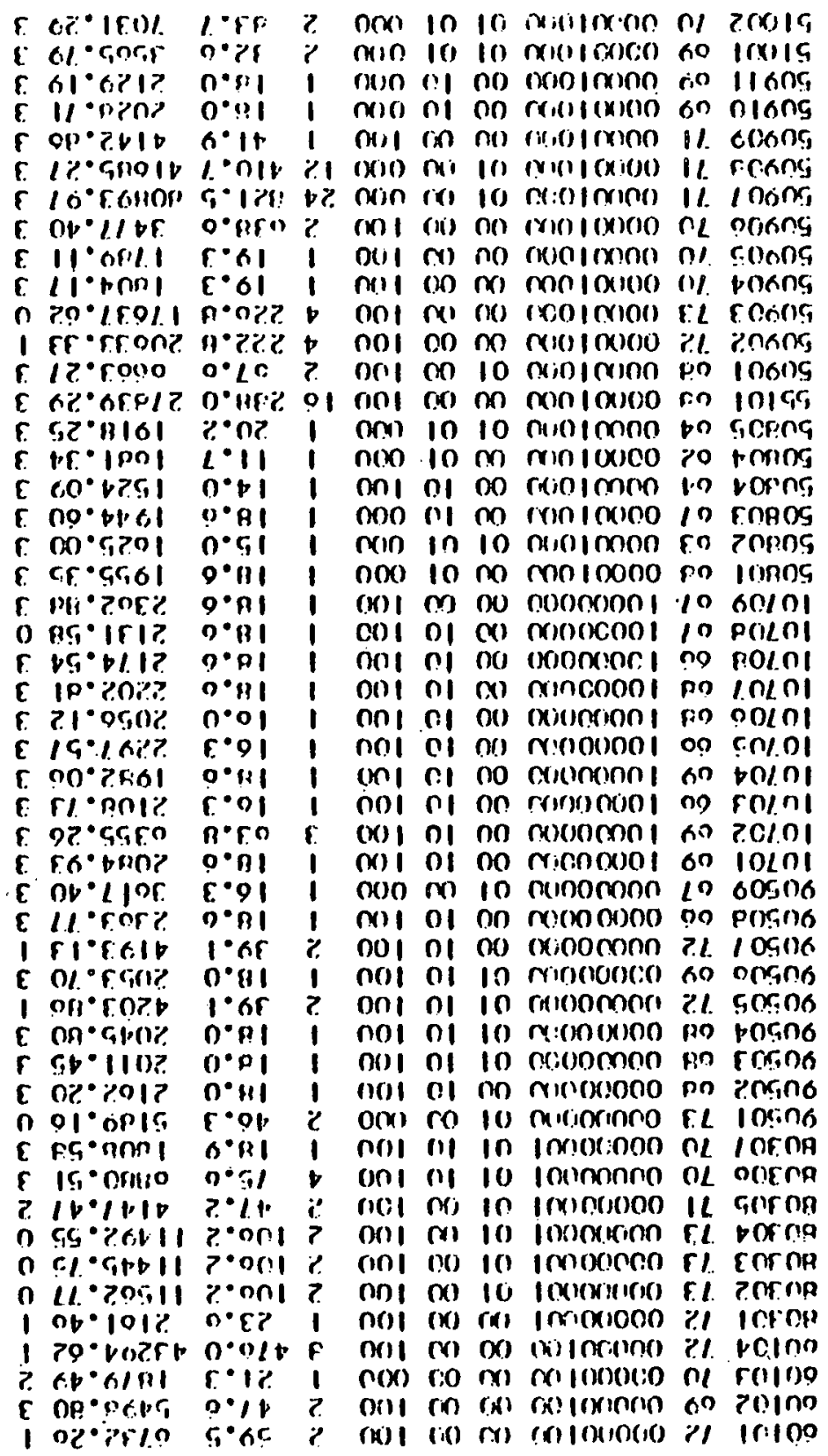

$\begin{array}{llllllllll}\boldsymbol{C} & \mathbf{1} & \mathbf{H} & \mathbf{9} & \mathbf{J} & \mathbf{G} & \mathbf{0} & \boldsymbol{9} & \boldsymbol{y} & \mathbf{V}\end{array}$




\begin{tabular}{|c|c|c|c|c|c|c|c|c|c|}
\hline A & $\mathbf{B}$ & C & D & $\mathbf{E}$ & $\mathbf{F}$ & C & $H$ & I & \\
\hline & 71 & $00(x) / 0(x)$ & 30 & 01 & oisu & 1 & 41.9 & $37 J 4.363$ & \\
\hline & 71 & $u(x) / 0(x)$ & 01 & UI & (1)(10) & \% & & $1094 \cdot 8.9$ & \\
\hline & 12 & $00001(j: x)$ & in & 01 & $I(x)$ & $\varphi$ & 400.0 & 411015.10 & \\
\hline Wis & 11 & $00 \cdot(0) \|(0, x)$ & in & UI & 000 & 3 & ن. د:1 & 11343.95 & \\
\hline .17 & 73 & $o w(w)(x)$ & ن & u! & onisj & 5 & 310.11 & 32443.01 & \\
\hline 8 & 71 & $\omega(x) \times l)(s)$ & 01 & $(x)$ & 0001 & 3 & 10.0 & & \\
\hline & 67 & (x)(u I (1in) & 01 & (vi) & vix & 1 & IH.O & 203 & \\
\hline & 01 & UI Dolsixis & 10 & (y) & i) & 1 & 12.0 & & \\
\hline & 11 & oul uousx & $0 !$ & 10 & (ivi) & $H$ & 152.0 & $|\vdots|$ & \\
\hline & 70 & $0 u 100(101)$ & 01 & 10 & $\ln 10$ & 10 & & & \\
\hline & oud & oul vouxk & $0 !$ & 10 & (un) & 12 & & & \\
\hline & 71 & 1000005 & 111 & 10 & 100 & 16 & & & \\
\hline & of & $j(1)$ & $0 !$ & IJ & $(u x)$ & u & & 31 & \\
\hline & 07 & njoljis & 01 & 10 & 1013 & J & .4 & 13 & \\
\hline OH & 兽 & & $\begin{array}{l}0 \mid \\
01\end{array}$ & 10 & $\lim _{100}$ & $\begin{array}{l}0 \\
0\end{array}$ & & & \\
\hline & c:3 & (1s)irs & $\infty 0$ & 10 & I00 & 4 & $1 ! 3:: 0$ & 1370 & \\
\hline & $\%$ & Jux & Uu & ov & 100 & 4 & & .0 .3 & \\
\hline & 10 & 0000 & 00 & $(x)$ & 100 & 4 & 25.2 & 1124 & \\
\hline & 01 & $J(x)$ & uo & U1) & $\ln x$ & 1 & .0 & 10\% & \\
\hline & 10 & $00(x)$ & 01 & $\omega 0$ & 100 & 4 & $0 \%$ & 095 & \\
\hline & 07 & $00 !$ & 00 & 100 & 1100 & 1 & & $.14 / 0$ & \\
\hline & od & 0000 & Ix) & 01 & $0(10$ & 1 & & 180 & \\
\hline & 08 & ursine & (นU & 01 & $(3, x)$ & 1 & & 192 & \\
\hline & 0.5 & (a) & 10 & UI & 0110 & 1 & & Ju & \\
\hline & 6.1 & (x)its) & 01 & (x) & 100 & I & & נע'J & \\
\hline & 01 & 00 & WI & $\omega$ & 1001 & 3 & .2 & $4 j$ & \\
\hline & 72 & out & ou & 0:) & $y(x)$ & 2 & 10. & $4 j$ & \\
\hline & od & (1):30 & 小 & $\omega$ & $0(j 0$ & 0 & 104 & 107 & \\
\hline & 71 & (a) & 01 & 01 & $I(x)$ & 1 & & 500 & \\
\hline & 04 & $(x)()$ & 10 & 10 & 1130 & $?$ & & 322 & \\
\hline & 70 & OiNI & 01 & 00 & 100 & 4 & & $\alpha$ & \\
\hline & oj & $0 \times 10$ & (10) & $0 \mathbf{3}$ & 100 & 4 & & 19 & \\
\hline & 01 & $0: x$ & 01 & vi & 100 & $\mathbf{u}$ & 124 & $141:$ & \\
\hline & ay & $0 i x$ & UI & 10 & 0010 & 2 & .0 & 212 & \\
\hline & 73 & Uine & 01 & 10 & 100 & $!$ & & 30 & \\
\hline & oy & 0.าง & 10 & $(x)$ & $1(x)$ & 1 & & & \\
\hline & 70 & $0(x)$ & 01 & (o) & $U(x)$ & $\mathbf{I}$ & 10 & 17 & \\
\hline & 71 & SiN & U! & 0.3 & Ulo & 2 & & & \\
\hline & (i) & OUUNSI IX) & 01 & 10 & 100 & & & & \\
\hline & ou & $I(x)$ & 10 & ():) & Iov & 1 & & & \\
\hline & uy & UOix & 10 & $i x$ & 100 & $!$ & & & \\
\hline & 71 & (U) & UI & (i) & 010 & 1 & & & \\
\hline & 10 & I $u(x$ & ov & (ix) & 0120 & 2 & & . 11. & \\
\hline & 07 & Uix & (x) & 10 & 100 & 1 & & مزن. & \\
\hline & 0. & $0 . x \omega] 0(x)$ & 10 & 10 & I (N) & ! & & & \\
\hline & $1 \%$ & (X) & 100 & 10 & 100 & 4 & & & \\
\hline & 70 & O(n) I I)(I!) & $(x)$ & (i) & 100 & 1 & & & \\
\hline & 137 & (1.). N I () U & (w) & 10 & 110 & 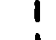 & & & \\
\hline & & ind1,110(10) & (N) & WJ & $I(x)$ & 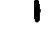 & & $|\cdot 0|$ & \\
\hline
\end{tabular}




\begin{tabular}{|c|c|c|c|c|c|c|c|c|c|}
\hline A & $\mathbf{B}$ & C & $\mathbf{D}$ & $\mathbf{E}$ & $\mathbf{F}$ & $\mathbf{G}$ & II & I & $\mathbf{J}$ \\
\hline <. & ou & (0):xilor) & IN & Ii) & $0(1) 0$ & $\mathbf{1}$ & I d . . 0 & & \\
\hline & 01 & $0: 1: 1.1(0 ; x)$ & ew & (j) & & & & & \\
\hline 52004 & 01 & (B)INI USOS & $\mathbf{w}$ & $\infty i$ & 100 & 1 & 10.2 & & \\
\hline & 09 & $1.01004)(x)$ & (x) & (x) & $I(x)$ & 2 & & & \\
\hline & 70 & li)on?00,00 & wu & $(x)$ & I $(x)$ & 1 & & & \\
\hline & 0 & I vixsusive & 100 & n) & I $(x)$ & 1 & & & \\
\hline & jo & 10000000 & (w) & (x) & $\ln (x)$ & 1 & & & \\
\hline & 71 & I U(h)(lix)il & in & ON & $\ln \mid$ & 2 & & & \\
\hline & 10 & I o(s)crixus & (1) & IU & 100 & 2 & & & \\
\hline & 11 & I ou(s)(xus) & (x) & $|i|$ & $f(x)$ & 2 & & & \\
\hline & 0.) & (i) $(x)(x)(x)$ & 100 & 01 & 100 & I & & & 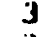 \\
\hline & 07 & I U(N)ixix) & (x) & (II) & $\operatorname{IIx}$ & 1 & & & 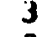 \\
\hline & oy & $(i)(j)(x)(x)$ & $(x)$ & 01 & $10 x$ & 1 & & & 3 \\
\hline & us & ( visuovis) & $(\boldsymbol{N})$ & U! & $\operatorname{lox}$ & $!$ & & & 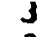 \\
\hline & oy & Iinguxid & $\mathbf{0}$ & 01 & 100 & 1 & & & 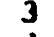 \\
\hline & 0,1 & $1 x)(10)$ & 00 & 115 & $\ln (x)$ & 1 & & & 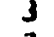 \\
\hline & 09 & 0015 & 10 & (n) & (1) & $?$ & & & . \\
\hline & 09 & WI & 10 & (r) & 100 & I & & & 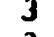 \\
\hline & od & .01 & 10 & 03 & 100 & 1 & & & Jִ \\
\hline & out & (1). & (4) & w & 100 & $\mathbf{I}$ & & & $\mathbf{J}$ \\
\hline & ou. & (2): I & (x) & 13 & 100 & 4 & & 54 & $\mathbf{J}$ \\
\hline & cod & (D) & 01 & 10 & 100 & 1 & & 240 & ? \\
\hline & ou & (3) 1010 & un & 15 & 100 & $d$ & & ji & 3 \\
\hline & 07 & Nh & 180 & U! & 1000 & 2 & & 40 & \\
\hline & Oy & Divi? & OI & $0 !$ & 000 & 4 & 12.0 & 23 & 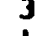 \\
\hline & 72 & $0(x) 10$ & (x) & UI & iviv & 0 & 380.4 & $300 d 5.32$ & I \\
\hline & 10 & $(0 ! n)$ & 01 & 01 & $(1)(x)$ & 1 & 12.0 & Ioyis. is & 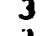 \\
\hline & נ) & & 01 & (1) & Uiso & J & 1.5 & 05 & \\
\hline 401 & 10 & 000 & 01 & (y) & 100 & $\mathbf{1}$ & $41 . .9$ & ou & J \\
\hline 902 & 07 & 000 & 10 & (x) & ive & ? & $\therefore$ & & \\
\hline & II. & 0.00 & 01 & (U) & 100 & & & & \\
\hline 42501 & 7.2 & $0 x$ & 00 & 10 & IUO & 2 & .0 & & \\
\hline 2230? & 07 & 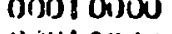 & 10 & 10 & $\mathrm{COU}$ & 1 & 23.11 & 343 & $\mathbf{J}$ \\
\hline 12503 & $7 \mathrm{~J}$ & $0(x)$ & 00 & 10 & 100 & 1 & 5.5 & 304 & \\
\hline I & 73 & $0: x$ & 00 & On & $\ln$ & 1 & $3 i s .1$ & $8+6$. & \\
\hline 12702 & 13 & $0, x$ & (2) & 100 & 100 & 1 & & UI & \\
\hline 12.1133 & 1.1 & $0 ; x)$ & U() & on & I & 1 & .7 & 02 & \\
\hline 12104 & 12 & Gin & 01. & (u) & $1(x)$ & 2 & (II).es & 1011 & \\
\hline d\%!luI & 73 & $0 x$ & (i) & II) & $\ln (x)$ & | & & & \\
\hline $62(4) 2$ & 70 & $0(x)(n)$ & 10 & (b) & I(x) & $t$ & & & \\
\hline |2901 & (1) & I'x)istsurs & 00 & (x) & (Jik) & ? & & & 3 \\
\hline 1290102 & עy & luil & (x) & (Ix) & $0(1)$ & I & .10 .0 & ניל & \\
\hline 905. & $71)$ & Iuv & W1 & (0i) & $\mid(x)$ & ! & 21.3 & .07 & 3 \\
\hline 123111 & ou & $10(x)(x) \cdot x$ & (x) & $(x)$ & $(0() !)$ & ! & 10.0 & $1119 \%$, dij & $J$ \\
\hline 1) & 01 & ol invive & 01 & (b) & $1 \times 1$ & I & 18.0 & 2341.315 & 3 \\
\hline 3:00? & (s) & Uf (bo)(k)u & $|x|$ & (1):J & 310 & 1 & (11. & 0047.13 & $\mathbf{j}$ \\
\hline N.3 & 10 & $01(1) .0(x)$ & 01 & (1). & In & 4 & ?.j!.? & $\mid, 100 \%,(j)$ & 3 \\
\hline & 71 & $1)(1(x))$ & ( ) & U. & $\ln (x)$ & is & 130.81 & $154 \% .8$. ys & 3 \\
\hline & 12. & OI (r)vituis & (I) & 0.1 & 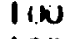 & 1 & 212.4 & 2.PIO. & 0 \\
\hline Rjijue & 11.. & $0.100(x) 10)$ & INU & $(0)$ & 100 & -1 & 2.12 .4 & ـ ـ & \\
\hline
\end{tabular}




\begin{tabular}{|c|c|c|c|c|c|c|c|c|c|}
\hline A & $\mathbf{B}$ & C & U & $\mathbf{E}$ & $\mathbf{F}$ & G & HI & I & \\
\hline & & U! 000(1)is & (u) & 10 & & & 4l..: & 3.1 .0 & \\
\hline & & & (10) & 10 & & & & & \\
\hline & & & 01 & Iu & & & & & \\
\hline & & (u) & 1)1 & (x) & & 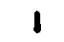 & & $1113 / 0: 12$ & \\
\hline & & II) & (I) & $(x)$ & 100 & 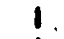 & & & \\
\hline & & (U). & (M) & 10 & IN & I. & & & \\
\hline & $\dot{\mathbf{o}}$ & $x u(x)(x)$ & 111 & (x) & 1001 & 1 & & & \\
\hline & & (His) & 10 & $(N)$ & $\operatorname{lox}$ & 0 & & & \\
\hline & & (1)ixulu & (x) & (ir). & lix) & 1 & & & \\
\hline & & ix) & 01 & $(x)$ & 100 & I & & & \\
\hline & & $(x)(x)$ & ix & (i) & $1: x$. & 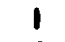 & & & \\
\hline & & $1 \times x !$ & $(x)$ & $(\dot{x})$ & $(i x)$ & 2 & & su: & \\
\hline 2113 & $\%$ & Ulo(x)(x)is & (x) & UI & 100 & 3? & & & \\
\hline & & onaxs & ixu & (11) & I (x) & 1 & & $3 \% 9$ & \\
\hline & is & & $\begin{array}{l}120 \\
0.1\end{array}$ & $\begin{array}{l}\text { U:. } \\
\text { Uil }\end{array}$ & $\begin{array}{l}\text { ONX) } \\
\text { IIN }\end{array}$ & $3 \frac{2}{2}$ & & & \\
\hline 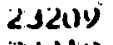 & (10.) & UU: & ix & us & 100 & $?$ & & 0 & \\
\hline & vil & & $1 x$ & ju & vois & 1. & & 0 & \\
\hline & $T_{11}$ & & wos & 10 & (xi) i & 1 & & .y & \\
\hline & i! & Nus & $\mathbf{Q u}$ & fu & $\operatorname{lix}$ & 1. & & 41 & \\
\hline & 01 & & $\left(w_{j}\right)$ & I.0: & $\operatorname{lox}$ & $\therefore$ & & 315 & \\
\hline & $7 !$ & & 00 & (10) & $f(x)$ & 1 & & & \\
\hline & 0.1 & & (N) & (4) & 100 & 1 & & $?$ & \\
\hline & 04 & $(0)$ & no & Iot & 10u & & & 12 & \\
\hline & 10 & & $\infty$ & ou & 104 & 4 & & & \\
\hline & 71 & !N & at & $(x)$ & 1005 & y: & & 4.1 & \\
\hline & oy. & vin & (2): & Quin & 100 & 1 & & ز5 & \\
\hline & 09 & ind & of & in. & 100 & 1 & & 10 & \\
\hline & 72 & & $\mathbf{w}$ & (10) & 100 & l. & & 34 & \\
\hline & 71 & $(x)$ & 10 & (x): & 100 & & & & \\
\hline & $7 \%$ & & $w$ & ix: & 100 & & & & \\
\hline & 72 & 000 & $\mathbf{0 0}$ & $\mathbf{w}$ & 100 & 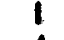 & & 14 & \\
\hline & $0 !$ & & is & ovi & 100 & 1 & & 50 & \\
\hline & o'? & & no & in & 100 & 2 & & & \\
\hline & 01 & & Ix) & ou. & 100 & 4 & & Ues & \\
\hline & $0 \%$ & & $\omega$ & (t) & .100 & 2 & & .10 & \\
\hline & $0 !$ & & $w$ & (x) & 100 & & & 23 & \\
\hline & (i) & $\mathbf{u}$ & ou & $\omega$ & 100 & t & & ju & \\
\hline & II & & Cu & or) & IIN & 1 & & 40 & \\
\hline & 10 & & (j) & (x) & 100 & 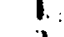 & & 71 & \\
\hline & $\pi$ & & 00 & (5) & Ix & ? & & (X) & \\
\hline & ע & & D & In & 100 & 2 & & & \\
\hline & 01 & & uU & Wu & (:N) & 2 & & & \\
\hline & (w) & & IN & uI & 100 & & & & \\
\hline & 10 & & $w$ & (1) & & 4 & & & \\
\hline & 10 & & in & Ut & & & & & \\
\hline & lis & & 141 & UI & love & 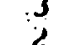 & & & \\
\hline & & $\mid(j \cdot \lambda)$ & U! & (iv) & Iisu. & (1) & & (i) & \\
\hline אים & & $(h): x ;) \cup(x)$ & UI & (h) & 100 & $\mathbf{J}$ & & 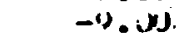 & \\
\hline
\end{tabular}




\begin{tabular}{|c|c|c|c|c|c|c|c|c|}
\hline A & B & C. & D & $\mathbf{E}$ & $F$ & G & II & I \\
\hline & uग & Uu: & (I) & ou & 11. & ? & & \\
\hline & OP. & (D) $)(x) !$ & & 01 & 106 & & & \\
\hline & 0.1 & ivis $10:$ : is & UI & (J) & 100 & 1 & & \\
\hline & iy & oi)(x; 1 uix & UI & 01 & 100 & $\therefore$ & & 4.143 .10 \\
\hline & ol & (1) & 10 & UI & 100 & & & \\
\hline & oll & 001 & 0:s & 01 & Iix & $\mathbf{I}$ & & I dos \\
\hline & קי7 & bue & 01 & U! & $\ln (x)$ & 2 & & \\
\hline & 01 & 0 & 01 & (1.) & 010 & & & 274 \\
\hline & 71 & $0: x$ & Uu & (1). & ind & 4 & & \\
\hline & ט9 & o:h & (ai) & 00 & $v(x)$ & 4 & & \\
\hline & od & Uix & (n) & $\omega$ & 000 & & & \\
\hline & uis & & ou & (N) & UiN & 1 & & \\
\hline J & ois & Q.). & 01 & (x) & 000 & 1 & & 315 \\
\hline & ن? & out & 01 & $\mathbf{\infty U}$ & $U(x)$ & 3 & & 72 \\
\hline & 71 & IN" & UI & $(x)$ & 000 & 4 & & 130 \\
\hline 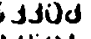 & $7 !$ & & wu & 10 & $f(x)$ & 2 & & \\
\hline תטג & $7 \%$ & & oi & (x) & 000 & 4 & 6 & 73 \\
\hline & io & isu & nu & 00 & (1) & 1 & & \\
\hline & oul & $O U(x)$ & 01 & $\omega$ & UI & 1 & & 11 \\
\hline & 10 & (Di) & ()) & in & & 1 & & 130 \\
\hline & 13 & Dor & IN & $w$ & $0(0)$ & ? & & \\
\hline & 12 & UU & 10 & Ou & nou & 2 & & \\
\hline & 12 & U() & $\mathrm{ON}$ & 100 & $O 00$ & 1 & & \\
\hline & 73 & OJ & (1) & OU & vix & 2 & & 132 \\
\hline & 01 & Uu & (1) & 10 & ocu & 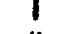 & & \\
\hline & 00 & Ou & 01 & 10 & oux & & & \\
\hline & od & נU & ov & (11) & vou & 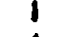 & & \\
\hline & u:j & & 10 & (i) & I & & & \\
\hline & 7 & & ev & Dis & 100 & & & \\
\hline & $7 !$ & & 00 & (i) & 100 & & & \\
\hline & 72 & & $(x)$ & WN & 100 & & & \\
\hline & 71 & & 100 & (u) & 100 & & & \\
\hline & 7? & & (x) & (D) & 100 & & & \\
\hline & 31 & & 01 & $w$ & 100 & 16 & & \\
\hline & $7 \%$ & & 01 & $\infty)$ & 100 & ?. & & 5 \\
\hline & 013 & & 10 & u. & wo & 6. & & \\
\hline & 07 & & Iu & (a) & 100 & & & \\
\hline & $0 !$ & & 10 & (w) & $U(\lambda)$ & & & \\
\hline & 01 & & 10 & (1) & 000 & & & \\
\hline & 03 & & (1) & 01 & Jidi & & & \\
\hline & 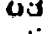 & & 10 & (iv) & 100 & & & \\
\hline & $0 ! 5$ & & 10 & U.) & & & & \\
\hline & ز' & & 10 & is & 0120 & & & 445 \\
\hline & $? 1$ & & 1)1 & IJ & Uu & & & \\
\hline & $\pi$ & & (x) & נ) & 10 & & & \\
\hline & 01 & & $(x)$ & (1) & I IN & & & \\
\hline & 12 & & טי & 10 & 100 & & & \\
\hline & $0: j$ & & $(x)$ & Io & IU & & & 1518 \\
\hline & 7\% & & (b) & $1 !$ & & & & \\
\hline & & & (अ) & & U & & & \\
\hline
\end{tabular}




\begin{tabular}{|c|c|c|c|c|c|c|c|c|}
\hline A. & $\mathbf{B}$ & $\mathbf{C}$ & D & $\mathbf{E}$ & $\mathbf{F}$ & $\mathbf{G}$ & II & 1 \\
\hline $400 \mathrm{~J}$ & 71 & 0:JUU I OIN & 0 & (b) & $1 ! x]$ & 4 & i32.11 & -4.00 \\
\hline $4(x) 4$ & نं & $0 . x) J \mid u(x)$ & du & (x) & $\ln (x)$ & () & 10.0 & -0.00 \\
\hline $5 a d i J l$ & 0) & (Ni) I IOUS) & no & (II) & U(N)J & 1 & & 93. 7.090 \\
\hline 34901 & 04 & 12,1100000 & 10 & (J) & (x) 1 & 1 & (1.2 & 2.20 \\
\hline $3440 \%$ & 64 & (fi) ( UUU, X) & 01 & (b): & $O(x)$ & 1 & & 45 \\
\hline $3+19$ & od & $(2) / 0() 0100$ & UI & $(\boldsymbol{N})$ & 1100 & ?. & Ju.0 & .30 \\
\hline $34 \% 04$ & oy & (2) I vursux & 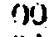 & (x) & IN & 1 & .0 & .16 \\
\hline .3490j & o: & (WI $000(x)$ & 01 & (x) & Int & 1 & 14.0 & 2401.05 \\
\hline 34800 & 07 & $0: 1 /(1) 0(x) 0$ & (i) & (0) & $11 x$ & 1 & נ!.|ز' & .95 \\
\hline $34 s$ & ou & $0(1)(00(x):)$ & 10 & (vi) & 100 & 1 & 10.0 & $1 / 1111.05$ \\
\hline OH & 73 & (N) Jixuld & o! & On & Nito & 2 & 1102.0 & 0041.95 \\
\hline & 12 & 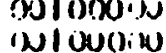 & 01 & Wi) & $\begin{array}{l}100 \\
100\end{array}$ & 2 & & 7149 \\
\hline & 71 & (10) & (I) & or) & 100 & I & $41 . ?$ & 1.11 \\
\hline & & JU/ (NoI)IKe & 01 & (w) & 10 & & & .37 \\
\hline
\end{tabular}


OPERATION AND MAINTENANCE: - GAS TURBINES:

Column A - Five-digit identification code

The first digit identifles: the plant by the Census Region in which it is located.

The second and thitrd digits are the state identification code. The state codes are numerically sequenced 01 to 50 and correspond to an alphabetical 1isting of the states. Code \#51 indicates the District of Columbia.

The final two digits denote the specific plant within a state.

Column B - Two-digit vintage: code

Year in which the plant: observed was brought into initial operation.

Column C - Eight-digit region code

Regional code constructed for analytical purposes. This code for the nine Census Regions is as follows:

$\begin{array}{lllllllll}\text { Region 1 } & 1 & 0 & 0 & 0 & 0 & 0 & 0 & 0 \\ \text { Region 2 } & 0 & 1 & 0 & 0 & 0 & 0 & 0 & 0 \\ \text { Region 3 } & 0 & 0 & 1 & 0 & 0 & 0 & 0 & 0 \\ \text { Region 4 } & 0 & 0 & 0 & 1 & 0 & 0 & 0 & 0 \\ \text { Region 5 } & 0 & 0 & 0 & 0 & 1 & 0 & 0 & 0 \\ \text { Region 6 } & 0 & 0 & 0 & 0 & 0 & 1 & 0 & 0 \\ \text { Region 7 } & 0 & 0 & 0 & 0 & 0 & 0 & 1 & 0 \\ \text { Region 8 } & 0 & 0 & 0 & 0 & 0 & 0 & 0 & 1 \\ \text { Region 9 } & 0 & 0 & 0 & 0 & 0 & 0 & 0 & 0\end{array}$

Column D.- Two-digit fuel type: code

Identifies the types of fuel for which the turbine was dssigned.

$\begin{array}{lll}\text { Oil } & 0 & 0 \\ \text { Gas } & 1 & 0 \\ \text { Mixed } & 0 & 1\end{array}$


Column E - Two-digit building code

Indicates the plant's construction type.

$\begin{array}{lll}\text { Conventional } & 0 & 0 \\ \text { Outdoor } & 1 & 0 \\ \text { Other } & 0 & 1\end{array}$

Column F - Three-digit operating code

Indicates the four different types of operation possible in gas turbine plants.

Semi-Automatic $\quad 0 \quad 0 \quad 0$

Automatic $\quad 1 \quad 0 \quad 0$

Manual 0110

Other $\quad \cdot \quad 0 \quad 0 \quad 1$

Column G - Contains the number of gas turbine units installed at the plants observed.

Column H - Indicates the total capacity of the plant in megawatts; the sum of the capacity of all units.

Column I - construction cost in $\$\left(x 10^{3}\right)$. The cost has been adjusted to a base year of 1975 .

Column J - Intermal code used for programming purposes only; indicates the number of years in which the plant was observed.

Column $\mathrm{k}$ - Net generation, in $\mathrm{kWh}\left(\mathrm{x} 10^{6}\right)$, of the plant in the year observed.

Columin L - Total Btu's $\left(x 10^{9}\right)$ of oil consumed by the plant in the year observed.

Column M - Total Btu's ( $\left.\times 10^{9}\right)$ of gas consumed by the plant in the year observed.

Column $N-$ Operating expense, in $\$\left(x 10^{3}\right)$, of the plant for the observation year.

Column 0 - Annual maintenance expense, in $\$\left(x 10^{3}\right)$, of the plant for the observation year.

Column P - Year in which observation was made. 


\begin{tabular}{|c|c|c|c|c|c|c|c|c|c|c|c|c|c|c|c|}
\hline A & B & C & D & E & $\mathbf{F}$ & G & II & I & $\mathbf{J}$ & K & L & M & $\mathbf{N}$ & $\mathbf{0}$ & \\
\hline & ?.? & I wo & Bis & or & & ? & 3.9. & $0 / 3<.20$ & 1 & क. 1 & 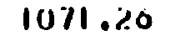 & U. & & & \\
\hline & uy & oolion & W & $0 \mathrm{~J}$ & 100 & a & 11.0 & D40.J.00 & & 4.1 .1 & & u. & & 13 & \\
\hline & & UUts) & $\omega$ & (u) & 100 & u & 410.0 & 43244.03 & 1 & 115.2 & 534 & & & 10 & \\
\hline إذ & 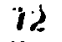 & D:k) uivi & bo & $0: 3$ & $1(x)$ & 1 & 23.0 & a101.105 & 1 & 3.1 & & & ؛ & 10 & \\
\hline & (i) & Jisoonol & 01 & 10 & 100 & 4 & 15.0 & اذاذ. U & 3 & 15.1 & j5 & 104, & & 44 & \\
\hline & 70 & UUUGikel & 01 & (1) & $11 x$ & 1 & 119.9 & lisuts.5s & 1 & 51 & 5. & 70. & 1 & & \\
\hline ? & 0.5 & ours ouixu & uo & 10 & 100 & 1 & 1 i. .0 & ט.2. & & 2. & 45. & 0. & 18 & 5 & \\
\hline 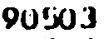 & & $w 0000(x)$ & 01 & 10 & 100 & 1 & 16.0 & 2011.43 & 1 & 11.0 & & 304 & & & \\
\hline 15t & & uociouves & 01 & 10 & 100 & 1 & 18.0 & 2445.00 & 3 & 1. & 5.84 & 123.0? & 1 & 03 & \\
\hline 5 & ד & & U1 & 10 & 100 & l. & 19.1 & 4201.00 & 1 & 78.1 & 10.110 & 1246.30 & & 43 & \\
\hline & 04 & & 01 & is & 100 & 1 & Iu.u & & & 121. & & 119.94 & 1 & 5 & \\
\hline & 12 & & $w$ & 10 & 100 & 2 & J9. & & & 6. & & & & 11 & \\
\hline ix & 00 & j00(N) & ou & iv & 100 & I & 13.6 & & 3 & 0.0 & & u. & & & \\
\hline & 01 & & 01 & O0 & ons & 1 & 10.3 & & & 10. & & 42.18 & & & \\
\hline 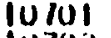 & ay & & 00 & 10 & $\operatorname{l} 100$ & $!$ & 10.0 & & & 11.5 & & & & & \\
\hline & 09 & I Ucivi & 00 & iv & f(x) & $j$ & 03.6 & od & 3 & 24.11 & & & & 219 & \\
\hline 1 & $\infty$ & 100 & $(x)$ & (i) & 100 & 1 & 10.3 & & & j.3 & & & 11 & $y$ & \\
\hline 510 & 09 & I Ucnovo(x) & 00 & (1.) & 100 & 1 & 10.0 & 1002 & 3 & 10.0 & 101 & $u$ & 4 & 10 & \\
\hline & oo & & no & 10 & 100 & I & 10.3 & & & & & & 4 & (jl & \\
\hline & od & & wo & 10 & 100 & 1 & 10.0 & & & 6.? & & & 4 & 39 & \\
\hline & O: & 1000 & 00 & iv & 100 & 1 & 18.0 & & $J$ & 13.1 & & u & 11 & 10 & \\
\hline & bo & & $\omega$ & 10 & 100 & 1 & 18,0 & 2.1 & & & & & I & & \\
\hline 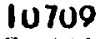 & 01 & 1050 & $\boldsymbol{w}$ & $\infty$ & 100 & 1 & 15.0 & 2302 & & 0.1 & $\dot{y}$ & u & 0 & 17 & \\
\hline & oid & & 00 & 01 & UINU & 1 & 111.0 & & & & & & ? & 19 & \\
\hline ע & 05 & & 01 & 01 & 000 & 1 & 15.0 & & & 6.9 & & u & v & 25 & \\
\hline & 01 & & ou & is & $u(x)$ & i & 111.0 & & & 13 & & & 0 & 24 & \\
\hline Jo & 04 & & 00 & 10 & 100 & 1 & 14.0 & ز & & 4. & & 0 & 1 & 4 & \\
\hline vido & o? & 00001000 & $\omega v$ & UI & 000 & 1 & 11.7 & 10.11 & 3 & 3. & & u & 0 & 24 & \\
\hline & 0. & & 01 & UI & ous & 1 & 20.2 & $|4|$ & & 10.0 & & 0 & & 12 & \\
\hline & od & & $\infty$ & 0.5 & 100 & 10 & 2:lH.0 & 2785 & 3 & 80.4 & 146 & u & d & 230 & \\
\hline ה & of & vou & 01 & Us & 100 & 2 & 07.6 & & $\mathbf{J}$ & 75. & & 131 & 7 & 300 & \\
\hline & 18 & & 100 & (.) & 100 & 4 & 222.0 & & & Jbs. & & U & 34 & 107 & \\
\hline 100 & $7 u^{\circ}$ & (x) & .100 & (N) & 100 & 1 & 19.3 & $|t|$ & : & 15.4 & & 0 & 1 & $y$ & \\
\hline$j$ & 70 & & 100 & (1). & 100 & 1 & 14.3 & & & & & 0 & 0 & 10 & \\
\hline b & 10 & & w0 & ou & 100 & ? & J13.0 & $34 !$ & 3 & $3 \%$ & & & 3 & 43 & \\
\hline & 71 & vo & 01 & $(\omega)$ & 000 & 24 & 4. 1.5 & & & & & Ju & 338 & 3183 & \\
\hline & 71 & & 01 & $\infty$ & 000 & $1 \%$ & 410.7 & & & & & 20 & 111 & & \\
\hline & 71 & & 10 & (x) & 1000 & 1 & & 41 & $j$ & & & $u$ & 10 & 170 & \\
\hline & 09 & & $\infty$ & 10 & $u(x)$ & 1 & & & & & & $\mathbf{0}$ & 2 & 10 & \\
\hline & oy & oor & 100 & IJ & oOu & 1 & & & 3 & & & 0 & 3 & 75 & \\
\hline 192 & 00 & diso & 01 & UI & vou & 2 & & & & & & & & Jy3 & \\
\hline & 70 & & 01 & 01 & uixu & ? & & & & & & & & 485 & \\
\hline 10 & 71 & & IN & UI & 000 & 1 & 41. & & & 11. & ניק\% & u. & 21 & 13 & \\
\hline & 11 & & & 01 & $0(x)$ & 2. & 113.7 & 1044.20 & & 118.4 & & 1 jbo. 14 & 20 & $2: 10$ & \\
\hline & 1\% & & $(x)$ & $0 !$ & 100 & ;) & $4 y_{i j} .6$ & 41749.10 & 3 & 500.4 & & 0 & 49 & 94 & \\
\hline & 71 & ouirsloos & 00 & 01 & (x)o & 3 & "נ.ניגו & $1 / 333.93$ & & 130.1 & & & 10 & 4 ס 4 & \\
\hline & 11 & 0000 & 01 & (2) & ow & 3 & 10.13 & & & 50.4 & & & 14 & 14 & \\
\hline & oy & & UI & (n) & 000 & 1 & IU. & & & 0.11 & 134 & & 11 & $v$ & \\
\hline & & & & & (1)(4) & & & & & 1.5 & & & 3 & 14 & \\
\hline & & & & & 00 & & & 10 & & 230.4 & 3.01 & 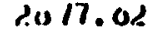 & 54 & Jy & \\
\hline
\end{tabular}




\begin{tabular}{|c|c|c|c|c|c|c|c|c|c|c|c|c|c|c|c|}
\hline Fl & $\begin{array}{l}0.17 \\
18\end{array}$ & 1 & & 511 & 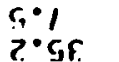 & 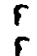 & 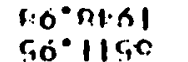 & $\begin{array}{l}n \cdot 81 \\
0.1 ! 1\end{array}$ & 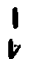 & (1) & 3 & no & & 180 & \\
\hline & n: & & in & & $n \cdot 6 i$ & & bo. & 0.01 & & 101 & 10 & (v) & rysti(y)ni & $: 0$ & nI 7.1 \\
\hline$i$ & 1.1 & & 0 & $|P|$ & . 6.1 & & $9.7 \cdot 7801$ & $0 \cdot 11$ & & 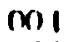 & in & (x). & rumornin i & 60 & molel \\
\hline$\xi_{i}$ & rn! & 11 & $\because$ & $\ln t$ & 1 ห? & & $F: F^{\circ} \mid I B F$ & 1. ar & & 1) 1 & ni & $C()^{\circ}$ & $n(x)() \operatorname{con} i$ & $1 L$ & (1) \\
\hline$F$ & $n !$ & & $\cdot n$ & P 1 & $\varphi^{\circ}$ OF & & $r \cdot$ tipt & 0.28 & & n) 1 & CI & $(x)$ & 0.1 & $0 L$. & $1 \%$ \\
\hline 61 & or & n & $\because$ & 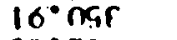 & $0 \cdot 5 ?$ & 1 & $\mathrm{rl}$ or er & nent. & 7 & 101 & (1) & (n) & nI & II. & \\
\hline f & 7. 1 & 7 & 0 & & $f \cdot r$ & $\Sigma$ & nonol & $7 \cdot \bullet 1$ & & 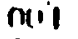 & 60 & nn & & 60 & \\
\hline F & 2.1 & 7. & n & $P^{\bullet} t 6$ & 1.0 & & OC̣ " OKE? & $n \cdot n 1$ & & mI & $m$ & (x) & & 00 & \\
\hline E & Op & 20 & $\because n$ & • & $p^{\circ} 01$ & 1. & 5606 & $0 \cdot 2.0$ & & (I) & (x) & $n !$ & & $n L$ & \\
\hline & $6 L$ & 8.0 & 0 & irol & ! ‘ ? & & $G S_{1} \cdot r, n l .8$ & p.raz. & & $x \mid 1$ & r.o & (O) & & 60 & \\
\hline & ne & 7 & 0 & 0・・b & $\mu^{\bullet} 2$ & & (1) & c I & & nI & $m$ & (n) & & 10 & \\
\hline r. & 061 & 1 & 0 & - $9 l$ & $x^{\bullet}:$ & & 16 & $3 \cdot 91$ & & nril & (n) & n: & 00 & 19 & \\
\hline$F L$ & S & o & -n & - 601 & $1 \cdot 7 !$ & & & $0 \cdot 01$ & & (M)n & "I' & no & & pon & \\
\hline & $\mathrm{HI}$ & Pl & $59^{\circ} \mathrm{r}$ & • & $1^{\circ} \circ \varepsilon$ & & & $5 \cdot|7|$ & 1 & $n(n) 1$ & $m$ & no & & no & 7.5 \\
\hline & $0: 1$ & $1 \%$ & $\because 0$ & $5+2$ & $x^{\bullet} \bullet 1$ & & 7. (1.7.14: & & 1 & xil & $n !$ & no & & $\angle 0$ & \\
\hline 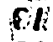 & mf: & 18 & $\cdot n$ & $\because 01 n 1$ & r.co & $\varepsilon$ & $r e \cdot 5 \circ 6 t$ & ?.1. & $b$ & & nI & (M) & & ne & \\
\hline$\varepsilon$ & 091: & 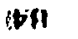 & $\cdot n$ & n6. 45 or? & $6 \cdot 10 \%$ & I & $10^{\circ}$ Gsinfr. & $4 \cdot 7.17$ & $b$ & nI & 01 & on & & 21. & $7 ?$ \\
\hline 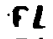 & 269 & . 6 & $2.0 * 0609$ & & 1०cr. & {[} & $\forall 0^{\circ}|T, G \vee|$ & $0 \cdot 51 \cdot 1$ & b & on & n! & 01 & & 60 & \\
\hline 5 & $n$ & $n$ & 'n & $50^{\circ} \mid 18 ?$ & $\bullet 1$ & & ọ̣ & 91 & & 001 & 01 & $n$ & & 10 & \\
\hline ? & ؟ & $\mathbf{0}$ & in & RG` ZE. & $0 z$ & $\boldsymbol{c}$ & je. & $G 5$ & ?. & non & nn & mo & & $0 \ell$ & \\
\hline . & $n ?$ & $\ell$ & $50^{\circ} \mathrm{n} / \mathrm{n}$ & GAt*6 & 69 & 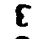 & 11 & 8. & & in & $m$ & in & & 11. & \\
\hline$L$ & $\boldsymbol{\Gamma}$ & $\boldsymbol{r}$ & n? & & & 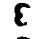 & & 91 & 1 & 1 & CO & n! & & 69 & \\
\hline$L$ & ?. & ' & $\bullet 1$ & -n & & ? & $O V$ & 01 & 1 & 001 & $m$ & 01 & & no & \\
\hline 2 & $E E$ & ถุต & 1.1.6 & 60.610 & $1:$ & 1 & CLI & $\varepsilon \subseteq$ & ? & In & ris & 10 & & 2.2 & \\
\hline$E$ & 1. & $i$ & .661 & $65^{*} \mid 1$ & & r & & & 1 & on & DO & 10 & & $r: L$ & \\
\hline .2 & $L$ & 1 & 6 & & & r. & $6 t$ & 1.1 & 1 & nol & (x) & n! & 0 & 60 & \\
\hline 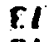 & nI & 9 & & $C 7^{\circ} \mathrm{OL}$ & & & \$?.1 & 98 & ?? & on & 01 & In & (:0 & 60 & \\
\hline 1. & AbV & 91 & & $61 \cdot 19$ & & & p.1 & 02.1 & f & m! & 10 & 10 & no & 10 & \\
\hline II. & 21 & $\varepsilon$ & & & & 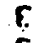 & & 10 & $b$ & $00 !$ & $m$ & $n$ & 200 & po & \\
\hline 1. & IE & p & & $n L^{\circ}<07$ & & & 8 & 10 & $p$ & m! & (1) & 10 & 200 & $0 L$ & \\
\hline I. & $\mathbf{A}$ & 1 & & & & & 7.5 & 8.7 & $?$ & On! & nI & nI & m & 60 & \\
\hline SI. & 67 & P & $60^{\circ} \mathrm{GS}$ & $79^{\circ} \mathrm{os}$ & & r. & I $9 n r_{1}$ & $1 \circ \mathrm{rc}$ & 1 & nol & 10 & in & 0 & 11. & \\
\hline I. & $0+1$ & 1 & & n! & & 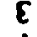 & 1.01 & $0 * 10 !$ & 0 & mn & $\infty$ & (x) & $\mathbf{0 0}$ & Fo & \\
\hline 1 & OV & $\downarrow$ & & ค!, & 7 . & & nnz.I. & (1) 8 (11) & 7 & $\operatorname{lnot}$ & $\infty$ & $m$ & no & ? 1. & \\
\hline 1 & r.o & 89 & $G^{\circ} r, n$ & $9 \zeta^{\circ} \mathrm{DS}$ & & $\boldsymbol{E}$ & 8.970 & $2 \cdot 7 !$ & $\xi$ & no! & $\infty 0$ & In & & 10 & \\
\hline$r$ & EIf. & 97. & I. & & & & $67^{\circ}$ or,as & $x^{\circ}+1$ & 1 & $\mathrm{mI}$ & $m$ & 10 & $m$ & 120 & \\
\hline r. & n? & $t$ & & & & & nf: 1.161. & $c^{\bullet}+1$ & 1 & mon & in & $I_{1}$ & n & no & \\
\hline$r .2$ & 6 & $b$ & & 27.1 & & & 7.TOY & r.GI & 1 & mn & 10 & $\mathbf{n}$ : & $(x)$ & HOr & \\
\hline C. & ni & $b$ & 0 & & & & $00 \times 1$ & & 1 & noo & 10 & $x:$ & & p.o & \\
\hline$t$ & 60 & 1 & 0 & & & & niti & $0 \cdot 07$ & 1 & (x) 1 & 00 & no & & 10 & \\
\hline 12 & 0.0 & $?$ & 01.7 & - PIII & p? & $f$ & 60.00 & $n \cdot 10$ & $b$ & mI & $m$ & 10 & & $n L$ & \\
\hline$E$ & olp & ?.? & $\cdot 0$ & - $5.91:$ & nv & $\varepsilon$ & GRIEE I & $0: \forall, c_{1}$ & 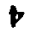 & col 1 & CI & $n$ & $n x_{1}$ & po & \\
\hline & t.f. & 2.0 & & - 5001 & b\%. & & $a p ! \mid+1$ & 1.001 & !! & mI & 01 & 10 & DO & $n l$ & \\
\hline & cor & r,01 & $\cdot 96$ & $C_{1} R^{\bullet}$ IF & $8^{\circ} 61.1$ & 5 & $r v^{\circ} \mid 1092.1$ & o•ir I & $?$ & $0(1) 1$ & nI & in & & no & \\
\hline & 091 & i.?. & .7 .11 & $00^{\circ}$ OSBI & 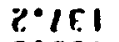 & E. & fporngel & 0.1 .01 & r! & nil & 01 & 10 & (1) & 69 & \\
\hline & $0 ? .1$ & & & $4.7^{\circ} 6618$ & $\boldsymbol{\varphi}^{\circ}$ & ह. & Tol a I cister & $11 \cdot 0 \mathrm{n}$ & pi & OnI & n & 10 & m) & HO & \\
\hline & 100 & & & $68^{\circ} 8698$ & $1.0 ?$ & C & $11^{\circ} 00060 \%$ & bor & ! & 01 & $r .1$ & In & 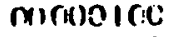 & II. & \\
\hline & & & & - cuar & & & $21018:$ & $n \cdot \ell n$ & 21 & (x)i & r. & 10 & no & 110 & \\
\hline & & & ת. & ? & $6^{\circ} 578$ & t. & 107.1 .7 & I I RC & 01 & $\mathrm{COt}$ & 111 & in & 20000101 & $n !$ & \\
\hline
\end{tabular}
d $\mathbf{O} \mathrm{N}$
w
7 .
$y \quad f$
I
II
$?$
a 9
J
ด $\forall$ 


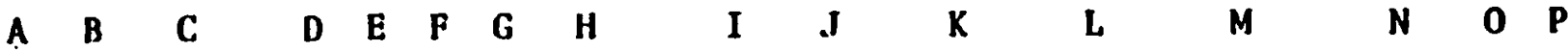

13.11\% oy 100000110 ou ol 100 32201 os ixilo0000 id ij) 100

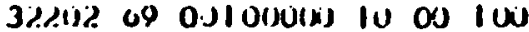

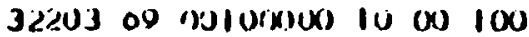

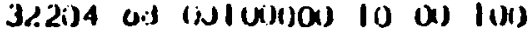

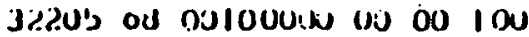

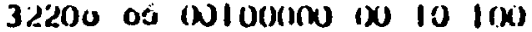

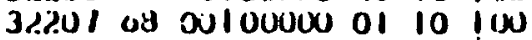
3220d os udiocineus on 10 jou 42341 of UINIINON 100 UI UIX

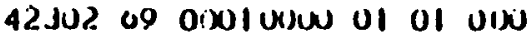
12303 7\% $0(x) 10010$ ix ol $0 i 10$

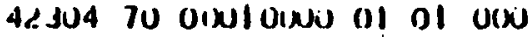

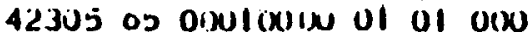
0240170 v01X001:20 01 Us 100 62402. ol 0xuixulu io (1.) 000 0240371 avoriol (x) of ix) 100 42501720 oiv1 0000 on 111 1100 42'ju? o7 $0 ; x) 1(x)(x)$ iv (2) 000 42701472 kix 82008. 70 00000ixl 10 (20 100 12901 oy 1J00000's as as aixo

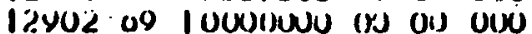

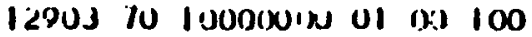
1290.1 od . I verivisex ov us wo

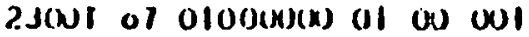
$23(x) 2$ oy 0101$) 0(3)(x)$ in ix ilo

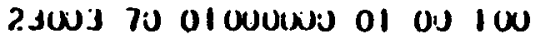

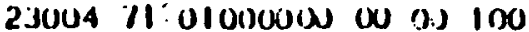
$251000 \quad 72$ UI UCUO)O (x) (x) 100

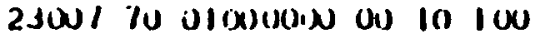
$2360 \mathrm{~d}$ of uluisueso 1010100

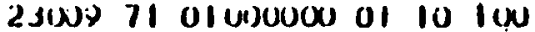
23010 ol ulo0030u ui 0:j 110

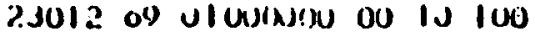

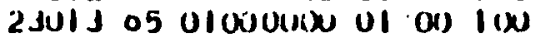
83101 of Oevorsixil io bo 100 $2.520170 .0100001 x$ on oj I(x) 2320\% oy v100(x)ix ul uil 100

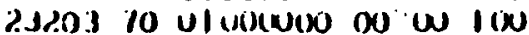
232.04 oy v10081010 (10. 00 100 2320571 vlo00iils ou UI I00

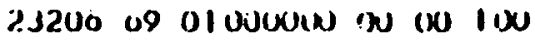

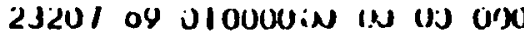
2.521) 72 Ui UinOiW ol UI INO

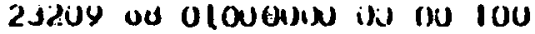
23210 o.s vivonis:x) ix w vos

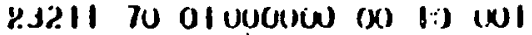

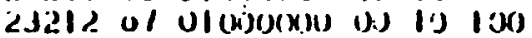

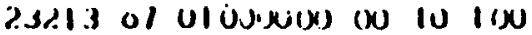
iv.0 2100.513 उ5ic 30.14.11:3 29.02214 .403 20.0 2141.22 .1 20.0 ilu4.413 $04.05421 .54 J$ 10.0 14.40\%.04 3 44.0 volol.05 3 $30.0 \quad 1450.403$ 12.0 74y.j.2. 3

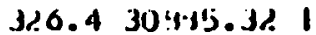

12.0 juyd.1.3 3 413.57004 .153 41.93741 .6013 .13 .2 vis? 1.553 41.4 40151.413 2100.04157 .101 11.8 3453.80 3 $2110.1110142 . j^{3} j 3$ 10.3 19isis. is 3 2 J1.2. 3114.4I 3

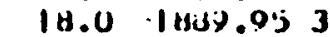
21.3 208.4.4/ 3 10.0 1892.115 3 1 I. 1.0 T.J.J15 3 1. is.8 $004 / .153$ 4 จ5.? 10000.50 3 $\begin{array}{llll}136.8 & 154 \% .13 & 3\end{array}$ $212.42 .81320 . i 141$ 42.54205 .103 10.6 $201 \% .143$ $1502.24,31 / 4.313$ I $11 \% .216310 .1 \% 3$ I 10.01759 .513 I 115.2 15.50 1.50 3 111.31057 .743 21.3 101 1.1593 21.3 10119.2.5 3

$10.3-0.003$ 34.2 bosj.ds 3

0.50 .0

10.0 Q.1.0 303.1 ? 11.2 19.1 1 . 1.1

1 (1).1) 10.0
$-9.100 .3$ .390 .613 1130.0\% 3 $-0.001$ OU.ग1.02 3 2104.04 1 . 101.923 2230.1343 19115.313
$12.8 \quad 1.13 .31$ $24.2 \quad 340.03$

ง!j. 3

(i). 4

27.0

21.9

45.1

11.5

10. 0

4.0

17.4 .9

112.0

$13 \% .0$

50.3

$3 \% .0$

2.j.

$3 ! j .0$

47.4

41.4

17.1

4. .4

47.3

10.5

10.2

11.4

16.1

19.0

109.9

324.3

453.7

2.1 .0

14.2

J'ji. 5

24.5

6.3.

u.

192.1

764.73

$17 \% .04$

700.59

90.915

$25 j .69$

4140.23

201.55

149.69

25.31

0.

200.05

001.41

0.

71.34

0.

?.4\%. 17

174.00

0.1 .30

$15 \% .91$

I5. dI

281.09

$19 \% 1.01$

45115.15

0.144 .15

291.35 :

$$
9.01
$$

5053.44

$\therefore 400.04$

$32.01,5150.310$

5.6 : 11.

14.0 203.42?

$27.0 \quad 14.39$

10.2 286.31

$25.040 \% .94$

1011.1 I UR.340.42

$10.32 \% .45$

15.? $21 j .55$

$123.010 \% 15.11$

$34.0 \quad 323.06$

$0.4 \quad 3.01$

$10.4 \quad 210.23$

$1.4 \quad 111.19$

I.3 13.11
0.

$13 d 1 ! .97$

$100 . \% .70$

349.04

0.

0.

1.01

u.

$U$.

$1 / 152.98$

$u$.

1949.80

104.01

479.60

4011.73

2.5 .94

0.

054.51

909.513

009.49

0 .

(1).

$|3| .00$

$u$.

247.82

$u$.

712.04

$\therefore 0$.

$\because 0$.

2.57 .40

90.01

$3: 72$

0.

$21: 82$

104.10

0.

Jo1.u9

0.

0.

u.

0 .

Ijod7.1 404

ט.

0.

0.

0.

0.

II) 13

18.13

$20 \quad 13$

15073

2.2 13

14473

$232 \quad 13$

3113

21073

53 75

11573

10373

20113

50573

25 o0 15

o. 21 is

$20 \quad 3473$

$24 \mathrm{IJ}$

Id 13

7571

973

10073

If 73

4873

$13 \quad 111.13$

$10 \quad 25 \cdot 73$

$55 \quad 4673$

10 00073

ó 3037.1

21 33\% is

30 7a 13

134273

235271373

$3951 \% 73$

$\begin{array}{lll}8 & 20 \%\end{array}$

2104473

313

12113

15. 73

157071

Iy 11273

$430 \quad 164375$

$\begin{array}{llll}29 & 104 & 13\end{array}$

10673

410.11

j5 73

11013 

A. H
C D E F
G $\quad$ I I I
K E
H
$\mathbf{N}$
O P

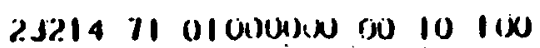

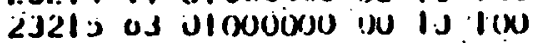
23210 on is/(H),x):4) ox 10 lix 2321110 ulurnosis in a0 100 23219 ay vivou(s) on (x) 100

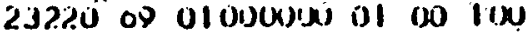

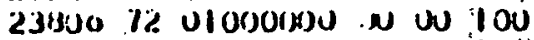
2.Sdu/ 71 ulfus(x)iso to w itxis $2 j$ ouj 72 Ulomijuin of (x) 100

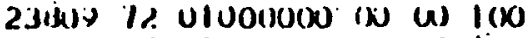

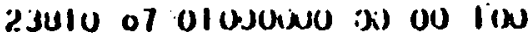
23411 ay 010000.25 is ind 100

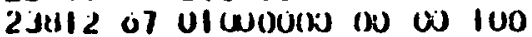

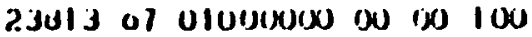

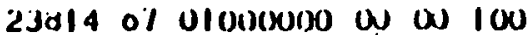

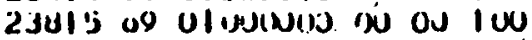
23810 II U10000ix wo ov 1110

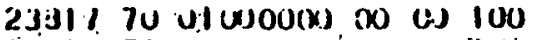
j.jula 71 jlovonson' ov ov '1 vis 23819 oy olotow(x) we ox 100

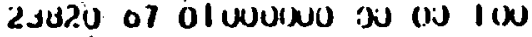

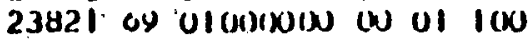

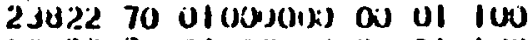

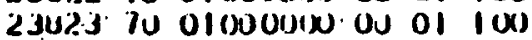

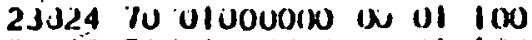

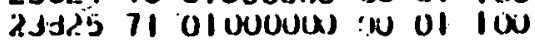
$541 \times 01$ II UOCUIOOJ OI UI) IDX) 54002 od visinluisu 01 as $\mathrm{I}(x)$ $54(x) 3$ oy $00(x) / 0(x)$ (11 200 iou 541K) o? Uisoulo:N UI ol 100 jalx'j of orxouluox ol ot 100 $54(x) 0$ of enix)lory ul ol 100

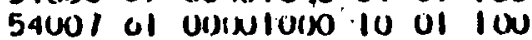

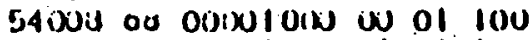
540009 12 00ivolocixs ol of 100 44101 ol oxvouvin ol 00 ula 5330171 000islous os 05000

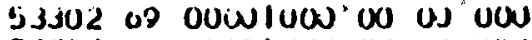
$5 j 301$ ou oOnoluin ov nis (i)is 53.104 os uU(x) $/ 0: x)$ ou les u.0 $53507 \%$ ouxulvive ol $(x)$ vixs

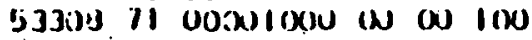

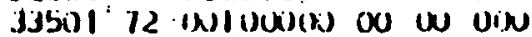
3350\% 00 ojs $100(1) 130$ ov ov 100

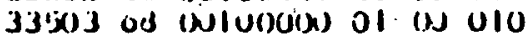

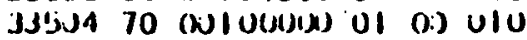

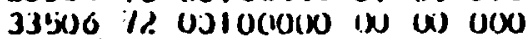

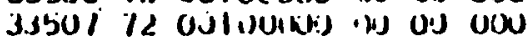
3j50y ol oulonisos ov lil vol) 33510 oo (x)IU(xi):xo (ol l.J vix)

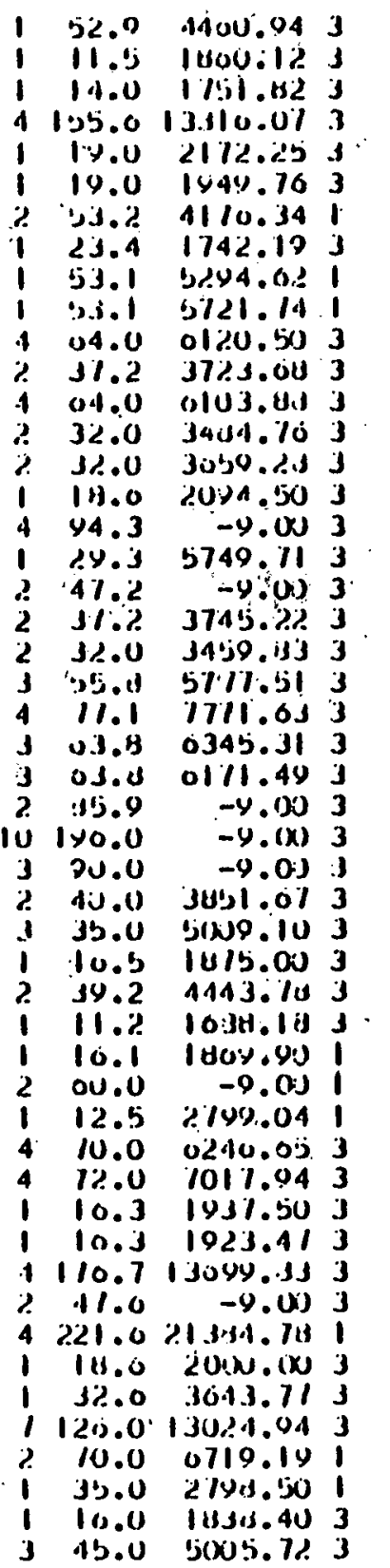

34.

1.8

0.1

il. 4

4.1

4.7

45.0

54.3

$-47.5$

34.1

41.5

13.4

37.0

7.0

13.0

1.11

u5. ?

0.1

211.8

17.1

10.9

15.2

24.3

2.0 .0

30.0

19.8

AA 1.0

105.4

11.0

0.1

2. 8

13.4

1.3

0.2

31.0

17.1

22.0

23.7

1.0

1.2

33.1

16.8

121.15

?.

23.15

06.13

$4 \% .0$

19.9

2.1

14.1
459.10

95.32

(1) . . 44

185.21

ors. 110

70.00

021.3 ?

u.

602.43

154.93

614.415

2215. 16

586.04

115.24

223.70

21.21

1221.11

41.10

3150.01

210.12

253.04

214.35

311.71

300.94

3U'j. 4'

304.16

3.322 .60

108.34

194.33

0.90

0.40

5. 10

0 .

1j. 100

104.91

IU.00

501.73

402.22

10.17

20.40

481.30

113.40

1504.04

32.40

IJ.bo

9013. 10

044.915

253.65

30.114

116.50 $u$.
$u$.
$u$.
$u$.
0.
73.24

(a) $3: 30$

0.

u.

0 .

u.

u.

o.

u.

o.

0 .

0 .

0 .

o.

0 .

(1.

is.

0.

0.

0 .

4300.41

1197.11

1.13

.133 .54

41.182

2. 50.00

29.41

0 .

$504.10)$

2015.00

0.

: 6.

o.

38.07

0 .

0.

0.

| j.2 |

19.33

0 .

0 .

0.

147.00
18875

50 is

4513

01013

613

413

4373

15313

21073

42873

$170 \% 3$

If 73

31 73

15173

$\begin{array}{lll}40 & 13\end{array}$

10513

I 5o 73

1013

2473

1413

$32 \quad 13$

10573

19713

13073

32073

0413

744 IJ

$47 \% 3$

$1 / 473$

1113

16071

13273

5 13

$5 \mathrm{ll}$

1073

10073

4473

- $167 \mathrm{~J}$

7573

$34 \quad 13$

.14573

26011

1673

073

0473

32073

25 13

3173

1573

1013 


\begin{tabular}{|c|c|c|c|c|c|c|c|c|c|c|c|c|c|c|c|}
\hline A & B & C. & D & $\mathbf{E}$ & $\mathbf{F}$ & G & H & 1 & .J & $\mathbf{K}$ & L & M & $\mathbf{N}$ & 0 & \\
\hline & 0 & & O() & Iu & 1000 & 1 & 14.0 & 2010.19 & $\mathbf{J}$ & j.3 & 101.04 & & $\boldsymbol{J}$ & & \\
\hline & & & 10 & (0) & 100 & 4 & 00.0 & o: & 3 & 5. & $\$ 5.41$ & .041 .00 & 11 & 100 & \\
\hline 40 & & OI(J)evos) & (x) & (i) & I Ois & 1 & 14.0 & $200 \% .0 .1$ & .1 & 13.4 & 202.831 & u. & 19 & 13 & \\
\hline & & ט & $(x)$ & 0)$. & 100 & 3 & 6. 18. & עי . & $\mathbf{3}$ & زن. & 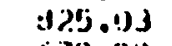 & o. & 3.1 & Bu & \\
\hline & 12 & 01000000 & ov & (x) & 100 & 2 & 2.ذנذ & $42+0.50$ & 1 & 40. & 619 & u. & D.9 & H & \\
\hline dO & $7 !$ & & ov & us & 100 & 1 & 14.0 & 10.02 .01 & 3 & 17. & & u. & 10 & 25 & \\
\hline su & 12 & O I Iovovis & Uis & 00 & 100 & 1 & 19.0 & 2240.24 & 1 & 25. I & & u. & 10 & 30 & \\
\hline 0 & 12 & & UI & wo & I(:) & 20 & 0.20 .0 & ذ'ט. 7.48\% & 1 & 138.2 & 1011. & 940.14 & 02 & $|3|$ & \\
\hline 30 & $\begin{array}{l}\text { od } \\
\text { ol }\end{array}$ & 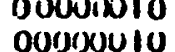 & 10 & $\begin{array}{l}\text { Ou } \\
\text { ou }\end{array}$ & $\begin{array}{l}0(x) \\
000\end{array}$ & i & 90.0 & -0.00 & 3 & 0 & u. & $115.3 d$ & u & 14 & 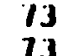 \\
\hline 4 & 07 & ou(x)ixilo & 10 & $\omega$ & $1 \times 0$ & $i$ & 10.3 & -9.00 & 3 & 1.3 & $\begin{array}{l}0 . \\
0 .\end{array}$ & $\begin{array}{l}24.20 \\
24.20\end{array}$ & $\begin{array}{l}0 \\
0\end{array}$ & & $\mathrm{~J}$ \\
\hline$j i$ & 07 & 000 & 10 & ois & ouv & 1 & 10.3 & -4.150 & 3 & 1.1 & 0 & 23.134 & u & $\theta$ & \\
\hline & 0.3 & (N)on) & 01 & U! & 000 & ? & د. & -9.00 & 3 & 6.4 & 20.73 & 100.60 & 47 & 10 & \\
\hline & ols & Oưve & 10 & 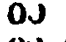 & vov & 3 & 49.0 & 5igis?.tso & 3 & 37.0 & 0 & 030.82 & 2 & 10 & \\
\hline 40 & $\begin{array}{l}0 j \\
03 \\
71\end{array}$ & 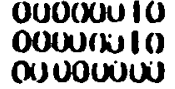 & $\begin{array}{l}10 \\
10 \\
01\end{array}$ & $\begin{array}{l}0.3 \\
00 \\
10\end{array}$ & $\begin{array}{l}010 \\
\text { Jno } \\
\text { O1X }\end{array}$ & i & $\begin{array}{l}13.3 \\
130.0 \\
10.0\end{array}$ & & $\begin{array}{l}3 \\
3 \\
3\end{array}$ & $\begin{array}{r}100.4 \\
204.4 \\
0 \% .2\end{array}$ & $\begin{array}{c}0 . \\
0.0 \\
290.12\end{array}$ & $\begin{array}{r}1050.80 \\
3541.34 \\
949.35\end{array}$ & $\begin{array}{l}34 \\
72 \\
0.4\end{array}$ & $\begin{array}{r}11 \\
153 \\
70\end{array}$ & \\
\hline ECO & 71 & 1001300000 & WN & 0.0 & 100 & 1 & 20.0 & $200 \% 10$ & 3 & 9.0 & 1413.05 & o. & is & 115 & $i$ \\
\hline & 01 & 10000 & $\mathbf{\infty}$ & 10 & 1100 & 1 & 13. & Iu: & & b. & & 0. & 11 & 25 & \\
\hline & 71 & & ov & 10 & 100 & I & 48.0 & 3304.52 & & 42.0 & 581.31 & 0 & 12 & 19 & \\
\hline & cj & 10000000 & 00 & 10 & 100 & 1 & 17.0 & 18111.9 .5 & 3 & 0.0 & & u & 9 & 11 & \\
\hline & 12 & & $\boldsymbol{w})$ & (10) & lov & I & 21.0 & $-y .00$ & $!$ & 23.3 & .336. & 0 & 0 & 14 & \\
\hline & 71 & Ur(x) & ou & $w$ & 100 & 4 & 12.11 & $-y .00$ & \} & oss.! & 107 & o & & & \\
\hline & 11 & OUIN & ou & $(x)$ & $I(x)$ & 4 & U.. & -8.00 & & 61. & & 0 & 4 & 15 & \\
\hline & 03 & $0000^{\circ}$ & $\alpha v$ & $(\mathbf{0})$ & 100 & 0 & 90.0 & -4.00 & & 90.5 & $1602 ! .04$ & $\mathbf{0}$ & 6 & OH & 13 \\
\hline & 07 & Ooxu & $\omega$ & w & $v(x)$ & 1 & 10.0 & 201. & & 0.4 & 41.02 & 0 & & & \\
\hline & 09 & & 10 & O) & wI & 1 & 2. 2. & $210 \% \cdot 2^{\prime \prime}$ & 3 & $3(1) .1$ & u. & 519 & 10 & II & \\
\hline & 04 & oulo & 0I & w & 000 & 1 & 13.1 & $224 \% .45$ & 3 & 2. & 2.09 & & & 12 & \\
\hline & $\begin{array}{l}0 d \\
00\end{array}$ & Wuld & 01 & $\infty$ & 100 & 2 & 10.0 & 1.30 & 3 & 24.7 & 10.18 & 308. & 12 & 15 & \\
\hline & $\begin{array}{l}09 \\
011\end{array}$ & (N)IO) & Ou & $(x)$ & $\log$ & ! & 19.0 & ج 105.10 & 3 & J. & & o. & 20 & 119 & \\
\hline & $\begin{array}{l}013 \\
01\end{array}$ & $\begin{array}{l}\text { woloc } \\
\text { ovive }\end{array}$ & $\begin{array}{l}01 \\
10\end{array}$ & ov & $\begin{array}{l}100 \\
100\end{array}$ & 1 & $\begin{array}{l}19.0 \\
57.5\end{array}$ & $\begin{array}{l}2401 \\
\text { J4U1 }\end{array}$ & 3 & & $\begin{array}{l}19.0 \\
0 .\end{array}$ & & $\begin{array}{r}19 \\
3\end{array}$ & $\begin{array}{l}40 \\
14\end{array}$ & \\
\hline & os & (1:)10 & iu & OUJ & 100 & i & 19.0 & $170 u$ & 3 & 25. & 0. & & & & i. \\
\hline & 71 & Noloourns & 01 & $\omega$ & 100 & 1 & 40.3 & 3819.11 & $J$ & 14.9 & 111.32 & $94 \%$ & 1 & 122 & \\
\hline & 09 & ojus & $\mathbf{0 u}$ & 0 & 100 & 2 & 47.0 & & 3 & $5 \%$ & & 0 & 33 & 30 & \\
\hline & 10 & Ou(1)' & is & ou & 000 & 1 & 21.3 & & & 24 & & & 6 & IUS & \\
\hline & 71 & & 01 & $w$ & I00 & 2 & 41.2 & & : & $\begin{array}{l}19 \\
20\end{array}$ & 2 & 241.93 & 11 & 28 & \\
\hline b) & $\begin{array}{l}70 \\
70\end{array}$ & $\begin{array}{l}\text { o:xuc } \\
\text { ovon? }\end{array}$ & $\begin{array}{l}01 \\
01\end{array}$ & $\begin{array}{l}10 \\
15\end{array}$ & $\begin{array}{l}100 \\
100\end{array}$ & 4 & 15.0 & & 3 & 20. & $\begin{array}{r}15 \\
2\end{array}$ & & & 13 & \\
\hline & ob & & $\infty$ & io & ins & i & $\begin{array}{l}13.9 \\
13.0\end{array}$ & & & & & & $\begin{array}{r}0 \\
12\end{array}$ & 6 & ק? \\
\hline & ou & & 01 & (:) & 100 & 1 & & & & & 11. & & iu & 9 & \\
\hline & ou & & 01 & 10 & 100 & ! & 16.0 & & 3 & 0.0 & & 111. & 11 & 10 & \\
\hline & 69 & & 01 & 10 & l(x) & ! & [113.0 & & & 11 & & 1142.33 & 0 & 10 & 12 \\
\hline & $\infty 0$ & & $\mathbf{w}$ & (1) & 100 & 1 & 18.0 & & & & & & & 12 & \\
\hline & 61 & & 01 & wi & $0(x)$ & ! & 10 & 5617. & 1 & UI. & & 144U.8? & 911 & 54 & \\
\hline & oy & & in & [1] & I00 & I & 111.0 & 20134. & 3 & Iy & & u. & 0 & & \\
\hline & y & & (3) & IU & 100 & 3 & & & & $4 \mathrm{H}$. & & 0 & U & $3 \%$ & \\
\hline & ou & & (x) & 10 & (1) & I & & & & 7.5 & & o. & 10 & 25 & \\
\hline & $0 y$ & Ivor)(x)(x) & ov & Iu & 1100 & I & 18.0 & & $j$ & 10.5 & & & o & ?: & \\
\hline & 00 & Uusuthe.) & 00 & 1.5 & 100 & I & 10.5 & 1987:397 & & (1.0) & & U. & 1 & 24 & \\
\hline
\end{tabular}




\author{
$\begin{array}{llllll}A & B & \text { C } & \text { D } & \mathbf{E} & \mathbf{F}\end{array}$
}

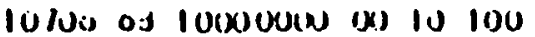

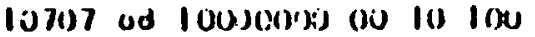

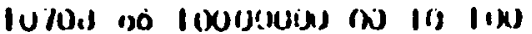

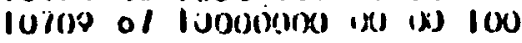

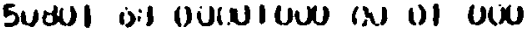

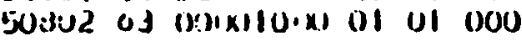
50.503 of voullares tos is wo

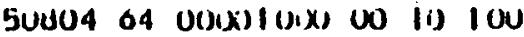

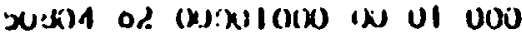

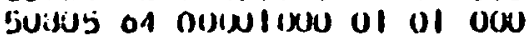
Tiblol ud oormlone in ou 100

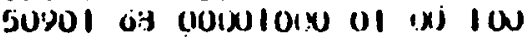

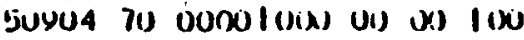
500057.5 vixuluon as ix 100

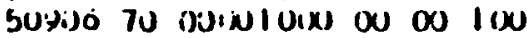
509(1) 71 vosxlu(x) of 10000

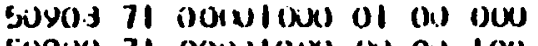
50909 71 0:5:1.110(x) ov no 100

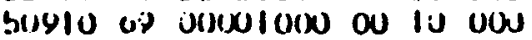
5uyll ay onexiuide 00 is 000

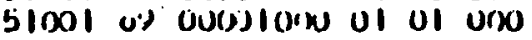

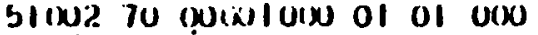

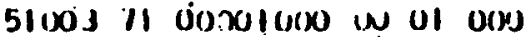
slous 71 uuwluirs oi ul vuis

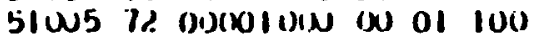
$5 /(x) 071$ vurxilarx ou ul uxu 51 ixis 71 orxuliuix of 00000 51009 6y $00, x) 11300$ uf $(x)$ uot

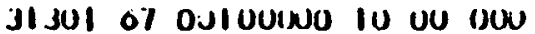

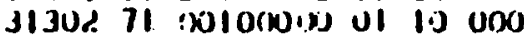
3130370 inluaisine os 10100 31304 of vill lliven 0.110100 31305 il 00100000 ol 10 loo

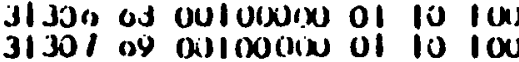
31308 oy inifionosj of 10 ins 3130470 molucoos of il IIx 31310 ord ow10001) 40 iv 100

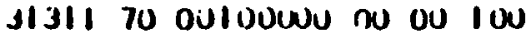
3131270 001000ixs we oj 100 3131470 in 100000 ol ov 100

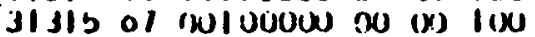
31401 od culouoco is 01 uov

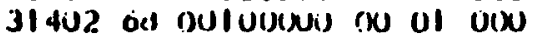
31 AUs os is

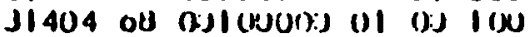

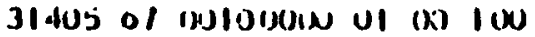

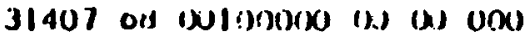
3140871 0jIJIsins of 01 I

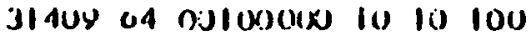

\begin{tabular}{|c|c|c|}
\hline & II & 1 \\
\hline & 10.0 & $2(112 ; 3.12$ \\
\hline & 10.0 & \\
\hline & $\mid \omega, \dot{0}$ & \% \\
\hline & | & 231,2 . ills \\
\hline & 15,0 & $19: j \$ .15$ \\
\hline & 15.0 & (6.,1., \\
\hline & 118.0 & 104.1 .00 \\
\hline & 14.0 & (5:4.4.1)? \\
\hline & 11.1 & 10.11 .34 \\
\hline & $20 . \%$ & 5.218.25 \\
\hline & U ט, & 218159.2 .4 \\
\hline & 01.0 & 360.1 .2 \\
\hline & 19.3 & 1 vild. 17 \\
\hline & 14.3 & $1 \operatorname{lng} 9$. \\
\hline & 383.0 & $34 / 1.46)$ \\
\hline & j & 80803.91 \\
\hline & 410. & 41035.21 \\
\hline & 41.9 & $4|4| .110)$ \\
\hline & 10.0 & 2020.71 \\
\hline & (1).1) & $21 \% .4 .11)$ \\
\hline & $3 \% .0$ & 3.301 .79 \\
\hline & $: 13.7$ & 1031.29 \\
\hline & 11.9 & $3734.3 d$ \\
\hline 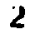 & .33 .7 & 1094.20 \\
\hline & 4911.6 & 41745.10 \\
\hline & 125.0 & 11503 \\
\hline & 40.8 & \\
\hline & 1.1 .0 & 2031 \\
\hline & & ub \\
\hline & I! & 1510 \\
\hline & & $27 \%$ \\
\hline & & ?1 \\
\hline & & \\
\hline & & ijiviv \\
\hline 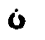 & 11 & 1200 \\
\hline 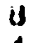 & & 1411 \\
\hline & & \\
\hline 4 & प5 & $112.49 .4 \%$ \\
\hline 1 & 01 & $09 . j 3$ \\
\hline & & $14 / 0$ \\
\hline I & |j.3 & $1 \% 09$ \\
\hline & 15.3 & 1922 \\
\hline & 15.3 & $121 \% .30$ \\
\hline & 33.8 & \\
\hline J & .32 .2 & $020 \% .41$ \\
\hline 0 & 104.0 & 10.745 .100 \\
\hline$!$ & & 13.81 \\
\hline & & \\
\hline
\end{tabular}

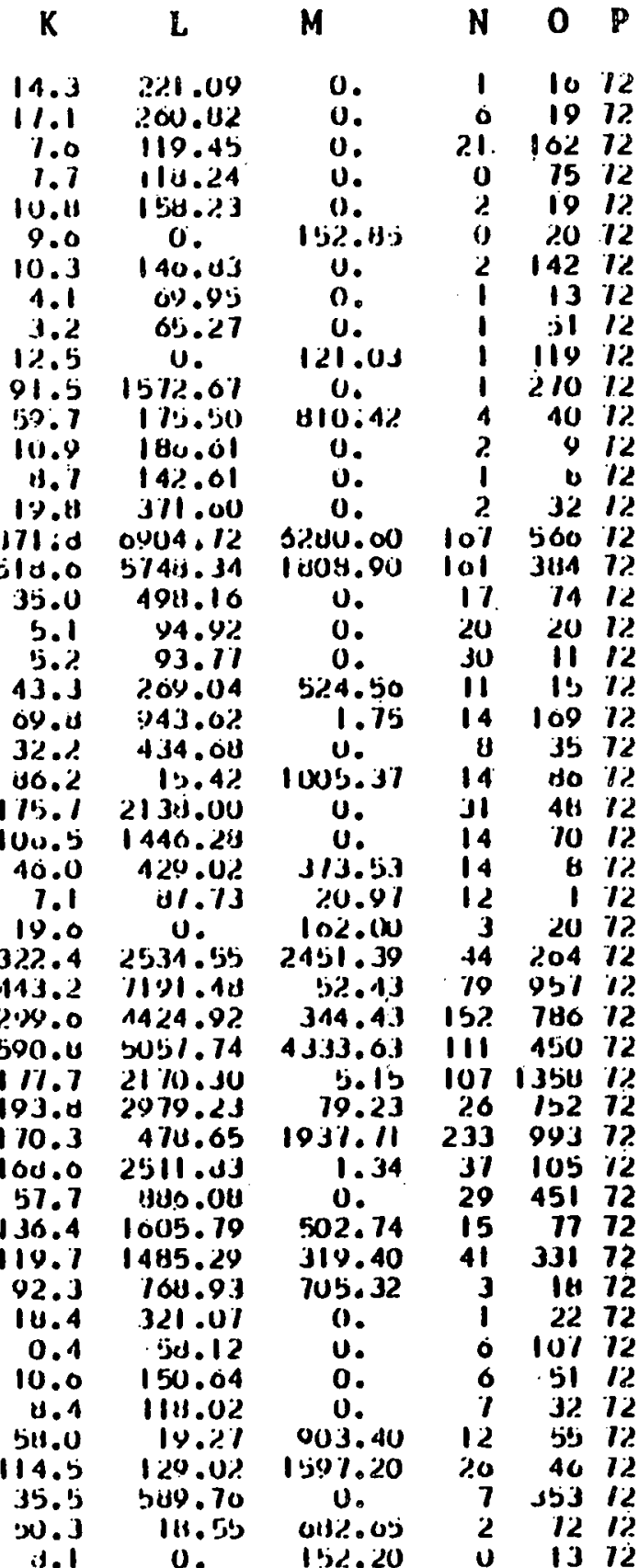




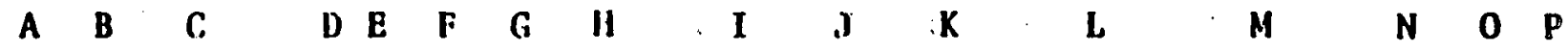

$4 ! 5$ IUI TO OENIIOIIIN III. 0.11010 41502 ad $000100(x)$ is ou 100

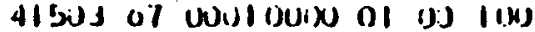
4150 ) 0 : 41002 ug owiluas 10 oJ los

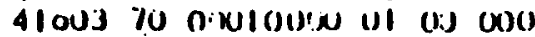
0110170 vuixuline al is 100

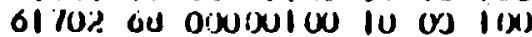
ol 103 0. (x)

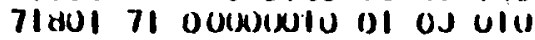
$11901 \%$ lo 1000010 ov os o(rs broxi al onowlons (x) 10 100) $52(x)$ ? 09 outxoluou lu is I 100 $52(x) 470$ owjulono ix is ino

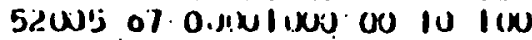
5200 oy ou(x)IUIN (x) (x) $\mid \alpha)$

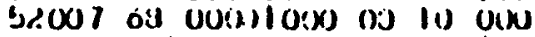

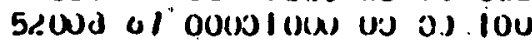
$5200 ?$ of 0ixulo00 is w 100

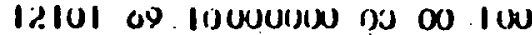

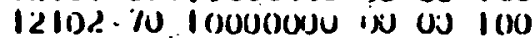

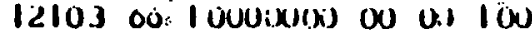
isiol os luixsouen us as 10is

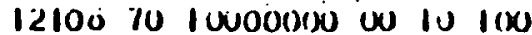

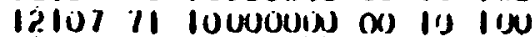
izlus oy lo0000!n an ol 100 1210907 . I vUiNouOd o0 01100

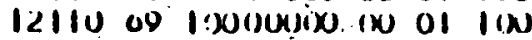
12111 od-10000000 ! 10 OI 1100 12112.09 100isexixe: : 01 I 100 32201 od nulo(x)(x) ou n.s ind

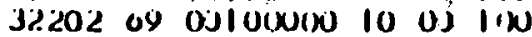
3.2 .03 oy is

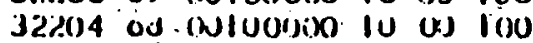

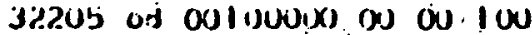
33200 oo nulorxin $(x)$ is ilx 32207 ad inliNourxs ol la 100

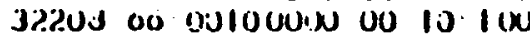
42301 ol $0 . x) 10000.1 \times 5$ ol 000 42302 oy oixul (sine of of vixu 42504 to orkllo(sin uI UI 100 42305 is $0 . x 10014101$ OI U(N) 0.40170 (xi) oulow ul (vi) lise

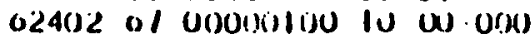
0240371 vorsuul O.J 01 (x) 1 :

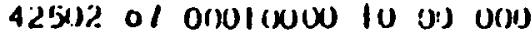
4270472 0ivilos:)

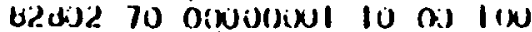

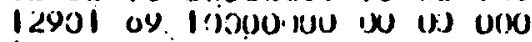

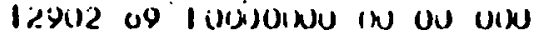

\begin{tabular}{|c|c|c|}
\hline & $\begin{array}{llll}0 & 1.4 \\
0 & 1\end{array}$ & $\begin{array}{r}-4.010 \\
0.310 .79\end{array}$ \\
\hline & $1<4.11$ & $\mid$ \\
\hline & $30: 0$ & ? \\
\hline & 17.1 & 2120.19 \\
\hline & $10 . .1$ & I/4. \\
\hline & 0.1 .11 & | \\
\hline & $10 . .3$ & (Y.s2. A \\
\hline & $1: 1.0$ & indu. \\
\hline & 22.11 & ئ. \\
\hline & $5 ! 3.1$ & 3500.153 \\
\hline & 10.0 & $20 ! 39$ \\
\hline & $1 / 4.0$ & $|A ! j|$. \\
\hline & (1). & $1043.2 \%$ \\
\hline & 10.0 & 21) \\
\hline & 121.5 & $\begin{array}{r}15019.14 \\
1040.13\end{array}$ \\
\hline & 10.2 & 2041.41 \\
\hline & 10.2 & 2139 \\
\hline & 21.4 & 2705 \\
\hline & $4 \% .6$ & 1404.11 \\
\hline & 13.0 & טذ. ر \\
\hline & 14.2 & I futh. \\
\hline & $4 \% .1$ & 1024.3 .1 \\
\hline & 30.1 & 3411.38 \\
\hline & 1.1 .6 & 197.7.7. \\
\hline & 10.0 & $2(1 \%)$ \\
\hline & 1.30 & ز' \\
\hline & 111,0 & Yus \\
\hline & I H. O & 1912 \\
\hline & 20.0 & 2109 \\
\hline & J & 364 \\
\hline & 25.0 & 2.214 \\
\hline & 20.0 & ק? \\
\hline & 20.0 & 41 \\
\hline & 04.0 & .54 \\
\hline & 111.6 & $240 ?$ \\
\hline & 04.0 & s0ul. \\
\hline & U. & 1430.40 \\
\hline & 12.0 & IAYS \\
\hline & 12.0 & I0YU \\
\hline & ز.5. & زلט. IU0A \\
\hline & 41.9 & 5111.60 \\
\hline & 3.2 & 0023 \\
\hline & 41.4 &.$|(1) i s| .47$ \\
\hline & 2.1 .18 & زازال3 \\
\hline & 110.0 & 1014 \\
\hline & 19.3 & 10.311 \\
\hline & & 371 \\
\hline & & \\
\hline
\end{tabular}

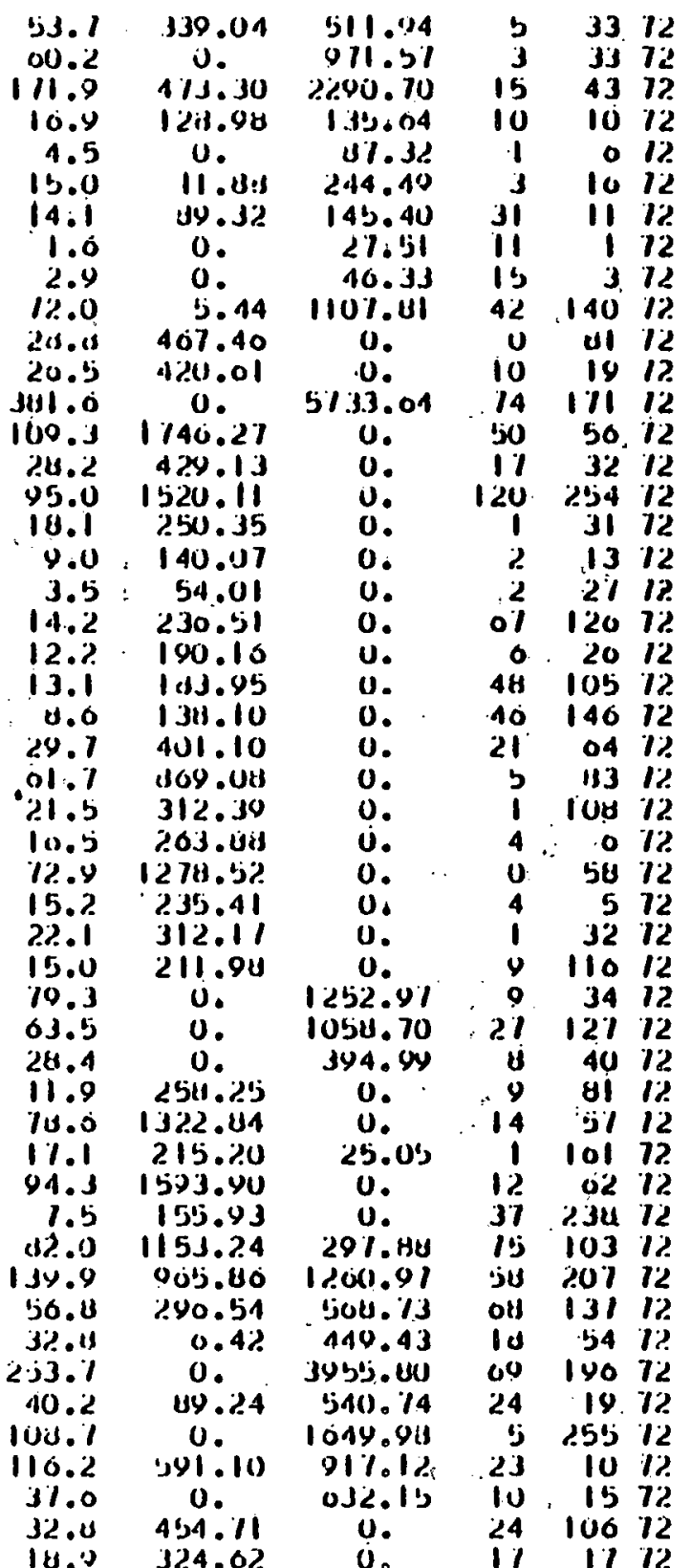




\begin{tabular}{|c|c|c|c|c|c|c|c|c|c|c|c|c|c|c|c|}
\hline A & B. & C & D & E & $\mathbf{f}$ & G & HI & I & $\mathbf{J}$ & $k$ & L & M & $\mathbb{N}$ & 0 & $\mathbf{P}$ \\
\hline & io & & (1) & ou 1 & $i ! x)$ & I & & & 3 & 20.0 & 53.05 & 11.4 .90 & & 71 & \\
\hline & ou & jouox) 0u & iv & oj 1 & invo & i & 10.0 & | BY\%., & 3 & 20.0 & & $u$ & .19 & 31 & 72 \\
\hline $3(y) 1$ & 07. & Ul (NOO: & 01 & (W) 1 & (x) & i & 10.0 & $2.09 \mathrm{~J} .1 \mathrm{~J}^{\prime}$ & $J$ & $1 . .3$ & ز'11.0 & o & $i j$ & 13 & 12 \\
\hline swe? & o) & (1)ou(x)os) & ov: & 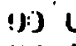 & Ulu & 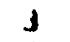 & $\because 4$ & $00.11 .1 \mathrm{~s}$ & 3 & 19.2 & 207.181 & 0 & ou & 240 & 7? \\
\hline$(x)$. & 70 & Oilojolouis & UI & UJ 1 & 1100 & 4 & $4 \cdot 2$ & 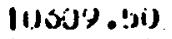 & $\mathbf{J}$ & 254.5 & 2700.40 & $1 \% 07.53$ & 31 & 157 & 72 \\
\hline & 71 & $u(u)(x) i x$ & Dis & 0.1) & $f(x)$ & H & 1.50 .0 & | & 3 & 350.5 & $5 \% 0.13$ & 0 & 39 & 187 & 72 \\
\hline & 70 & $010: 0000$ & $(x)$ & 101 & 100 & 2. & 4 & (1). & 3 & $43 . .1$ & 'j/2.0.1 & u. & 21 & 200 & 12 \\
\hline -08 & 07 & vi wovesto & 10 & i.e) & ivo & 1 & 10.0 & $2012.11)$ & $J$ & 13.0 & 0 & 2800.30 & 4 & 205 & ?ִ? \\
\hline 230 & 11 & olo000u & OI & 10 & $I(x)$ & $3:$ & 2 & $n(1 / 4) / 4,3.1$ & 3 & 350.8 & 4990.5i & $|B| .50$ & 1150 & 702 & 12 \\
\hline & 01 & Jivo0000 & vi & (v) & ino & i & . & $18.3 / 81.12$ & 3 & 23.2 & 300.113 & 46.50 & 11 & 704 & 12 \\
\hline & 07 & $0 \mid(x) 0(x) v$ & 01 & ou & Iex & 1 & "113.נ & 8.70 & 2 & U. ט. & 417.23 & 30.03 & 20 & 377 & $1 \%$ \\
\hline & Oy & "I DOU(K)U & $\infty$ & 101 & 100 & 1 & 111.6 & 1715.57 & 3 & 15.0 & 2.19 .07 & u. & 9 & 112 & 72 \\
\hline & oj & & oI & $\omega$ & $I(x)$ & 1 & 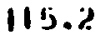 & $15.50 / .30$ & 3 & 03.9 & 1114.42 & 11.35 & 24 & 118 & \% \\
\hline נJIOI & os & u(x)isor(x) & 10 & 001 & lixu & I & ز. & .01 .14 & 3 & 3.4 & o. & 05.40 & 1 & 2 & 72 \\
\hline & 10 & U10000(x) & ov & $\omega$ & 100 & i & ج1. & | & 1 & 12.3 & 109.17 & U. & j & 33 & 72 \\
\hline & 69 & & 01 & ou & $(x)$ & $!$ & 21.1 & 19.50 .2 .1 & 3 & 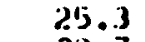 & 0.04 & 5.43 .21 & J & 41 & ? \\
\hline & 10. & 011 & dN & ov & 100 & I & 10.3 & -0.02 & 3 & $2 . .7$ & 411.15 & 0. & -4 & 18 & 12 \\
\hline 2. 1204 & 69 & $00: 30$ & 00 & 0:) & I160 & 2 & 14.2 & 5053.0 .1 & 3 & 30.7 & 3015.55 & 0. & 17 & 101 & 12 \\
\hline & 11 & Ulix)o(s) & (u) & 01 & $I(x)$ & $3 \%$ & $0.3 t 3.0$ & $-y$ & 3 & 1030.0 & $2.1533 .0 ?$ & 0 . & 497 & 1509 & 72 \\
\hline & 09 & ol o00000y & ov & (u) & Ino & 1 & 10.0 & 32.80 & J & 1.1 & 20.23 & 0. & ts & ע9 & 72 \\
\hline & 09 & & $(x)$ & ou & visu & 2 & 211.0 & & & 29.2 & 470 & 0. & 24 & 10 & ? \\
\hline Uy & oud & $0100(n)(x)$ & $\alpha u$ & (ou) & 100 & ? & 31.2 & 1. & 3 & 10.5 & 013 & 0 . & 15 & 700 & 12 \\
\hline & oul & & 00 & (j) & (x)0 & 1 & $1 y .0$ & 210 & 3 & 10.0 & 170.90 & u & -9 & 1,14 & 12. \\
\hline & 70 & & ou & $10 i$ & 001 & I & 2.3 & 2101 & 3 & 14.0 & 220 & 0 & 2.? & 189 & 72 \\
\hline & ol & Ulu & uis & iv & 100 & i & 1.0 .0 & 2250.11 .1 & & 5.1 & Yo. & u. & 1 & 100 & $7 \%$ \\
\hline & 07 & & 00 & 10 & I I.x & 1 & 10.0 & & & & & 0. & $y$ & 18 & 72 \\
\hline & 11 & 010 & $\infty 0$ & Io & $I(x)$ & 1 & ب..رد & 4.10 & 3 & 32.5 & 413. & 0. & 28 & 91 & 72 \\
\hline & 0.3 & U l voox & 120 & 10 & 100 & 1 & 11.5 & & $j$ & 3.0 & & u & 9 & 13 & 12 \\
\hline & 04 & 011 & $w$ & 10 & ion & i. & 19.0 & 115 & 3 & $4 . y$ & & u. & 21 & 30 & 12 \\
\hline & & Ull & Os & $(\infty)$ & 100 & 4 & ا & 1.33 & 1 & 9\%. 11 & 1204 & 255.34 & 51 & 474 & 12 \\
\hline & 71 & & 01 & 00 & I & d & 105.6 & 12.1 & 2 & 113.5 & 140 & 144.13 & 63 & u() & 72 \\
\hline & oy & oli & ov & (x) & 100 & 1 & 14.0 & & & 2.0 & 40.30 & u. & 0 & & 12 \\
\hline & 09 & & $0 i$ & Uu & ino & i & & & 7 & & & 34.71 & 0 & 4 & $7 \%$ \\
\hline & 11 & olo & 10 & $(10)$ & 100 & i & .3 .4 & $174 \%$ & 3 & 03.4 & & $80 \% .10$ & 6 & $5 H$ & 12 \\
\hline & 01 & & ou & $(x)$ & 100 & 1 & & & & 10 & 1178 & $u$ & 25 & 300 & 12 \\
\hline & & & 00 & DJ. & 100 & $\therefore$ & & & & & & 0. & 10 & 140 & 72 \\
\hline 230 & 01 & & $(x)$ & (w) & 100 & 1 & 04.0 & 010 & & 83.4 & 12.41 .63 & u. & 5 & $10 \%$ & 12 \\
\hline & & & ou & $0^{\prime} J$ & 110 & 2 & & & & & & & & 28 & $1 \%$ \\
\hline & oli & ois & in & UIJ & 100 & ? & U. U & 305 & & 40. & 021 & 0 & 0 & 20 & 72 \\
\hline & & & DJ & 00 & 100 & 1 & & 2091. & & 1 & & 0 & 5 & 400 & 12 \\
\hline & 71 & & U: & 00 & I wo & 4 & 24.3 & & & 94 & 201 & u & $y$ & 94 & 72 \\
\hline 230 & .70 & 010 & $w$ & (u) & 100 & 1 & 3. & 57.19 .11 & & & & 0 & 21 & 11 & 12 \\
\hline & 71 & & or & $0: 3$ & ins & 2 & & & & & & & 1 & $3 j$ & $; 1 \%$ \\
\hline & oy & vit & in & $o v$ & 100 & ? & 51.2 & $374 !$ & & 47 & & (1) & 0 & 204 & 72 \\
\hline & 07 & & 000 & $w$ & 100 & 2 & $32: 0$ & 3454 & & 30 & & & 2 & 30 & I? \\
\hline & oy & & $(x)$ & 01 & 100 & 3 & 14.8.5 & 5717 & & 40 & 04 & () & 30 & YI & 12 \\
\hline & 70 & & 0. & UI & 100 & 1 & 11.1 & 1711 & & . & $84 !$ & & 10 & 249 & $1 ?$ \\
\hline & 10 & & $d v$ & 01 & $\operatorname{lix}$ & 3 & 3.13 & & & & $1(x) i$ & 0 & 3 & $34 \mathrm{~J}$ & 1? \\
\hline & 7.1 & & JJ & (j)! & 100 & 3 & & & & & $: 097.00$ & U. & 15 & 201 & 12 \\
\hline 25U? & 11 & Jluluixus & nu & 01 & i (is) & 2 & .115 .9 & -9.00 & & 01.2 & 1140.90 & 0. & 27 & io & 12 \\
\hline
\end{tabular}




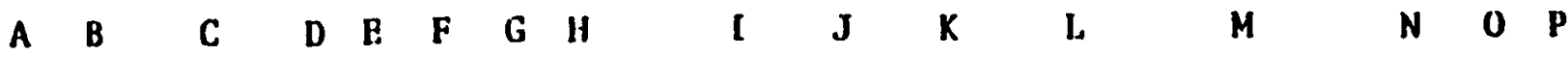

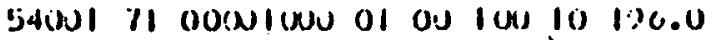

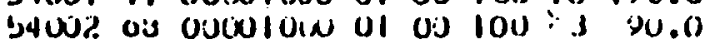

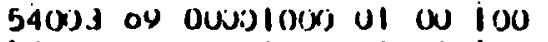

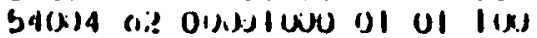

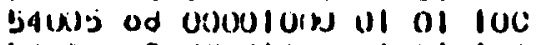

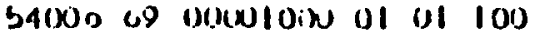

5400l al ondisuluain la ol lix

5330171 (nomlons is as one

533020000031000 is 00 jis

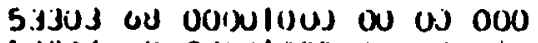

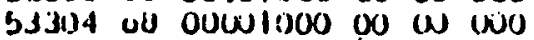

53305 ob ooxulous ol os ow

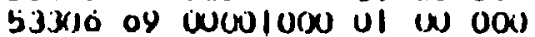

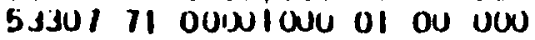

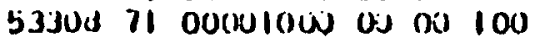

331002 io (x) $1000(x)$ n) (x) 100

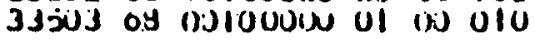

3350470 . WI00000 UI w Ulo

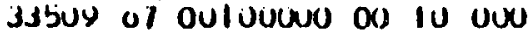

$3 j 510$ os

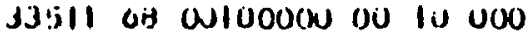

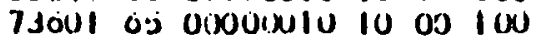

23130171 ol ondonos os (x) 100

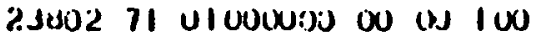

2380471 010000(x) as (10) 101

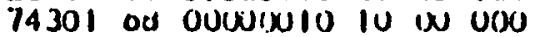

74ju? ol o:xiditulu lu no Uix

74303 of Woorulo iv id 000

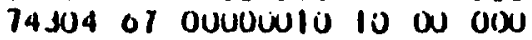

74305 63 solowils ol ol ouv

$74300^{\circ}$ ou ocxonosito lo as 000

74301 is ouculeula lo $00 \mathrm{WIO}$

74.300 of 00000010 IU vo 000

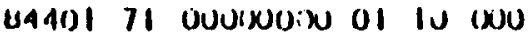

145is1 71 1:x0000(x) ov (x) 100

14:30\% al 100001000 00 10100

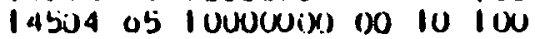

5401)? $7100001 \mathrm{U}(\mathrm{N})$ (x) $310 \mathrm{100}$

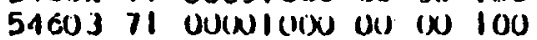

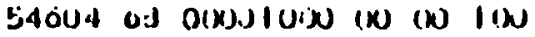

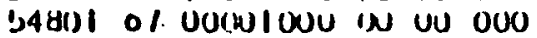

j4: 01 o) (3) IOUXO) 10 WJ (NI

3440? 04 OOI:JO1):N U1 OS OUU

34903 ues idivonise ol we 100

34004 o8 0j/vixins ix (x) / (x)

3490 ' of U'sluor(x) UI US 100

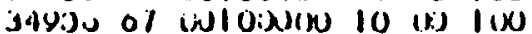

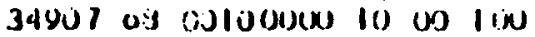

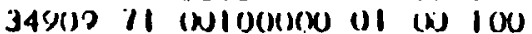

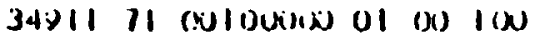

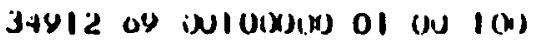

\section{in. 10}

$13 \div 11$

110.5

1
1
1

111.2

410.0

112.0

10.3

10.3

110.3

3.1 .3

4170.7 1 J040.115 J

$241.0 \quad-4.053$

111.02000 .033

I $32.0 \quad 30.13 .173$

$7 \quad 1 \% 0.0 \quad 13024.943$

$1 \quad 10.01834 .403$

345.0 jovt.it. 3

119.02010 .143

4 uU.0 0\%3j.2U 3

19.02002 .0 .53

3511.45012 .001

19.0 145\%.01 3

प0.1 10.003

$16.3-4.103$

$10.3-0.013$

$10.3-9.003$

$22.5-4.003$

$44.0 \quad 5207.003$

$13.3 \quad 1205.1143$

1\%.0 1454.U5 3

$10.0 \quad 3423.94 \quad 3$

218.021801 .103

$13.2 \quad \mid 831.303$

$17.0 \quad 1318.9053$

ग2.1 -4.013

U?.8 -9.003

05.0 - 0.003

113.0 20j1.04 3

$41.2 \quad 2102.203$

$13.5 \quad 3.41 .43$

10.03917 .103

$10.0 \quad 2305.163$

$14.0 \quad 2401.053$

j1.5 ja01.93 j

$14.0 \quad 110 \times .653$

90.531310 .7 .53

11.9 Jisl 1.442

21.5 0113.31 ?

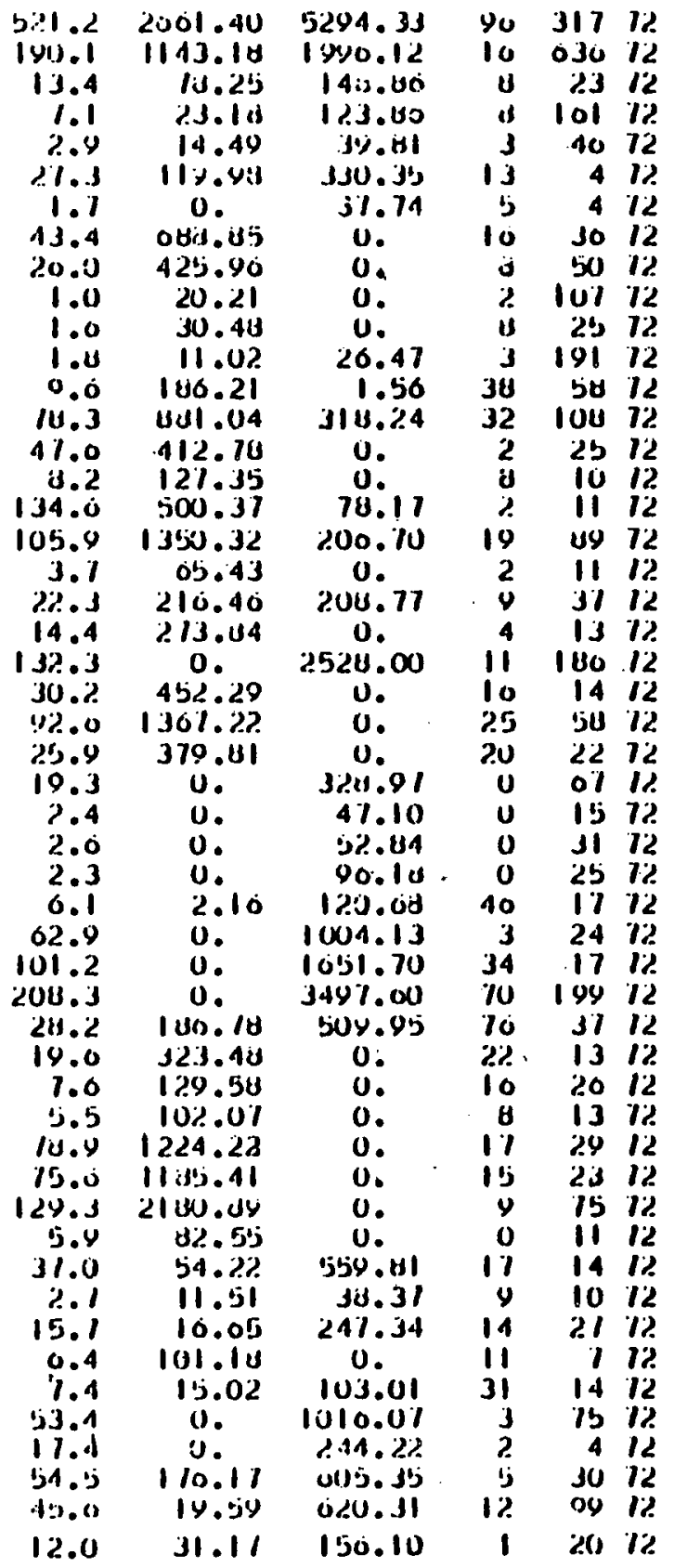




$$
\text { C-5 }
$$

PLANT CHARACTERISTICS/OPERATION AND MAINTENANCE

HYDRO-ELECTRIC PLANTS

Column A - Three-digit identification code

The first digit identifies the plant by the Census Region in which it is located.

The final two digits denote the specific plant within a state.

Column B - Two-digit vintage code

Year in which the plant observed was brought into initial operation.

Column C - Eight-digit region code

Regional code constructed for analytical purposes. This code for the nine Census Regions is as follows:

$\begin{array}{llllllllll}\text { Region 1 } & 1 & 0 & 0 & 0 & 0 & 0 & 0 & 0 \\ \text { Region 2 } & 0 & 1 & 0 & 0 & 0 & 0 & 0 & 0 \\ \text { Region 3 } & 0 & 0 & 1 & 0 & 0 & 0 & 0 & 0 \\ \text { Region 4 } & 0 & 0 & 0 & 1 & 0 & 0 & 0 & 0 \\ \text { Region 5 } & 0 & 0 & 0 & 0 & 1 & 0 & 0 & 0 \\ \text { Region 6 } & 0 & 0 & 0 & 0 & 0 & 1 & 0 & 0 \\ \text { Region 7 } & 0 & 0 & 0 & 0 & 0 & 0 & 1 & 0 \\ \text { Region 8 } & 0 & 0 & 0 & 0 & 0 & 0 & 0 & 1 \\ \text { Region 9 } & 0 & 0 & 0 & 0 & 0 & 0 & 0 & 0\end{array}$

Column D - One-digit construction code

Constructed by Corps of Engineers - 1

other

Column E - Four-digit operating type code

$\begin{array}{lllll}\text { Automatic } & 1 & 0 & 0 & 0 \\ \text { Manual } & 0 & 1 & 0 & 0 \\ \text { Semi-Automatic } & 0 & 0 & 1 & 0 \\ \text { Automatic w/pump storage } & 0 & 0 & 0 & 1 \\ \text { Manual w/pump storage } & 0 & 0 & 0 & 0\end{array}$

Column F - Indicates the total capacity of the plant in megawatts; the sum of the capacity of all units. 
Column G - Construction cost in $\$\left(x 10^{6}\right)$. The cost has been adjusted to a base year of 1975 .

Column $\mathrm{H}$ - Average number of employees.

Column I - Net generation, in $\mathrm{kWh}\left(\times 10^{6}\right)$, of the plant in the year observed.

Column $\mathrm{J}-$ Total operating and maintenance expense, in $\$\left(\begin{array}{ll}x_{1} & 3\end{array}\right.$, of the plant for the observation year. 


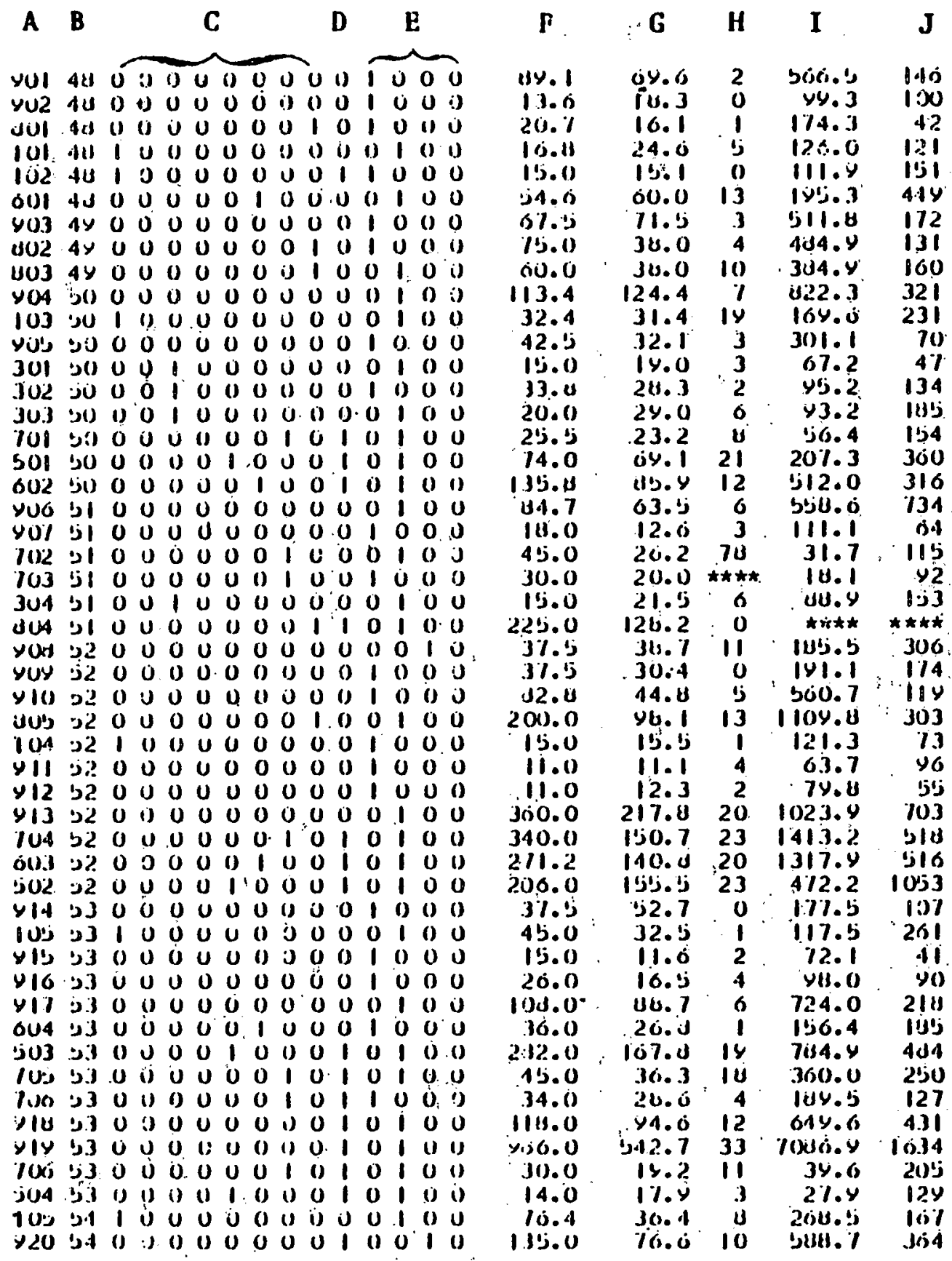




\begin{tabular}{|c|c|c|c|c|c|c|c|c|c|c|c|c|c|c|c|c|c|c|c|}
\hline A & $\mathbf{B}$ & & & & C & & & & & n & & 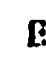 & & & f & G & H & $\mathbf{I}$ & $\mathbf{J}$ \\
\hline & $\begin{array}{l}34 \\
34\end{array}$ & $\begin{array}{l}u \\
u\end{array}$ & $\begin{array}{l}0 \\
0\end{array}$ & $u$ & & (1) & u & i) & u & 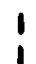 & & 1 & 0 & & (ji). 10 & נ4 - 171 & 31 & 11366.3 & 310 \\
\hline & ניכי & 01 & U) & () & $u$ & o & (j) & $u$ & 0 & $u$ & & $u$ & 0 & $u$ & Y 0.0 & ju. 3 & $u$ & & 233 \\
\hline & 35 & 1 & (i) & i) & $u$ & 0 & 0 & $u$ & (1) & 0 & I & (1) & 0 & $\mathbf{u}$ & & & 2 & & 76 \\
\hline & ע'י & 6 & i & u & (1) & 0 & 0 & $u$ & u & u & i & i & $\mathbf{u}$ & 11 & 32 & & $x d x$ & & .34 \\
\hline & נ'י & U & $\mathbf{U}$ & 0 & $u$ & I & 0 & $\mathbf{u}$ & $u$ & i) & U & () & 1 & $u$ & (i) & 60.4 & 13 & & jyy \\
\hline & زند & 0 & u & $\mathbf{0}$ & $u$ & $\dot{0}$ & 0 & $u$ & 0 & 1) & I & 0 & 0 & 0 & & & 4 & & $\times 4$ \\
\hline & زंग: & 01 & 0 & 0 & 0 & $u$ & 0 & 0 & U & 0 & $\mathbf{u}$ & 1 & () & 0 & & & 14 & & $3+1$ \\
\hline & ز'5 & 01 & () & 0 & $u$ & 0 & 0 & i & $v$ & 1 & () & 1 & $\dot{u}$ & i) & & jo. I & 11 & & $23 y$ \\
\hline & jं & $u$ & 0 & 0 & $u$ & $\mathbf{u}$ & 0 & 0) & 1 & i & (1) & $i$ & () & 1) & & & 15 & & 5112 \\
\hline & j's & 01 & v & 0 & 0 & 0 & $\mathbf{0}$ & 0 & i) & 1 & (1) & $i$ & () & u & 022 & & oti & Yo: & 1002 \\
\hline & 30 & $\boldsymbol{U}$ & 1 & 0 & $\mathbf{u}$ & $u$ & $\mathbf{u}$ & $u$ & 0 & 0 & 1 & U & 0 & u & & 13.6 & 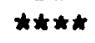 & & 31 \\
\hline & ó & $\mathbf{U}$ & 0 & 0 & $\mathbf{u}$ & 0 & 0 & 0 & 0 & 0 & & (1) & 0 & $\mathbf{u}$ & & 26.3 & $!$ & & $120^{\circ}$ \\
\hline & 6 & 0 & 0 & 0 & 0 & 1 & 0 & $u$ & 0 & 0 & I & C & $\mathbf{u}$ & 0 & & 0. & 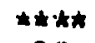 & & ó \\
\hline & 36 & 01 & u & $\mathbf{u}$ & 1 & 0 & $\mathbf{0}$ & u & 0 & I & 0 & ! & $\mathbf{0}$ & 0 & 4 & $30 \div .1$ & 30 & 212 & lojy \\
\hline & نذن & 0 & 0 & 0 & 1 & $u$ & 0 & $u$ & $u$ & 1 & 0 & $!$ & ) & 0 & 10 & 74 & 21 & & $\$ 38$ \\
\hline & 7 & $u$ & $u$ & $u$ & $\mathbf{u}$ & u & 0 & $v$ & $\mathbf{u}$ & 0 & u & ! & 0 & () & & & 10 & & \\
\hline & 37 & 11 & $\mathbf{u}$ & 0 & $\mathbf{u}$ & 0 & 0 & 0 & $u$ & u & $u$ & 1 & $\mathbf{u}$ & 0 & 14 & & $\star \star \star \star \star \star$ & & 23.1 \\
\hline & 1) & 0 & 1 & () & $\mathbf{u}$ & 0 & 0 & $U$ & 0 & u & 1 & C & 0 & 0 & & & $\star \star \star \star \star$ & & 40 \\
\hline & 37 & $u$ & 0 & 0 & $\mathbf{u}$ & $\mathbf{U}$ & 0 & u & $\mathbf{u}$ & 0 & 0 & I & $\mathbf{u}$ & $\mathbf{u}$ & & & $\mathbf{3}^{\mathbf{j}}$ & & j) \\
\hline & t) & U & () & $u$ & 0 & 1 & 0 & 0 & 0 & 0 & I & i & 0 & U & & & $\boldsymbol{U}$ & & \\
\hline & 37 & 01 & $\mathbf{u}$ & $\mathbf{u}$ & $\boldsymbol{U}$ & 1 & $\mathbf{0}$ & U & 0 & I & 0 & I & 0 & 1) & & & 17 & & \\
\hline & $! j !$ & 0 & c) & $\mathbf{U}$ & $\mathbf{u}$ & 1 & $\dot{0}$ & () & 0 & I & 1 & $\mathbf{U}$ & 0 & 0 & & & $1 ;$ & & \\
\hline & 7 & U & 1) & $\mathbf{U}$ & $\dot{u}$ & 0 & 1 & () & $\mathbf{u}$ & I & U & 1 & $\mathbf{U}$ & 0 & 10 & & $2 U$ & & \$02 \\
\hline 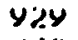 & i7 & 0 & 0 & $\mathbf{u}$ & $\mathbf{u}$ & 0 & 0 & 0 & U & I & 0 & c & 1 & 0 & 112 & 2 & 52 & & 13 \\
\hline 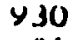 & Sن & $\mathbf{0}$ & $u$ & $\mathbf{u}$ & 0 & 0 & $\mathbf{0}$ & $\boldsymbol{U}$ & 0 & 0 & 1 & c & 0 & 0 & & & 0 & & \\
\hline & bu & 0 & 0 & $\mathbf{u}$ & 0 & 0 & 0 & 0 & $\mathbf{v}$ & () & 1 & I & 0 & 0 & & & u & & \\
\hline$z$ & 25 & 0 & $u$ & U & $\mathbf{u}$ & 0 & 0 & 0 & 0 & 0 & 1 & ( & 0 & u & & & 0 & & ניני \\
\hline & bu & 0 & 0 & $U$ & $\mathbf{u}$ & 0 & 0 & $\mathbf{u}$ & 0 & $\dot{\mathbf{u}}$ & C & 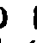 & $\mathbf{u}$ & 0 & & & 0 & & \\
\hline & كاد & $\mathbf{u}$ & 0 & $\mathbf{u}$ & (1) & 0 & 0 & 0 & 0 & 0 & 1 & C & 0 & iv & & & $\mathbf{0}$ & & $2 ! 7$ \\
\hline & נט & $\mathbf{0}$ & $\mathbf{u}$ & i) & $\boldsymbol{u}$ & 0 & 0 & 0 & I & u & 0 & 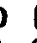 & 0 & 0 & & 7 & 11 & 24 & $3: j \mathrm{~d}$ \\
\hline & ju & 0 & 0 & 0 & 1) & $\mathbf{U}$ & 0 & 0 & 1 & U) & 1 & 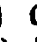 & 0 & () & & & 0 & & 112 \\
\hline 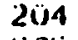 & لهد & 0 & 1 & () & $\mathbf{u}$ & $u$ & 0 & 0 & $u$ & 0 & $c$ & & 0 & 0 & & & 1011 & & 1177 \\
\hline & 3 & $\mathbf{0}$ & $\mathbf{u}$ & 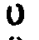 & $\dot{\mathbf{u}}$ & $U$ & $\mathbf{U}$ & $u$ & 0 & 0 & C & ) & 1 & $\mathbf{u}$ & & & 1 & & 3137 \\
\hline & Ju & 0 & 0 & 0 & $\dot{0}$ & $\mathbf{U}$ & $\mathbf{0}$ & u & $\mathbf{u}$ & o & 1 & 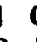 & 0 & $\mathbf{0}$ & & & 15 & & 204 \\
\hline & ') & 0 & () & 0 & $u$ & $\mathbf{u}$ & $\mathbf{u}$ & u & $\mathbf{u}$ & $u$ & c & & $\mathbf{0}$ & 0 & 204 & & a & & \\
\hline $100^{\circ}$ & ناد & $\mathbf{u}$ & $u$ & 1) & $u$ & $\mathbf{U}$ & I & $\mathbf{U}$ & $u$ & () & c & & () & U & & & $\dot{0}$ & & \\
\hline & עי & 0 & () & () & $u$ & 1 & 0 & 0 & 0 & () & I & & 0 & 1) & & & 2 & & \\
\hline & עل & $\mathbf{U}$ & 0 & 0 & 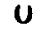 & $\mathbf{u}$ & 0 & 0 & 1 & $U$ & 1 & & 0 & (1) & $2 J$ & & 12 & 171 & \\
\hline & עיני & 0 & I & (1) & 0 & $\mathbf{u}$ & U & u & 0 & 1) & I & & 0 & ') & & & $A 2+x=t$ & & \\
\hline & עy & 0 & u & 0 & $u$ & $\mathbf{u}$ & 0 & () & $u$ & 1) & I & & u & $:$ & & & $\star \star \star \star \star$ & & 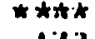 \\
\hline & עy & $\mathbf{0}$ & 0 & (3) & $\dot{u}$ & () & $\mathbf{0}$ & J & $\mathbf{u}$ & 0 & ( & 0 & 10 & a) & & & is & & 13 \\
\hline & بزن & $\mathbf{0}$ & 0 & (1) & 1 & (1) & 0 & 1) & 0 & I & c & 0 & 0 & u & & & 17 & & \\
\hline & 00 & 0 & 0 & u & $u$ & $\mathbf{u}$ & $\mathbf{0}$ & :) & 0 & 0 & I & I & u & i) & & & 0 & & *to \\
\hline & iv & 0 & $u$ & $u$ & U & $u$ & 0 & U & 0 & (1) & & I & u & u & & & 0 & & 12i \\
\hline & OU) & $u$ & 0 & $u$ & $\mathbf{U}$ & u & 0 & 0 & U & 0 & & U & u & u & & & 33 & ز زاز & 2112 \\
\hline & (iv) & 0 & $u$ & $\mathbf{U}$ & $u$ & $\mathbf{0}$ & 0 & $\mathbf{u}$ & () & $u$ & & $u$ & U & u & & & 14 & $21 \%$ & 510 \\
\hline & 01 & 0 & $\mathbf{u}$ & $\mathbf{u}$ & $\dot{0}$ & 0 & 1 & a & u & !) & & & 1) & i. & & & 12 & & 114 \\
\hline & 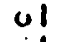 & $u$ & j) & $U$ & u & $\mathbf{u}$ & 1 & u & 0 & 1 & & & u & () & & & 13 & & 310 \\
\hline & & 0 & 1 & & & & & & & & & & 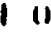 & & & & لע'? & & \\
\hline
\end{tabular}




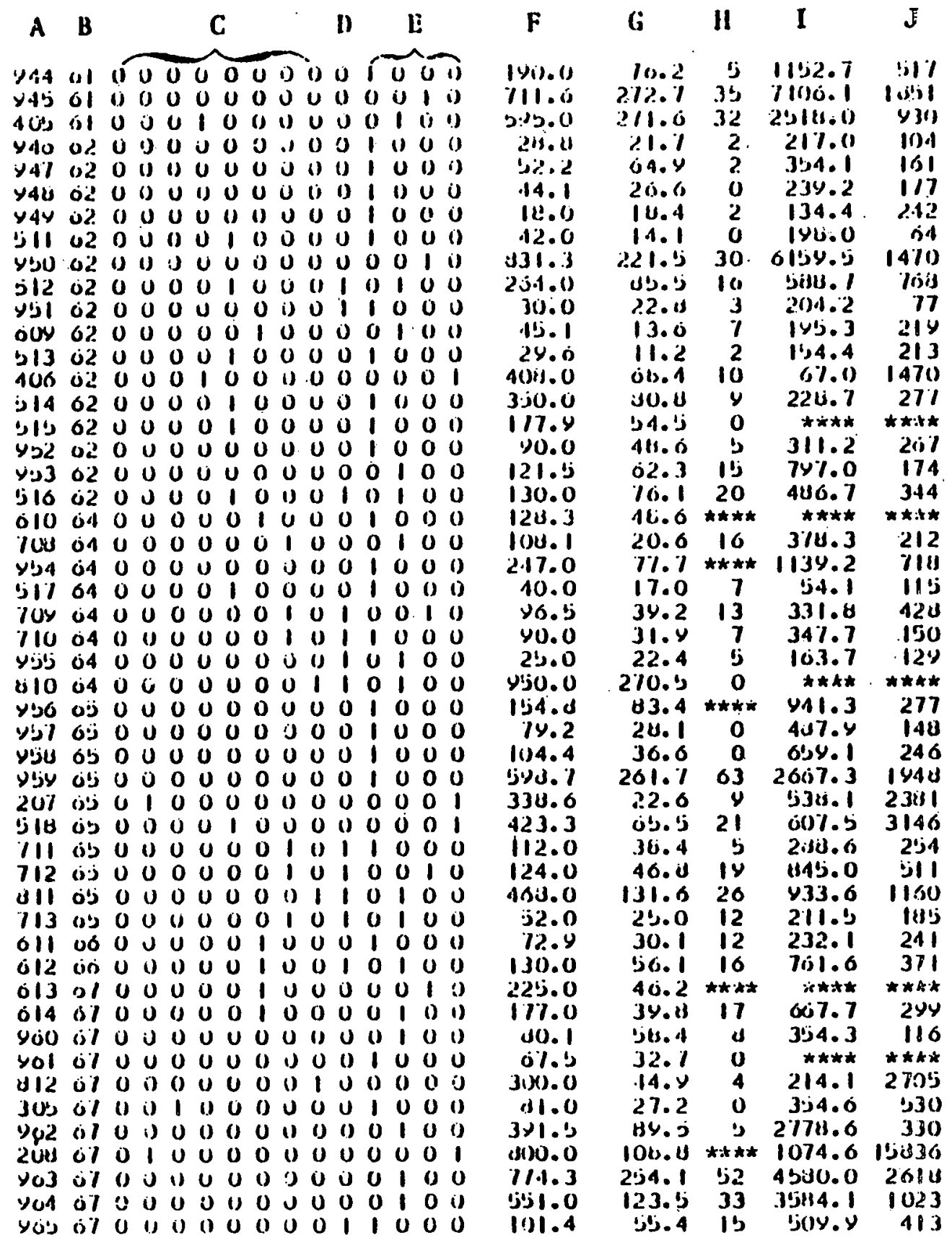




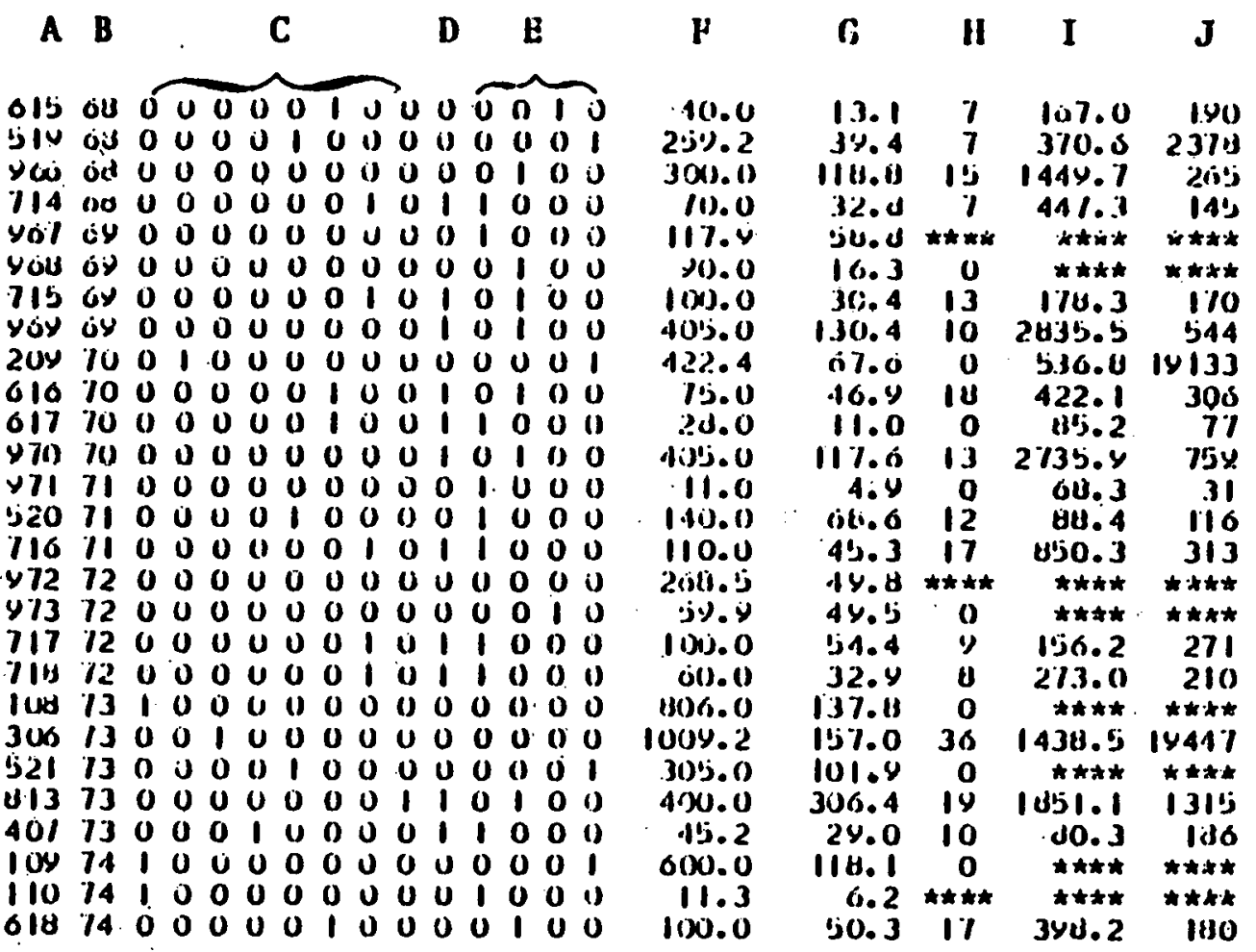




$$
\text { C-6 }
$$

PLANT CHARACTERISTICS/OPERATION AND MAINTENANCE -

NUCLEAR-POWERED PLANTS

Column A - Five-digit Identification code

The first digit identifies the plant by the Census Region in which it is located.

The second and third digits are the state Identification code. The state codes are numerically. sequenced 01 to 50 and correspond to an alphabetical listing of the states. Code $\# 51$ indicates the District of Columbia.

The final two digits denote the specific plant within a state.

Column B - Two-digit vintage code

Year in which the plant observed was brought into initial operation.

Column C - Eight-digit region code

Regional code constructed for analytical purposes. This code for the nine Census Regions is as follows:

$\begin{array}{lllllllll}\text { Region } 1 & 1 & 0 & 0 & 0 & 0 & 0 & 0 & 0\end{array}$

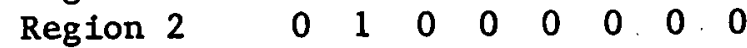

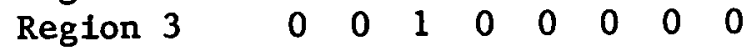

$\begin{array}{lllllllll}\text { Region } 4 & 0 & 0 & 0 & 1 & 0 & 0 & 0 & 0\end{array}$

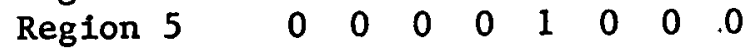

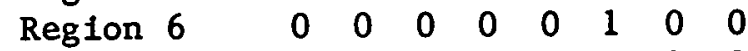

Region 7 - $0 \begin{array}{lllllll}0 & 0 & 0 & 0 & 0 & 1 & 0\end{array}$

$\begin{array}{lllllllll}\text { Region } 8 & 0 & 0 & 0 & 0 & 0 & 0 & 0 & 1\end{array}$

Region 9000000000000

Column D - Reactor type code

Identifies the type of reactor for which the plant was designed.

Pressurized water reactor 0

Boiling water reactor 1 
Column E - Four-digit container type code

Indicates the type of container used in the plant.

$\begin{array}{lllll}\text { Steel sphere } & 1 & 0 & 0 & 0 \\ \text { Steel cylinder } & 0 & 1 & 0 & 0 \\ \begin{array}{l}\text { Reinforced concrete } \\ \quad \text { w/steel liner }\end{array} & 0 & 0 & 1 & 0 \\ \text { Steel drywell \& wetwell } & 0 & 0 & 0 & 1 \\ \begin{array}{l}\text { Reinforced concrete drywell } \\ \quad \text { wetwell w/steel liner }\end{array} & 0 & 0 & 0 & 0\end{array}$

Column F - Denotes whether or not the data observed are for the first unit of a planned multi-unit facility.

Yes 1

No 0

Column G - Cooling type code; denotes the cooling method used by the nuclear plant.

Column $\mathrm{H}$ - Contains the number of units installed at the plant observed.

Column I - Indicates the total capacity of the plant in megawatts; the sum of the capacity of all units.

Column J - Boller pressure.

Column K - Boiler temperature.

Column L - Construction cost, in $\$\left(x 10^{3}\right)$. The cost has been adjusted to a base year of 1975 .

Column M - Construction time (in months) to complete the facility.

Column N - Net generation, in $\mathrm{kWh}\left(\mathrm{x} 10^{6}\right)$, of the plant in the year observed.

Column 0 - Total Btu's $\left(\times 10^{9}\right.$ ) of nuclear fuel consumed by the plant in the year observed.

Column $\mathrm{P}$ - Operating expense, in $\$\left(x 10^{3}\right)$, of the plant for the observation year.

Column Q - Annual maintenance expense, in $\$\left(x 10^{3}\right)$, of the plant for the observation year.

Column R - Average employment at the plant in the year observed.

Column S - Year in which observation was made. 


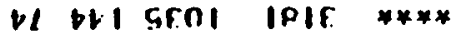

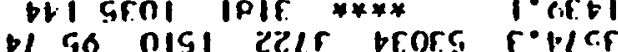
טL bl onI 7.RLI OL Of - 16 nator L/b

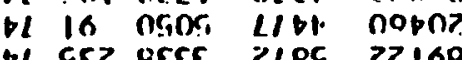
PL *** 1759 LFIP POFOA

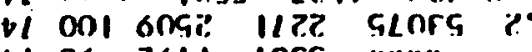
$\checkmark 1$ A6 7.6LI lore ****

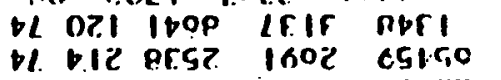
- 56 pole loir olor?

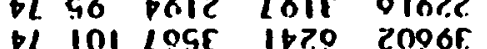
bl. InI loGe Ib7. 2096f.

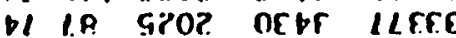
4 CD $\triangle O B I$ IFIF IGOA bl 50 76R BOCI ObAS LL IP IDEI COOP NGGOI GL OGं 9०5 olli ozCOS GI LOI PEPI GEAI VICAE GL OGI OOIA LOGE OLPOZ GL ILZ BCOZ SL 061 LSDZ GL ACE GObG GL 9116265 GL GOI S902 GL 001 ?.b0 Sl OGI PISI द) G?C 95,4 GL IE 066 G1. 1910612 GL $\mathrm{FOI}+161$ Gl 662 or, द) 601 ic दI 101 Iिएट GL 12.1 GEI दो I0? 6909 GL **** 6180 G1. InI I GEE c) nol prit GL GFI 0010 द) AI? brद दो KR noze G1 101 CEIO cl 001 b द) GnI S70? Gl EA rG़lb SL KE PLE

जl 101 lo91 000? 11515

i.0zis o. iche. o.ritz? s.tent $1 \cdot$ c.col. $r^{\circ}\|\mathrm{f}\|$

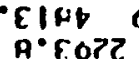
$c \cdot \mathrm{Rl}$ o.p.ro $\mathrm{c}^{\circ} \mathrm{O} / \mathrm{l}$ o. Innt: $i$ - mi 25 c.0115 a. into $G \cdot 1$ I.E S.916 7.8 .160 I r r 6 S

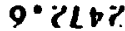
$0^{\circ} 2900$

$2 \cdot 1+5 \mathrm{CE}$

0699

४GZS

Sor

1891

CLOE

GOOS

6160

100

bror

stir

if
icoc

rदि

1050

GFP

GOC

\%.:

itipt

nolet

sille 0191 (riso aroor iror cobil is Ifr IESIV $6 . \mathrm{punf}$ 6.1 1.:8 $6 \%$ lite L.bII
A2695

on Horles on ov rISGC\% III

Bद COAFEO WU a l5,01/t cos no nz?.दcl lb? Or. ERAFPR CBS co linflü l?bG in ropnoz nis 69 IIOP.6 **** po hirufl silc G) Hoz.oll fnc If KILIPI IR. I. co?nII OIS GG LSGPZI CVC

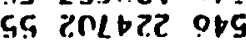
Iद सHóll द़or C० 7.RI K?.1 7.5 19 60016 965 PL DroRg IRV 9A ISPOFS lOS R.L IOgOZ.V rG.9 on 6Gbitr nog

$\checkmark L$ all:IIG CLC

IL $2+L L I Z$ SOG

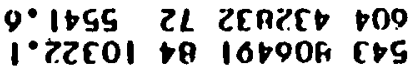

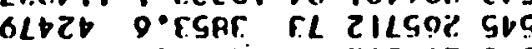

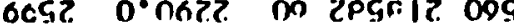

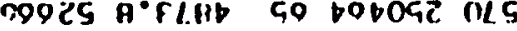

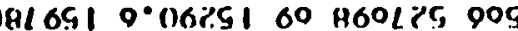

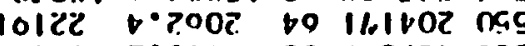

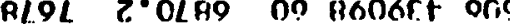

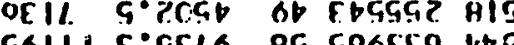
o.

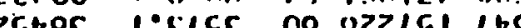

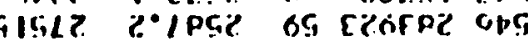
- ropl ve proro litr

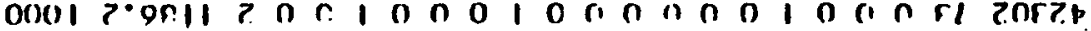

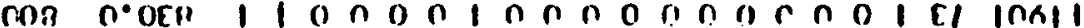
Gail z•onte?

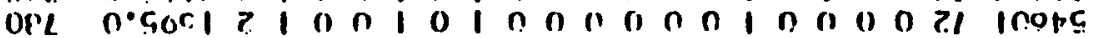

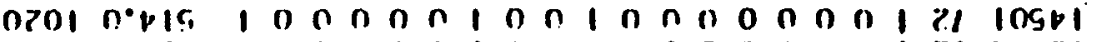

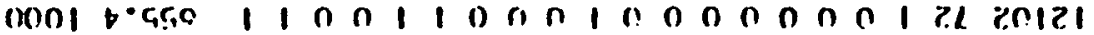

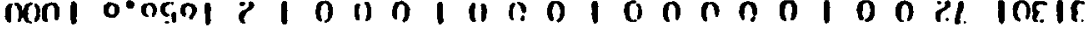

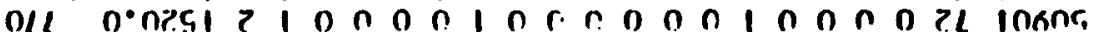

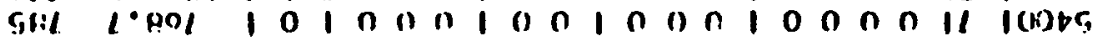

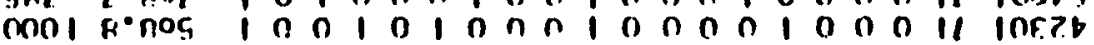

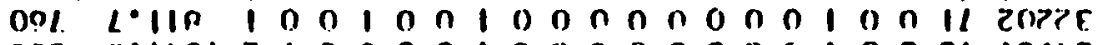

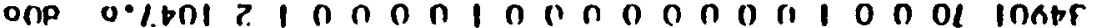

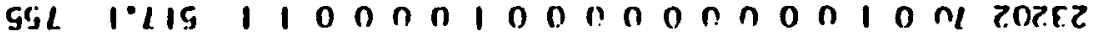

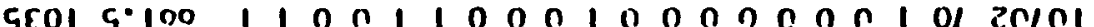
nool $a^{\circ} 1$ क

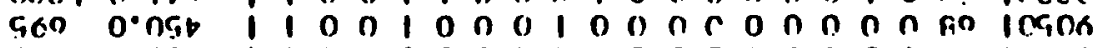

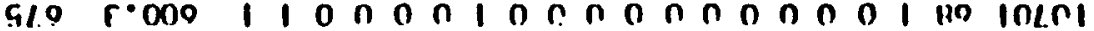

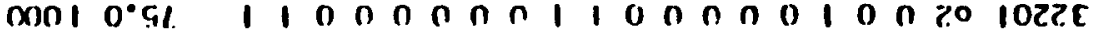

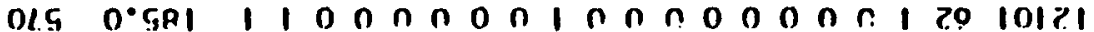
nGZC $1^{\circ}$ oROI I

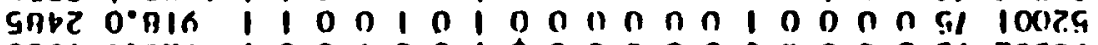

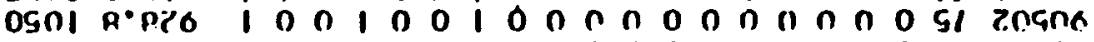
GOM। $0^{\circ}$ bOE.

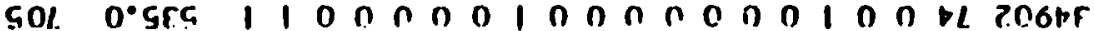

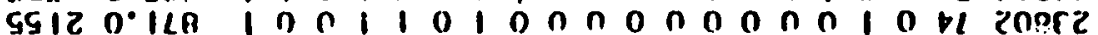

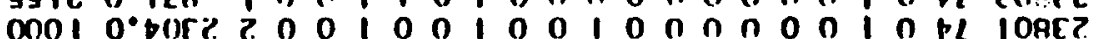

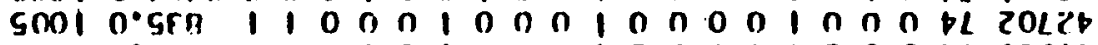

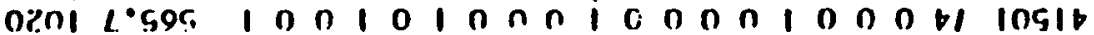

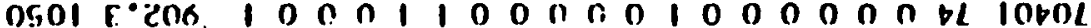
oso lenogz c o l

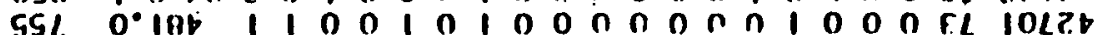

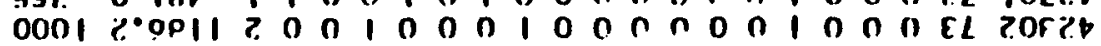

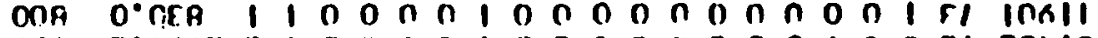

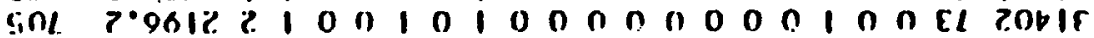

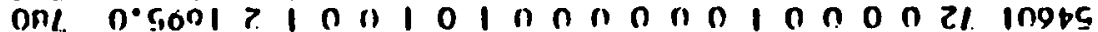

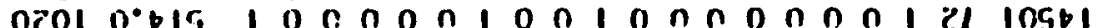
oril pgGn I wonl nongel

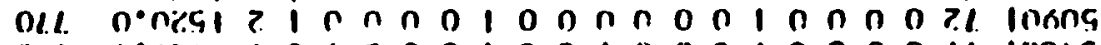

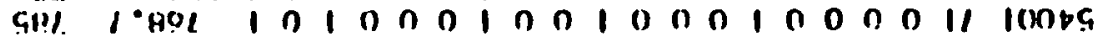

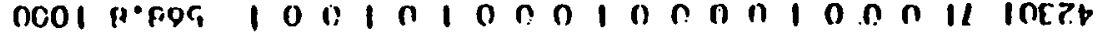

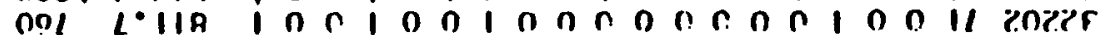

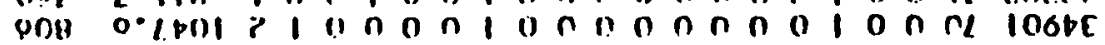

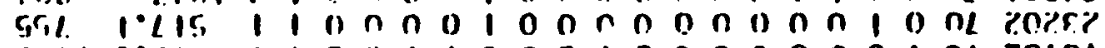

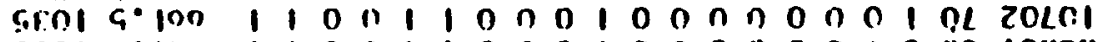

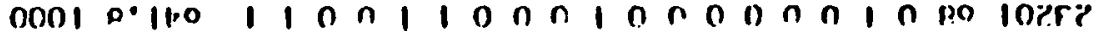

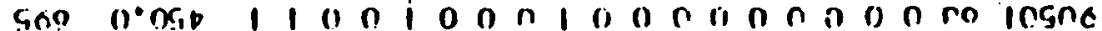

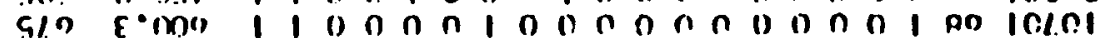

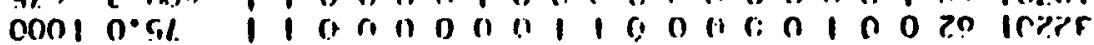

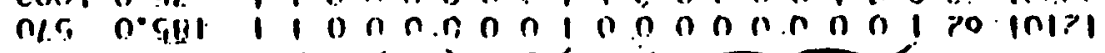

$9 \quad 1$ I

N N T $\quad X$
C

I H 9

$\mathbf{S}$ d

d

0

(n)




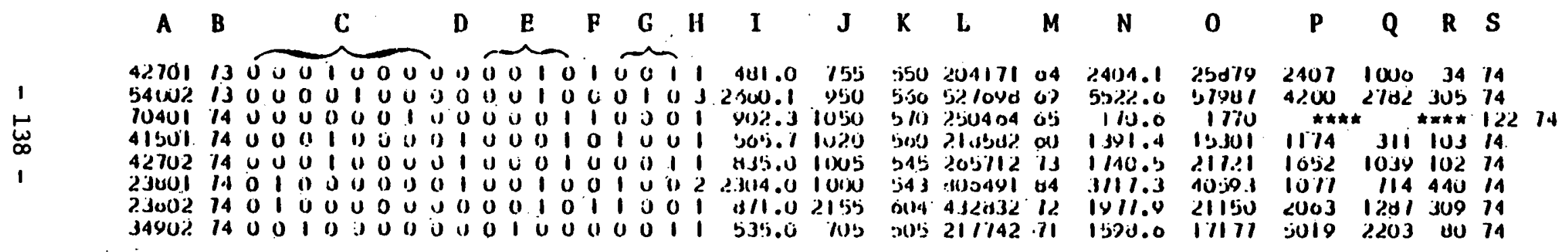


ELECTRICITY UTILITY SYSTEMS - ANNUAL EXPENSE AND PHYSICAL CHARACTERISTICS DATA

Column A - Five-digit identification code

The first digit identifies the system by the Census Region in which it is located.

The second and third digits are the state identification code. The state codes are numerically sequenced 01 to 50 and correspond to an alphabetical listing of the states. Code \#51 indicates the District of Columbia.

The final two digits in the identification code denote the specific system within a state.

Column B - Eight-digit region code

Regional code constructed for analytical purposes. This code for the nine Census Regions is as follows:

$\begin{array}{lllllllll}\text { Region 1 } & 1 & 0 & 0 & 0 & 0 & 0 & 0 & 0 \\ \text { Region 2 } & 0 & 1 & 0 & 0 & 0 & 0 & 0 & 0 \\ \text { Region 3 } & 0 & 0 & 1 & 0 & 0 & 0 & 0 & 0 \\ \text { Region 4 } & 0 & 0 & 0 & 1 & 0 & 0 & 0 & 0 \\ \text { Region 5 } & 0 & 0 & 0 & 0 & 1 & 0 & 0 & 0 \\ \text { Region 6 } & 0 & 0 & 0 & 0 & 0 & 1 & 0 & 0 \\ \text { Region 7 } & 0 & 0 & 0 & 0 & 0 & 0 & 1 & 0 \\ \text { Region 8 } & 0 & 0 & 0 & 0 & 0 & 0 & 0 & 1 \\ \text { Region 9 } & 0 & 0 & 0 & 0 & 0 & 0 & 0 & 0\end{array}$

Column C - Transmission operation and maintenance expenses in $\$\left(x 10^{3}\right)$. Column D - Distribution operation and maintenance expenses in $\$\left(x 10^{3}\right)$. Column E - General and administrative expenses in $\$\left(x 10^{3}\right)$.

Column F - Number of residential and small light \& power customers (x $10^{3}$ ). Column G - Number of large light \& power customers $\left(x 10^{2}\right)$. Column $\mathrm{H}$ - Annual $\mathrm{kWh}$ sales to large light \& power customers $\left(\mathrm{x} 10^{3}\right)$. Column I - Annual $\mathrm{kWh}$ sales to residential and small light \& power customers $\left(x 10^{3}\right)$.

Column J - Total annual kWh sales to all ultimate users $\left(x 10^{3}\right)$. 
Column $\mathrm{K}$ - Structure miles of transmission lines.

Column L - Total circuit miles.

Column M - Total underground and submarine circuit lines.

Column N - Capacity of transmission substation transformers in kilowattamperes $\left(x 10^{3}\right)$.

Column 0 - Capacity of distribution substation transformers in kilowattamperes $\left(x 10^{3}\right)$.

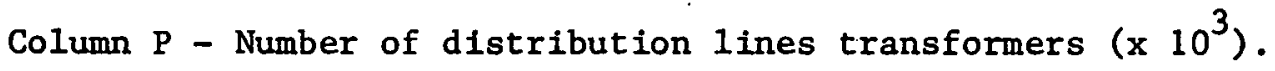

Column Q - Capacity of distribution line transformers in kilowatt-amperes (x 10 ${ }^{3}$.

Column R - Number of meters. 


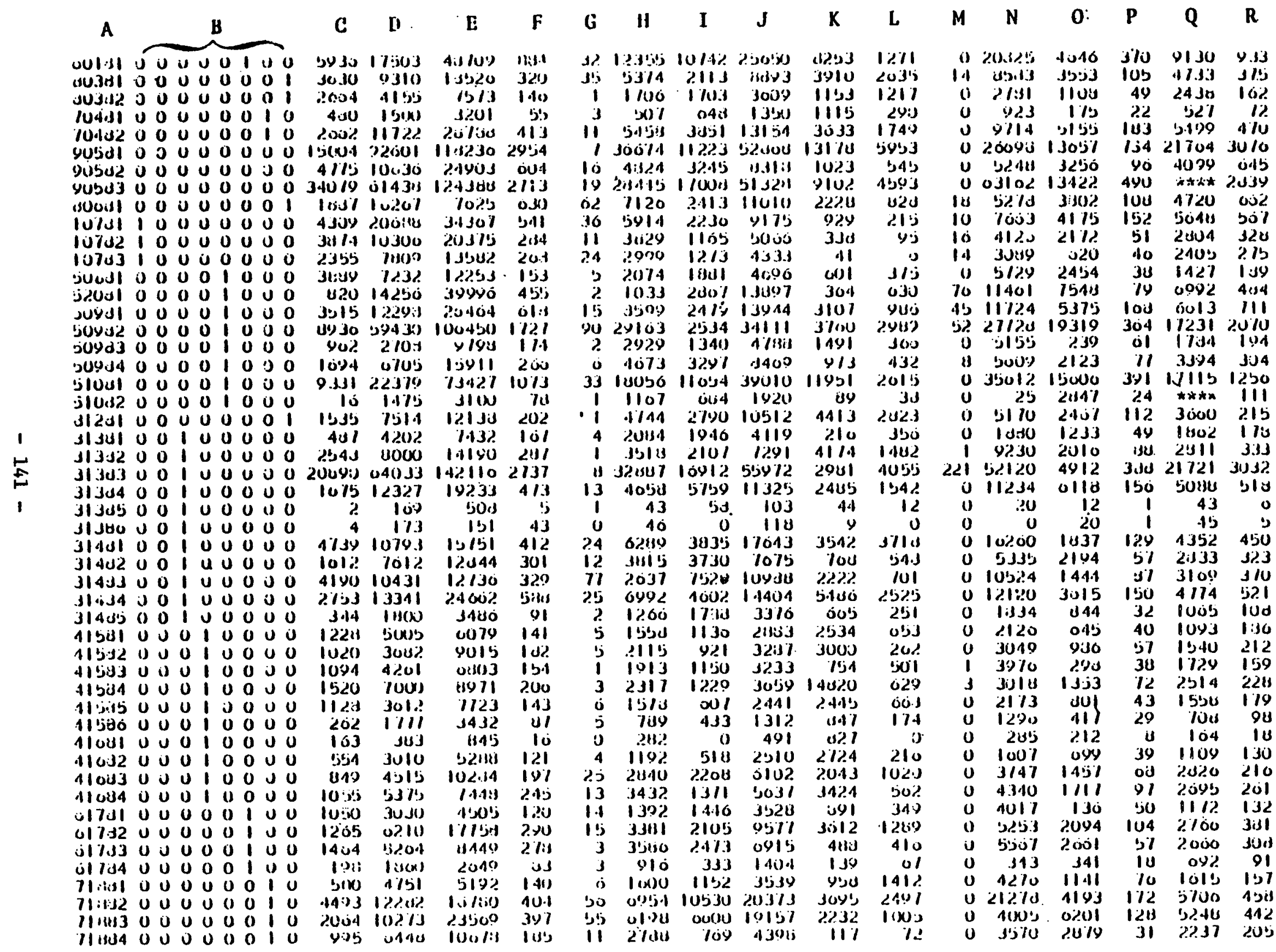




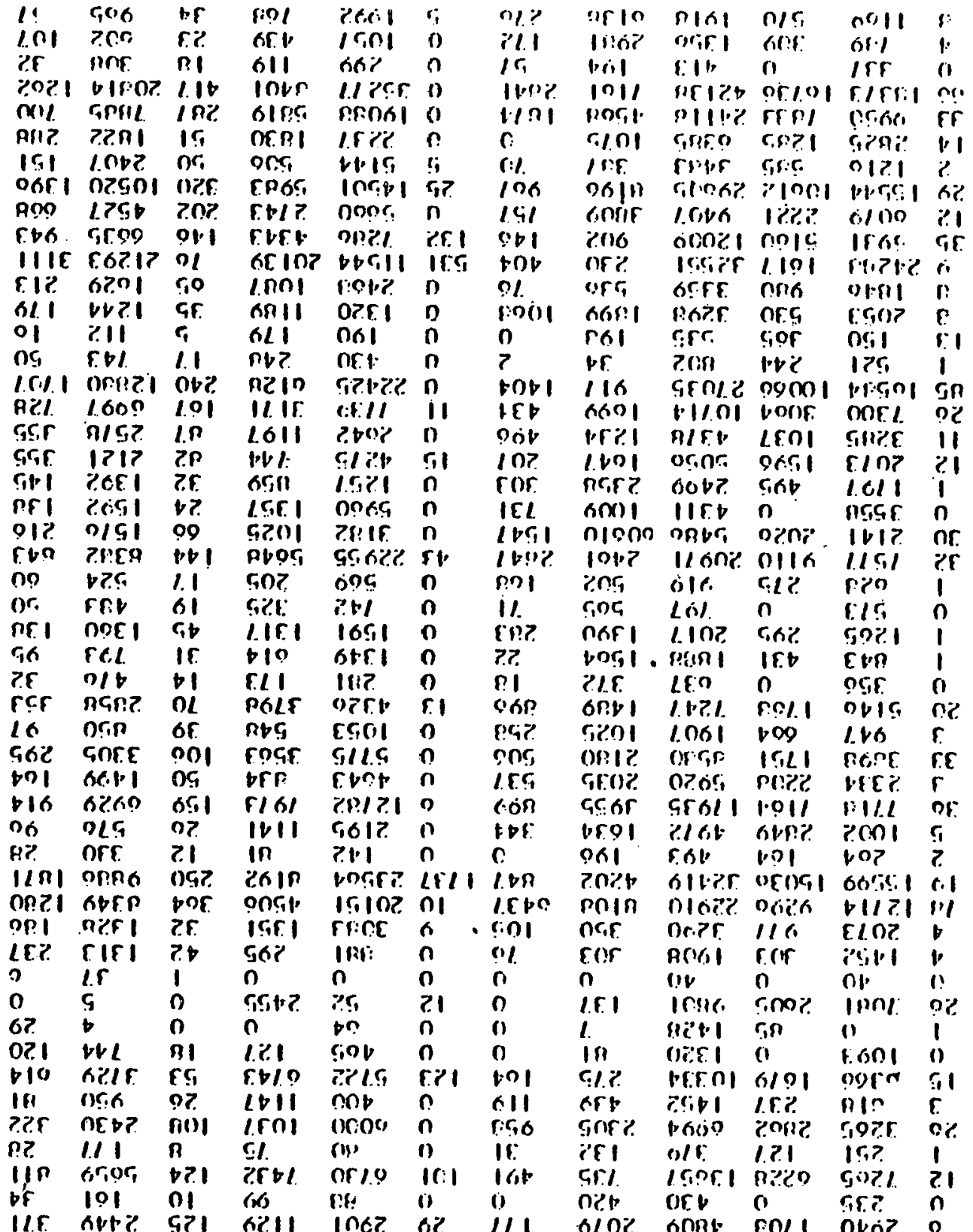

iill old Ifl birit bir misi

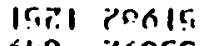
oun igntir ni. r. riln rif I Treren he? cintert II0 lineis. nin nentir Printe wonkis

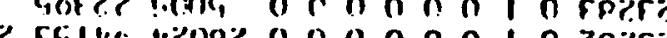

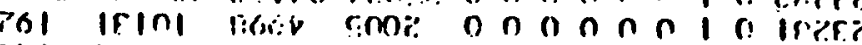

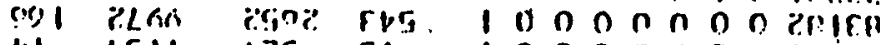
11 wril we si 10000001 inirs

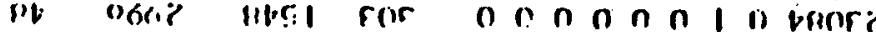

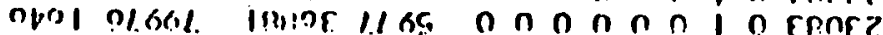

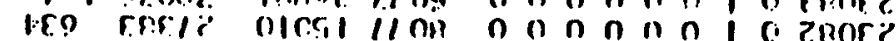

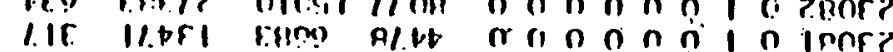

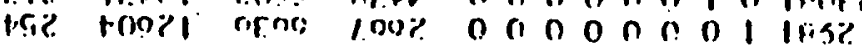

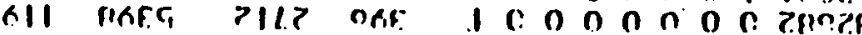

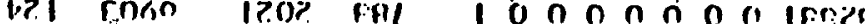

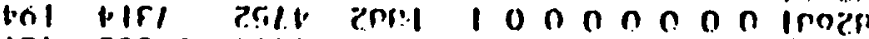

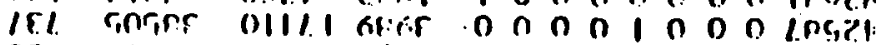

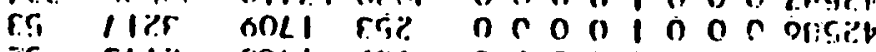

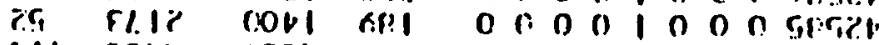

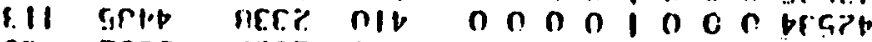

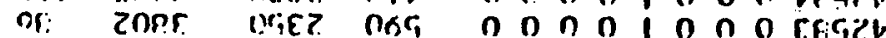

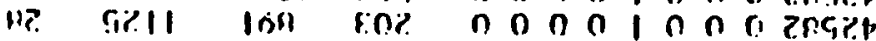

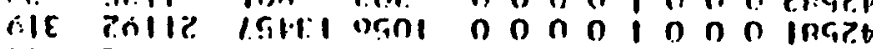

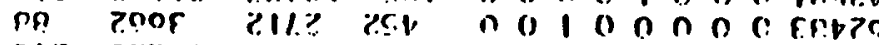

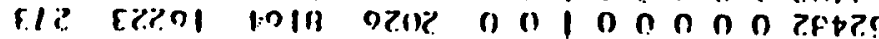

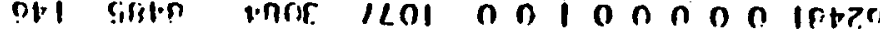

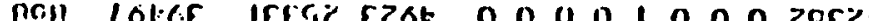

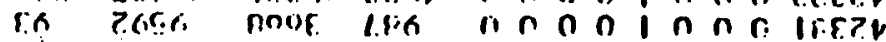

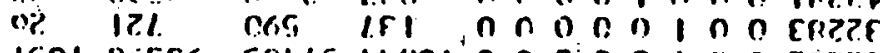

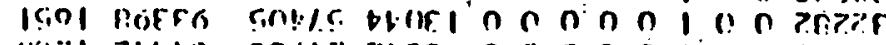

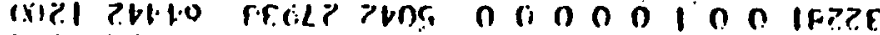

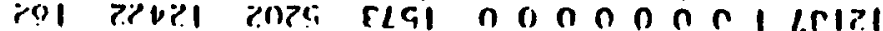

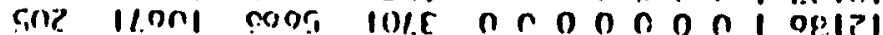

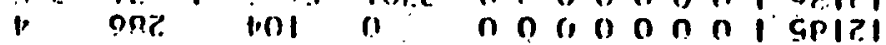

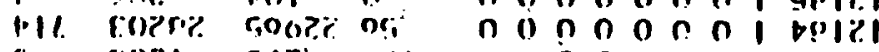
i EOP.

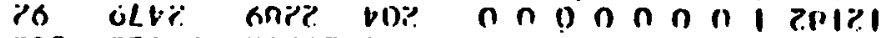

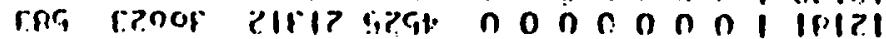
n!. tr.t mor cro non

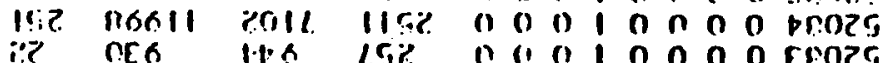
i:t nes l.

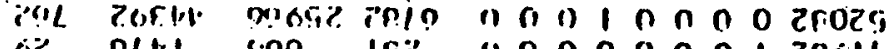

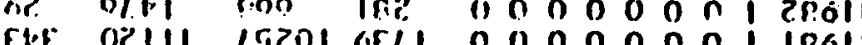
no o o n c i ipoll

\begin{abstract}
o
d

O

N W $T$
\end{abstract}

y

i'

1

II

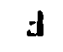

3

0

g. 
$3 3 5 0 1 0 \longdiv { 0 1 0 0 0 0 }$

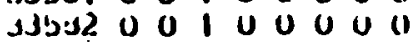
\begin{tabular}{lllllllll}
\hline Jjous & 0 & 0 & 1 & 0 & 0 & 0 & 0 & 0
\end{tabular}

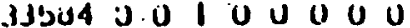
Jjod Jjs

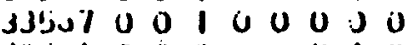
13oul 0 o

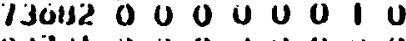

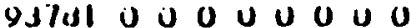

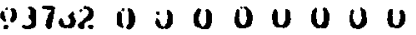
.3.jssl 0

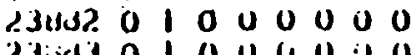

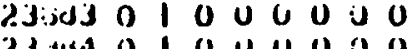

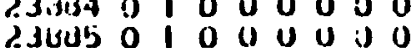
ijosido 00 1 asised 011000000

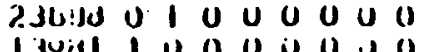

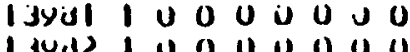

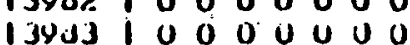

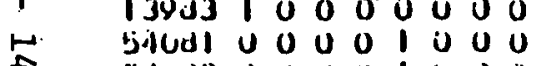

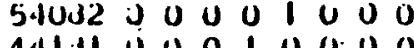
44131 0.0 0010000

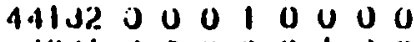

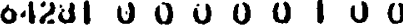
7430100000000 $743+$ ?

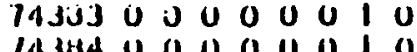
19384000000000 74300 o

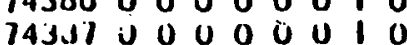

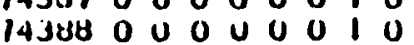
14304 i) 0 o 0 u 000 $74 j 400000000010$ 74341 o 00000010

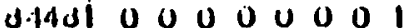

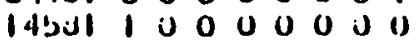

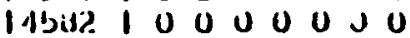

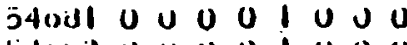
b4ovid 0 u

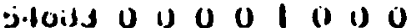
gallisl 0000000000

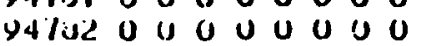

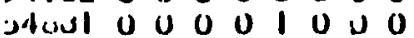

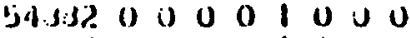

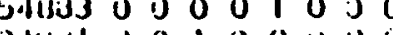
उ.tyal 400100000

c D

E

Ji) is - I I.jA1

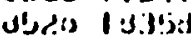

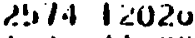
|cily | |ci2'

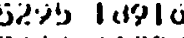
हशuा objis 2ii II 1 3y lli zUú प्याII עu 131! 35) 2.223 1052.2 3live 101\%7 11/U 1733 4t) jo 31013 JuU.1 Jप्यश1) 130313,10 13.5 1373 lyess osd's

131 111 $\begin{array}{rr}30 & 12.3 \\ 1791 & 4 / 10\end{array}$ $1791 \quad 4110$ Aly 1310 ily $1 \% 1$ 3020 I5'j 1973 |ư's 150 J15411 242.3 ?पण0 Iro: प/ $110 \quad 511$ 2ע: 12.43i 33 1) $\mid 1$.101 uso rexpes 310.3 10093 $\begin{array}{ll}40.30 & 2.310 \\ 1240 & 150\end{array}$ $1240 \quad 1500$ of jọ 400? 111\% ונأlilis I'sive 5171 14.2. $124 \% 3$ 1117 का

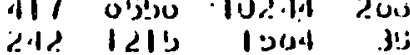

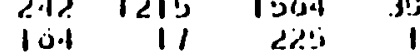

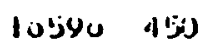
3047.1079 10401 jith 3\%ive 77 21940 j 12.579 24!5 i2.9ul 49,3 10:08 3.1 |lisel Jil

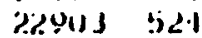
11701 1:? ow4 113 40.j'Jll yos oivisil 1211 از jous 11 II Yण0 2A1 III) 23 $2 \% 115$
2015 2104 J. श्र4.1 40 oyil 30 $\begin{array}{ll}10009 & 3.14 \\ 1500 & 1.315\end{array}$ $1027 \%$ 2.40 jusl 1.11 ij\%31 700 11902 राs Iasy 54 $20 \%$ 411 $29410 \quad 564$ نl34 12:5 $21 \times 4 \%$ ग राणे Uा। iJ jijl 21 4.11.16 11.3.3 lasue dol iा 14000

G

H

2.1 गiit)

i? 1010 Juos IIy20

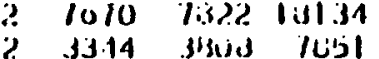

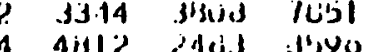

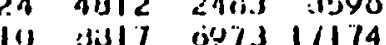
jis IuAd labis. 520\%3 $1: 2013 \quad 3011$ a0ja al covos 33isis 13110

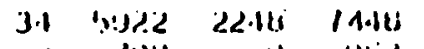

$$
\text { 11)!s } 0 \text { 10.jट }
$$

11151 2000 |laila 4 ujues jiild lialay

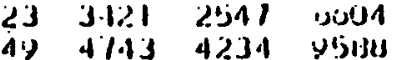
I $\mid 100$ |j1| 2.jilo in IIJis I0?0 |y|lo

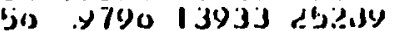
. 4U1 0त 513 17 521? $5009^{\circ} 1 \% 414$ 90 buy 4jo vol

11 i.5\% 04\% $51 \% 4$

$\begin{array}{llll}0 & 295 & 0 & 315 \\ 1 & 43 & 147 & 211\end{array}$ $\begin{array}{llll}1 & 43 & 147 & 211\end{array}$ 11 :5040 2?97 $8503 \quad 240$

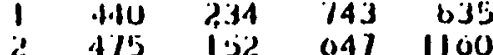
i jyo 3.1 yju

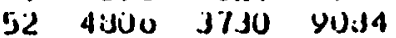
2 145j 1412 J35s

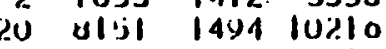
1 109\% 514 321\% $121577320124 \quad 30147$ 6033012600 u480 U 101 o 351

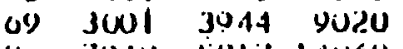
Uo 79.15 5H17 1.1\%64 وक 17. 14\%2 93\% 40\% 300u 66. 10 A(u) Jols |luशl 020\% $30 \%$ 1 7.54 4\% lis/1 vis 0 $1 \quad 139$

1 2015 125 \$ll 1\%0 31 $\begin{array}{rr}0 & 1001 \\ 2.4 & 2.44\end{array}$ $27 \%$

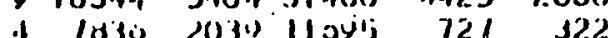

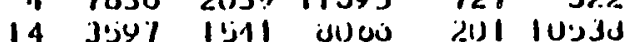
ز.8

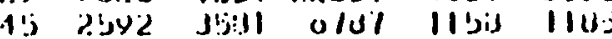
? $51111 \%$ 1101 loj

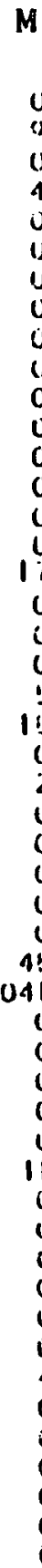

\begin{tabular}{|c|c|c|c|c|c|}
\hline U & Ysis & 2073 & 101 & ز5) & 40 \\
\hline ) & Y:isll & 2401 & 110 & 5241 & 121 \\
\hline (1) & 10414 & $24 t i{ }^{i} j$ & lud & 4007 & |زا، \\
\hline 4 & Yง.) 3 & 1212 & 110 & 4020 & 417 \\
\hline v & קלjל! & $\angle 100$ & 201 & 5210 & 969 \\
\hline U) & 24050 & 1020 & IU9 & 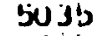 & 014 \\
\hline$u$ & 431.1 & 1372 & 乡ע & 2310 & 203 \\
\hline u & 1201\% & 3920 & l'jó & j)!nti & ذ:j! \\
\hline ن & b/lu & 3504 & $4 !$ & $34 / 2$ & Jut \\
\hline u & 110 & 310 & إ. & 017 & 31 \\
\hline O & bists & 2701 & $12 \%$ & 1.130 & 443 \\
\hline $\mathbf{U}$ & טנ:0 & 4113 & d] & 4104 & bo\% \\
\hline & $3.1 \%$ & 2007 & IU? & 3i) 24 & טנjo \\
\hline & 1201 & 427 & 133 & 1559 & ? \\
\hline 0 & lovo & ذالj & 30 & $73 u$ & 143 \\
\hline $\mathbf{U}$ & ל & 年 & 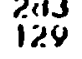 & $\begin{array}{l}1002 \\
00: 36\end{array}$ & iali \\
\hline 0 & 504 & 60 & 11 & $34 \%$ & שט \\
\hline 0 & 5.106 & 'j2UA & 103 & 3121 & \\
\hline 0 & 310 & UOo & 10 & 328 & 30 \\
\hline j & प? ? & 1142 & 41 & 13015 & $20 \%$ \\
\hline [3] & 231 & 90 & 3 & 112 & 29 \\
\hline 0 & 30 & .120 & 2 & 40 & \\
\hline 2 & 7334 & 25099 & 110 & 4093 & 328 \\
\hline U & 254 & 104 & 12 & 404 & 17 \\
\hline 0 & 034 & 217 & 13 & bij4 & 25 \\
\hline 0 & 2.11 & 179 & 10 & 300 & 33 \\
\hline U & j5j' & 2730 & $|J|$ & 4290 & 104 \\
\hline $\mathbf{U}$ & $13 \%$ & wo5 & 52 & 1350 & |53 \\
\hline & bjoll & 3220 & 05 & 3/43 & 204 \\
\hline & & 2290 & 31 & 1060 & 207 \\
\hline U & 1501? & 12306 & 233 & 11931 & UUu \\
\hline 0 & 4704 & $21 \%$ & 111 & 3054 & 313 \\
\hline $\mathbf{0}$ & 14\% & 245 & 14 & 304 & 35 \\
\hline 0 & oistl & 2373 & UY & $2: 3 \mathbf{3 1}$ & 204 \\
\hline u & 9022 & 4070 & 121 & טניj'jا & 477 \\
\hline & $15 y 04$. & 0032 & 234 & 7322 & טuj 7 \\
\hline J & 23114 & 897 & do & 1300 & 1.10 \\
\hline 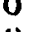 & $0 / 00$ & 4019 & 117 & 30100 & Jy2 \\
\hline 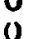 & 280 & הו1 & $4 !$ & 073 & 120 \\
\hline & 194 & 301 & 21 & 496 & \\
\hline & נדי & 90 & 5 & 124 & 10 \\
\hline & 110 & 123 & 9 & 211 & 20 \\
\hline J & Coग? & 19220 & 314 & 12109 & 1213 \\
\hline 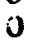 & ? & 3.59 & 132 & 21 & A.1 \\
\hline U & (1) & 1280 & 38 & 11, & כ0ק \\
\hline 0 & נטاנن? & S fillit & (2) & 1034 & $08 \%$ \\
\hline J & 2315 & 120 & 10 & 323 & \\
\hline & 17 & & & . & \\
\hline
\end{tabular}




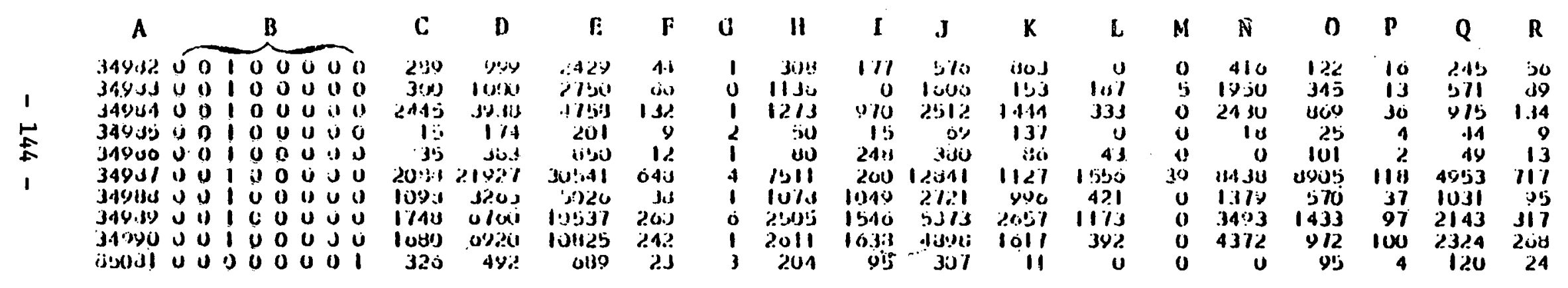


•

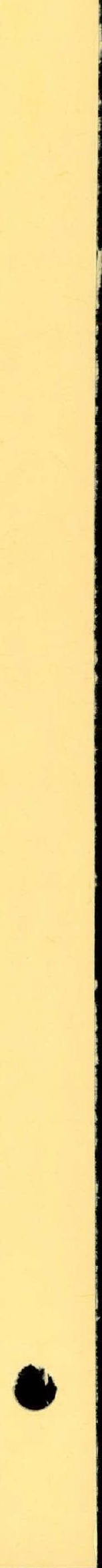

